\title{
Prävalenz und Risikofaktoren von Eisenmangel bei jungen Müttern
}

\author{
D I S S E R T A T I O N \\ zur Erlangung des akademischen Grades \\ doctor medicinae \\ (dr. med.) \\ im Fach Humanmedizin \\ eingereicht an der \\ Medizinischen Fakultät Charité \\ Humboldt-Universität zu Berlin \\ von \\ Frau Iris Elisabeth Wagener \\ geboren am 04.10.1973 in Köln
}

Präsident der Humboldt-Universität zu Berlin:

Prof. Dr. Jürgen Mlynek

Dekan der Medizinischen Fakultät Charité:

Prof. Dr. Dr. h.c. R. Felix

Gutachter:

1. Priv.-Doz. Dr. Renate L. Bergmann

2. Prof. Dr. Klaus Friese

3. Prof. Dr. Horst Halle

eingereicht am:

27. Juni 2000

Tag der mündlichen Prüfung:

2. Februar 2001 


\begin{abstract}
Qualitiy of life and achievements are impaired by unrecognised iron deficiency. The iron requirement of women during their child-bearing age is high and increases in pregnancy. The aim of this study was to determine the prevalence and risk factors for iron deficiency in young mothers under contemporary German life conditions. Between September 1997 and August 1998 the iron status of 507 mothers of one-year old children was assessed. The data was derived from venous blood and questionnaires. Besides conventional methods, the concentration of soluble transferrin receptor was used as leading indicator of iron status. 9,5\% had cellular iron deficiency and 2,2\% of all mothers had iron deficiency anemia. In addition to absence of menstruation one year postpartum, vegetarian foood, a high number of children and non-German nationality are risk factors for iron deficiency. Associated with low maternal hemoglobin concentration are body mass index below 19,8, age below 25 years, low level of education and high birth weight of the child. In contrast, high alcohol intake and cigarette smoking are associated with a better iron status and higher hemoglobin concentrations. Children of mothers with insufficient iron supply are also at higher risk of iron deficiency.
\end{abstract}

\title{
Keywords:
}

Iron Deficiency, Mothers, Prevalence, Risk Factors 


\section{Zusammenfassung}

Lebensqualität und Leistungsfähigkeit werden durch einen unbemerkten Eisenmangel beeinträchtigt. Frauen im gebärfähigen Alter haben einen erhöhten Eisenbedarf, der in der Schwangerschaft noch zunimmt. Ziel der Untersuchung war, die Prävalenz von Eisenmangel bei Müttern unter deutschen Lebensbedingungen zu evaluieren. Der Eisenstatus von 507 Müttern wurde zwischen September 1997 und August 1998 untersucht. Datenquellen waren venöse Blutentnahme und Fragebogen. Neben konventionellen Messgrößen wurde eine erhöhte Konzentration des löslichen Transferrinrezeptors als Leitindikator für einen Eisenmangel verwendet. Bei 9,5\% der Mütter besteht ein zellulärer Eisenmangel, eine Eisenmangelanämie bei nur 2,2 \% aller Mütter. Abgesehen von fehlendem Einsetzen der Menstruation ein Jahr post partum, sind rein vegetarische Ernährung, Multiparität und nicht deutsche Nationalität Risikofaktoren für einen Eisenmangel. Assoziiert mit geringen mütterlichen Hämoglobinkonzentrationen sind Body-Mass-Index unter 19,8, Alter unter 25 Jahren, fehlende Berufsausbildung und hohes Geburtsgewicht des Kindes. Alkoholkonsum und Rauchen scheinen vor Eisenmangel und Anämie zu schützen. Kinder von Müttern mit unzureichender Eisenversorgung neigen ebenfalls verstärkt zu einem Eisenmangel.

\section{Schlagwörter:}

Eisenmangel, Mütter, Prävalenz, Risikofaktoren 


\title{
Danksagung
}

\author{
Vielen Dank
}

Frau PD Dr. Renate L. Bergmann und Herrn Prof. Dr. Karl E. Bergmann für die ständige Betreuung und die große Geduld,

Herrn P. Kamtsiuris für die Unterstützung bei der statistischen Auswertung,

Herrn Dr. Müller, Frau U. Friesicke und Mitarbeiterinnen für die Auswertung der Blutproben,

allen Kinderärztinnen und -ärzten, ohne deren Mitarbeit diese Studie nicht möglich gewesen wäre und allen Müttern und Kindern, die trotz Blutentnahme und trotz des langen Fragebogens an der Untersuchung teilnahmen,

Bernhard, Björn, Conny (auch für die Auswertung des löslichen Transferrinrezeptors) und Ingo für die gute und harmonische Zusammenarbeit,

Rosi, meinen Eltern, Brüdern und Thomas für unermüdliches Korrekturlesen, Formatieren und für die seelische Unterstützung. 


\section{Inhaltsverzeichnis}

1 Einleitung $\quad 1$

1.1 Geschichte . . . . . . . . . . . . . . . . . . . 2

1.2 Eisenstoffwechsel . . . . . . . . . . . . . . . . . 2

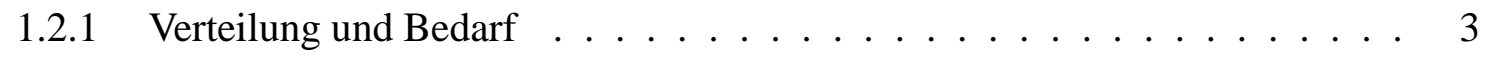

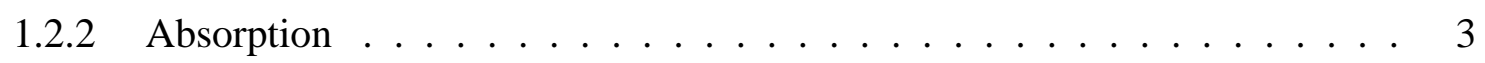

1.2 .3 Verluste ......................... 5

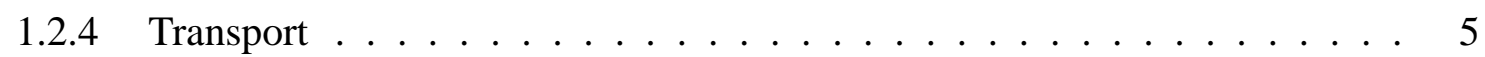

1.2 .5 Aufnahme in die Zelle . . . . . . . . . . . . . . . . . 7

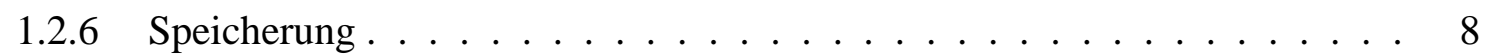

1.2.7 Regulation der Eisen-Homöostase . . . . . . . . . . . . . . . 8

1.3 Eisenstoffwechsel in der Schwangerschaft . . . . . . . . . . . . . . . . 10

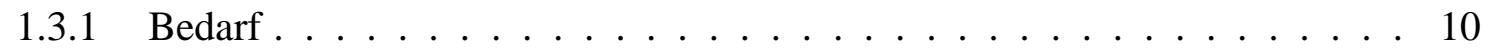

1.3 .2 Eisenumverteilung . . . . . . . . . . . . . . . 12

1.3.3 Eisentransport über die Plazenta . . . . . . . . . . . . . . . . . . . . . . . . . . . . 13

1.4 Diagnostik und Therapie von Eisenmangel . . . . . . . . . . . . . . . . . 13

1.4.1 Klinische Zeichen ...................... 13

1.4 .2 Laborindikatoren . . . . . . . . . . . . . . . . . . . . 14

1.4 .3 Definition ......................... 20

1.4.4 Kombination mehrerer Indikatoren . . . . . . . . . . . . . . . 21

1.5 Auswirkungen von Eisenmangel . . . . . . . . . . . . . . . . . . . . 24

1.5.1 Produktivität . . . . . . . . . . . . . . . . 24

1.5 .2 Müttersterblichkeit . . . . . . . . . . . . . . . . 24

1.5 .3 Immunsystem . . . . . . . . . . . . . . . . . . . . 24

1.5.4 Folgen von mütterlichem Eisenmangel für das Kind . . . . . . . . . . . . . 24

1.5.5 Verhalten von Mutter und Kind . . . . . . . . . . . . . . 27

1.5.6 Entwicklung und schulische Leistung . . . . . . . . . . . . . . . 27

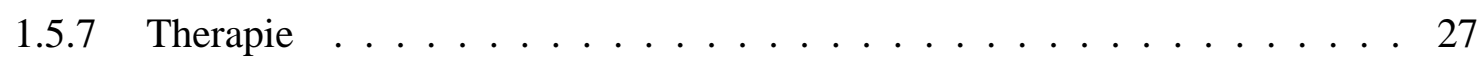

1.6 Prävalenz von Eisenmangel . . . . . . . . . . . . . . . . . . . . . . . 29

1.6.1 Nicht schwangere Frauen . . . . . . . . . . . . . . . . . . 29 


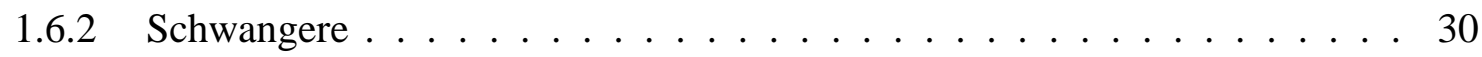

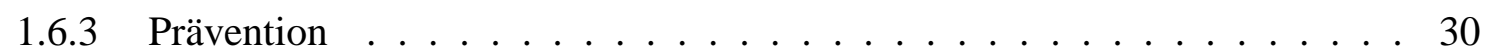

1.7 Risikofaktoren für Eisenmangel . . . . . . . . . . . . . . . . 31

1.8 Fragestellung der Arbeit . . . . . . . . . . . . . . . . . 32

2 Methodik $\quad 34$

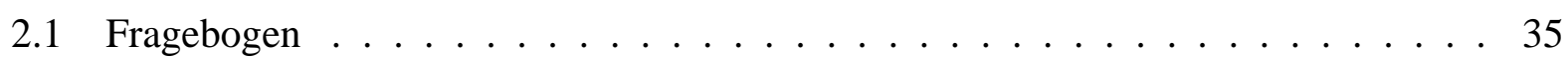

2.2 Gewinnung und Transport der Blutproben . . . . . . . . . . . . . . 36

2.3 Labor . . . . . . . . . . . . . . . . . . . . . 37

2.4 Dateneingabe . . . . . . . . . . . . . . . . . . 39

2.5 Definition zellulären Eisenmangels und der Anämie . . . . . . . . . . . . . . . 39

2.6 Statistik . . . . . . . . . . . . . . . . . . 40

2.6.1 Gruppierung der metrischen Variablen . . . . . . . . . . . . . . . 40

2.6.2 Beschreibung der Stichprobe . . . . . . . . . . . . . . . . . 40

2.6.3 Analysen in Bezug auf die Eisenstatusindikatoren . . . . . . . . . . . . . . 42

3 Ergebnisse $\quad 44$

3.1 Beschreibung der Stichprobe . . . . . . . . . . . . . . . . . . . 44

3.1 .1 Soziodemographie . . . . . . . . . . . . . . . . 44

3.1.2 Lebensgewohnheiten und Schwangerschaft . . . . . . . . . . . . . . 47

3.2 Konzentrationen von Hämoglobin und löslichem Transferrinrezeptor der Mutter . . 48

3.2.1 Prävalenz in der Stichprobe . . . . . . . . . . . . . . . . . . . 49

3.2 .2 Prävalenz in Untergruppen . . . . . . . . . . . . . . . . . . 50

3.2 .3 Korrelationen . . . . . . . . . . . . . . . . . 58

3.2.4 Multiple lineare Regressionsanalyse . . . . . . . . . . . . . . . . . 59

3.2.5 Multiple logistische Regressionsanalyse . . . . . . . . . . . . . 61

3.3 Zusammenfassung der Ergebnisse . . . . . . . . . . . . . . . . 61

4 Diskussion $\quad 63$

4.1 Fehlermöglichkeiten . . . . . . . . . . . . . . . . 64

4.1.1 Population und untersuchte Stichprobe . . . . . . . . . . . . . . . 64

4.1.2 Kinderarztpraxen . . . . . . . . . . . . . . . 65

4.1 .3 Sozialstatus . . . . . . . . . . . . . . . . . 65

4.1.4 Probleme des Fragebogens . . . . . . . . . . . . . . . . . . . 67

4.1.5 Blutproben, Labor und Dateneingabe . . . . . . . . . . . . . . 67

4.2 Interpretation der Ergebnisse . . . . . . . . . . . . . . . . 68

4.2.1 Vergleichbarkeit der Stichprobe . . . . . . . . . . . . . . 69

4.2.2 Einsetzen der Menstruation post partum . . . . . . . . . . . . . 70

4.2 .3 Alkoholkonsum . . . . . . . . . . . . . . . . . . . 71 
4.2 .4 Vegetarische Ernährung . . . . . . . . . . . . . . 73

4.2 .5 Nationalität . . . . . . . . . . . . . . . . . . . . 74

4.2 .6 Kinderzahl . . . . . . . . . . . . . . . . . . . . 74

4.2 .7 Rauchen . . . . . . . . . . . . . . . . . . . 75

4.2 .8 Body-Mass-Index . . . . . . . . . . . . . . . 75

4.2 .9 Bildungsstand . . . . . . . . . . . . . . . . 76

4.2 .10 Alter . . . . . . . . . . . . . . . . 77

4.2 .11 Geburtsgewicht . . . . . . . . . . . . . . 78

4.2 .12 Einzelfälle mit Eisenmangelanämie . . . . . . . . . . . . . . 78

4.2.13 Zusammenhang Mutter-Kind . . . . . . . . . . . . . 78

4.3 Schlußfolgerungen . . . . . . . . . . . . . . . . . . . . 79

$\begin{array}{lll}5 & \text { Zusammenfassung } & 85\end{array}$

$\begin{array}{llll}\text { A Tabellen } & \text { I }\end{array}$

B Fragebogen (Ausschnitt) XVI 


\section{Abbildungsverzeichnis}

1.1 Eisenbedarf in der Schwangerschaft . . . . . . . . . . . . . . . . . 11

1.2 Eisendefizit in der Schwangerschaft . . . . . . . . . . . . . . . . . . . . . . . . . . . . . . .

1.3 Stadien des Eisenmangels . . . . . . . . . . . . . . . . . . . 20

1.4 Prävalenz von Eisenmangel . . . . . . . . . . . . . . . . . . . . 30

3.1 Prävalenzen: zellulärer Eisenmangel, Anämie und Eisenmangelanämie . . . . . . . 49

3.2 Mittelwerte $\mathrm{Hb}$ und sTfR: Nationalität . . . . . . . . . . . . . . . . . . . 50

3.3 Mittelwerte Hb und sTfR: Alkoholkonsum nach der Schwangerschaft . . . . . . . 51

3.4 Mittelwerte Hb und sTfR: Rauchen zur Zeit der Studie . . . . . . . . . . . . . . 52

3.5 Prävalenzen: verschiedene Altersgruppen . . . . . . . . . . . . . . . 52

3.6 Mittelwerte $\mathrm{Hb}_{\text {min }}$ : Alter . . . . . . . . . . . . . . . . . . 53

3.7 Mittelwerte $\mathrm{Hb}$ und $\mathrm{Hb}_{\text {min }}$ : Body-Mass-Index . . . . . . . . . . . . . . . . 54

3.8 Mittelwerte $\mathrm{Hb}_{\text {min }}$ : Vegetarische Ernährung . . . . . . . . . . . . . . . . 55

3.9 Odds-Ratios: zellulärer Eisenmangel . . . . . . . . . . . . . . . . . 62

4.1 Eisenspeicher von Frauen im gebärfähigen Alter . . . . . . . . . . . . . . 81 


\section{Tabellenverzeichnis}

1.1 Referenzwerte . . . . . . . . . . . . . . . . . . . 17

1.2 Anämiegrenzen in der Schwangerschaft . . . . . . . . . . . . . . . 21

1.3 Empfohlene Gewichtszunahme in der Schwangerschaft . . . . . . . . . . . . . 32

2.1 Bestimmungsmethoden . . . . . . . . . . . . . . . . 38

4.1 Prävalenzvergleich Studie-Berlin und Studie-Deutschland . . . . . . . . . . . . 70

A.1 Soziodemographie . . . . . . . . . . . . . . . . . . . I

A.2 Lebensgewohnheiten und Schwangerschaft . . . . . . . . . . . . . . . II

A.3 Mittelwerte der Indikatoren und Prävalenzen abweichender Werte . . . . . . . . . III

A.4 Perzentilen: sTfR . . . . . . . . . . . . . . . . . . . . III

A.5 Prävalenzen in Untergruppen: $\mathrm{Hb}<12 \mathrm{~g} / \mathrm{dl} \ldots \ldots \ldots \ldots$. . . . . . . . III

A.6 Prävalenzen in Untergruppen: $\mathrm{sTfR}>3,3 \mathrm{mg} / \mathrm{l} \ldots \ldots \ldots \ldots \ldots$

A.7 Mittelwerte in Untergruppen: $\mathrm{Hb} \ldots \ldots \ldots \ldots$. . . . . . . . . . . VI

A.8 Mittelwerte in Untergruppen: sTfR . . . . . . . . . . . . . . . . . . VIII

A.9 Mittelwerte in Untergruppen: $\mathrm{Hb}_{\min } \ldots \ldots \ldots \ldots \ldots$. . . . . . . . . . . . .

A.10 Fallbeispiele . . . . . . . . . . . . . . . . . . . X

A.12 Korrelationen: Hämoglobin und löslicher Transferrinrezeptor . . . . . . . . . . . . XI

A.13 Korrelation: Hb, sTfR, $\mathrm{Hb}_{\min }$-gruppenbildende Variablen . . . . . . . . . . . . . . XI

A.14 Lineare Regression: Bestimmtheitsmaße für $\mathrm{Hb}$, sTfR und $\mathrm{Hb}_{\min }$. . . . . . . . . . XII

A.15 Lineare Regression: Varianzanalyse für $\mathrm{Hb}$, sTfR und $\mathrm{Hb}_{\min }$. . . . . . . . . . . . XII

A.16 Lineare Regression: Koeffizienten für $\mathrm{Hb}$, sTfR und $\mathrm{Hb}_{\min }$. . . . . . . . . . . . . XII

A.17 Lineare Regression: ausgeschlossene Variablen für $\mathrm{Hb}$, sTfR und $\mathrm{Hb}_{\min } \ldots$. . . . . XIII

A.18 Odds-Ratios: Hb und sTfR . . . . . . . . . . . . . . . . . . . . . . XIII

A.19 Rangwerte: Hb und sTfR . . . . . . . . . . . . . . . . . . . XIV

A.20 Zusammenfassung der Ergebnisse . . . . . . . . . . . . . . . . XV 


\section{Abkürzungsverzeichnis}

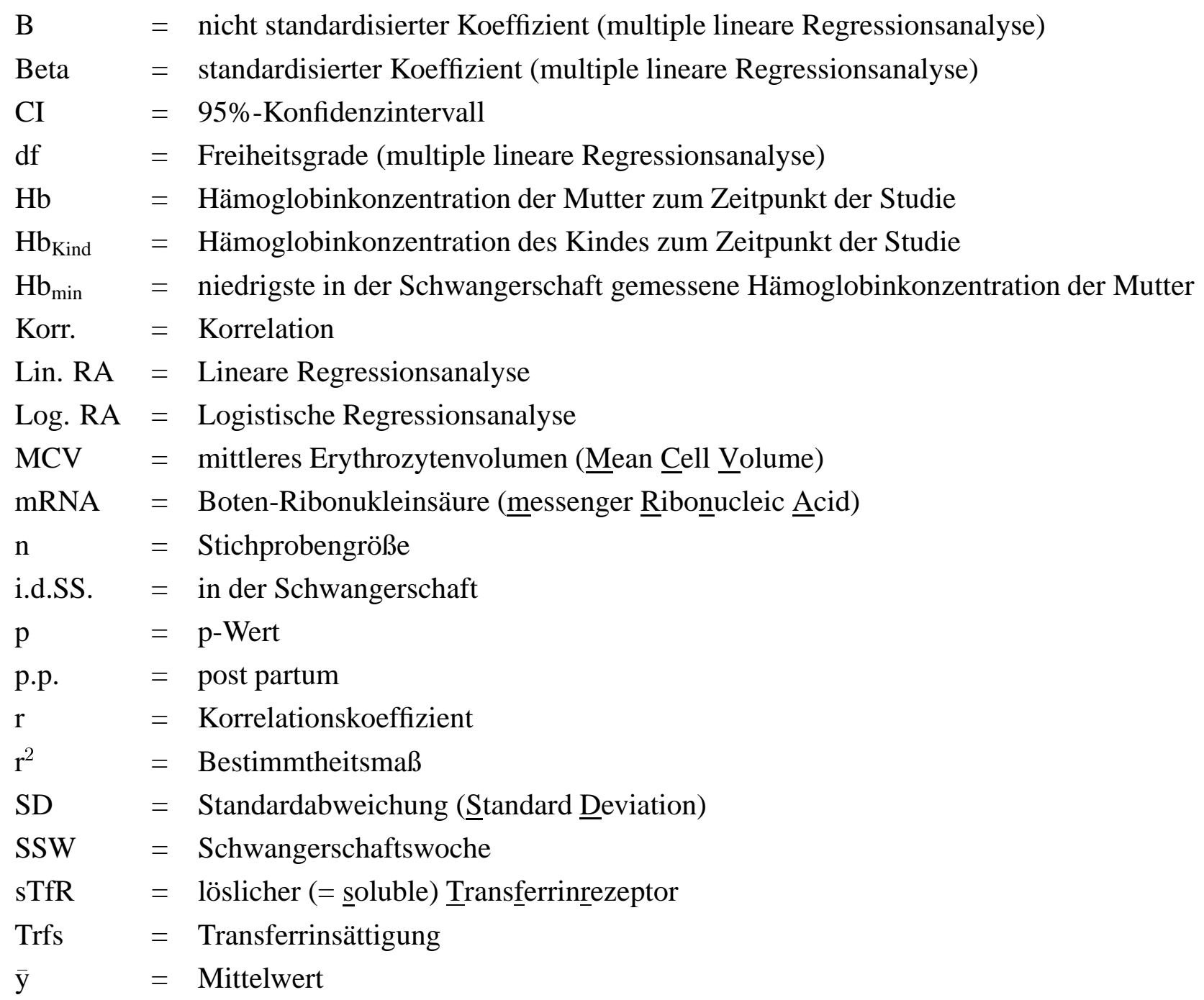




\section{Kapitel 1}

\section{Einleitung}

Eisen ist das vierthäufigste aller Elemente und das häufigste Übergangselement auf der Erdoberfläche und in lebenden Organismen (Petrides, 1997). Trotzdem kann es wegen seiner Unlöslichkeit in Wasser, außer in saurem Milieu, nicht leicht absorbiert werden. Seine vielseitige biologische Verwendbarkeit ist darauf zurückzuführen, daß es in mehreren Oxidationsstufen stabil existieren kann und in der Lage ist, unterschiedliche Komplexe zu bilden (Worwood, 1995). Außerdem ist Eisen (wie auch Kupfer) in der Lage, mit neutralen Elementen wie Sauerstoff zu reagieren. Dagegen können andere Metalle nur mit Anionen reagieren (Petrides, 1997).

Lebensqualität und Leistungsfähigkeit werden durch einen unbemerkten Eisenmangel beeinträchtigt. Obwohl Eisenmangel der häufigste Mangel an einem einzelnen Nährstoff auf der Welt ist (Lönnerdal and Dewey, 1995), zählt er zu den am häufigsten übersehenen oder fehlgedeuteten Mangelerscheinungen (Wick et al., 1996). Frauen im gebärfähigen Alter haben einen erhöhten Eisenbedarf, der in der Schwangerschaft bis auf das Zehnfache ansteigt (Hallberg, 1992). Auch in Deutschland müssen Frauen im gebärfähigen Alter auf ihre Eisenversorgung achten (Bergmann et al., 1997). In der vorliegenden Dissertation soll daher der Eisenversorgungszustand junger Mütter in Berlin ein Jahr nach der Geburt untersucht und auf die gesamte Bundesrepublik übertragen werden.

Die bislang sicherste Erfassung von Eisenmangel ohne Anämie ist die Ferritinbestimmung (Wick et al., 1996). Ferritin steigt jedoch im Rahmen einer Akutphase-Reaktion und bei chronischen Krankheiten an. Als weitgehend unberührt von Infektionen gilt der lösliche Transferrinrezeptor, der noch nicht routinemäßig angewendet wird (Cook et al., 1993). Daher wird in der vorliegenden Untersuchung der lösliche Transferrinrezeptor neben herkömmlichen Meßgrößen als Leitindikator verwendet.

Die Studie wurde im September 1997 durch die Ethik-Kommission der Charité, Humboldt-Universität zu Berlin, Campus Virchow-Klinikum bewilligt. 


\subsection{Geschichte}

Die Eisenversorgung prähistorischer Menschen war aufgrund der Nahrungsvielfalt adäquat, was auf die heutige Weltbevölkerung zum Teil nicht mehr zutrifft (Eaton and Konner, 1985). Schon die alten Araber, Chinesen, Ägypter, Griechen und Römer sprachen Eisen einen therapeutischen Nutzen zu, obwohl sie dessen Bedeutung für die Ernährung nicht kannten. So gaben die alten Griechen ihren verwundeten Soldaten Eisen, um ihre Muskelkraft wieder herzustellen. Alchemisten und Ärzte des 16. Jahrhunderts verschrieben Eisen als Medikament. Junge Frauen erhielten Eisensalze zur Behandlung von Chlorose (Bleichsucht), die einer Anämie aufgrund von Eisen- oder Proteinmangel entspricht. Verschiedene Ärzte, die in dieser Zeit Eisentabletten gegen Anämie verschrieben, wurden von ihren Nachfolgern verspottet.

$\mathrm{Zu}$ Beginn des 18. Jahrhunderts wurde Eisen als Bestandteil von Blut und tierischer Leber identifiziert. 1825 wurde ein Eisengehalt von $0,35 \%$ in Hämoglobin bestimmt, was fast identisch mit dem Eisengehalt ist, der mit modernen Geräten gemessen wird (0,347 \%). Zwischen 1832 und 1843 wurde Chlorose über niedrige Eisenkonzentrationen im Blut und verringerte Erythrozytenzahlen definiert. Im Jahr 1872 ordnete Boussignault als erster Eisen als essentiellen Nahrungsbestandteil ein. 1895 beschrieb Bunge die Anämie der Chlorose in der Form, wie man heute noch einen ernährungsbedingten Eisenmangel definiert.

Obwohl die Grundlagen der Aufnahme von Nahrungseisen schon seit der ersten Hälfte dieses Jahrhunderts bekannt sind, werden die molekularen Mechanismen des Eisenmetabolismus' auch heute noch erforscht (Beard et al., 1996).

\subsection{Eisenstoffwechsel}

Eisen kann als Übergangselement in den Oxidationsstufen von -2 bis +6 existieren. Unter physiologischen Bedingungen sind diese allerdings auf +2 bis +4 reduziert. Der Wechsel zwischen den Oxidationsstufen ermöglicht es Eisen nicht nur, am Elektronentransfer teilzunehmen, sondern auch, verschiedene Liganden (Sauerstoff, Stickstoff oder Schwefel) reversibel zu binden.

Die Schlüsselfunktion von Eisen ist der Transport von Sauerstoff als Bestandteil von Hämoglobin und die Sauerstoffversorgung der Muskulatur als Teil von Myoglobin. Außerdem ist Eisen enthalten in Cytochromen und Eisen-Schwefel-Proteinen der Atmungskette sowie in den Cytochromen des mikrosomalen P 450 Enzymsystems. Mit Ausnahme der Glutathion-Peroxidase enthalten bei Säugern auch alle Peroxidasen Eisen (Beard et al., 1996). 


\subsubsection{Verteilung und Bedarf}

Der Eisenversorgungszustand und Eisenbedarf jedes Einzelnen hängt von dem Eisengehalt der Nahrung ab, der Bioverfügbarkeit dieses Eisens (Beard et al., 1996) und dem individuellen Eisenstatus. So sind die natürlichen Eisenverluste bei Eisenmangelanämie eingeschränkt sowie die Resorption erhöht, bei Eisenüberladung hingegen sind die Basalzellverluste des Darms gesteigert (Hallberg and Rossander-Hultén, 1991).

Der Körper einer $55 \mathrm{~kg}$ schweren Frau enthält etwa 3,2-3,7 g Eisen, der eines $70 \mathrm{~kg}$ schweren Mannes circa 4-5 g. Dieses Eisen verteilt sich bei Frauen (Männern) wie folgt:

- 84 (80) \% auf das Funktionseisen (70 (66) \% Hämoglobin, 10 \% Myoglobin, 4 \% Enzyme (Katalase, Peroxidase, Cytochrome)),

- 16 (20) \% auf das Depoteisen (Ferritin und Hämosiderin),

- 0,1-0,2\% auf das Transporteisen (Transferrin) (Wick et al., 1996).

In der Regel benötigen Frauen nach der Menopause und Männer etwa 1 mg Eisen pro Tag (Wick et al., 1996). Der Eisenbedarf menstruierender Frauen liegt im Mittel bei 1,4 mg pro Tag (Hallberg, 1994), zur Deckung des Tagesbedarfs bei $95 \%$ aller Frauen sind sogar bis zu 2,84 mg an resorbiertem Eisen nötig. Um sicherzustellen, daß 2,84 mg absorbiert werden, muß die tägliche Nahrung $18,9 \mathrm{mg}$ verfügbares Eisen enthalten, da aus der durchschnittlichen Nahrung in Industrieländer nur zwischen 5 und $15 \%$ des Eisens absorbiert werden können. Bei Eisenmangelzuständen kann die Absorption allerdings auf etwa $30 \%$ ansteigen (Hallberg and Rossander-Hultén, 1991). Bei schwangeren Frauen kann der Bedarf zum Ende der Schwangerschaft auf zehn Milligramm pro Tag ansteigen. Diese hohe Menge kann allein durch erhöhte Absorption nicht gedeckt werden (Hallberg, 1992).

\subsubsection{Absorption}

Die Absorption ist der wichtigste Kontrollmechanismus des Körpers zur Regulation des Eisenhaushalts. Sie findet nach der Passage von Mund, Ösophagus und Magen in drei Phasen statt: Eisenaufnahme, intraenterozytärer Transport sowie Speicherung und extraenterozytärer Transport (Beard et al., 1996).

Dabei wird Hämeisen (10-40 \%) (Hallberg, 1994) besser absorbiert als Nicht-Hämeisen (2-20 \%) (Beard et al., 1996). Außerdem ist die Absorption von Hämeisen weitgehend unabhängig von der Zusammensetzung der Nahrung und dem jeweiligen Eisenstatus. Dagegen wird die NichtHämeisen-Absorption maßgeblich vom Eisenstatus und den Nahrungskomponenten beeinflußt. Das bedeutet, daß bei gutem Eisenstatus weniger Eisen absorbiert wird als bei Eisenmangel (Hallberg and Rossander-Hultén, 1991). Deswegen stellt Hämeisen, obwohl es nur etwa $10 \%$ des 
Nahrungseisens ausmacht, ein Drittel des absorbierten Eisens dar. Nicht-Hämeisen, aus dem die übrigen $90 \%$ des Nahrungseisens bestehen, macht die übrigen zwei Drittel des absorbierten Eisens aus. Tierisches Eisen besteht zu $40 \%$ aus Hämeisen und zu $60 \%$ aus Nicht-Hämeisen. Pflanzliches Eisen liegt dagegen ausschließlich als Nicht-Hämeisen vor. Deswegen wird das tierische Eisen besser absorbiert als das pflanzliche. 10 bis $15 \%$ des Nicht-Hämeisens in der Nahrung stammt aus einer bewußten Anreicherung der Nahrung mit Eisen oder durch Kontamination bei der Zubereitung (Beard et al., 1996). Durch Zubereitung der Mahlzeiten in Eisentöpfen kann der Eisengehalt der Nahrung sogar verdoppelt werden (Adish et al., 1999).

\section{Passage von Mund, Ösophagus und Magen}

Zwar wird vor Erreichen des Duodenums kein Eisen absorbiert, jedoch werden hier die Voraussetzungen für eine erleichterte Absorption geschaffen. Da die Salzsäure im Magen mit Hilfe von Pepsin zu einer Denaturierung der Proteine führt, kommt es zu einer Lösung der Hälfte der Proteinbindungen von Eisen. Außerdem reduziert die Magensäure das Eisen zu einem Drittel von der relativ unlöslichen dreiwertigen zur löslicheren zweiwertigen Form. Antagonistisch dazu wirkt das Bikarbonat, das vom Pankreas sezerniert wird und den $\mathrm{pH}$-Wert innerhalb des Duodenums anhebt. Andererseits lösen pankreatische Proteasen Nicht-Hämeisen aus seiner Bindung an die Nahrung (Beard et al., 1996).

\section{Eisenaufnahme}

Das mit der Nahrung aufgenommene Eisen wird im Duodenum und oberen Dünndarm bei physiologischen Konzentrationen ausschließlich rezeptorvermittelt als $\mathrm{Fe}^{2+}$ aufgenommen. Das ist einer der Gründe dafür, daß das Häm-gebundene Eisen $\left(\mathrm{Fe}^{2+}\right)$ besser absorbiert wird als das Eisen aus pflanzlicher Nahrung, welches hauptsächlich als $\mathrm{Fe}^{3+}$ vorliegt. Damit auch das dreiwertige Eisen über Rezeptoren resorbiert werden kann, muß es reduziert werden, was zum Beispiel durch Ascorbinsäure möglich ist (Wick et al., 1996; Beard et al., 1996).

Häm- und Nicht-Hämeisen binden an unterschiedliche Rezeptoren auf der luminalen Seite der Enterozyten. Dabei wird das schwer lösliche Nicht-Hämeisen vorher an ein Bindungsprotein gekoppelt, von dem es erst innerhalb des Enterozyten gelöst und an ein Transferrin-ähnliches Protein gebunden wird. Auch Hämeisen wird erst in der Zelle durch die Häm-Oxygenase in Eisen, Kohlenmonoxid und Bilirubin IXa gespalten. Beide Eisentypen werden dann entweder an Ferritin gebunden gespeichert oder über die basolaterale Seite der Enterozyten an die Blutbahn abgegeben. Vor ihrem Übertritt in das Blut werden sie durch Endoxidase I (Coeruloplasmin) zu Fe $\mathrm{Fe}^{3+}$ oxidiert und dann an Transferrin gebunden. Bei höheren Eisenkonzentrationen im Darm erfolgt möglicherweise eine passive parazelluläre Aufnahme von Eisen (Beard et al., 1996). 


\subsubsection{Verluste}

Da kein Mechanismus existiert, über den der Körper Eisen aktiv ausscheidet, geht es ausschließlich über den Verlust von Zellen der Körperoberflächen (Haut, Gastrointestinaltrakt, Harntrakt und Luftwege) verloren. Dabei ist die Eisenausscheidung wie die Eisenabsorption abhängig von Körpergröße und Eisenstatus. Hier steigt die Ausscheidung bei Eisenüberladung und sinkt bei Eisenmangel (Beard et al., 1996).

Eine $55 \mathrm{~kg}$ schwere Frau verliert im Durchschnitt 0,77 mg, ein Mann von $70 \mathrm{~kg}$ 0,98 mg am Tag. Die interindividuellen Schwankungen werden auf $\pm 15 \%$ geschätzt (Hallberg and RossanderHultén, 1991). Die Ausscheidung von Eisen erfolgt hauptsächlich über den Darm (0,6 mg/Tag), aber zum Teil auch über Haut ( $>0,1 \mathrm{mg} / \mathrm{Tag})$ und Urin $(0,3 \mathrm{mg} / \mathrm{Tag})$, wobei die Zahlen für Männer gelten (Beard et al., 1996). Die Verluste über den Schweiß sind gering (etwa 0,02 mg/l) (Hallberg and Rossander-Hultén, 1991).

Während der Menstruation verlieren Frauen monatlich weitere zirka $15 \mathrm{mg}$ Eisen (Institute of Medicine, 1990), was für sie den Eisenbedarf entsprechend steigert, der aber in der Regel durch vermehrte Absorption gedeckt werden kann (Wick et al., 1996). Der Blutverlust durch die Menstruation verringert sich bei Eisenmangelanämie nicht (Hallberg and Rossander-Hultén, 1991). Erhöhte Verluste durch Hypermenorrhoe (mehr als $80 \mathrm{ml} /$ Monat; entspricht einem zusätzlichen Eisenverlust von $>1 \mathrm{mg} / \mathrm{Tag}$ ) oder häufiges Blutspenden prädestinieren jedoch für Eisenmangel (Wick et al., 1996).

\subsubsection{Transport}

Freies Eisen ist extrem toxisch, da es viele schädliche Reaktionen katalysiert. Außerdem wird es in einer sauerstoffreichen Umgebung, wie sie unter physiologischen Bedingungen vorkommt, leicht zu unlöslichem $\mathrm{Fe}^{3+}$ oxidiert. Daher ist es notwendig, daß das Eisen im Körper gebunden an Proteine transportiert und gespeichert wird (Beard et al., 1996).

In der Regel wird Eisen im Plasma durch Transferrin befördert. Ausschließlich bei Eisenüberladungszuständen wird das Eisen zusätzlich an andere Transportproteine wie zum Beispiel an Albumin unspezifisch gebunden. Wird eine größere Menge von Hämeisen über den Darm aufgenommen, so kann ein Teil der $\mathrm{Fe}^{2+}$-Häm-Komplexe, ohne vorherige Oxidation in der Mukosazelle, an Haptoglobin oder Hämopexin gebunden zur Leber transportiert werden (Wick et al., 1996). Auch Lactoferrin, welches in Milch, Plasma und Schleimhaut-Sekreten vorkommt, kann Eisen transportieren, wobei es mit dessen Hilfe bakterio- und fungistatisch wirkt. Des weiteren transportiert H-Ferritin, das aus von Kupffer'schen Sternzellen freigesetzt wird, einen Teil des Eisens. Auf Hepatozyten wurden entsprechende Ferritinrezeptoren identifiziert (Beard et al., 1996). 


\section{Transferrin}

In der Regel wird das Eisen im Blut als $\mathrm{Fe}^{3+}$ gebunden an Transferrin zu den Zielorganen befördert. So wird zum einen verhindert, daß das Eisen polymerisiert oder über den Urin ausgeschieden wird und zum anderen einer toxischen Schädigung der Gewebe durch Eisen vorgebeugt (Petrides, 1997). Transferrin ist ein in der Leber synthetisiertes Glykoprotein mit einem Molekulargewicht von 80 kDalton und einer Halbwertszeit von 8 bis 12 Tagen (Beard et al., 1996). Es existieren über 20 genetische Varianten von Transferrin. Jedes Transferrinmolekül kann maximal zwei $\mathrm{Fe}^{3+}$-Moleküle - unter gleichzeitiger Aufnahme eines Bikarbonatanions - binden (Petrides, 1997). Abgesehen von Eisen kann Transferrin auch Mangan und Aluminium binden (Beard et al., 1996). Außer im Blutplasma findet sich Transferrin in interstitiellen Flüssigkeiten und im Liquor cerebrospinalis (Wick et al., 1996).

\section{Transferrinrezeptor}

Auf der Oberfläche von sämtlichen Körperzellen befinden sich Transferrinrezeptoren, über die die Zellen ihre Eisenversorgung regulieren. Ein Teil der Transferrinrezeptoren findet sich in modifizierter Form gelöst im Plasma. Die Konzentration dieses löslichen Transferrinrezeptors ist proportional zur Menge des Zell-assoziierten Rezeptors und steigt bei Eisenmangel an (Baynes et al., 1991). Dabei beginnt der Konzentrationsanstieg dann, wenn die Eisenspeicher nahezu entleert sind und die Erythropoese schon beeinträchtigt ist, aber noch keine Anämie besteht (Skikne et al., 1990).

Bei Menschen ohne Eisenmangel repräsentiert die steigende Konzentration des löslichen Transferrinrezeptors das Ausmaß der Erythropoese (Cook et al., 1993). Die Ursache hierfür liegt darin, daß sich $80 \%$ aller Transferrinrezeptoren in den Vorläuferzellen der Erythropoese befinden, da hier der Großteil des Eisens zur Hämoglobinsynthese benötigt wird (Thorstensen and Romslo, 1993). Der Anstieg des löslichen Transferrinrezeptors bei Eisenmangel überdeckt dabei den Anstieg, den eine verstärkte Erythropoese verursacht (Skikne et al., 1990). Außerdem findet sich eine große Zahl der Rezeptoren auf der Leber (Baynes, 1996), auf Zellen mit hoher Teilungsrate und auf der Plazenta (Cook et al., 1993).

Der zelluläre Transferrinrezeptor ist ein dimeres Protein, welches aus zwei Untereinheiten von je 95 kDalton besteht. Jede Untereinheit besteht aus einem Transmembransegment, gebildet aus 28 Aminosäuren, einer N-terminalen cytoplasmatischen Domäne aus 61 und einem C-terminalen extrazellulären Anteil aus 671 Aminosäuren (Shih et al., 1990). Diese Untereinheiten sind durch Disulfidbrücken an Cystein 89 und 98 nahe der Zelloberfläche miteinander verbunden. Die Gene sowohl für Transferrin als auch für den Transferrinrezeptor befinden sich auf dem Chromosom 3 (Cook et al., 1993).

Bei dem im Serum befindlichen löslichen Transferrinrezeptor handelt es sich um intakten Rezep- 
tor von 85 kDalton, dem allerdings das Transmembran- und das intrazytoplasmatische Segment fehlen. Er zirkuliert im Plasma gebunden an Transferrin (Shih et al., 1990).

\subsubsection{Aufnahme in die Zelle}

Jede der beiden Untereinheiten des Transferrinrezeptors kann ein Molekül Transferrin binden (Eisenstein and Blemings, 1998). Die Affinität zwischen Transferrin und Transferrinrezeptor steigt mit wachsender Eisenbeladung des Transferrins, hat also ihren Maximalwert, wenn das Transferrin mit zwei Eisenatomen beladen ist. Nach der Bindung der $\mathrm{Fe}^{3+}$-Transferrinkomplexe an den Transferrinrezeptor gelangt der gesamte Komplex durch Rezeptor-vermittelte Endozytose als Endosom in die Zelle. Sobald der pH-Wert in dem Endosom unter 5,5 fällt, sinkt die Affinität des Transferrins zu Eisen und das Eisen dissoziiert (Cook et al., 1993). Danach festigt sich die Bindung zwischen Transferrin und Transferrinrezeptor und löst sich erst wieder bei der Exozytose des Transferrin-Transferrirezeptorkomplexes in das Blutplasma durch den höheren plasmatischen pH-Wert (Wick et al., 1996). Letztendlich kommt es so zur Dissoziation von Apotransferrin sowie dem Verbleiben des Transferrinrezeptors auf der Zellmembran bis zur nächsten Bindung von Transferrin (Thorstensen and Romslo, 1990). Ein kleiner Teil der endozytierten Vesikel, auf denen sich die Transferrinrezeptoren befinden, sammelt sich vor der Exozytose in Form von multiplen 50 nm großen Vesikeln innerhalb einer größeren Vesikelmembran (Baynes, 1996). Vor der Exozytose findet in diesen multivesikulären Endosomen möglicherweise der größte Anteil der Proteolyse statt, durch die der lösliche Transferrinrezeptor entsteht (Rutledge et al., 1994).

\section{Ferritin}

$60 \%$ des gesamten im Körper enthaltenen Ferritins befinden sich in der Leber. Die übrigen $40 \%$ finden sich in der Muskulatur und in den Zellen des retikuloendothelialen Systems (Beard et al., 1996). In der Regel wird ein bestimmter Anteil des Ferritins an das Blutplasma abgegeben, der mit der Ferritinsynthese korreliert (Wick et al., 1996).

Als Makromolekül hat Ferritin ein Molekulargewicht von mindestens 440 kDalton, was abhängig von dem Eisengehalt ist. Dabei steht $1 \mathrm{mg}$ Ferritin pro Liter für etwa $10 \mathrm{mg}$ Speichereisen (Cook, 1982). Es besteht aus 24 Untereinheiten und einem Eisenkern von durchschnittlich etwa 2500 $\mathrm{Fe}^{3+}$-Ionen, kann sich aber auch zu Oligomeren (etwa 10-15\%) umbilden und bei Eisenüberschuß zu Hämosiderin in den Lysosomen kondensieren. Mindestens 20 Isoferritine sind bekannt (Wick et al., 1996). Diese Isoformen unterscheiden sich in ihrem Gehalt an sauren H(Heavy)und schwach basischen L(Light)-Untereinheiten. Das Gen für die H-Untereinheit ist lokalisiert auf Chromosom 11 und das für die L-Untereinheit auf Chromosom 19 (Baynes, 1996). Eine Eisenspeicherfunktion haben hauptsächlich die basischen Isoformen, die sich vorwiegend in Leber, Milz und Knochenmark finden. Die sauren Isoferritine stammen hauptsächlich aus Herzmuskel, 
Plazenta, Tumorgewebe und nur in kleinen Mengen aus den Speicherorganen. Sie speichern geringere Eisenmengen und dienen möglicherweise als Eisenüberträger bei Syntheseprozessen (Wick et al., 1996).

\subsubsection{Speicherung}

Die Eisenspeicherung erfolgt nach einer Oxidation des $\mathrm{Fe}^{2+} \mathrm{zu} \mathrm{Fe}^{3+}$ über Ferritin und sein halbkristallines Kondensationsprodukt Hämosiderin in Leber, Milz und Knochenmark (Wick et al., 1996). Dabei wird Eisen in der Leber zu $95 \%$ an Ferritin und zu $5 \%$ an Hämosiderin gebunden gespeichert. Bei Eisenüberladung hingegen kann Hämosiderin das 10-fache der Ferritinkonzentration betragen, wobei das Eisen aus Hämosiderin möglicherweise weniger gut mobilisierbar ist (Beard et al., 1996). Bei der Eisenspeicherung nehmen Leber und Milz eine Sonderstellung ein, da die Hepatozyten in der Lage sind, Häm-Fe ${ }^{2+}$ aus Haptoglobin, Hämopexin, intravasaler Hämolyse oder gesteigerter Hämresorption zu Ferritin-Fe ${ }^{3+}$-Speichereisen umzuwandeln. Außerdem bauen die retikulo-endothelialen Zellen in der Milz das aus den abgebauten Erythrozyten stammende $\mathrm{Fe}^{2+}$-Hämoglobin direkt zu Fe ${ }^{3+}$-Speichereisen um (Wick et al., 1996).

\subsubsection{Regulation der Eisen-Homöostase}

Etwa 16 bis 20 mg Eisen benötigt ein Mensch täglich zur Regeneration der Erythrozyten. Durch den täglichen Abbau von etwa 2 x $10^{11}$ (0,8 \%) Erythrozyten und dem damit verbundenen Katabolismus von circa 6,5 g Hämoglobin entsteht ein Eisenumsatz von ungefähr $25 \mathrm{mg} / 24 \mathrm{~h}$.

Da täglich nur 1 bis $3 \mathrm{mg}$ Eisen resorbiert werden, muß das freigesetzte Eisen möglichst vollständig wieder dem Stoffwechsel zugänglich gemacht werden. Dies geschieht durch Speicherung von anfallendem Eisen gebunden an Ferritin in Makrophagen des retikuloendothelialen Systems der Milz. Von hier wird das Eisen über den Transport durch Transferrin zum Knochenmark wieder der Hämoglobinsynthese zugeführt (Wick et al., 1996).

Die wichtigsten Prozesse, über die die ausreichende Versorgung des Körpers mit zusätzlich benötigtem Eisen reguliert wird, sind die intestinale Absorption, der Transport zu den Organen, die Aufnahme in die Zelle und der zelluläre Eisenbedarf (Beard et al., 1996).

\section{Steigerung der Absorption}

Eisenmangel ist der stärkste Aktivator der Eisenabsorption (Beard et al., 1996). Auch Hypoxie steigert sowohl die zelluläre als auch die intestinale Eisenabsorption (Thorstensen and Romslo, 1990). Zusätzlich stimuliert eine verstärkte aber auch eine ineffektive Erythropoese zum Beispiel bei Thalassämie, Blutungen oder hämolytischer Anämie die Absorption (Beard et al., 1996).

Die Regulation der Absorption erfolgt zum einen über gesteigerte Transferrinsynthese bei Hy- 
poxie und Anämie, wobei die gesteigerte Transferrinkonzentration zu besseren Absorptions- und Transportbedingungen führt (Wick et al., 1996). Die Transkription des Gens für Transferrin kann außerdem über Schwermetalle, Glukokortikoide, Akut-Phase-Reaktion, Insulinähnliche Wachstumsfaktoren, Plättchenspezifischen Wachstumsfaktor, epidermalen Wachstumsfaktor und Retinoide gesteuert werden. Eisen beeinflußt die Expression von Transferrin nur in der Leber, wobei es auf den posttranskriptionalen Weg einwirkt (Beard et al., 1996).

Auch die Synthese des Transferrinrezeptors wird zum Teil über die Transkription reguliert. Das trifft zumindest auf Hämoglobin-synthetisierende Zellen zu. Die Transkription ist hier allerdings von der intrazellulären Eisenkonzentration unabhängig (Chan and Gerhardt, 1992). Der Proliferationsstatus der Zelle ist ein weiterer Mechanismus, der die Zahl der Transferrinrezeptoren auf der Zelloberfläche reguliert (Thorstensen and Romslo, 1993). Außer durch Beeinflussung der Synthese wird die Eisenaufnahme möglicherweise durch Umverteilung der Transferrinrezeptorzahl innerhalb der Zelle reguliert, indem der Anteil der Rezeptoren variiert, die sich normalerweise zu einem Drittel auf der Zelloberfläche befinden (Cook et al., 1993).

Des weiteren induziert Eisenmangel die Häm-Oxygenase, die bei der Aufnahme von Hämeisen für dessen Aufspaltung sorgt (Beard et al., 1996).

\section{Verminderung der Absorption}

Eine verringerte Absorption von Eisen findet sich hingegen beispielsweise bei Infektionen, möglicherweise vermittelt durch Freisetzung von Cytokinen, die einen direkten Einfluß auf die Enterozyten haben.

Bei Eisenüberladung wird der Körper durch vermehrte Expression von Transferrinrezeptoren an der basolateralen Seite der Enterozyten (Beard et al., 1996) und Speicherung von an Ferritin gebundenem Eisen in der Mukosazelle vor einem Teil des überflüssigen Eisens geschützt. Dieses Eisen wird im Rahmen des physiologischen Zellumsatzes im Darm nach ein bis zwei Tagen ausgeschieden (Wick et al., 1996).

Die Erhöhung von Ferritin und damit die verstärkte Bindung von Eisen (und damit eine erniedrigte Konzentration von Eisen im Serum) bei einer Akut-Phase-Reaktion läßt sich auf eine Induktion der Apoferritinsynthese durch Interleukin-1 zurückführen (Worwood, 1997). Durch Anlagerung an die zytoplasmatischen Ribosomen kann Eisen auch direkt die Produktion von Apoferritin induzieren. Folglich ist die Ferritinkonzentration im Blutplasma ein Indikator für den Füllungszustand der Eisenspeicher (Wick et al., 1996).

\section{Molekulare Mechanismen}

Die Mechanismen, über die die beschriebenen Vorgänge reguliert werden, sind noch nicht vollständig erforscht. Bekannt sind zur Zeit die im Zytoplasma aller Zellen befindlichen eisensensorische 
Proteine IRP1 und IRP2 (IRP=Iron Regulatory Protein) (Eisenstein and Blemings, 1998) mit einem Molekulargewicht von 90 kDalton (Baynes, 1996), die auf Chromosom 9 lokalisiert sind (Beard et al., 1996). Diese regulieren über die Bindung an ,iron responsive elements“ (IRE = spezifische Bindungsstellen auf der mRNA) die Translation von Ferritin und dem Transferrinrezeptor (Eisenstein and Blemings, 1998).

Die Eisenbeladung der eisensensorischen Schwefel-Proteine reguliert ihre Affinität zu den „,iron responsive elements“. Ihre vier Eisenbindungsstellen sind bei ausreichender intrazellulärer Eisenkonzentration vollständig mit Eisen besetzt. Erniedrigt sich die intrazelluläre Eisenkonzentration und damit die Eisenbeladung der eisensensorischen Proteine, steigt ihre Affinität zu den ,iron responsive elements“" und es kommt zur Bindung an die mRNA. Dadurch wird einerseits die Expression von Ferritin blockiert und andererseits die Stabilität der Transferrinrezeptor-mRNA erhöht, so daß die Transferrinrezeptorsynthese zunimmt (Baynes, 1996). Erhöht sich die intrazelluläre Eisenkonzentration, so verlieren die eisensensorischen Proteine ihre RNA-Bindungsaktivität, so daß die Ferritinsynthese wieder ansteigt und die Transferrinrezeptorkonzentration sinkt.

Außer durch Eisen wird die Aktivität der eisensensorischen Proteine durch Stickoxide, Phosphorylierung durch die Proteinkinase C, oxidative Prozesse, Hypoxie und Reoxygenierung beeinflußt. Hierbei werden Einzelheiten noch erforscht.

Weitere Enzyme, die beim Menschen durch eisensensorische Proteine reguliert werden sind 5Aminolävulinat-Synthase (Hämbiosynthese), mitochondriale Aconitase (Citratzyklus) und das „natural resistance associated macrophage protein 2“ (nRAMP2). Das nRAMP2 spielt vermutlich ebenfalls eine Rolle bei der intestinalen Absorption und der intrazellulären Abgabe von Eisen (Eisenstein and Blemings, 1998).

Da diese Regulationsmechanismen nur in begrenzten Ausmaß wirksam sein können, werden extreme Abweichungen des Eisenangebots langfristig nicht ausgeglichen (Wick et al., 1996).

\subsection{Eisenstoffwechsel in der Schwangerschaft}

Schwangere Frauen und Kinder zwischen sechs und zwölf Monaten haben einen Eisenbedarf, der sonst in keiner anderen Lebensphase eines gesunden Menschen so hohe Werte erreicht (Hallberg, 1988). Beide Gruppen müssen deutlich mehr Eisen absorbieren, als der Körper verliert (Institute of Medicine, 1990).

\subsubsection{Bedarf}

Der gesamte Eisenbedarf in der Schwangerschaft beträgt $1040 \mathrm{mg}$. Er setzt sich für eine $55 \mathrm{~kg}$ schwere Frau zusammen aus 


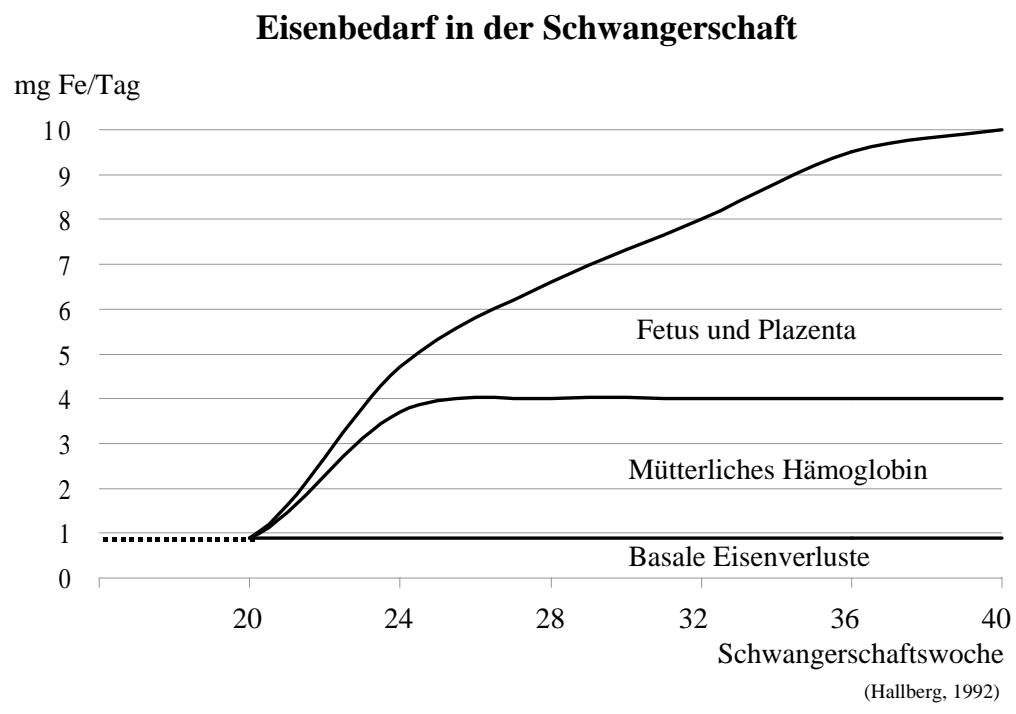

Abbildung 1.1: Entwicklung des täglichen Eisenbedarfs im Verlauf der Schwangerschaft.

- 300 mg für den Feten,

- 50 mg für die Plazenta,

- 450 mg für die Zunahme der roten Blutzellen der Mutter,

- $240 \mathrm{mg}$ für die basalen Eisenverluste der Mutter.

Zusätzlich verliert die Frau durch den Blutverlust bei der Geburt 250 mg Eisen. Durch den Abbau der Erythrozyten nach der Geburt und dadurch den Zurückgewinn von $450 \mathrm{mg}$ Eisen werden zum einen die Verluste der Geburt und weitere $200 \mathrm{mg}$ des in der Schwangerschaft verbrauchten Eisens wieder ausgeglichen. Somit ergibt sich ein Nettoverlust von $840 \mathrm{mg}$ Eisen.

Im Verlauf der Schwangerschaft sinkt die Eisenabsorption zunächst ab und steigt von der Mitte bis zum Ende der Schwangerschaft an. In der 24. Schwangerschaftswoche werden etwa 1,8 mg/Tag resorbiert; am Ende der Schwangerschaft etwa 5,4 mg/Tag. Auch in den ersten Monaten post partum ist die Absorption noch erhöht (Hallberg, 1992).

Korrespondierend zu dem Absorptionsabfall im ersten Trimenon der Schwangerschaft sinkt zunächst auch der Eisenbedarf auf 0,8 mg/Tag, und die Eisenspeicher können sogar ansteigen, da die Menstruationsverluste wegfallen (Abbildung 1.1 auf Seite 11). Etwa ab der 20. Schwangerschaftswoche steigt der Eisenbedarf zunächst stark an auf Werte, die über der resorbierten Eisenmenge liegen (Abbildung 1.2 auf Seite 12). Danach ist die Zunahme zwar schwächer aber kontinuierlich und erreicht am Ende der Schwangerschaft etwa 10 bis $12 \mathrm{mg} / \mathrm{Tag}$ (das Doppelte der resorbierten Eisenmenge). Im Mittel beträgt das Defizit an resorbiertem Eisen in der zweiten Schwangerschaftshälfte $3 \mathrm{mg} /$ Tag. Dieses Defizit muß durch Speichereisen gedeckt werden (Hallberg, 1988). 


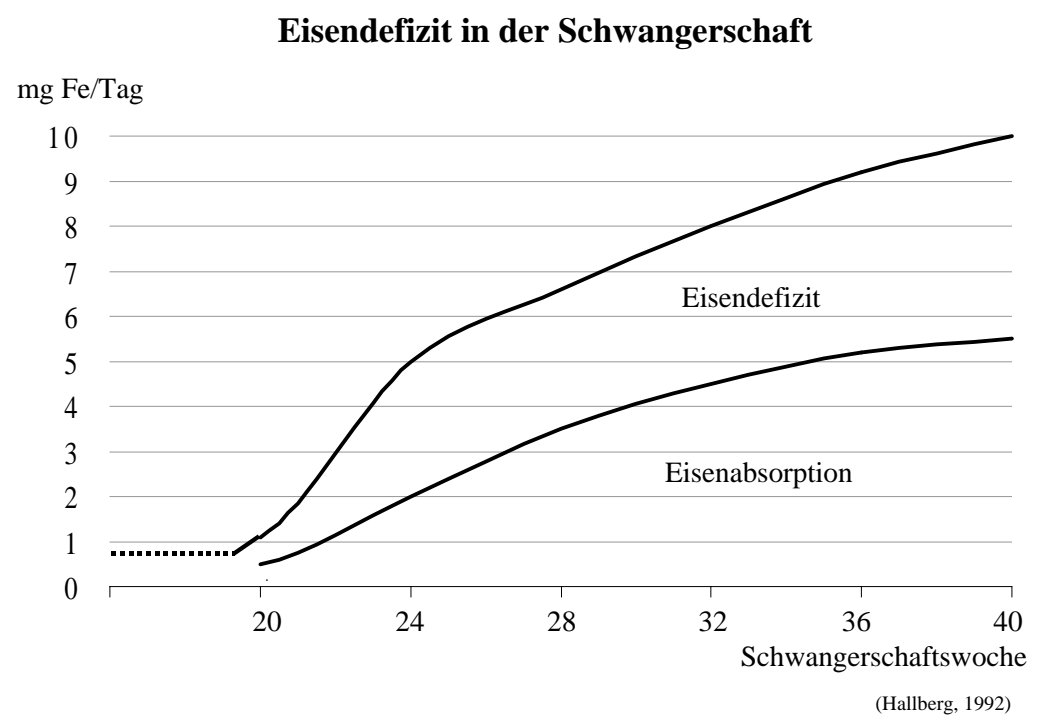

Abbildung 1.2: Täglicher Eisenbedarf und tägliche Eisenabsorption in der Schwangerschaft.

\subsubsection{Eisenumverteilung}

Zwischen der sechsten und achten Schwangerschaftswoche beginnt das mütterliche Plasmavolumen, sich auszudehnen. Bis zum Ende der Schwangerschaft nimmt es langsam aber kontinuierlich um insgesamt etwa $42 \%$ zu.

Das exponentielle Wachstum des Feten führt dazu, daß der Eisenbedarf für Fetus und Plazenta im ersten Trimenon beinahe vernachlässigbar gering ist, dafür aber im dritten Trimenon mehr als 80 \% dieses zusätzliches Eisenbedarfs gedeckt werden müssen (Hallberg, 1988).

Die Hämoglobinkonzentration nimmt während der Schwangerschaft bis etwa zur 16. Woche kontinuierlich ab, ist dann für zwei Wochen konstant und nimmt danach wieder zu. Sie bleibt auch zum Ende der Schwangerschaft unter den durchschnittlichen Konzentrationen von nicht Schwangeren. $\mathrm{Ab}$ der 16. bis 17. Schwangerschaftswoche beginnt sich, parallel zu dem Stopp des Hämoglobinabfalls, die Masse der Erythrozyten zu vergrößern (Hallberg, 1988). Die Erythrozytenmasse dehnt sich unter anderem durch eine Zunahme des mittleren Erythrozytenvolumens um etwa $5 \%$ aus (Scholl et al., 1992). Ab der 20. Woche findet sich bis zum Ende der Schwangerschaft ein fast linearer Anstieg der Erythrozytenmasse, welcher täglich etwa 3,2 mg Eisen verbraucht (Hallberg, 1988).

Ferritin zeigt während des zweiten und dritten Trimenons einen starken Abfall der Konzentration (Carriaga et al., 1991), der zum einen hormonell und zum anderen durch die Plasmaexpansion bedingt sein kann (Beard, 1994). Trotz dieser Änderungen der Ferritinkonzentration existieren keine für die Schwangerschaft korrigierten Grenzwerte für Ferritin (Carriaga et al., 1991), und es ist nicht sicher, ob die Ferritinkonzentration in der Schwangerschaft valide Rückschlüsse auf die Eisenspei- 
cher zuläßt (Beard, 1994). Eine mögliche Folge von Östrogenen ist der Anstieg von Transferrin in der gesamten Schwangerschaft um etwa $250 \%$. Dieser Transferrinanstieg und der Abfall von Serumeisen durch die Eisenaufnahme der Plazenta bedingt eine Verringerung der Transferrinsättigung (Allen, 1997). Der lösliche Transferrinrezeptor ist möglicherweise der einzige Indikator des Eisenstatus', der in der Schwangerschaft nahezu unverändert bleibt (Carriaga et al., 1991).

Stillende Frauen haben einen Eisenbedarf von etwa 1,1 mg/Tag (0,8 mg für die basalen Eisenverluste und 0,3 mg für das Eisen in der Muttermilch) (Hallberg, 1992). Der Wegfall der Menstruation begünstigt in dieser Zeit eine Erholung der Eisenspeicher. Bei Frauen, die in der Schwangerschaft Eisensupplemente eingenommen haben, können die Eisenspeicher zwei Monate post partum höher sein als vor der Schwangerschaft. Eisenspeicher, die allerdings in der Schwangerschaft entleert wurden, werden in den ersten Monaten post partum nicht wieder voll aufgefüllt (Allen, 1997).

\subsubsection{Eisentransport über die Plazenta}

Mütterliches mit Eisen beladenes Transferrin bindet sich an Transferrinrezeptoren an der apikalen Seite der Synzytiotrophoblasten. Diese Zellen endozytieren das Holotransferrin, wonach Apotransferrin wieder an die Zelloberfläche abgegeben und das Eisen an Ferritin gebunden zur basolateralen Seite transportiert wird. Hier wird das Eisen an fetales Apotransferrin gebunden und erreicht so als Holotransferrin den kindlichen Kreislauf (Allen, 1997).

Die Menge des auf diese Weise übertragenen Eisens wird durch zwei Faktoren beeinflußt:

- die Zahl der Transferrinrezeptoren auf der apikalen Seite

- die Ferritinkonzentration in den Synzytiotrophoblasten.

Die Menge der Transferrinrezeptoren steigt bei hohem und sinkt bei geringem Eisenbedarf des Feten. Die Ferritinkonzentration in den Synzytiotrophoblasten erhöht sich mit ansteigender Eisenkonzentration und verhindert so, daß zu viel Eisen in den fetalen Kreislauf gelangt. Gleichzeitig stellt dieses Ferritin einen fetalen Eisenspeicher dar (Starreveld et al., 1995).

\subsection{Diagnostik und Therapie von Eisenmangel}

\subsubsection{Klinische Zeichen}

Schon zellulärer Eisenmangel ohne Anämie kann zu erhöhter Anfälligkeit für Candida- und Herpes-simplex-Infektionen sein. Auch die Leistungsfähigkeit von Schwerstarbeitern kann eingeschränkt sein (Cook and Lynch, 1986). Bei Eisenmangelanämie kann es zusätzlich zu Blässe, Schwäche, Konzentrationsstörungen, Belastungsdyspnoe und gesteigerter Infektanfälligkeit kommen (Wick et al., 1996). 
Die wichtigsten nicht-hämatologischen Folgen von Eisenmangel sind Beeinträchtigungen des Immunsystems, der Arbeitsleistung und der neurologischen Funktionen. Ein Defekt der zellvermittelten Immunabwehr und der Funktion von neutrophilen Granulozyten (Cook and Lynch, 1986) kann bei Patienten mit Eisenmangel nachgewiesen werden und führt möglicherweise zu einer Prädisposition für respiratorische (Andelman and Sered, 1966) und gastrointestinale Infekte. Auch schon leichter Eisenmangel kann die Anfälligkeit für mukokutane Candidiasis und Herpes simplexInfektionen steigern. Andererseits kann eine verstärkte Eisensupplementierung insbesondere bei Immunsupprimierten das Risiko für bestimmte Infektionen verstärken, da es auch das mikrobielle Wachstum fördert (zum Beispiel bei Malaria). Eine Beseitigung einer Anämie und möglicherweise auch von zellulärem Eisenmangel erhöht die Leistungsfähigkeit von Schwerstarbeitern. Die neurologische Funktion wird durch Eisenmangel im Hinblick auf Aufmerksamkeitsspanne und kognitive Entwicklung beeinträchtigt, was insbesondere Kleinkinder, Vorschul- und Schulkinder betrifft (Cook and Lynch, 1986; Walter et al., 1997).

Weitere Effekte von Eisenmangel betreffen den Gastrointestinaltrakt, der besonders empfindlich auf schweren chronischen Eisenmangel reagiert. Klinische Manifestationen (Spätzeichen) sind neben Glossitis, Stomatitis, Mundwinkelrhagaden, chronischer Gastritis und Malabsorption auch Haar- und Nagelatrophie. Da die klinischen Zeichen für Eisenmangel erst bei einer manifesten Anämie auftreten, sollte die Diagnose anhand der Laborindikatoren gestellt werden (Wick et al., 1996; Cook and Lynch, 1986).

\subsubsection{Laborindikatoren}

Es gibt viele Labormethoden, die der Identifikation von Eisenmangel und seinem Ausmaß dienen können. Wenn nur ein oder zwei Methoden für das Screening verwendet werden, ist die Spezifität und Sensitivität besonders wichtig. Daher sind isolierte Messungen einerseits von PlasmaTransport-Variablen (Serumeisen, totale Eisenbindungskapazität, Transferrinsättigung) und Blutbild-Indikatoren (MCV, ,red cell distribution width“) entweder zu kostspielig oder nicht spezifisch genug in Bezug auf Eisenmangel, um für ein Screening Verwendung zu finden. Cook et al. (1992) schlagen für das Screening vier Verfahren vor: Hämoglobin oder Hämatokrit, Serum Ferritin, erythrozytäres Protoporphyrin und löslichen Transferrinrezeptor (Cook et al., 1992).

Bei der Diagnostik von Eisenmangel bei menstruierenden Frauen anhand von aus dem Blut gewonnenen Indikatoren ist die Schwankung der Konzentrationen im Rahmen des Menstruationszyklus zu beachten. So liegen die Hämoglobin-, Serumeisen- und Ferritinkonzentrationen sowie die Transferrinsättigung (TS) während der Menstruation signifikant unter den Werten, die sie in der späten Lutealphase erreichen (Kim et al., 1993). Die Grenzwerte für die Eisenstatusindikatoren bei Frauen finden sich in Tabelle 1.1 auf Seite 17. 


\section{Hämoglobin, Hämatokrit und mittleres Erythrozytenvolumen}

Hämoglobin ist ein tetrameres Protein mit einem Molekulargewicht von 64 kDalton. Der Globinanteil besteht aus je zwei $\alpha$ - und zwei $\beta$-Ketten. An jede dieser Untereinheiten ist ein HämMolekül in Form von Protoporphyrin IX gebunden, an dessen Eisenatom Sauerstoff reversibel gebunden werden kann.

Bei einer Anämie ist die Hämoglobinkonzentration des Blutes verringert (Beard et al., 1996). Sie ist eine der gebräuchlichsten Screening-Methoden, obwohl Hämoglobin nur eine geringe Spezifität und Sensitivität in Bezug auf Eisenmangel aufweist (Cook, 1982; Cook et al., 1992). Deswegen wird die Verwendbarkeit von Hämoglobin durch das Hinzuziehen einer zweiten spezifischeren Methode deutlich verbessert (Cook et al., 1992).

Außer durch Eisenmangel kann die Hämoglobinkonzentration durch Polyzythämie, Dehydratation, Rauchen, chronischen Krankheiten, Hämorrhagie, Unterernährung, Vitamin $\mathrm{B}_{12}$-Mangel, Folsäuremangel, Hämoglobinopathien und in der Schwangerschaft verändert werden (Beard et al., 1996).

Eine Hämoglobinkonzentration von $12 \mathrm{~g} / \mathrm{dl}$ wird in den meisten Untersuchungen als Anämiegrenze für menstruierende Frauen verwendet (Cook et al., 1986; Thefeld and Ellert, 1998; Ferguson et al., 1992; Kuvibidila et al., 1996). Auch die WHO empfiehlt 12 g/dl als Grenzwert für Frauen (Thomas, 1992). Nach dem Labor des Virchow-Klinikums (1997) liegt der Referenzbereich für Frauen zwischen 12 und 16 g/dl, was den Referenzwerten nach Worwood (1997) entspricht. Schwarze weisen um 0,5 bis 0,9 g/dl geringere Hämoglobinkonzentrationen als Weiße auf, auch wenn sie sich gleich ernähren. Die Ursachen für diesen Unterschied sind noch nicht vollständig geklärt, obwohl die höhere Prävalenz von Thalassämie bei der schwarzen Bevölkerung als Erklärung herangezogen wird (Perry et al., 1992; Yip, 1989).

Für den Hämatokrit findet sich für nicht schwangere Frauen ein Referenzbereich zwischen 0,36 und 0,45 (Thomas, 1992). Bei Schwarzen dagegen finden sich um bis zu $3 \%$ niedrigere Hämatokritwerte (Yip, 1989).

Die in den Laboren des Virchow-Klinikums verwendeten Referenzwerte für das mittlere Erythrozytenvolumen liegen bei Erwachsenen zwischen 86 und 96 fl. Nach Thomas (1992) liegen die Referenzwerte zwischen 80 und 96 fl.

\section{Serum-Ferritin}

Ferritin ist der einzige Indikator, der die Eisenspeicher repräsentiert. Sobald diese Speicher entleert sind (Konzentration < $12 \mu \mathrm{g} / \mathrm{l}$ ) (Åkesson et al., 1998; Carriaga et al., 1991; Flowers et al., 1989; Kuvibidila et al., 1996; Mast et al., 1998; Baynes, 1996) und die Erschöpfung des Funktionseisens fortschreitet, finden nur noch geringe Änderungen der Ferritinkonzentration statt. Deswegen 
lassen sich durch Ferritin allein nur eingeschränkte Aussagen über einen Funktionseisenmangel machen (Skikne et al., 1990).

Dadurch, daß Ferritin ein Akute-Phase-Protein ist, steigt dessen Konzentration auch bei Infektionen, Entzündungen und Tumorerkrankungen an, was in einem solchen Fall die Diagnose von Eisenmangel anhand von Ferritin unmöglich macht (Baynes, 1996; Ferguson et al., 1992). Außerdem können Alkoholabusus und Leber-Parenchymverletzungen die Ferritinkonzentration erhöhen. Zudem steigt die Ferritinkonzentration mit zunehmendem Body-Mass-Index (Worwood, 1997). Unter Bedingungen, in denen die Eisenspeicher erniedrigt sind, wie etwa bei Kleinkindern, heranwachsenden Jugendlichen, Schwangeren und Leistungssportlern, können ebenfalls anhand von Ferritin nur bedingt Aussagen über eventuelle Eisenmangelzustände gemacht werden (Baynes, 1996).

Die Ferritinkonzentration im Serum bleibt über den Tag verteilt relativ konstant. Die Referenzintervalle für Ferritin sind alters- und geschlechtsabhängig. Sie liegen für Frauen unter 50 Jahren zwischen 23 und $110 \mu \mathrm{g} / \mathrm{l}$ (Thomas, 1992) (Referenzbereich des Virchow-Klinikums (1997): 10 bis $200 \mu \mathrm{g} / \mathrm{l}$ für Frauen).

\section{Erythrozytäres Protoporphyrin}

Freies erythrozytäres Protoporphyrin (EP) ist ein Zwischenprodukt der Hämsynthese und steigt bei inadäquater Eisenversorgung der Hämsynthese an (Yip, 1989). Für Erwachsene liegen die normalen Werte unter 1,24 $\mu \mathrm{mol} / \mathrm{l}$ Erythrozyten (Looker et al., 1990). Bei ein- bis dreijährigen Kindern finden sich etwas höhere Konzentrationen (Worwood, 1997). Außer bei Eisenmangel wird die Konzentration des erythrozytären Protoporphyrins bei Bleivergiftungen erhöht, was die Verwendung dieses Indikators limitiert (Cook et al., 1992).

Dieser Test wird in deutschen Laboratorien nicht durchgeführt (Worwood, 1997) und auch in der vorliegenden Untersuchung nicht verwendet.

\section{Löslicher Transferrinrezeptor}

Die neueste Methode zur Bestimmung des Eisenstatus' ist die Messung der Konzentration des löslichen Transferrinrezeptors. Anders als Ferritin, welches die Eisenspeicher repräsentiert, steht der lösliche Transferrinrezeptor für den Gewebseisenbedarf. Er kann auch das Ausmaß eines Funktionseisenmangels identifizieren, wogegen Ferritin nur eine qualitative Aussage zuläßt (Cook et al., 1992).

Gegenüber Ferritin hat der lösliche Transferrinrezeptor außerdem den Vorteil, daß seine Konzentration durch Anämie aufgrund von akuten Infekten und chronischen Krankheiten nahezu unverändert bleibt. Somit kann ein Anstieg der Konzentration des löslichen Transferrinrezeptors im Falle einer chronischen Krankheit eine Knochenmarkspunktion zur Diagnose von Eisenmangel 
Tabelle 1.1: Referenzwerte der Eisenstatusindikatoren bei Frauen: 1: Institut für Klinische Chemie und Biochemie, Virchow-Klinikum (1997); 2: Thomas (1992); 3: Looker et al. (1990); 4: Suominen et al. (1998); 5: Institute of Medicine (1990).

\begin{tabular}{|c|c|c|c|}
\hline \multicolumn{4}{|c|}{ Referenzwerte } \\
\hline & \multirow[b]{2}{*}{ nicht schwangere Frauen } & \multicolumn{2}{|c|}{ schwangere Frauen } \\
\hline & & 12. SSW & Termin \\
\hline Eisen $(\mu \mathrm{g} / \mathrm{dl})^{1}$ & $40-160$ & $42-177$ & $25-137$ \\
\hline Totale Eisenbindungskapazität $(\mu \mathrm{g} / \mathrm{dl})^{2}$ & $257-402$ & $235-413$ & $369-615$ \\
\hline Transferrin $(\mathrm{mg} / \mathrm{dl})^{2}$ & $200-310$ & $210-370$ & $310-630$ \\
\hline Transferrinsättigung $(\%)^{2}$ & $16-45$ & $18-50$ & $2-30$ \\
\hline Hämoglobin $(\mathrm{g} / \mathrm{dl})^{1}$ & $12-16$ & $10,5-?^{5}$ & $11-?^{5}$ \\
\hline Hämatokrit $^{2}$ & $0,36-0,45$ & & \\
\hline Mittleres Erythrozytenvolumen $(\mathrm{fl})^{2}$ & $80-96$ & & \\
\hline Serum Ferritin $(\mu \mathrm{g} / 1)^{2}$ & $23-110$ & & \\
\hline Erythrozytäres Protoporphyrin $(\mu \mathrm{mol} / 1 \text { Erythrozyten })^{3}$ & $<1,24$ & & \\
\hline Löslicher Transferrinrezeptor $(\mathrm{mg} / \mathrm{l})^{4}$ & $1,3-3,3$ & & \\
\hline TfR-F Index ${ }^{4}$ & $0,63-1,8$ & & \\
\hline
\end{tabular}

ersetzen (Ferguson et al., 1992; Mast et al., 1998). Außerdem weist der lösliche Transferrinrezeptor geringere intraindividuelle Schwankungen auf als Ferritin (Cooper and Zlotkin, 1996). Gegenüber dem mittleren Erythrozytenvolumen und dem erythrozytären Protoporphyrin hat der lösliche Transferrinrezeptor den Vorteil, daß er sich bei Veränderungen der Eisenspeicher schneller ändert. Somit ist er auch gut geeignet, um den Erfolg einer Eisentherapie zu überwachen (Cook et al., 1993).

Insbesondere in der Schwangerschaft kann die Konzentration des löslichen Transferrinrezeptors als Indikator für Eisenmangel dienen, da in dieser Zeit die Ferritinkonzentration aufgrund der Mobilisation von mütterlichen Eisenreserven fällt und somit nicht mehr zuverlässig einen Eisenmangel aufdeckt (Cook et al., 1993). Die Konzentration des löslichen Transferrinrezeptors hingegen steigt zwar im Verlauf der Schwangerschaft als Zeichen der zunehmenden Erythropoese an, weist aber trotzdem eine Spezifität von $100 \%$ bei einer Sensitivität von $71 \%$ in Bezug auf Eisenmangel auf (Åkesson et al., 1998). Trotz des Anstiegs unterscheiden sich die mittleren Konzentrationen des löslichen Transferrinrezeptors in der Schwangerschaft nicht von denen bei nicht-schwangeren Frauen (Carriaga et al., 1991).

Anstieg der Konzentration Erhöhte Konzentrationen an löslichem Transferrinrezeptor finden sich außer bei Eisenmangel im Rahmen einer gesteigerter Erythropoese infolge hämolytischer Anämie und Anämie aufgrund von Reifungsstörungen (Cook et al., 1993) sowie bei chronisch lymphatischer Leukämie (als einzige der Leukämien) (Klemow et al., 1990).

Abfallen der Konzentration Ein Absinken der Konzentration des löslichen Transferrinrezeptors findet sich dagegen bei eingeschränkter Erythropoese zum Beispiel verursacht durch aplastische Anämien (um mehr als $50 \%$ ), schweren Nierenerkrankungen (um etwa $40 \%$ ) und Einnahme 
von Knochenmark-suppressiven Medikamenten (um mehr als 50 \%) (Huebers et al., 1990). Die Diagnose von aplastischer Anämie durch den löslichen Transferrinrezeptor ist allerdings dadurch limitiert, daß sich etwa ein Drittel der Rezeptoren auf Zellen befinden, die nicht an der Erythropoese beteiligt sind (Cook et al., 1993).

Bei Eisenüberladung findet sich ebenfalls eine erniedrigte Konzentration des löslichen Transferrinrezeptors im Serum (Khumalo et al., 1998).

Referenzwerte Die Transferrinrezeptorbestimmung ist eine Methode, die zur Zeit in der Routine nur selten durchgeführt wird (Wick et al., 1996). Da noch keine Standardmethode vorliegt, variieren die Referenzwerte mit der jeweilig verwendeten Methode. Das 95\%-Konfidenzintervall für Erwachsene wird für die in der vorliegenden Studie verwendete Methode (IDeA von Orion Diagnostica) mit 1,3 bis 3,3 mg/l bei einem Mittelwert von 2,1 mg/l angegeben (Suominen et al., 1997). Bei der zur Gewinnung der Referenzwerte untersuchten Studienpopulation konnte jedoch aufgrund von fehlender Knochenmarksuntersuchung ein zellulärer Eisenmangel nicht vollständig ausgeschlossen werden. In einer weiteren Studie wurden die zu Beginn der Untersuchung gesunden und nicht-anämischen Studienteilnehmer drei Monate mit Eisen supplementiert. Danach ergaben sich geringere Referenzwerte für den löslichen Transferrinrezeptor (1,15-2,75 mg/l). Nach dieser Studie wurde als Grenze für beginnenden Funktionseisenmangel eine Konzentration von 2,75 mg/l definiert (Suominen et al., 1998).

Die Referenzintervalle von Frauen und Männern sind gleich und zeigen zwischen 19 und 79 Jahren keine Altersabhängigkeit (Huebers et al., 1990; Allen et al., 1998). Auch Frauen vor und nach der Menopause zeigen gleiche Konzentrationen. Des weiteren bleibt die Konzentration des löslichen Transferrinrezeptors bei Unterernährung ohne Eisenmangel konstant (Kuvibidila et al., 1996). Neugeborene dagegen zeigen signifikant höhere Konzentrationen als Erwachsene (Kuiper-Kramer et al., 1998). Allen et al. (1998) fanden um etwa $9 \%$ höhere Transferrinrezeptorkonzentrationen bei Schwarzen als bei Weißen, was möglicherweise mit der um etwa $5 \%$ geringeren Hämoglobinkonzentration bei Schwarzen zusammenhängt. Ebenfalls um $9 \%$ höhere Konzentrationen haben Menschen, die in höheren Lagen wohnen als solche, die auf Meereshöhe leben (Allen et al., 1998).

\section{Speichereisen im Knochenmark}

Die ursprüngliche Methode zur Erfassung der Eisenspeicher ist die Bestimmung von Eisen aus dem Knochenmark (Beard, 1994). Da die Zellen des retikuloendothelialen Systems die Haupteisenquelle für das rote Knochenmark darstellen, können die Eisenspeicher durch eine histologische Untersuchung des Knochenmarks direkt bestimmt werden. Die Anwesenheit von Speichereisen im Knochenmark schließt eine Anämie aufgrund von Eisenmangel aus. Deswegen dient diese Untersuchung der Differentialdiagnose bei Anämie (Cook, 1982). Jedoch ist die Analyse des Knochenmarks aufgrund der Invasivität für den routinemäßigen Gebrauch nicht geeignet (Yip, 1989). 


\section{Eisen und Eisenbindungskapazität}

Die Verwendung von Eisen bei der Diagnose von Eisenmangel hat nur eine geringe Aussagekraft, da die Eisenkonzentration im Serum sowohl einer circadianen Rhythmik (zwischen Morgen und Abend kann der Unterschied bis zu $50 \mu \mathrm{g} / \mathrm{dl}$ betragen) als auch Tag-zu-Tag-Schwankungen unterliegt (Wick et al., 1996; Worwood, 1997). Außerdem finden sich erniedrigte Eisenkonzentration im Serum bei Infektionen, Entzündungen Verletzungen und nach Operationen.

Eisen kann aus Serum oder Heparinplasma bestimmt werden, wogegen EDTA-Plasma zu Interferenzen führen kann und Hämolyse störend wirkt. Das Referenzintervall von der SerumEisenkonzentration liegt zwischen 40 und $160 \mu \mathrm{g} / \mathrm{dl}$ (Wick et al., 1996) (38,9-160,7 $\mu \mathrm{g} / \mathrm{dl}$ für Erwachsene (Institut für Klinische Chemie und Biochemie, Virchow-Klinikum, 1997)). Jedoch zeigt Eisen keine Normalverteilung, sinkt mit zunehmendem Alter signifikant ab und liegt bei Männern um etwa 15-20 \% höher als bei Frauen. Nach wochenlanger Lagerung von Serum bei +4 Grad Celsius wurden keine meßbaren Veränderungen gefunden (Wick et al., 1996).

Die Bestimmung der totalen Eisenbindungskapazität (TEBK) und der latenten Eisenbindungskapazität (LEBK) wurde mittlerweile von der Bestimmung des Transferrins und der Transferrinsättigung ersetzt. Die TEBK ist die Eisenmenge, die von Transferrin in einem definierten SerumVolumen gebunden werden kann, die LEBK ist die Eisenmenge, die notwendig wäre, um das Transferrin vollständig mit Eisen zu sättigen. Es gilt: TEBK = LEBK + Plasma-Eisen.

Der Referenzbereich für die totale Eisenbindungskapazität liegt für nicht schwangere Frauen zwischen 257 und $402 \mu \mathrm{g} / \mathrm{dl}$. Bei Schwangeren in der 12. Schwangerschaftswoche findet sich ein erniedrigter Referenzbereich (235-413 $\mu \mathrm{g} / \mathrm{dl})$, am Ende der Schwangerschaft dagegen ein erhöhter Referenzbereich (369-615 $\mu \mathrm{g} / \mathrm{dl})$. Sechs Wochen post partum liegt der Referenzbereich wieder niedriger (246-380 $\mu \mathrm{g} / \mathrm{dl})$ (Thomas, 1992).

\section{Transferrin und Transferrinsättigung}

Zwar existieren von Transferrin etwa 20 Isoformen, doch unterscheiden sich diese kaum in ihrer Eisenbindungskapazität und ihren immunologischen Eigenschaften. Somit ist dies für die Transferrinbestimmung ohne Bedeutung. Wie Ferritin ist auch die Serum-Transferrinkonzentration nahezu unabhängig von der Tageszeit. Ein Transferrinmolekül kann höchstens zwei Fe ${ }^{3+}$ binden, was etwa 1,41 mg Eisen pro $1 \mathrm{mg}$ Transferrin entspricht (Wick et al., 1996). Wie die Konzentration von Eisen wird auch die Transferrinkonzentration im Rahmen einer Infektion erniedrigt (Suominen et al., 1997). Gabe von oralen Kontrazeptiva wiederum kann die Transferrinkonzentration erhöhen (Wick et al., 1996).

Die Transferrinkonzentration liegt für nicht schwangere Frauen in einem Referenzintervall zwischen 200 mg/dl und 310 mg/dl (Virchow-Klinikum (1997): 200mg/dl bis 360 mg/dl für Erwachsene). Bei Schwangeren in der 12. Schwangerschaftswoche finden sich Referenzwerte zwischen 
$210 \mathrm{mg} / \mathrm{dl}$ und $370 \mathrm{mg} / \mathrm{dl}$, am Termin zwischen $310 \mathrm{mg} / \mathrm{dl}$ und 630 mg/dl (Thomas, 1992).

Die Transferrinsättigung (TS) steht für die Sättigung des Transferrins mit Eisen (siehe 2.3 auf Seite 37). Sie sollte für nicht schwangere Frauen zwischen $16 \%$ und $45 \%$ liegen (Schwangere: 12. Woche: $18 \%$ bis $50 \%$, Termin: $2 \%$ bis $30 \%$ ) (Thomas, 1992).

Die Transferrinsättigung schwankt im Tagesverlauf mit dem Eisengehalt des Plasmas. Nach NHANES III (dritter National Health and Nutrition Examination Survey) ist die Transferrinsättigung aber am Morgen höher als später am Tag (Looker et al., 1995). Deshalb ist zur Beurteilung der Eisenspeicher das relativ konstante Ferritin der Transferrinsättigung vorzuziehen (Wick et al., 1996). Jedoch hat die Bestimmung der Transferrinsättigung gegenüber der alleinigen Eisenbestimmung den Vorteil, daß die Einflüsse unterschiedlicher Blutabnahmetechniken, unterschiedlicher Hydratationszustände des Patienten und der unterschiedlichen Transferrinkonzentrationen keine Auswirkungen haben (Wick et al., 1996).

\subsubsection{Definition}

Anhand der labormedizinischen Untersuchung lassen sich zwei Stadien des Eisenmangels unterscheiden:

- Speichereisenentleerung

- manifester Eisenmangel (Eisenmangelanämie) (Thefeld and Ellert, 1998).

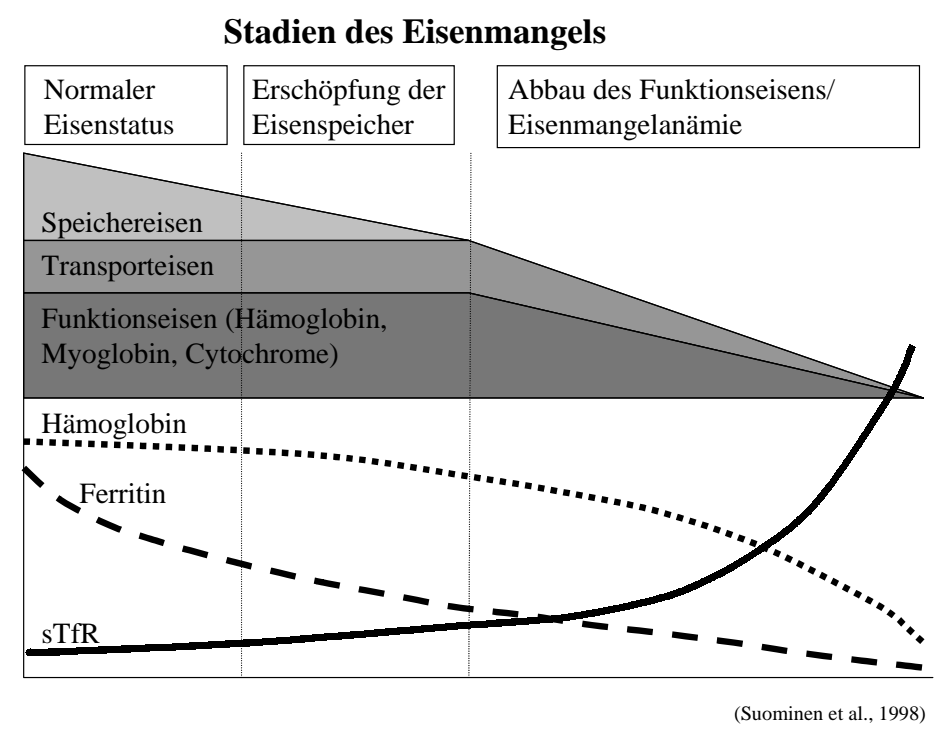

Abbildung 1.3: Entstehung von Eisenmangel in verschiedenen Stadien.

Bei einer Entleerung der Eisenspeicher ist das Depoteisen nahezu erschöpft (Ferritin $<12 \mu \mathrm{g} / \mathrm{l}$ ) und das Transporteisen (Transferrinsättigung < 16 \% (Kuvibidila et al., 1996; Worwood, 1997). ) 
sowie das Serumeisen erniedrigt (Eisen $<60 \mu \mathrm{g} / \mathrm{dl}$ (Thefeld and Ellert, 1998)); das Funktionseisen (Hämoglobin) liegt noch im Normbereich (Wick et al., 1996; Thefeld and Ellert, 1998). Gleichzeitig wird die enterale Absorption gesteigert.

Sobald ein Eisenmangel so ausgeprägt ist, daß die Hämoglobinsynthese beeinträchtigt wird, spricht man von einer Eisenmangelanämie (siehe Abbildung 1.3 auf Seite 20). Die Hämoglobinkonzentration bei Frauen liegt dann unter 12 g/dl (Thefeld and Ellert, 1998; LSRO (Life Science Research Office), 1984), das MCV (mittleres Zellvolumen) unter 80 fl (Thomas, 1992). Es entwickelt sich eine mikrozytäre, hypochrome Anämie mit Anulozyten, Poikilo- und Anisozytose, die bei Frauen ab einer Hämoglobinkonzentration von $<10 \mathrm{~g} / \mathrm{dl}$ als ausgeprägte Eisenmangelanämie eingestuft werden kann (Thefeld and Ellert, 1998). Da bei Eisenmangel die Expression des Transferrinrezeptors auf den Zellen der Erythropoese zur Verbesserung der Eisenaufnahme ansteigt, erhöht sich auch die Konzentration des im Plasma befindlichen löslichen Transferrinrezeptors (Wick et al., 1996).

Aufgrund der Blutverdünnung im zweiten Trimenon einer Schwangerschaft definiert die WHO

Tabelle 1.2: Grenzwerte für Hämoglobin und Häma-

tokrit in der Schwangerschaft.

\begin{tabular}{lll}
\hline \multicolumn{3}{c}{ Anämiegrenzen in der Schwangerschaft } \\
\hline & Hämoglobin $(\mathrm{g} / \mathrm{dl})$ & Hämatokrit \\
\hline erstes Trimenon & 11,0 & 0,33 \\
zweites Trimenon & 10,5 & 0,32 \\
drittes Trimenon & 11,0 & 0,33 \\
\hline
\end{tabular}

(World Health Organization) für Schwangere einen Grenzwert von $11 \mathrm{~g} / \mathrm{dl}$ für Hämoglobin (US Preventive Services Task Force, 1993). Die „Centers for Disease, Control and Statistics“ änderten diese Definition, um den Hämoglobinabfall im zweiten Trimenon mit einzubeziehen, in die in Tabelle 1.2 gezeigten Grenzwerte für Hämoglobin und Hämatokrit (US Preventive Services Task Force, 1993).

\subsubsection{Kombination mehrerer Indikatoren}

Die Idee, Eisenmangel über mehr als eine Variable zu definieren, stammt von Cook et al. (1976), in dessen Studie sich zeigte, daß Personen mit nur einem veränderten Eisenstatusindikator keine signifikant erhöhte Prävalenz von Anämie zeigten. Dagegen wiesen Personen mit zwei bis drei Meßgrößen jenseits der Grenzwerte eine deutlich erhöhte Prävalenz auf (Looker et al., 1990).

\section{Drei Variablen}

Die Definition von Eisenmangel erfolgte nach HANES (Health and Nutrition Examination Surveys) in den USA über ein ,three-variable MCV model“, nach welchem bei Eisenmangel zwei 
von drei Meßgrößen (MCV, EP (erythrozytäres Protoporphyrin) und TS (Transferrinsättigung)) unter dem Grenzwert liegen müssen. Neben dem MCV-Modell wird auch oft das Ferritin-Modell (Serum Ferritin, Transferrinsättigung und erythrozytäres Protoporphyrin) angewendet (Yip, 1989).

\section{Zwei Variablen}

Weitere gebräuchliche Kombinationen von nur zwei Variablen sind Hämoglobin und Ferritin, Hämoglobin und erythrozytäres Protoporphyrin, Hämoglobin und löslicher Transferrinrezeptor oder Ferritin und löslicher Transferrinrezeptor. Dabei ist die Kombination von Hämoglobin und Ferritin am gebräuchlichsten, da hier sowohl die Eisenspeicher als auch die Entwicklung einer Anämie erfaßt werden. Dabei liegt der größte Nachteil in den Kosten für die Ferritinbestimmung.

Der Vorteil einer gleichzeitigen Verwendung von Hämoglobin und erythrozytärem Protoporphyrin ist, daß die Ergebnisse der Laboruntersuchungen schnell vorliegen.

Auch der lösliche Transferrinrezeptor zusammen mit Hämoglobin kann sowohl einen Gewebseisenmangel als auch das Ausmaß einer Anämie erfassen, jedoch wird eine Verringerung der Eisenspeicher nicht genau erfaßt.

Sowohl das Ausmaß von Anämie als auch die Entleerung der Eisenspeicher kann außerdem durch die Kombination von Ferritin und löslichem Transferrinrezeptor bestimmt werden (Cook et al., 1992).

\section{sTfR-Ferritin-Quotient und TfR-F Index}

Da Ferritin das Speichereisen und der lösliche Transferrinrezeptor das Funktionseisen repräsentiert, verwenden einige Autoren den Quotienten aus Konzentration des löslichen Transferrinrezeptors und der Ferritinkonzentration (sTfR-Ferritin-Quotient), um damit sowohl einen beginnenden Eisenmangel als auch den Grad eines Funktionseisenmangels beurteilen zu können. Dieser Quotient korreliert negativ mit dem Eisenstatus. Der Mittelwert liegt bei adäquaten Eisenspeichern unter 100. Dagegen steigt er bei entleerten Speichern auf Werte über 2000 (Skikne et al., 1990).

In anderen Studien wird der Quotient aus der Konzentration des löslichen Transferrinrezeptors und dem Logarithmus der Ferritinkonzentration (TfR-F Index) benutzt, der sich ebenfalls bei zunehmender Entleerung der Eisenspeicher erhöht. Dieser Index steigert möglicherweise die diagnostische Effizienz im Vergleich zur alleinigen Messung des löslichen Transferrinrezeptors (Punnonen et al., 1997). Dabei liegt das Referenzintervall bei einer Stichprobe nach Eisensupplementation zwischen 0,63 und 1,8 (Suominen et al., 1998). 


\section{Differentialdiagnose}

Weitere Ursachen für eine mikrozytäre Anämie können sowohl ein erhöhter Eisenbedarf mit Eisenumverteilung bei chronischen Infekten oder maligne Neoplasien als auch Eisenverwertungsstörungen (zum Beispiel bei Erythropoetinmangel) darstellen. Diese Anämieursachen unterscheiden sich vom Eisenmangel dadurch, daß hier die Ferritinkonzentration erhöht ist (Wick et al., 1996).

Die Gründe dafür liegen bei chronischen Entzündungen und Tumoren in einer Umverteilung des Körpereisens zugunsten des Speichereisens. Die Ursache für die begleitende Anämie liegt in den freigesetzten Zytokinen (Tumor-Nekrosefaktor, Interleukin 1, $\gamma$-Interferon, $\beta$-Interferon). Diese inhibieren die „,colony-forming-units“ der Erythrozyten und lösen dadurch eine Anämie aus. Außerdem wird die Serumeisenkonzentration dadurch erniedrigt, daß die retikuloendothelialen Zellen kein Eisen mehr freisetzen, so daß dieses Speichereisen nicht zu Funktionseisen umgesetzt werden kann. Dadurch kommt es außerdem zu einer verminderten Transferrinsättigung. Das ungesättigte Transferrin wiederum bindet verstärkt das noch vorhandene freie Eisen, welches somit nicht als Nährstoff für die infektauslösenden Erreger dienen kann (Walter et al., 1997). Bei Tumoren kann außerdem die Freisetzung von basischen und sauren Isoferritinen zu einer Erhöhung der Ferritinkonzentration führen. Die Ferritinkonzentration erhöht sich im Rahmen der AkutePhase-Reaktion, spielt also die Rolle eines Akutphase-Proteins. In diesen Fällen repräsentiert die Ferritinkonzentration nicht mehr die Eisenspeicher, das heißt, daß trotz erhöhter Ferritinkonzentration ein zusätzlicher Eisenmangel vorliegen kann.

Andererseits muß bei einer Ferritinkonzentration von über $400 \mu \mathrm{g} / 1$ eine mögliche Eisenüberladung des Organismus ausgeschlossen werden, bei der die Transferrinsättigung über $50 \%$ liegt. Im Gegensatz zur Akute-Phase-Reaktion ist bei der Eisenüberladung das C-reaktive Protein nicht erhöht, was ebenfalls zur Differentialdiagnose dienen kann (Wick et al., 1996).

Von der Eisenmangelanämie abzugrenzende Erythropoesestörungen können bedingt sein durch Vitamin $B_{12}$ - und Folsäuremangel (makrozytäre, hyperchrome Anämie), Hämoglobinopathien (zum Beispiel Sichelzellanämie mit Sichelzellen, Thalassämien mit mikrozytärer Anämie und TargetZellen sowie pathologisch gesteigerter Hämolyse) und Porphyrinsynthesestörungen. Diesen Störungen lassen sich ebenfalls durch erhöhte Ferritinkonzentrationen von einem Eisenmangel differenzieren.

Die erniedrigte Ferritinkonzentration ist somit das wichtigste gebräuchliche differentialdiagnostische Zeichen einer Eisenmangelanämie (Wick et al., 1996).

Liegen bei Patienten Infekte oder Tumoren vor, kann der lösliche Transferrinrezeptor zur Diagnose eines zusätzlichen Eisenmangels dienen, da seine Konzentration, im Gegensatz zu der von Ferritin, in diesen Situationen stabil bleibt (Ferguson et al., 1992). 


\subsection{Auswirkungen von Eisenmangel}

Eisenmangel kann schon ohne Anämie zu Abgeschlagenheit, verminderte Konzentrationsfähigkeit und herabgesetztem Erinnerungsvermögen führen (Hendricks and Herbold, 1998). Er hat neben einer Beeinträchtigung der Feinmototik und des Verhaltens bei Kindern möglicherweise Auswirkungen auf dopaminerge Neuronen (Ballabriga, 1988). Außerdem zeigen sich Zusammenhänge mit den im Folgenden beschriebenen Faktoren.

\subsubsection{Produktivität}

Frauen mit Anämie zeigen eine geringere Arbeitsleistung als Frauen mit normalen Hämoglobinkonzentrationen (Untoro et al., 1998).

\subsubsection{Müittersterblichkeit}

Zwar gibt es sowohl Studien, nach denen bei schwerer Anämie (Hämoglobin $<4 \mathrm{~g} / \mathrm{dl}$ ) eine erhöhte perinatale Müttersterblichkeit festgestellt wurde, als auch Untersuchungen, nach denen dies bei moderaterer Anämie zutrifft. Jedoch sind die Zusammenhänge hierbei noch nicht hinreichend geklärt (Allen, 1997).

\subsubsection{Immunsystem}

Obwohl Eisenmangel das Immunsystem beeinträchtigen kann, ist wenig über den Zusammenhang von Eisenmangel und der Schwere von Krankheiten in der Schwangerschaft bekannt. Allerdings hatten Schwangere mit Eisenmangel erniedrigte Lymphozyten-Stimulations-Indices, und bei Schwangeren, die Eisenpräparate erhielten, verbesserte sich die Lymphozytenstimulation (Allen, 1997).

Bei Versuchen an Ratten fanden sich bei Eisenmangel eine erniedrigte Zahl von Abwehrzellen im Peritonealexsudat sowie eine eingeschränkte Zytotoxizität der peritonealen Makrophagen und der peritonealen T-Killerzellen (Hallquist et al., 1992).

\subsubsection{Folgen von mütterlichem Eisenmangel für das Kind}

Die Tatsache, daß auch ein Jahr nach der Geburt noch $70 \%$ des kindlichen Hämoglobins über die Plazenta aufgenommenes Eisen enthält, zeigt die Bedeutung einer ausreichenden Eisenversorgung des Neugeborenen auch auf längere Sicht gesehen (Andelman and Sered, 1966). 


\section{Eisenstatus und Gesundheit des Kindes}

Über den Zusammenhang zwischen mütterlichem Eisenstatus und dem des Kindes gibt es Untersuchungen mit unterschiedlichen Ergebnissen. In manchen Studien fand sich keine Korrelation zwischen Eisenstatus der Mutter in der Schwangerschaft und dem Nabelschnurblut bei der Geburt (Rios et al., 1975). Bei anderen Studien war entweder die mütterliche Ferritinkonzentration ein Prädiktor für die Ferritinkonzentration im Nabelschnurblut (Ajayi, 1988) oder eine Anämie der Mutter (Hämoglobin $<11 \mathrm{~g} / \mathrm{dl}$ ) war assoziiert mit niedrigeren Werten im Nabelschnurblut für Erythrozytenzahl, Hämoglobin und Hämatokrit (Gaspar et al., 1993). Auch wurde ein Zusammenhang zwischen der Hämoglobinkonzentration anämischer Schwangerer und der Ferritinkonzentration des Nabelschnurbluts festgestellt (Agrawal et al., 1983).

Möglicherweise zeigen sich die Auswirkungen von Eisenmangel in der Schwangerschaft bei dem Kind auch erst einige Monate nach der Geburt. Hierzu gibt es nur wenige Studien, bei denen sich einmal ein Zusammenhang zwischen mütterlicher Anämie und kindlichen Hämoglobinkonzentrationen zwar nicht bei der Geburt aber mit einem Jahr zeigte (Strauss, 1933). Auch in neueren Untersuchungen findet sich ein signifikanter Zusammenhang zwischen Eisenmangelanämie der Mutter in der Schwangerschaft und Entwicklung eines Eisenmangels des Kindes innerhalb des ersten Lebensjahrs (Colomer et al., 1990; Kilbride et al., 1999).

Inwieweit der mütterliche Eisenstatus eine Auswirkung auf die Gesundheit des Kindes hat, ist umstritten und noch nicht ausreichend untersucht (US Preventive Services Task Force, 1993). Zwar wurden bei zu hohen und zu niedrigen mütterlichen Hämoglobinkonzentrationen vermehrt fetale Mißbildungen und fetaler Tod festgestellt, jedoch wurden hier andere Einflußgrößen wie die Gesundheit der Mutter nicht überprüft. Weil bei mütterlichem Eisenmangel das Risiko für Frühgeburtlichkeit steigt, erhöht sich auch das damit verbundene Risiko für vermindertes Wachstum, frühe Entleerung der Eisenspeicher und Krankheitsanfälligkeit des Kindes (Allen, 1997). Bei einer Untersuchung nach Beard et al. (1994) hatten die Mütter aller Kinder mit einem Geburtsgewicht unter $2500 \mathrm{~g}$ im ersten Trimenon einen Eisenmangel.

\section{Plazenta}

Bei Frauen mit Hämoglobinkonzentrationen, die im Normbereich liegen, besteht in der neunten bis elften Schwangerschaftswoche eine negative Korrelation zwischen mütterlicher Hämoglobinkonzentration und sowohl humanem Choriongonadotropin als auch plazentärem Prolactin (Wheeler et al., 1994). In der 18. Schwangerschaftswoche sind mütterliches Hämoglobin und Ferritin negativ mit dem Volumen der Plazenta korreliert (Howe et al., 1995). Plazentas von Frauen mit erniedrigter Hämoglobinkonzentration haben aufgrund von Hypoxie ein erhöhtes Gewicht (Godfrey et al., 1991), einen reduzierten Zottenbaum und dünnere Zellmembranen (Allen, 1997). Unabhängig von der Hämoglobinkonzentration ist auch ein verringertes mittleres Erythrozytenvolu- 
men mit erhöhtem Plazentagewicht assoziiert (Godfrey et al., 1991).

\section{Frühgeburtlichkeit und Geburtsgewicht}

Bei Eisenmangelanämie, die zwischen der 12. und 23. Schwangerschaftswoche auftritt, besteht eine Odds-Ratio von 2,5 für eine Geburt vor der 37. Schwangerschaftswoche und eine Odds-Ratio von 3 für ein geringeres Geburtsgewicht, jedoch kein erhöhtes Risiko für intrauterine Wachstumsretardierung (Scholl et al., 1992). Eine alleinige Erniedrigung der Ferritinkonzentration dagegen beeinflußt nach Scholl et al. (1992) das Risiko einer Frühgeburt nicht.

Jedoch findet sich sowohl bei erhöhten als auch bei erniedrigten mütterlichen Hämoglobinkonzentrationen eine vermehrte Frühgeburtlichkeit ( $<37$ Schwangerschaftswochen). Ein daraus resultierendes verringertes Geburtsgewicht $(<2500 \mathrm{~g})$ zeigt sich allerdings nur bei erniedrigter Hämoglobinkonzentration (Zhou et al., 1998). So fanden Zhou et al. (1998) bei mütterlichen Hämoglobinkonzentrationen unter $11 \mathrm{~g} / \mathrm{dl}$ zwischen der siebten und neunten Schwangerschaftswoche ein zweifach erhöhtes Risiko für eine Frühgeburt und ein dreifach höheres Risiko für erniedrigtes Geburtsgewicht. Bei über $13 \mathrm{~g} / \mathrm{dl}$ erhöhter Hämoglobinkonzentration zum gleichen Zeitpunkt fand sich für Frühgeburtlichkeit ein zweieinhalbfach erhöhtes Risiko. Dagegen ließ sich hier kein Zusammenhang zwischen verschiedenen Hämoglobinkonzentrationen und einer Hypotrophie der Neugeborenen feststellen. Bei einer weiteren Untersuchung fanden sich auch bei erhöhten Hämoglobinund Hämatokritkonzentrationen der Schwangeren aufgrund von mangelnder Hämodilution sowohl ein erniedrigtes Geburtsgewicht des Kindes als auch häufigere Frühgeburtlichkeit. Hier wird die Hypothese unterstützt, daß erhöhte Blutviskosität einen Risikofaktor für suboptimale Perfusion der Plazenta darstellt (Knottnerus et al., 1990).

Im Gegensatz dazu stehen Ergebnisse von Tierversuchen an Ratten, wobei die mütterliche Eisenaufnahme keinen Einfluß auf das Geburtsgewicht der Jungtiere hat (Hallquist et al., 1992).

Die Ursache für die vermehrte Frühgeburtlichkeit bei erhöhter Hämoglobinkonzentration in der frühen Schwangerschaft könnte nach Zhou et al. (1998) in einer geringeren Entwicklung der Plazenta liegen. Die eigentliche Ursache für erniedrigtes Geburtsgewicht kann einerseits die Eisenmangelanämie an sich sein (Zhou et al., 1998). Andererseits führt kalorienarme oder unzureichende Ernährung sowohl zu geringem Geburtsgewicht (Lechtig et al., 1975), als auch zu erniedrigten Hämoglobinkonzentrationen (Allen, 1997).

Der Mechanismus, der bei Eisenmangelanämie eine Frühgeburt verursacht, ist genausowenig bekannt, wie der Grund dafür, daß eine Anämie ohne Eisenmangel keine Frühgeburt auslöst (Allen, 1997). 


\subsubsection{Verhalten von Mutter und Kind}

Es ist wahrscheinlich, daß Eisenmangel das Maß an Aktivität, Motivation und Aufmerksamkeit der Mutter beeinträchtigt, was wiederum die Dauer und Häufigkeit der Mutter-Kind-Interaktion herabsetzt. So beschäftigen sich Mütter mit unauffälligem Eisenstatus doppelt so lange mit ihrem Kind wie solche mit Eisenmangel.

Über das Verhalten von Kindern anämischer Mütter ist wenig bekannt. Jedoch fand sich in Studien ein Zusammenhang zwischen Eisenmangelanämie bei Kleinkindern und deren schlechterem Abschneiden bei Entwicklungstests (Allen, 1997). Diese Testergebnisse konnten durch Eisensupplementierung verbessert werden (Idjradinata and Pollitt, 1993). Die Ursache für diesen Zusammenhang wird darin gesucht, daß bei Eisenmangel die Monoaminooxidase vermindert und die Funktion von $\mathrm{D}_{2}$-(Dopamin)Rezeptoren reduziert ist, was die Reizübertragung möglicherweise stört und somit zu kognitiven Störungen führt (Yehuda and Youdim, 1989).

\subsubsection{Entwicklung und schulische Leistung}

Eisenmangel kann die psychomotorische Entwicklung von Kindern beeinträchtigen, noch bevor eine Eisenmangelanämie auftritt (Bergmann et al., 1989; Bergmann et al., 1978). Eine Eisenmangelanämie kann möglicherweise zu schlechteren schulischen Leistungen führen als sie bei Kindern ohne Anämie die Regel sind. Dabei kann eine Supplementierung der anämischen Kinder mit Eisen zwar eine Verbesserung der Resultate aber keine Angleichung an diejenigen ohne Anämie bewirken (Pollitt, 1997).

\subsubsection{Therapie}

\section{Orale Eisensubstitution}

Als Goldstandard wird von manchen Autoren die Therapie mit Eisensulfat über drei Tagesdosen verteilt angesehen. So kann die Absorption auf 10 bis 20 mg pro Tag gesteigert werden. Die Dauer der Therapie ist abhängig von der Normalisierung der Konzentrationen der Eisenindikatoren. Dabei kommt es innerhalb von etwa drei Wochen zu einem signifikanten Hämatokritanstieg und nach zwei Monaten zu einer Normalisierung des roten Blutbildes. Danach muß die Therapie noch drei bis sechs Monate, bis zum Erreichen einer ausreichenden Ferritinkonzentration weitergeführt werden (Wick et al., 1996).

Schwangerschaft Um eine Interferenz mit der Absorption von anderen Spurenelementen wie zum Beispiel Zink zu vermeiden und trotzdem eine ausreichende Dosis zu erreichen, sollte die routinemäßige Einnahme von Eisen bei etwa $30 \mathrm{mg}$ pro Tag für alle Schwangeren ohne Eisenmangel im zweiten und dritten Trimenon liegen (Institute of Medicine, 1990). Höhere Dosen sind nicht 
zu empfehlen, da bei einer Einnahme von 38 bis 65 mg Eisen pro Tag die Absorption von Zink beeinträchtigt sein kann. Weniger als $30 \mathrm{mg}$ pro Tag wiederum decken nicht den vollen Bedarf (zum Beispiel reichten 18 mg nicht aus, um die Eisenspeicher zu erhalten) (Allen, 1997).

Eine tägliche Dosierung zwischen 60 und 100 mg Eisen benötigen schwangere Frauen mit einer Eisenmangelanämie. Sobald sich ihre Hämoglobin- und Ferritinkonzentrationen wieder normalisieren, erhalten sie wieder die 30 mg-Dosierung (Institute of Medicine, 1990).

Nach der Häufigkeit von Eisenmangel in der entsprechenden Region richten sich die Empfehlungen des United Nations Administrative Committee on Coordination/Sub Committee on Nutrition: in Gegenden mit niedriger Prävalenz von Eisenmangelanmie (Hämoglobin $<11 \mathrm{~g} / \mathrm{dl}$ bei weniger als $20 \%$ der Frauen in der zweiten Schwangerschaftshälfte) erhalten alle Schwangeren 60 mg Eisen, und in Gebieten mit hoher Prävalenz von Eisenmangelanämie liegt die Eisendosis für alle schwangeren Frauen bei 120 mg pro Tag (Allen, 1997).

Die Deutsche Gesellschaft für Ernährung empfiehlt für schwangere Frauen ab dem vierten Schwangerschaftsmonat eine tägliche Zufuhr von 30 mg Eisen durch die Nahrung (Bergmann et al., 1997) und eine Supplementierung von $15 \mathrm{mg}$ pro Tag während der gesamten Schwangerschaft (Deutsche Gesellschaft für Ernährung, 1991).

\section{Parenterale Eisensubstitution}

Eine intravenöse Eisengabe sollte nur erfolgen bei

- Notwendigkeit einer schnellen Supplementierung,

- Intoleranz gegenüber oraler Eisengabe,

- mangelnder Eisenabsorption,

- gastrointestinalen Erkrankungen,

- Eisenverwertungsstörungen.

Die zuzuführende Eisenmenge wird berechnet nach

Gesamtmenge benötigtes Eisen $=$

$\frac{\mathrm{Hb} \text {-Defizit } \cdot \text { Blutvolumen } \cdot \text { Eisengehalt } \mathrm{Hb}}{\mathrm{Hb}}+$ Eisenreserven in Depots.

Normalerweise liegt die zu verabreichende Dosis bei Eisenmangelanämie zwischen 1,5 und $2 \mathrm{~g}$. In Europa wird vorwiegend Eisensaccharose zur parenteralen Eisensubstitution verwendet, da sie ein nur geringes anaphylaktoides Potential besitzt. Andererseits setzt sie Eisen in der Leber aus 
den Komplexen frei und wirkt somit hepatotoxisch. Weitere zur Verfügung stehende Substanzen sind Eisendextranverbindungen, Eisenglukonat, Eisenascorbat, Eisencitrat und Mischpräparate.

Die Verabreichung erfolgt in Europa in fraktionierten, steigenden Dosen, wogegen in Amerika nach einer Testdosis die Gesamtdosis über vier bis sechs Stunden gegeben wird (Wick et al., 1996).

\section{Nebenwirkungen}

Nebenwirkungen von höheren Dosierungen der Eisensubstitution können Metallgeschmack (Yip, 1996), Diarrhoe, Obstipation, Erbrechen und Sodbrennen sein (Allen, 1997). Außerdem besteht für Menschen mit hohen Eisenreserven möglicherweise ein erhöhtes Risiko für Neoplasien (Cook et al., 1992) und Atherosklerose (Baynes, 1996).

Eine Gefahr von Eisenpräparaten ist die Intoxikation von Kindern, die die Tabletten finden und aufgrund ihres süßen Geschmacks essen. 1988 wurden in Amerika 13416 Fälle von Eisenintoxikationen bei Kindern gemeldet. Am häufigsten sind hierbei Kinder im Alter von 12 bis 24 Monaten betroffen, bei denen eine Dosis von ein bis zwei Gramm tödlich sein kann (US Preventive Services Task Force, 1993).

\subsection{Prävalenz von Eisenmangel}

Eisenmangel ist der häufigste Mangel an einem einzelnen Nährstoff auf der Welt (Lönnerdal and Dewey, 1995). 15 \% der Weltbevölkerung leiden an Eisenmangel, in Risikopopulationen kann die Prävalenz sogar auf $50 \%$ ansteigen (Beard et al., 1996).

\subsubsection{Nicht schwangere Frauen}

Weltweit liegt die Prävalenz von Eisenmangelanämie menstruierender Frauen nach der WHO (1992) in Entwicklungsländern bei etwa $43 \%$ und in Industrieländern bei etwa 12 \% (Allen, 1997), wie auch Abbildung 1.4 auf Seite 30 zeigt. Nach Daten aus NHANES III findet sich in den vereinigten Staaten bei $11 \%$ der Frauen zwischen 20 und 49 Jahren ein zellulärer Eisenmangel (zwei unterschwellige Werte von Ferritin $<12 \mu \mathrm{g} / \mathrm{l}$, TS $<15 \%$, EP $>1,24 \mu \mathrm{mol} / 1$ Erythrozyten) und bei $5 \%$ der Frauen im Alter von 20 bis 49 Jahren eine Eisenmangelanämie ( $\mathrm{Hb}<12 \mathrm{~g} / \mathrm{dl}$ und zellulärer Eisenmangel) (Looker et al., 1997).

In Deutschland finden sich bei den menstruierenden Frauen ähnliche Prävalenzen. Hier weisen 2,5 $\%$ der 25- bis 54-jährigen eine Eisenmangelanämie und 9,3\% einen Eisenmangel ohne Anämie auf (Thefeld and Ellert, 1998).

In den Niederlanden findet sich zellulärer Eisenmangel (Ferritin $<30 \mu \mathrm{g} / \mathrm{l}$ ) bei $16 \%$ und eine 


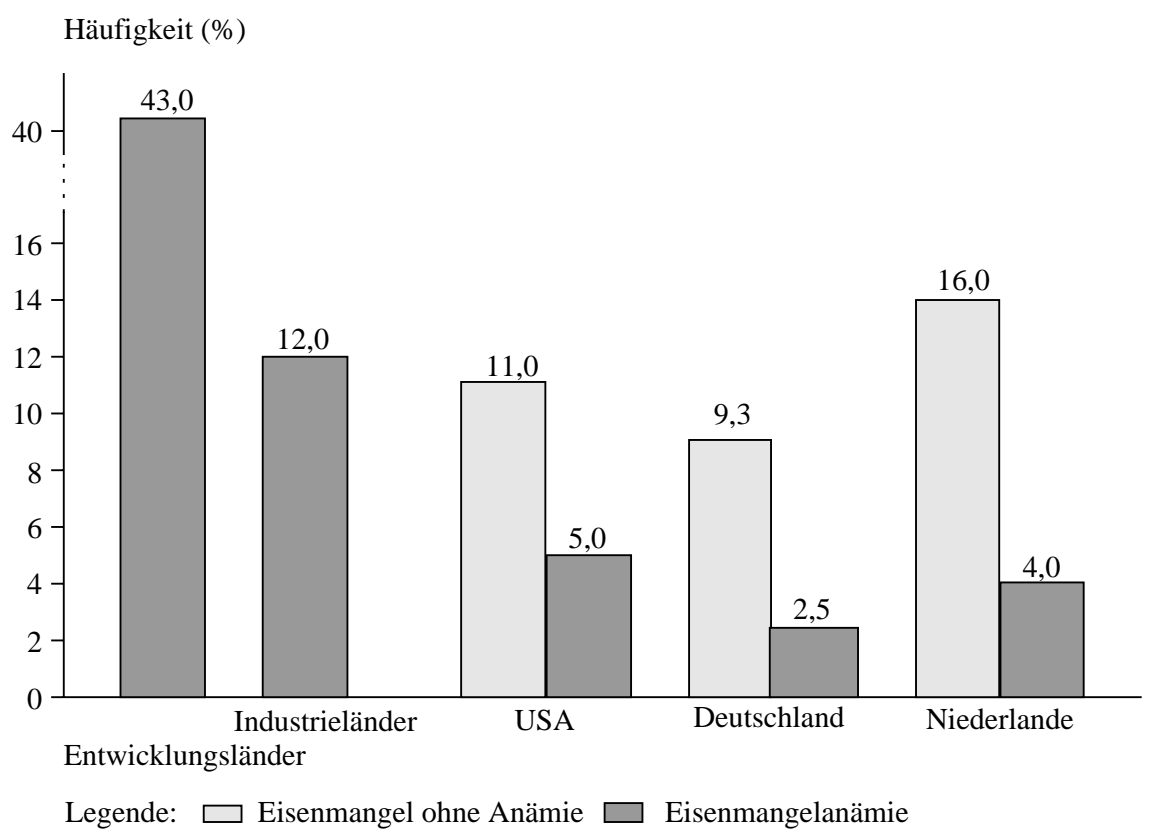

Abbildung 1.4: Prävalenz von Eisenmangel bei Frauen im gebärfähigen Alter; Entwicklungs- und Industrieländer: WHO (1992) nach Allen (1997), USA: Looker et al. (1997), Deutschland: Thefeld und Ellert (1998), Niederlande: Brussaard et al. (1997).

Eisenmangelanämie bei $4 \%(\mathrm{Hb}<12 \mathrm{~g} / \mathrm{dl}$, Ferritin $<30 \mu \mathrm{g} / \mathrm{l})$ der Frauen zwischen 20 und 49 Jahren (Brussaard et al., 1997).

\subsubsection{Schwangere}

In Entwicklungsländern liegt die Prävalenz von Eisenmangelanämie in der Schwangerschaft bei 56 $\%$ und in Industrieländern bei $18 \%$. Allerdings zeigte sich in einer Studie in Camden, New Jersey von Scholl et al. (1992) zwar bei 27,9 \% der untersuchten Schwangeren eine Anämie, unabhängig von der Ursache; jedoch lagen hier Eisenmangelanämien nur bei 3,5 \% der Schwangeren vor.

Der Median der tatsächlichen Zufuhr von Eisen bei Frauen im gebärfähigen Alter liegt unter der von der Deutschen Gesellschaft für Ernährung empfohlenen Menge. Man kann davon ausgehen, daß Eisenmangel bei Schwangeren auch in Deutschland häufig vorkommt. Die genaue Prävalenz ist jedoch nicht bekannt (Bergmann et al., 1997).

\subsubsection{Prävention}

Zur Prävention von Eisenmangel gibt es zwei Hauptansatzpunkte: entweder die Reduktion der Eisenverluste oder die Steigerung der Eisenaufnahme (Hallberg, 1994). Bei der Reduktion der Eisenverluste wird deren Ursache bekämpft. Eine häufige Ursache für Eisenmangel in weniger entwickelten Ländern ist zum Beispiel der Befall mit Hakenwürmern und der damit verbundene Blutverlust über den Darm. In einem solchen Fall müssen zunächst die Hakenwürmer bekämpft 
werden, bevor eine Supplementierung mit Eisen tatsächlich Erfolg haben kann (Yip, 1997).

Es gibt drei ernährungsbezogene Strategien zur Steigerung der Absorption: Supplementierung, Eisenanreicherung und Modifikation der Nahrung und der Ernährung. Davon sind die gebräuchlichsten, insbesondere in weniger industrialisierten Ländern, die Supplementierung und die Eisenanreicherung der Nahrung (Gibson, 1997). Bei dem Versetzen der Nahrung mit Eisen gibt es zum einen den Ansatz, Lebensmittel, die von Risikogruppen der Bevölkerung konsumiert werden, bei der Herstellung mit Eisen zu versehen (Hallberg, 1994). Eine weitere Methode kann darin liegen, den Ferritingehalt von Saaten auf biotechnologische Weise zu erhöhen und somit Grundnahrungsmittel mit erhöhtem Eisengehalt zu züchten (Theil et al., 1997).

Bei der Prävention von Eisenmangel in weniger entwickelten Ländern ist wegen der hohen Prävalenz eine globale Eisensupplementierung sinnvoller. In weiter entwickelten Ländern sollte dagegen ein Screening und dann eine gezielte Supplementierung durchgeführt werden (Yip, 1997).

Ein weiterer Ansatz der Supplementierung wiederum ist der, daß alle menstruierenden Frauen einmal in der Woche eine $60 \mathrm{mg}$ Tablette mit Eisen und Folat einnehmen sollten. So würden Eisenmangel beseitigt, Eisenspeicher erhöht und auch die Folatversorgung verbessert. Auf diese Weise würden Frauen die Schwangerschaft mit ausreichenden Eisenreserven beginnen und es reichte eine Verdopplung der Dosierung auf $120 \mathrm{mg}$ einmal wöchentlich, um einen Eisenmangel in der Schwangerschaft zu vermeiden (Viteri, 1997).

\subsection{Risikofaktoren für Eisenmangel}

Weltweit sind die wichtigsten Ursachen von Eisenmangel schwere Unterernährung und Hakenwurminfektionen. Beide Ursachen sind in industrialisierten Ländern selten. In diesen Ländern besteht ein erhöhtes Risiko für Kleinkinder, Jugendliche, Schwangere, ältere Personen, Blutspender, Leistungssportler und Auswanderer. Das schwerwiegendste medizinische Problem von Menschen mit Anämie sind Blutverluste (21\% der Anämien), wobei Eisenmangelanämie oft das erste Zeichen für schwere gastrointestinale Erkrankungen darstellt (Marx, 1997).

Für Frauen, deren Schwangerschaft ein Jahr zurückliegt, müssen außer der vorausgegangenen Schwangerschaft noch andere Risikofaktoren für Eisenmangel in Frage kommen. Naheliegend ist eine unzureichende Eisenzufuhr durch die Nahrung oder die Behinderung der Eisenabsorption durch Nahrungsbestandteile. Es gibt Hinweise, daß Frauen, die in der Schwangerschaft eine Eisenmangelanämie aufweisen (unabhängig von Alter, Kinderzahl, Schwangerschaftswoche und Body-Mass-Index), zu Beginn der Schwangerschaft signifikant weniger Kalorien und signifikant weniger Eisen zu sich genommen haben als Schwangere ohne Anämie. Schwangere mit Anämie ohne Eisenmangel ernähren sich dagegen ähnlich wie diejenigen, die keine Anämie aufweisen (Scholl et al., 1992). Viele Nahrungsbestandteile können die Absorption von Eisen beeinflussen. 
Eine absorptionshemmend Wirkung wird starkem Kaffee- oder Teegenuß aufgrund von Komplexbildung, fleischarmer Ernährung, verminderter Magensaftproduktion (Wick et al., 1996), Phytaten (in Getreide, Nüssen, unpoliertem Reis, Bohnen und Erbsen), Polyphenolen (in Tee), Ballaststoffen (Gibson, 1997), Phosphaten und Galloylgruppen (in Tee, Kakao, Kaffee, Rotwein, Oregano, Spinat) (Hallberg, 1994) zugeschrieben. Der Verzehr von Fleisch (Hämeisen), Ascorbinsäure und fermentierten Lebensmitteln (zum Beispiel Sauerkraut) soll die Aufnahme von Nicht-Hämeisen fördern (Hallberg, 1994).

Es gibt auch Hinweise darauf, daß die Lebensweise den Eisenstatus sowohl positiv als auch negativ beeinflussen kann. So soll Stillen sechs Monate nach der Geburt (Kalkwarf and Harrast, 1998) neben Alkoholkonsum und Rauchen (Mechanismen unbekannt) (Brussaard et al., 1997; Milman et al., 1995; Thefeld and Ellert, 1998) positiv auf den Eisenstatus wirken. Dagegen können Leistungssport (durch gastrointestinale Blutungen bei mechanischer Irritation (Bärtsch et al., 1998)) niedriger Body-Mass-Index (Scholl et al., 1992), zu geringe Gewichtszunahme in der Schwangerschaft (Tabelle 1.3 auf Seite 32) und Blutungen in der Schwangerschaft (Hallberg and RossanderHultén, 1991)) mit niedrigeren Eisenspeichern assoziiert sein.

Je nach ökonomischer Entwicklung und damit verbundenen Gesundheits- und Ernährungsvoraus-

\begin{tabular}{|c|c|}
\hline \multicolumn{2}{|c|}{ Empfohlene Gewichtszunahme in der Schwangerschaft } \\
\hline Mütterlicher & Gewichts- \\
\hline Body-Mass-Index & zunahme $(\mathrm{kg})$ \\
\hline niedrig $(<19,8)$ & $12,5-18,0$ \\
\hline normal $(19,8$ bis 26,0$)$ & $11,5-16,0$ \\
\hline $\operatorname{hoch}(>26,0$ bis 29,0$)$ & $7,0-11,5$ \\
\hline adipös $(<29,0)$ & $>6,0$ \\
\hline
\end{tabular}

setzungen, kann sich das Risiko für Eisenmangel in verschiedenen Ländern unterscheiden. So ist das Eisenmangel-Risiko für Frauen und Kinder in weniger entwickelten Ländern größer als in weiter entwickelten Ländern (Yip, 1997). Aber auch unterschiedliche Soziodemographie innerhalb eines Landes (verschiedenes Alter, verschiedene Nationalität, unterschiedlicher Sozialstatus, verschieden lange Ausbildung) führt zu Unterschieden des Eisenstatus' (Brussaard et al., 1997; Marx, 1997; Looker et al., 1997; Guesry, 1998).

\subsection{Fragestellung der Arbeit}

Lebensqualität und Leistungsfähigkeit werden durch einen unbemerkten Eisenmangel beeinträchtigt. Frauen im gebärfähigen Alter haben einen erhöhten Eisenbedarf, der in der Schwangerschaft noch zunimmt. Ziel der Untersuchung ist deshalb, die Prävalenz von Eisenmangel bei jungen 
Müttern unter den Lebensbedingungen in der Bundesrepublik zu erheben, den Einfluß von Risikofaktoren zu evaluieren und Präventionsmaßnahmen zu diskutieren. 


\section{Kapitel 2}

\section{Methodik}

Von September 1997 bis August 1998 wurden 507 Mütter, die zur U6 ihrer neun bis zwölf Monate alten Kinder in 69 Berliner Kinderarztpraxen konsekutiv erschienen, hinsichtlich ihres Eisenstatus' untersucht.

Es wurden alle Berliner Kinderarztpraxen telefonisch kontaktiert und durch ein Anschreiben über die Studie informiert (Quelle: Gelbe Seiten 1996/97, D-Info '97). Es erklärten sich 69 Arztpraxen zur Teilnahme bereit. Diese wurden durch ein persönliches Gespräch über den Ablauf der Studie informiert. Die Person, die dieses Gespräch führte, war für die Zeit der Studie der Ansprechpartner der jeweilige Praxis.

Bei diesem Gespräch erhielten die Praxen einen Informationshefter, in dem

- eine Patientenliste (Registrierung der Studienteilnehmer und Zuordnung zu Barcodes),

- ein Ablaufschema (Ablauf innerhalb der Praxis),

- Elternanschreiben (Information für die Eltern),

- ein Blutabnahmeschema (richtiges Füllen der Blutröhrchen),

- Wegbeschreibungen zu dem Raum im Virchow-Klinikum, in dem der Bayley II-Entwicklungs-Test stattfand

- und eine Referenzwertetabelle des Zentrallabors des Virchow-Klinikums

enthalten waren.

In die Patientenliste sollten alle Kinder, die konsekutiv innerhalb eines Zeitraums von drei Monaten zur U6 kamen, eingetragen werden. Bei Teilnahme an der Studie wurde sowohl den Kindern als auch deren Müttern eine Barcodenummer zugewiesen. Das Datum der Blutabnahme und die Bereitschaft, an dem Entwicklungstest teilzunehmen, vermerkt. Die Kinder, deren Eltern nicht an der Studie teilnehmen wollten, erhielten keine Nummer. Es wurde lediglich der Grund für die 
Ablehnung in die Liste eingetragen. Die Barcodenummern wurden doppelt in die Liste eingeklebt, da diese nach Abschluß der Studie durchtrennt wurde. Den Teil mit den Namen und den zugehörigen Nummern behielten die Kinderärzte und -Ärztinnen, den Teil, auf dem Nummern, Datum der Blutabnahme, Bereitschaft zum Bayley-Test und Gründe für Nicht-Teilnahme eingetragen waren, diente zur weiteren Auswertung der Studie.

Das Ablaufschema gab den Ablauf der Studie in den Praxen vor und wurde von den Kinderärzten und -Ärztinnen an die jeweiligen Umstände angepaßt. In dem Ablaufschema und auf einer zusätzlichen Abbildung waren die Seiten des Mutterpasses angegeben, aus denen die Hämoglobinkonzentrationen in der Schwangerschaft, das Geburtsdatum, Geburtsgewicht und Geburtsgröße des Kindes durch Kopieren gewonnen wurden. Die kopierten Seiten enthielten in der Regel keine Namen. Vorhandene Namen wurden von dem Praxispersonal unkenntlich gemacht.

Die Elternanschreiben informierten die Eltern, abgesehen von dem persönlichen Gespräch mit den Ärzten und Ärztinnen, über die Studie.

Auf dem Blutabnahmeschema wurde anhand von Bildern illustriert, wie die Röhrchen gefüllt werden sollten.

An die Eltern, die mit ihren Kindern am Bayley II-Entwicklungs-Test teilnehmen wollten, wurde ein Lageplan des Virchow-Klinikums zur besseren Orientierung auf dem Gelände verteilt.

Die Referenzwertetabelle diente als Information für die Ärzte und Ärztinnen.

Abgesehen von diesem Informationshefter erhielten die Kinderarztpraxen Emla-Pflaster für die Blutabnahme bei den Kindern und die für die Blutabnahme verwendeten Unterlagen nebst Fragebogen und Einwilligungserklärung. Hierbei erwies es sich als praktikabel, alle Unterlagen, die für einen Studienteilnehmer benötigt wurden, in einer Klarsichthülle zu sammeln und erst die fertigen Klarsichthüllenpäckchen an die Ärzte und Ärztinnen auszuteilen. Ein Päckchen enthielt je einen mit Barcodenummern versehenen Fragebogen, eine von den Eltern zu unterschreibende Einwilligungserklärung für die Blutabnahme und die Teilnahme an dem Entwicklungstest, die Blutröhrchen für Kind und Mutter, jeweils mit Barcode versehen (je zwei Serum- und EDTA-Röhrchen und zwei Röhrchen zum Einfrieren der Serumreste) und zwei Pädiatriebelege für das Labor.

Bei Studienabschluß erhielten die Kinderärztinnen und - ̈̈rzte pro teilnehmendem Mutter-KindPaar 60 DM als Aufwandsentschädigung für die Blutabnahmen.

\subsection{Fragebogen}

Bei der Entwicklung des Fragebogens wurden die Fragebögen der MAS-90-Studie (MAS = Multizentrische Allergie-Studie) und der KESS-Skalen (KESS = im Rahmen der MAS-Studie übersetzte und gekürzte KID-Skalen (Reuter and Wozniak, 1996)) zur Hilfe genommen, die ebenfalls 
bei der MAS-90-Studie verwendet wurden (Kulig et al., 1998).

Der Fragebogen untergliedert sich in drei Teile.

Zu dem Teil I des Fragebogens gehören folgende Rubriken:

- Angaben zur Lebenssituation:

Abgefragt werden hier Alter und Anzahl der zu dem Haushalt gehörenden Personen, sowie Sozialstatus und Nationalität. Diese Fragen wurden teils mit Hilfe von Fragen aus der MASStudie und teils selbst entwickelt.

- Angaben zum Kind:

Diese Fragen beziehen sich auf die Versorgung, die Ernährung und den Gesundheitszustand des Kindes. Zum Teil stammen die Fragen ebenfalls aus der MAS-Studie und zum größeren Teil sind sie selbst entworfen. Diese Fragen werden in der vorliegenden Arbeit nicht verwendet.

- Angaben zur Schwangerschaft:

Hier werden Fragen zu Ernährung und Nikotinabusus während und nach der Schwangerschaft, Alkoholabusus kurz vor, während und nach der Schwangerschaft, Sport während und nach der Schwangerschaft, Größe und Gewicht von Mutter und Vater und Einsetzen der Menstruation nach der Schwangerschaft beantwortet. Die Fragen zur Schwangerschaft wurden selbst entwickelt.

Der zweite Teil des Fragebogens enthält Fragen zur Entwicklung des Kindes, die vollständig aus den KESS-Skalen stammen. Auch die Temperamentfragen des dritten Teils wurden aus den KESSSkalen übernommen. Außerdem ergänzen zehn Fragen von Dr. P. Melchers, Köln, zur Entwicklungsdiagnostik bei der U6 den Fragebogen, die anhand der KESS-Skalen validiert werden sollten. Die bei der Auswertung berücksichtigten Fragen finden sich in Anhang B.

In der Regel füllten die Mütter, Väter oder beide Elternteile gemeinsam den Fragebogen selbständig aus. Bei etwa einem Viertel der nicht deutschen Teilnehmerinnen (ca. $5 \%$ aller Mütter) halfen beim Ausfüllen die Mitarbeiter der Studie oder das Praxispersonal.

\subsection{Gewinnung und Transport der Blutproben}

Die Blutproben wurden venös von den Kinderärzten und -Ärztinnen so, wie es in den Praxen üblich war, gewonnen. Bei den Müttern wurde in der Regel aus der Cubitalvene, bei den Kindern sowohl der Cubitalvene als auch Venen des Handrückens, des Fußrückens und des Schädels Blut entnommen und entweder direkt in die dafür vorgesehen Röhrchen getropft oder erst mit einer Einmalspritze entnommen und dann umgefüllt. Nach dem Ermessen der Eltern und der Ärzte und 
Ärztinnen wurde entschieden, ob die Entnahmestelle des Kindes vorher mit einem durch die Studie bereitgestellten Emla-Pflaster anästhesiert wurde.

Nach Entnahme wurde das Blut durch die Mitarbeiter der Eisenstudie (B. Andres, C. Eckert, B. Eisenreich, M. Schmidt, I. Steffen, I. Wagener) direkt abgeholt und zum Labor transportiert. Dort fand die Auswertung von Blutbild, Eisen, Ferritin und Transferrin vor 15.00 Uhr direkt statt. Der Großteil der Blutabnahmen erfolgte zwischen 8.00 und 12.00 Uhr. Die Lagerungszeit der Proben betrug im Durchschnitt etwa dreieinhalb Stunden, wobei etwa 30 Prozent in dieser Zeit im Kühlschrank aufbewahrt wurden.

Etwa fünf Prozent der Blutabnahmen fanden nach 14.00 Uhr statt und konnten somit erst am nächsten Tag ausgewertet werden, nachdem sie über Nacht gekühlt gelagert wurden. Drei Proben wurden per Post geschickt (etwa drei Tage Lagerung ohne Kühlung), und fünf Proben wurden drei Tage gekühlt gelagert.

Die Ergebnisse der Blutuntersuchungen teilten die Kinderärzte und -Ärztinnen den Studienteilnehmern mit.

\subsection{Labor}

Die Auswertung der Blutproben erfolgte im Zentrallabor des Virchow-Klinikums. Direkt nach Eintreffen der Blutproben wurden Blutbild, Eisen, Ferritin und Transferrin bestimmt. Das Restserum wurde bei -20 Grad Celsius für ein bis zehn Monate eingefroren. Es diente der Bestimmung der Konzentration des löslichen Transferrinrezeptors.

Die Bestimmung von Eisen, Transferrin, Ferritin und Transferrinrezeptor aus $700 \mu 1$ Serum erfolgte mit den folgenden Methoden:

- Die Eisenkonzentration wurde durch einen Zweipunkt-Kinetiktest mit Hilfe von Vitros FeAnalyseplättchen der Firma Vitros Chemistry Products gemessen (siehe Tabelle 2.1 auf Seite 38). Hierbei wird das Eisen nach Abspaltung von Transferrin und anschließender Reduktion durch Ascorbinsäure an ein Chromogen gebunden und die Eisenkonzentration durch photometrische Messung mit Vitros III der Firma Kodak bei 600nm bestimmt (Thomas, 1992; Wick et al., 1996).

- Ferritin wurde anhand von Tina-quant Ferritin der Boehringer Mannheim Systems durch immunturbidimetrischen Messung mit dem Hitachi (Firma Boehringer Mannheim) mit Reaktionsverstärkung durch an die Ferritinantikörper gebundene Latexpartikel quantifiziert (Müller, 1993; Wick et al., 1996). 
Tabelle 2.1: Methoden zur Bestimmung der Eisenstatusindikatoren.

\begin{tabular}{|c|c|c|}
\hline \multicolumn{3}{|c|}{ Bestimmungsmethoden } \\
\hline Parameter & Methode & Gerätetyp \\
\hline Eisen & 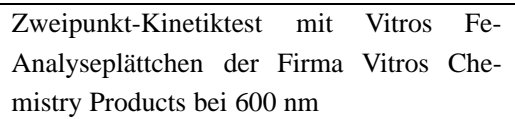 & Vitros III (Kodak) \\
\hline Ferritin & $\begin{array}{l}\text { immunturbidimetrische Messung mit Tina- } \\
\text { quant von Boehringer Mannheim bei } 700 \\
\mathrm{~nm}\end{array}$ & Hitachi (Boehringer Mannheim) \\
\hline Transferrin & $\begin{array}{l}\text { immunturbidimetrische Messung (ent- } \\
\text { wickelt im Virchow-Klinikum) bei } 340 \\
\mathrm{~nm}\end{array}$ & Hitachi (Boehringer Mannheim) \\
\hline Löslicher Transferrinrezeptor & $\begin{array}{l}\text { quantitativer enzymimmunometrischer Test } \\
\text { mit iDeA }{ }^{\mathrm{TM}} \text { STfR IEMA von Orion Diagno- } \\
\text { stica }\end{array}$ & MR 7000 (Dynatech) \\
\hline Leukozyten & $\begin{array}{l}\text { Widerstandsmeßprinzip und optisches Prin- } \\
\text { zip }\end{array}$ & Cell-Dyn 3500 (Abbott) \\
\hline $\begin{array}{l}\text { Thrombozyten, MPV, Erythrozyten, } \\
\text { MCV }\end{array}$ & $\begin{array}{l}\text { Widerstandsmeßprinzip und volumetrische } \\
\text { Absolutmessung }\end{array}$ & Cell-Dyn 3500 (Abbott) \\
\hline Hämoglobin & Hämoglobincyanidmethode & Cell-Dyn 3500 (Abbott) \\
\hline MCH, MCHC, Hämatokrit & $\begin{array}{l}\text { Berechnung nach } \\
\mathrm{MCH}(\mathrm{pg})=\frac{\mathrm{Hb}(\mathrm{g} / \mathrm{l})}{\operatorname{Erythrozyten}\left(\mu \mathrm{l}^{-1}\right)} \\
\mathrm{MCHC}(\mathrm{g} / \mathrm{l} \text { Erythrozyten })=\frac{\mathrm{Hb}(\mathrm{g} / \mathrm{l})}{\mathrm{Hkt}} \\
\mathrm{Hkt}=\mathrm{MCV}(\mathrm{fl}) \cdot \text { Erythrozyten }\left(\mu \mathrm{l}^{-1}\right)\end{array}$ & Cell-Dyn 3500 (Abbott) \\
\hline
\end{tabular}

- Für die Transferrinbestimmung wurde eine im Virchow-Klinikum entwickelte immunturbidimetrischen Messung bei $340 \mathrm{~nm}$ mit Hitachi der Firma Boehringer Mannheim durchgeführt. Nach Messung dieser beiden Werte konnte die Sättigung des Transferrins mit Eisen nach der Formel berechnet werden:

$$
\begin{aligned}
\text { Transferrinsättigung }(\%) & =\frac{\text { Serumeisen }(\mu \mathrm{g} / \mathrm{dl})}{\operatorname{TEBK}^{1}(\mu \mathrm{g} / \mathrm{dl})} \cdot 100 \\
& =\frac{\text { Serumeisen }(\mu \mathrm{g} / \mathrm{dl})}{\text { Transferrin }(\mu \mathrm{g} / \mathrm{dl})} \cdot 70,9
\end{aligned}
$$

beziehungsweise

$$
\begin{aligned}
\text { Transferrinsättigung }(\%) & =\frac{\text { Serumeisen }(\mu \mathrm{mol} / \mathrm{l})}{\operatorname{TEBK}(\mu \mathrm{mol} / \mathrm{l})} \cdot 100 \\
& =\frac{\text { Serumeisen }(\mu \mathrm{mol} / \mathrm{l})}{\text { Transferrin }(\mathrm{mg} / \mathrm{dl})} \cdot 398
\end{aligned}
$$

Dabei gilt

$$
\operatorname{TEBK}(\mu g / d l)=\operatorname{Transferrin}(m g / d l) \cdot 1,41,
$$

beziehungsweise

$$
\operatorname{TEBK}(\mu \mathrm{mol} / l)=\operatorname{Transferrin}(g / l) \cdot 25,2 \quad \text { (Thomas, 1992). }
$$

- Die Konzentration des Transferrinrezeptors wurde ermittelt durch einen quantitativen enzymimmunometrischen Test mit Hilfe des iDeA ${ }^{T M}$ sTfR IEMA-Tests der Firma Orion Diagnostica. Hierbei wurde die Serum-Probe mit monoklonalen anti-TfR-Antikörpern versetzt, nach einer Inkubationszeit gewaschen und die verbliebenen Antikörper (direkt proportional 
zu der Menge der vorhandenen Transferrinrezeptoren) photometrisch bei $405 \mathrm{~nm}$ (MR 7000 der Firma Dynatech) bestimmt (Wick et al., 1996).

- Aus $250 \mu$ EDTA-Blut wurde mit den folgenden Methoden ein kleines Blutbild gewonnen: Die Bestimmung von Leukozyten-, Thrombozyten- und Erythrozytenzahlen, sowie Hämoglobin, Hämatokrit (Hkt), Red Cell Distribution Width (RDW), Mean Corpuscular Volume (MCV), Mean Corpuscular Hemoglobin (MCH), Mean Corpuscular Hemoglobin Concentration (MCHC) und Mean Platelet Volume (MPV) wurde mit Hilfe des Cell-Dyn 3500 der Firma Abbott durchgeführt. Dabei wurde die Leukozytenzahl durch doppelte Zählung in getrennten Kanälen - Widerstandsmeßprinzip und optisches Prinzip - erfaßt. Thrombozyten, MPV, Erythrozyten und MCV wurden nach dem Widerstandsmeßprinzip mit einem von Behrens-Meßwandler und durch volumetrische Absolutmessung gemessen. Die Bestimmung der Hämoglobinkonzentration erfolgte anhand der Methämoglobincyanidmethode und MCH und MCHC sowie Hämatokrit berechnet nach

$$
\begin{aligned}
\text { Hämatokrit }(\%) & =\frac{\text { Erythrozytenzahl }}{\operatorname{MCV}(\mathrm{fl})} \\
\operatorname{MCH}(\mathrm{pg}) & =\frac{\operatorname{Hämoglobin}(\mathrm{g} / \mathrm{l})}{\text { Erythrozytenzahl }\left(10^{12} / \mathrm{l}\right)} \\
\operatorname{MCHC}(\mathrm{g} / \mathrm{dl}) & =\frac{\text { Hämoglobin }(\mathrm{g} / \mathrm{l})}{\text { Hämatokrit }(\mathrm{l} / \mathrm{l})}
\end{aligned}
$$

(Thomas, 1992).

\subsection{Dateneingabe}

Die Labordaten wurden doppelt eingegeben, die anderen einfach. Nach der Eingabe der Fragebögen und Kopien von Mutterpaß und Untersuchungsheft, erfolgte eine visuelle Überprüfung auf Vollständigkeit.

\subsection{Definition zellulären Eisenmangels und der Anämie}

Für den zur Bestimmung der Konzentration des löslichen Transferrinrezeptors (sTfR) verwendeten Test der Firma Orion Diagnostica gilt für Erwachsene ein 95\%-Konfidenzintervall von 1,3 bis 3,3 mg/l (Suominen et al., 1997). Danach liegt ein zelluärer Eisenmangel ab einer Konzentration von über $3,3 \mathrm{mg} / \mathrm{l}$.

Eine Anämie wird in den meisten Untersuchungen für Frauen im gebärfähigen Alter definiert als 
Hämoglobinkonzentration unter 12 g/dl (Cook et al., 1986; Thefeld and Ellert, 1998; Ferguson et al., 1992; Kuvibidila et al., 1996). Dieser Grenzwert wird in der vorliegenden Untersuchung verwendet.

\subsection{Statistik}

Der größte Teil der Auswertung wurde mit Hilfe von SPSS (Version 8.0) durchgeführt. Die Berechnung der 95\%-Konfidenzintervalle für die Prozentwerte der mütterlichen Soziodemographie erfolgte nach Clauß und Ebner (1977). Für den Binomialtest wurde ein MS-DOS-Programm von G. von Collani (1987) verwendet.

\subsubsection{Gruppierung der metrischen Variablen}

Für die Analysen, in denen bevorzugt gruppierte Variablen (Mittelwert- und Kreuzvergleiche, logistische Regression) verwendet werden und für die Beschreibung der Stichprobe, erfolgt eine Aufteilung der metrischen Variablen in Gruppen.

Das Familiennettoeinkommen ist zum einen in Anlehnung an die Armutsgrenze in Deutschland für 1997 aufgeteilt in Einkommen unter und über der Armutsgrenze (bis 1500 und über 1500 DM). Dabei liegt die Armutsgrenze 1997 bei 1355 DM (die Hälfte des Durchschnittseinkommens) (bmb+f, 1998). Zum anderen ist es wie die anderen metrischen Variablen in kleinere Untergruppen gesplittet.

Die Gruppierung des mütterlichen Body-Mass-Index erfolgte nach dem Institute of Medicine (1990) in die Gruppen ,niedrig“ (< 19,8), ,normal“ (19,8-26,0), ,hoch“ (> 26,0-29,0) und ,,adipös“.

Bei der Gliederung des kindlichen Geburtsgewichts verwendete gruppenbildende Grenzen sind $<2500 \mathrm{~g}$ für niedriges Geburtsgewicht, 2500-4000 g für normales und $>4000 \mathrm{~g}$ für hohes Geburtsgewicht (Institute of Medicine, 1990).

Für die Schwangerschaftsdauer erfolgt die Einteilung in Gruppen so, daß eine Gruppe die Frühgeburten (vor der vollendeten 37. Schwangerschaftswoche (Goerke et al., 1997)) enthält. Die übrigen metrischen Variablen (Alter der Mutter, Zahl der Kinder, Stilldauer) sind in Gruppen von möglichst ähnlicher Größe eingeteilt.

\subsubsection{Beschreibung der Stichprobe}

Die Soziodemographie der Stichprobe wurde mit der der Berliner Gesamtbevölkerung verglichen. Dabei dienen für den Vergleich von Alter, Nationalität und Berufstätigkeit der Mutter Zahlen über Mütter mit Kindern unter drei Jahren (Statistisches Landesamt Berlin, 1998). Die für den Vergleich 
verwendete Kinderzahl stammt aus der gleichen Erhebung für Berlin, wobei das Alter der Kinder nicht berücksichtigt ist. Die Angaben zu Schulabschluß und Berufsausbildung werden nicht mit dem Berliner Mikrozensus verglichen, da hier weder diejenigen erfaßt sind, die die Schule ohne Abschluß verließen noch die, die noch keine Berufsausbildung vorweisen können.

Die Angaben über das Nettoeinkommen von Berliner Familien entstammen dem Mikrozensus von April 1997 und beziehen sich auf alle Familien, unabhängig davon, ob Kinder vorhanden sind (Statistisches Landesamt Berlin, 1997). Da die genaue Armutsgrenze für Deutschland (1997) weder in der vorliegenden Befragung noch im Mikrozensus genau erfaßt wird, wird ersatzweise in Annäherung an die tatsächliche Armutsgrenze ein Familiennettoeinkommen für die Studie von bis 1500 DM und für den Mikrozensus bis 1400 DM verwendet. Es ist zu beachten, daß im Mikrozensus Gruppen ab einer Größe von unter 5000 ausgeschlossen werden.

Der Vergleich mit der gesamtdeutschen Bevölkerung erfolgt anhand von Daten einer repräsentativen deutschlandweiten Befragung aus dem Jahr 1997 (Bergmann et al., 2000). Dabei wurden in der deutschlandweiten Befragung Eltern ohne Deutschkenntnisse ausgeschlossen, weswegen der Ausländerinnenanteil nicht repräsentativ ist.

Für die Berechnung der 95\%-Konfidenzintervalle der prozentualen Anteile der Stichprobe an soziodemographischen Merkmalen wurde zuerst der Standardfehler $s_{p}$ des Prozentsatzes $p$ in der Stichprobe berechnet mit der Formel

$$
s_{p}=\sqrt{\frac{p(1-p)}{n}}=\sqrt{\frac{p \cdot q}{n}}, \text { wobei } q=1-p
$$

Das 95\%-Konfidenzintervall wurde dann ermittelt nach der Formel $\mathrm{p} \pm 1,96 \mathrm{~s}_{\mathrm{p}}$ (Clauß and Ebner, 1977). Die Abweichung zwischen den Prozentsätzen der Stichprobe und den Vergleichszahlen aus Berlin und Gesamtdeutschland sind signifikant, sobald die Prozentsätze der Vergleichsdaten außerhalb der Vertrauensgrenzen liegen.

Zusätzlich wurde ein Chiquadrat-Test, um die Soziodemographie der Stichprobe mit der Berlinund der Deutschland-weiten Soziodemographie zu vergleichen.

Nach der Berechnung der theoretischen Prävalenzen von Eisenmangel für den Fall, daß die Soziodemographie der Stichprobe der von Deutschland und Berlin entsprechen würde (Dreisatz) erfolgte ein Binomialtest, der die Signifikanz der Unterschiede zwischen den Prävalenzen aufdeckte (siehe Kapitel 4, Seite 70, Tabelle 4.1). 


\subsubsection{Analysen in Bezug auf die Eisenstatusindikatoren}

Mütterliche Hämoglobinkonzentration und die Konzentration des löslichen Transferrinrezeptors zum Zeitpunkt der Befragung sowie ihre minimale Hämoglobinkonzentration in der Schwangerschaft werden bei der weiteren Auswertung als abhängige Variablen betrachtet. Dabei ist die minimale in der Schwangerschaft gemessene Hämoglobinkonzentration die geringste in den Mutterpaß eingetragene Konzentration, unabhängig von der Schwangerschaftswoche der Messung.

Verwendete Methoden sind die Häufigkeitsanalyse, Analysis of Variance (ANOVA) der Mittelwerte, Kreuzvergleiche, logistische Einzelregression, Korrelationsanalyse, multiple lineare Regressionsanalyse und multiple logistische Regressionsanalyse. Die Übertragung Prävalenz von Eisenmangel der Stichprobe auf Berlin und Deutschland erfolgte mit Hilfe von Dreisatz; der Test auf signifikante Unterschiede zwischen den so erhaltenen Prävalenzen und den Prävalenzen der Studie erfolgte mit Hilfe eines Chiquadrat-Tests.

\section{ANOVA der Mittelwerte}

Der Vergleich der Mittelwerte der drei betrachteten abhängigen Variablen erfolgte in Bezug auf Untergruppen verschiedener gruppenbildender Variablen. Dabei wurde zunächst ein Test auf Homogenität der Varianzen (Levene-Test) durchgeführt. Liegt die Signifikanz für den Levene-Test bei $\mathrm{p} \leq 0,05$, so kann die ANOVA durchgeführt werden. Die Arbeitshypothese lautet hier: „Es gibt Unterschiede zwischen den Mittelwerten.“ Die Nullhypothese lautet:,Es gibt keine Unterschiede zwischen den Mittelwerten.“ Dabei wird das Signifikanzniveau für die ANOVA auf $\mathrm{p} \leq$ 0,1 festgelegt.

\section{Kreuzvergleiche und logistische Einzelregression}

Anhand von Kreuzvergleichen wurde nur für die Konzentrationen von Hämoglobin und löslichem Transferrinrezeptor die Prävalenz in den Untergruppen ermittelt. Dabei gilt als Grenze für Hämoglobin eine Konzentration unter $12 \mathrm{~g} / \mathrm{dl}$ (Thefeld and Ellert, 1998) und für den löslichen Transferrinrezeptor über 3,3 mg/l (Suominen et al., 1997). Die verwendete Methode ist ein ChiquadratTest, wobei die Signifikanzgrenze auf 0,1 festgelegt wurde.

Zur Ermittlung der Odds-Ratios für die verschiedenen Einflußvariablen diente bei der logistischen Einzelregression die Einschlußmethode. Dabei sind die Odds-Ratios statistisch signifikant, wenn das Konfidenzintervall 1,0 ausschließt. 


\section{Korrelationen}

Korreliert wurden die mütterlichen Konzentrationen von Hämoglobin und löslichem Transferrinrezeptor sowie der minimalen Hämoglobinkonzentration in der Schwangerschaft zum einen mit den Konzentrationen von Hämoglobin und löslichem Transferrinrezeptors des Kindes zum Zeitpunkt der Befragung. Zum anderen wurden die mütterlichen Eisenindikatoren mit den aus der multiplen linearen Regression als signifikant hervorgegangenen Einflußvariablen korreliert. Um den Vergleich zwischen den Eisenstatusindikatoren nachvollziehen zu können, finden sich hier auch die Korrelationen jedes Indikators mit den in der linearen Regression für die beiden anderen Indikatoren signifikanten Einflußvariablen. Bei den Korrelationen gilt das Ergebnis als signifikant ab einem $\mathrm{p} \leq 0,05$.

\section{Multiple lineare und multiple logistische Regression}

Die multiple lineare (Vorwärts-Methode) und die multiple logistische Regression (Methode: vorwärts bedingt) enthalten nur Einflußvariablen, die entweder bei den vorher beschriebenen Analysen und bei Einbeziehung aller vorher verwendeten Variablen in die lineare Regression signifikante Ergebnisse zeigten oder die die gesamte in die Analyse einbezogene Fallzahl nicht zu stark erniedrigten. Deswegen wurde die Zahl der Kinder, über die vergleichsweise wenig Daten vorliegen (n = 322) nur für die Regressionen des löslichen Transferrinrezeptors einbezogen, für den diese Variable signifikante Ergebnisse vorweist. Aus demselben Grund wird das Geburtsgewicht $(\mathrm{n}=345)$ nur bei der linearen Regressionsanalyse der minimalen Hämoglobinkonzentration der Mutter in der Schwangerschaft eingesetzt. Dabei wurden bei der multiplen logistischen Regression, wie bei dem Chiquadrat-Test, nur die aktuellen Konzentrationen von Hämoglobin und löslichem Transferrinrezeptor der Mutter als abhängige Variablen betrachtet. Die Grenzwerte wurden ebenfalls wie bei den Kreuzvergleichen gewählt. Die Ergebnisse sind signifikant ab einem $p \leq 0,1$. Für die Odds-Ratios liegt ein signifikantes Ergebnis vor, wenn 1,0 außerhalb des Konfidenzintervalls liegt. 


\section{Kapitel 3}

\section{Ergebnisse}

Als Indikatoren für den aktuellen mütterlichen Eisenstatus dienen die im Rahmen der Studie gemessenen Konzentrationen von Hämoglobin ( $\mathrm{Hb}$ ) und dem löslichen Transferrinrezeptor (sTfR). Dabei wird die Konzentration des löslichen Transferrinrezeptors als Leitindikator für einen zellulären Eisenmangel verwendet, da er im Gegensatz zu Ferritin kein Akute-Phase-Protein und somit stabiler ist. Die Hämoglobinkonzentration dient als Indikator für Funktionseisen.

Nach einer Beschreibung von Soziodemographie, Lebensweise und Angaben zur Schwangerschaft der untersuchten Stichprobe folgt die Darstellung der Prävalenz von zellulärem Eisenmangel und Anämie sowie der Mittelwerte von den Eisenstatusindikatoren bei der gesamten Stichprobe und bei Untergruppen der gruppenbildenden Variablen. Die darauffolgenden Korrelationen und multiple lineare sowie multiple logistische Regressionsanalyse lassen den Zusammenhang der mütterlichen Konzentrationen von $\mathrm{Hb}$ und sTfR mit unterschiedlichen Variablen erkennen.

Bei der Beschreibung aller Ergebnisse beziehen sich die genannten Variablen auf die Mutter, soweit sie nicht anders gekennzeichnet sind.

\subsection{Beschreibung der Stichprobe}

\subsubsection{Soziodemographie}

Die Altersverteilung der Mütter ist der einzige soziodemographische Indikator, der sich nicht signifikant von der bundesweiten repräsentativen Befragung junger Eltern $(n=5900)$, die im gleichen Zeitraum durchgeführt wurde unterscheidet (Bergmann et al., 2000). Das Familiennettoeinkommen der Stichprobe ist vergleichbar mit dem aller Berliner Familien (Statistisches Landesamt Berlin, 1997). Alle anderen soziodemographischen Merkmale unterscheiden sich signifikant von Berlin- (Statistisches Landesamt Berlin, 1998) beziehungsweise bundesweiten Daten (Anhang A Tabelle A.1, Seite I). 


\section{Alter}

In dem Altersbereich 25 bis $29(32,9 \%)$ und 30 bis 34 Jahre $(36,8 \%)$ finden sich mehr als zwei Drittel aller Mütter. Das übrige Drittel verteilt sich unter den bis 24- (15,5\%) und ab 35-jährigen $(14,8 \%)$ Müttern. Das Alter der Probandinnen ist somit vergleichbar mit der bundesweiten Altersstruktur (Wagener et al., 1999a), (Wagener et al., 1999b)(Wagener et al., 2000).

Signifikante Unterschiede der Altersgruppen in Bezug auf die Berliner Bevölkerung finden sich bei den Müttern über 30. Dabei sind die 30- bis 34-jährigen in der Studie (CI = 32,3-37,3\%) stärker vertreten als in Berlin (31,9\%). Die ab 35-jährigen dagegen haben an der Berliner Bevölkerung $(19,4 \%)$ einen größeren Anteil als an der Stichprobe $(\mathrm{CI}=11,5-18,1 \%)$.

\section{Familiennettoeinkommen}

12,3\% der Mütter, die an der Studie teilnahmen haben ein Familiennettoeinkommen unter oder nahe der Armutsgrenze (9,0-15,6\%). Die Zahlen für Berlin entsprechen diesem Anteil (15,1\%).

\section{Zahl der Kinder}

Fast die Hälfte der Probandinnen (45,7 \%) haben ein Kind, $37 \%$ weisen zwei und 17,4 \% ab drei Kinder auf.

Nach dem statistischen Landesamt gibt es in Berlin (55,6 \%) mehr Mütter mit nur einem Kind als in der Studie (CI = 40,3-51,1\%). Dagegen nahm an der Untersuchung (CI = 13,3-21,5\%) ein größerer Anteil an Müttern mit ab drei Kindern teil, als er in Berlin vertreten ist $(9,5 \%)$.

\section{Schulabschluß der Mutter}

Etwa ein Drittel der Studienteilnehmerinnen weisen Abitur (34,7 \%, CI = 30,1-39,3\%) auf. Das sind signifikant mehr Abiturientinnen als sie bundesweit vertreten sind. Ein weiteres Drittel der Mütter (34,2 \%, CI = 29,6-38,8 \%) sind Realschul- und $18 \%$ (CI = 14,3-21,7 \%) Hauptschulabsolventinnen. Diese beiden Gruppen sind wiederum bundesweit deutlich häufiger vertreten. 8,4 \% der Probandinnen erreichten die Fachhochschulreife, und 4,7 \% der Mütter verließen die Schule ohne Abschluß (Wagener et al., 1999a), (Wagener et al., 1999b), (Wagener et al., 2000).

\section{Berufsausbildung der Mutter}

Mehr als die Hälfte der Probandinnen haben eine Lehre $(41,0 \%, \mathrm{CI}=37,2-44,8 \%)$ oder eine Fachschule $(16,3 \%, \mathrm{CI}=11,7-20,8 \%)$ abgeschlossen. Einen Hochschulabschluß weisen 19,8\% (CI $=15,9-23,7 \%)$ der Mütter auf. $23 \%$ der Mütter haben ihre Berufsausbildung (noch) nicht abgeschlossen $(\mathrm{CI}=18,9-27,1 \%)$.

In der bundesweiten Befragung ist der Anteil der Mütter mit Lehre $(64,1 \%)$ höher als in der 
vorliegenden Studie. Dagegen gibt es in Deutschland weniger Mütter mit Hochschulabschluß (12,3 $\%)$ sowie ohne Berufsausbildung $(10,0 \%)$ als sie in der Untersuchung vertreten sind. Der Anteil der Mütter, die bundesweit einen Fachschulabschluß vorweisen können $(11,7 \%)$ unterscheidet sich nicht signifikant von dem der vorliegenden Stichprobe.

\section{Berufstätigkeit der Mutter}

$80,7 \%$ der Mütter gaben im Rahmen der Studie an, nicht berufstätig zu sein. Dagegen sind nur $54,2 \%$ der Berliner Mütter nicht berufstätig.

\section{Nationalität der Mutter}

Die Mütter nicht-deutscher Nationalität machen in der Studie einen Anteil von 19,2\% aus (CI = $15,6-22,8 \%)$.

In Berlin liegt dieser Anteil mit 26,4 \% höher; in der bundesweiten Befragung ist dieser Anteil geringer (4,5\%), da nicht-deutschsprachige Mütter ausgeschlossen waren.

Von den nicht-deutschen Müttern der vorliegenden Untersuchung sind fast die Hälfte $(41,9 \%)$ türkischer Abstammung und 26,7 \% anderer Nationalität als die im Fragebogen vorgegebenen. Die übrigen Nationalitäten finden sich in Anhang A, Tabelle A.1, Seite I.

Zusammenfassend kann gesagt werden, daß die Altersstruktur in der untersuchten Stichprobe mit der bundesweiten, aber nicht mit derjenigen von Müttern in Berlin vergleichbar ist: die Gruppe der 30- bis 34-jährigen ist über-, ältere Mütter (über 35 Jahren) sind unterrepräsentiert. Die Bildungsstruktur unterscheidet sich deutlich von derjenigen der bundesweiten Bevölkerung (über die Berliner Bevölkerung lagen keine Angaben zu Bildungsabschlüssen vor). Mütter mit Abitur sind deutlich über- und Mütter mit mittleren Abschlüssen unterrepräsentiert. Weitergehende Bildungsabschlüsse waren ebenfalls im mittleren Bereich (Lehre) seltener und Hochschulabschlüsse häufiger als bundesweit vorhanden.

Die Verteilungen der übrigen soziodemographischen Merkmale (Zahl der Kinder, Berufstätigkeit, Einkommen und Nationalität) unterscheiden sich sämtlich von derjenigen der Berliner Bevölkerung (bundesweite Vergleichszahlen lagen nicht vor). In der untersuchten Stichprobe sind Mütter mit mehreren (mehr als zwei) Kindern, ohne Berufstätigkeit und mit deutscher Nationalität überrepräsentiert.

Die Verteilungen der soziodemographischen Merkmale weisen insgesamt darauf hin, daß in der untersuchten Stichprobe mehrfachgebärende Mütter (Anfang 30) aus bessergestellten Familien, in denen sich gut ausgebildete Frauen (zunächst) ohne Berufstätigkeit ihren Kindern widmen können, im Vergleich zur Berliner Bevölkerung häufiger vertreten sind. 


\subsubsection{Lebensgewohnheiten und Schwangerschaft}

Die Ergebnisse zu Lebensgewohnheiten und Schwangerschaft finden sich in Anhang A, Tabelle A.2, Seite II.

\section{Alkoholkonsum}

Fast drei Viertel der Mütter (72,4 \%) geben an, in der Schwangerschaft nie Alkohol getrunken zu haben. Ein Viertel nahm in der Schwangerschaft selten $(26,7 \%)$ und 0,9 \% öfter Alkohol zu sich.

Nach der Schwangerschaft halbiert sich die Gruppe der Frauen, die nie Alkohol trinken (37,3\%). Dafür wächst die Gruppe derer, die selten Alkohol zu sich nehmen auf das doppelte und macht somit mehr als die Hälfte aller Mütter aus (54,6 \%). Der Anteil der Mütter, die öfter Alkohol konsumieren, macht nach der Schwangerschaft $8,1 \%$ aus.

\section{Vegetarische Ernährung}

Mehr als die Hälfte aller Mütter ernährt sich gar nicht (53,5 \%) und etwa ein Drittel nur selten vegetarisch (35,0\%). Die übrigen Mütter achten zum Großteil vorwiegend auf vegetarische Ernährung $(10,2 \%)$, und zum geringeren Teil ernähren sie sich ausschließlich vegetarisch (1,3\%).

\section{Rauchen}

In der Schwangerschaft rauchten fast ein Drittel aller Mütter (27,1\%). Dieser Anteil steigt bis zu dem Studienzeitpunkt auf ein gutes Drittel (35,3\%). Die übrigen zwei Drittel sind Nichtraucherinnen.

\section{Passivrauchen in der Schwangerschaft}

Etwa ein Fünftel der Mütter waren in der Schwangerschaft nie dem Passivrauchen ausgesetzt (22,4 $\%)$. Fast zwei Drittel dagegen hielt sich selten in verrauchten Räumen auf $(61,7 \%)$ und 15,9 \% öfter.

\section{Sport}

Mehr als $80 \%$ aller Mütter trieben in der Schwangerschaft nicht regelmäßig Sport (83,4 \%). Dieser Anteil verringert sich nach der Schwangerschaft auf $75 \%$. Die übrigen Mütter betätigten sich regelmäßig sportlich.

\section{Einsetzen der Menstruation nach der Geburt}

Bei etwa drei Viertel der Mütter setzte die Menstruation innerhalb des ersten Jahres nach der Entbindung wieder regelmäßig ein (73,8\%). In 18,1\% der Fälle setzte die Menstruation post 
partum unregelmäßig ein und bei 8,1\% hatte sie zu dem Zeitpunkt der Studie noch nicht wieder eingesetzt.

\section{Stärke der Menstruationsblutung}

Knapp zwei Drittel der Mütter haben eine mäßige Menstruationsblutung (56,5\%). Mehr als ein Drittel zeigen eine starke Blutung $(37,9 \%)$ und 2,6 \% kaum Blutungen.

\section{Stilldauer}

Die Gruppe mit der geringsten Stilldauer (0 bis 1 Monat) macht von allen Müttern den geringsten Anteil aus (14,5\%). Diejenigen, die 2 bis 4 Monate stillen, stellen dagegen mit einem Anteil von einem Viertel die größte Gruppe dar (26,5\%). Die übrigen drei Gruppen machen jeweils etwa ein Fünftel aller Frauen aus ( 5 bis 6 Monate: 18,6 \%, 7 bis 9 Monate: 20,5 \%, über 9 Monate: 19,8 $\%)$.

\section{Body-Mass-Index}

Ein Fünftel aller Mütter (15,2 \%) hat mit unter 19,8 einen niedrigen Body-Mass-Index. Einen normalen Body-Mass-Index zwischen 19,8 und 26 weisen mehr als die Hälfte der Mütter auf (58,5 $\%)$, und ein hoher Body-Mass-Index kommt bei $12,8 \%$ vor. Die kleinste Gruppe $(8,4 \%)$ ist adipös mit einem Body-Mass-Index von über 29.

\section{Schwangerschaftsdauer}

Eine Schwangerschaftsdauer von 37 Wochen und weniger kam bei 14,5 \% der Studienteilnehmerinnen vor. 8,9 \% der Schwangerschaften endete nach 38 und 15,7 \% nach 39 Wochen. Etwa die Hälfte der Schwangerschaften hatten eine normale Dauer von 40 (23,4\%) oder 41 Wochen $(25,4$ $\%) .12,1 \%$ der Schwangerschaften betrugen 42 Wochen und länger.

\section{Geburtsgewicht}

79,4 \% aller zum Zeitpunkt der Studie einjährigen Kinder kamen mit einem Gewicht zwischen 2500 und $4000 \mathrm{~g}$ zur Welt. Je etwa ein Zehntel liegen darüber $(12,2 \%)$ und darunter $(8,4 \%)$.

\subsection{Konzentrationen von Hämoglobin und löslichem Transfer- rinrezeptor der Mutter}

Im Folgenden wird das Auftreten von Eisenmangel bei den Probandinnen beschrieben, definiert anhand von löslichem Transferrinrezeptor und Hämoglobin. Dabei werden betrachtet: Prävalenz 
von Eisenmangel, Eisenmangel in Abhängigkeit von gruppenbildenden Variablen, Einfluß der Variablen in der multivariaten Analyse und Zusammenhang zwischen mütterlichen und kindlichem Eisenstatus.

\subsubsection{Prävalenz in der Stichprobe}

Die Hämoglobinkonzentration ist der gängigste Indikator für das Funktionseisen und der lösliche Transferrinrezeptor, der den zellulären Eisenbedarf repräsentiert, hat gegenüber Ferritin den Vorteil hat, daß er kein Akute-Phase-Protein ist. Deswegen werden in den folgenden Ausführungen nur diese beiden Indikatoren betrachtet. In Anhang A zeigt Tabelle A.3 auf Seite III die Mittelwerte und die Prävalenz von abweichenden Werten der beiden Indikatoren.

Bei fast einem Zehntel (9,5 \%) der Mütter liegt ein zellulärer Eisenmangel vor, bei 4,0 \% eine

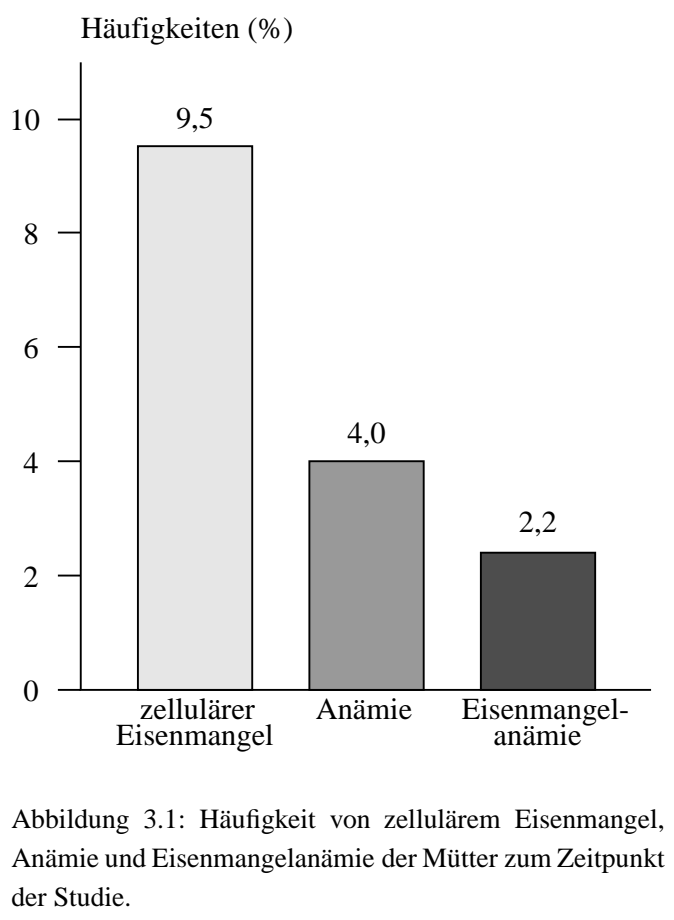

Anämie und bei 2,2 \% der Mütter eine Eisenmangelanämie (Abbildung 3.1, Seite 49) (Wagener et al., 1999a), (Wagener et al., 1999b), (Wagener et al., 2000). Die mittlere Hämoglobinkonzentration in der Stichprobe beträgt 13,7 g/dl, die mittlere Konzentration des sTfR liegt bei 2,22 mg/l (Median: 1,98 mg/l).

Das 90. Perzentil der Konzentration des sTfR findet sich bei 3,27 mg/l. Die übrigen Perzentilangaben für den löslichen Transferrinrezeptor (auch in Bezug auf verschiedene Altersgruppen) zeigt der Anhang A in Tabelle A.4, Seite III.

Beim Vergleich der 90. Perzentile bei den verschiedenen Altersgruppen zeigt diejenige der jüngsten Mütter (bis 24 Jahre) die höchste Konzentration (4,67 mg/l). Die Gruppe von 25 bis 29 Jahren 
dagegen weist die niedrigste 90 . Perzentile auf (3,14 mg/l). Die der älteren Mütter liegen dazwischen ( 30-34 Jahre: 3,25 mg/l; ab 35 Jahre: 3,19 mg/l).

\subsubsection{Prävalenz in Untergruppen}

Nachfolgend werden die Prävalenz von Eisenmangel (Anhang A, Tabellen A.5, Seite III und A.6, Seite V) und die Mittelwerte der Indikatoren (Anhang A, Tabellen A.7, Seite VI, A.8, Seite VIII und A.9, Seite IX) in Abhängigkeit von verschiedenen gruppenbildenden Variablen beschrieben. Dabei zeigt sich eine höhere Prävalenz von Eisenmangel bei bestimmten Risikogruppen, die charakterisiert sind durch Merkmale der Ernährung (Fleischkonsum), Lebensweise (Alkohol, Rauchen) und Soziodemographie (z. B. Bildung, Zahl der Kinder).
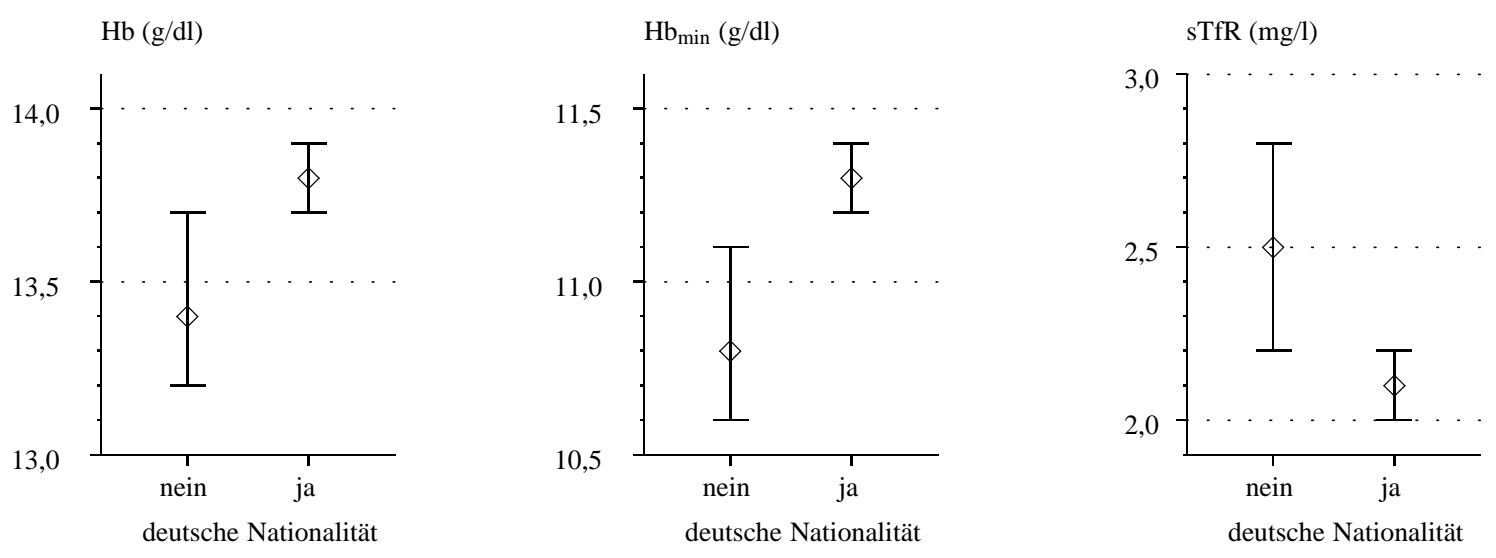

Abbildung 3.2: Mittelwerte mit 95\%-Konfidenzintervallen in Abhängigkeit von der Nationalität.

\section{Nationalität}

Nicht deutsche Mütter zeigen sowohl in der Schwangerschaft ( $\overline{\mathrm{y}}=10,8 \mathrm{~g} / \mathrm{dl}, \mathrm{CI}=10,6-11,1 \mathrm{~g} / \mathrm{dl}$ ) als auch zum Zeitpunkt der Studie $(\overline{\mathrm{y}}=13,4 \mathrm{~g} / \mathrm{dl}, \mathrm{CI}=13,2-13,7 \mathrm{~g} / \mathrm{dl})$ geringere Hämoglobinkonzentrationen und außerdem höhere sTfR-Konzentrationen $(\overline{\mathrm{y}}=2,5 \mathrm{mg} / \mathrm{l}, \mathrm{CI}=2,2-2,8 \mathrm{mg} / \mathrm{l})$ als deutsche Mütter $\left(\mathrm{Hb}_{\min }: \overline{\mathrm{y}}=11,3 \mathrm{~g} / \mathrm{dl}, \mathrm{CI}=11,2-11,4 \mathrm{~g} / \mathrm{dl} ; \mathrm{Hb}: \overline{\mathrm{y}}=13,8 \mathrm{~g} / \mathrm{dl}, \mathrm{CI}=13,5-13,8 \mathrm{~g} / \mathrm{dl}\right.$; sTfR: $\bar{y}=2,1 \mathrm{mg} / \mathrm{l}, \mathrm{CI}=2,0-2,2 \mathrm{mg} / \mathrm{l})($ Abbildung 3.2, Seite 50).

Die Prävalenzen von Anämie und zellulärem Eisenmangel zur Zeit der Studie liegen zwar für nicht-deutsche Mütter (Anämie: 6,5\%; zellulärer Eisenmangel: 12,8 \%) ebenfalls höher als für deutsche Mütter (Anämie: 3,2 \%; zellulärer Eisenmangel: 8,0 \%), die Unterschiede sind aber mit $\mathrm{p}=0,170$ für Anämie und $\mathrm{p}=$ 0,179 für zellulären Eisenmangel nicht signifikant (Wagener et al., 1999a), (Wagener et al., 1999b), (Wagener et al., 2000).

Damit ist nicht deutsche Nationalität sowohl in als auch nach der Schwangerschaft als Risikofaktor für geringere Hämoglobinkonzentrationen und höhere sTfR-Konzentrationen anzusehen. 

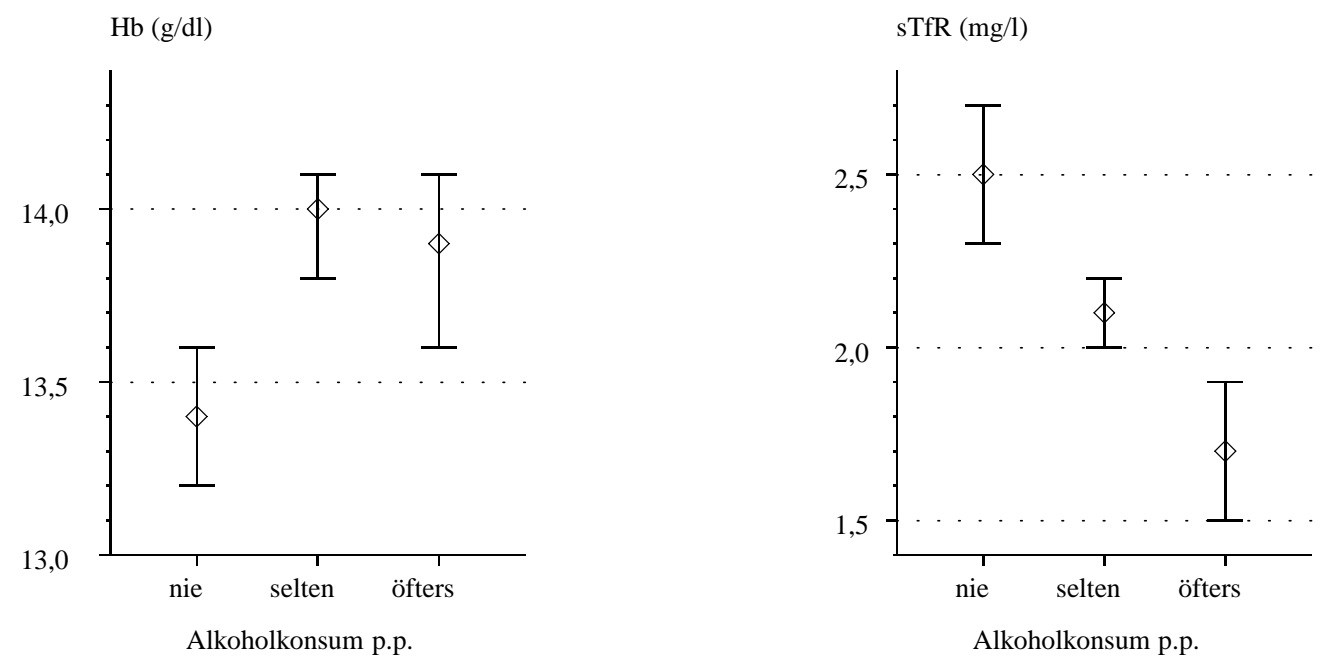

Abbildung 3.3: Mittelwerte mit 95\%-Konfidenzintervallen bei steigendem Alkoholkonsum nach der Schwangerschaft.

\section{Alkoholkonsum nach der Schwangerschaft}

Bei steigendem Alkoholkonsum nach der Schwangerschaft sinkt die Prävalenz von Anämie und zellulärem Eisenmangel. Frauen, die nie Alkohol trinken, weisen die höchste Prävalenz von Anämie $(7,7 \%$, Odds-Ratio = 1) und zellulärem Eisenmangel $(12,4 \%$, Odds-Ratio $=1)$ sowie die geringsten mittleren Hämoglobin- $(\bar{y}=13,4 \mathrm{~g} / \mathrm{dl}, \mathrm{CI}=13,2-13,6 \mathrm{~g} / \mathrm{dl})$ und die höchsten mittleren sTfR-Konzentrationen ( $\overline{\mathrm{y}}=2,5 \mathrm{mg} / \mathrm{l}, \mathrm{CI}=2,3-2,7 \mathrm{mg} / \mathrm{l})$ auf. Bei Müttern, die selten Alkohol trinken, findet sich die zweithöchste Prävalenz von Anämie $(1,7 \%$, Odds-Ratio $=0,21)$ und zellulärem Eisenmangel $(7,6 \%$, Odds-Ratio $=0,581)$, sowie die höchste mittlere Hämoglobinkonzentration $(\mathrm{Hb}: \overline{\mathrm{y}}=14,0 \mathrm{~g} / \mathrm{dl}, \mathrm{CI}=13,8-14,1 \mathrm{~g} / \mathrm{dl}$ ) und die zweithöchste mittlere sTfR-Konzentration (sTfR: $\bar{y}=2,1 \mathrm{mg} / \mathrm{l}, \mathrm{CI}=2,0-2,2 \mathrm{mg} / \mathrm{l})$. Diejenigen, die öfter Alkohol zu sich nehmen weisen weder eine Anämie, noch einen zellulären Eisenmangel auf und zeigen eine geringere mittlere Hämoglobinund sTfR-Konzentration als die Mütter mit mittlerem Alkoholkonsum ( $\mathrm{Hb}: \overline{\mathrm{y}}=13,9 \mathrm{~g} / \mathrm{dl}, \mathrm{CI}=$ 13,6-14,1 g/dl; sTfR: 1,7 mg/l, CI = 1,5-1,9 mg/l; siehe Abbildung 3.3, Seite 51) (Wagener et al., 1999a), (Wagener et al., 1999b), (Wagener et al., 2000). Diese Gruppe weist allerdings eine geringe Fallzahl auf $(n=4)$.

Rauchen zur Zeit der Studie Raucherinnen weisen eine höhere mittlere Hämoglobinkonzentration $(\overline{\mathrm{y}}=13,9 \mathrm{~g} / \mathrm{dl}, \mathrm{CI}=13,7-14,1 \mathrm{~g} / \mathrm{dl})$ und eine niedrigere mittlere Konzentration des sTfR auf $(\overline{\mathrm{y}}=2,1 \mathrm{mg} / \mathrm{l}, \mathrm{CI}=1,9-2,2 \mathrm{mg} / \mathrm{l})$ als Nichtraucherinnen $(\mathrm{Hb}: \overline{\mathrm{y}}=13,7 \mathrm{~g} / \mathrm{dl}, \mathrm{CI}=13,5-13,8$ g/dl; sTfR: $\bar{y}=2,3 \mathrm{mg} / \mathrm{l}, \mathrm{CI}=2,1-2,4 \mathrm{mg} / \mathrm{l}$ )(Abbildung 3.4 auf Seite 52). Die niedrigere Prävalenz von zellulärem Eisenmangel bei Raucherinnen $(6,0 \%)$ im Vergleich zu Nichtraucherinnen $(9,3 \%)$ liegt mit $p=0,238$ über dem Signifikanzniveau von $p=0,1$. Für die Prävalenz von Anämie wird das Signifikanzniveau noch stärker überschritten $(\mathrm{p}=0,749)$ (Wagener et al., 1999a), (Wagener et al., 1999b), (Wagener et al., 2000). 

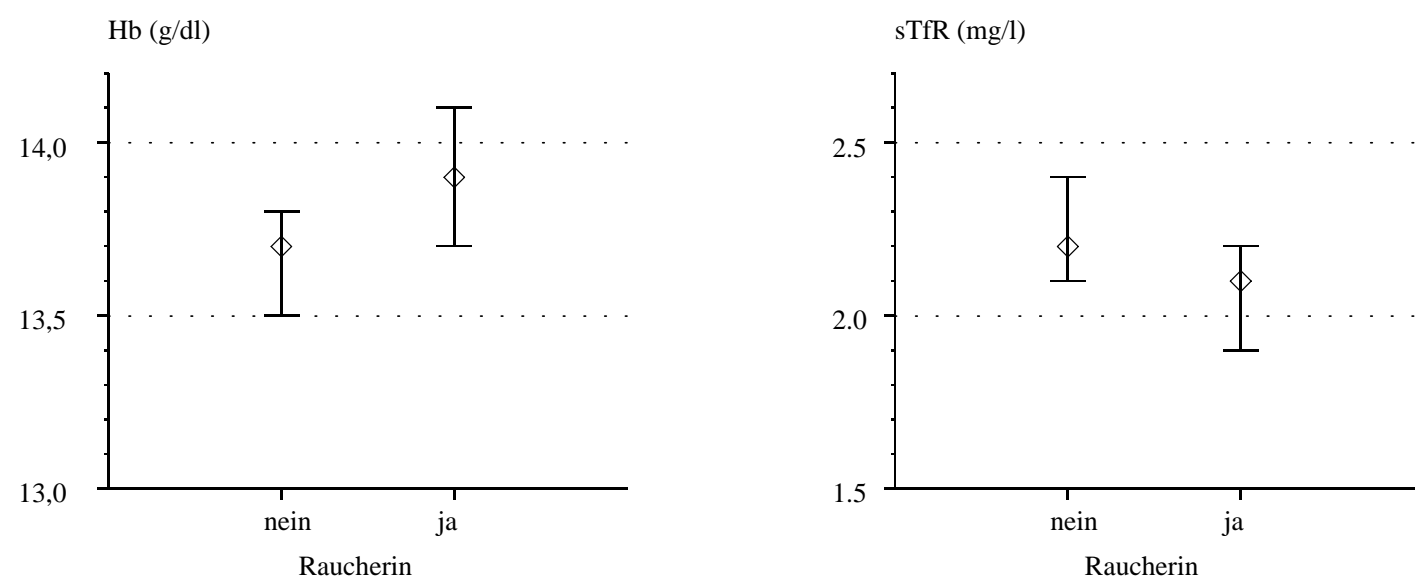

Abbildung 3.4: Mittelwerte mit 95\%-Konfidenzintervallen in Abhängigkeit vom Raucherstatus zum Zeitpunkt der Studie

Demzufolge neigen Nicht-Raucherinnen trotz geringerer Eisenreserven nicht häufiger zu einem Eisenmangel als Raucherinnen.

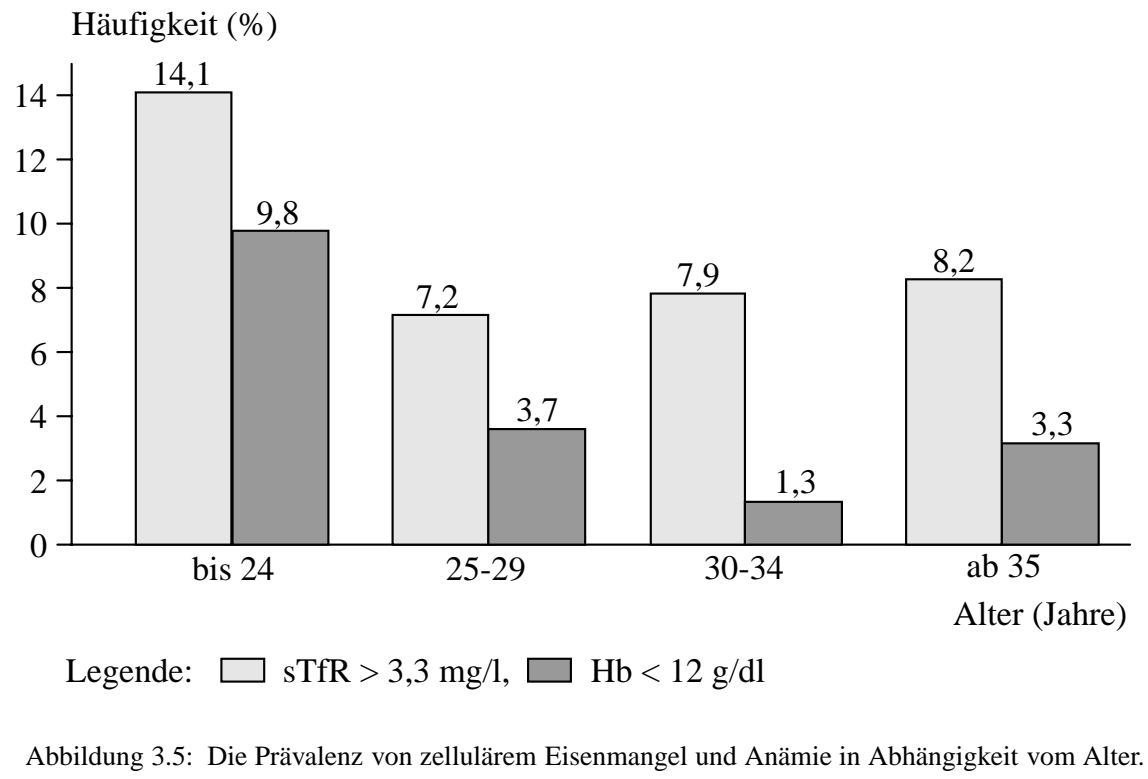

\section{Alter, Berufsausbildung und Body-Mass-Index}

Die jüngsten Mütter haben am häufigsten Anämien (siehe Abbildung 3.5, Seite 52). Auch ein Trend zu häufigerem zellulären Eisenmangel findet sich bei dieser Altersgruppe (obwohl dieses Ergebnis nicht signifikant ist). In der Schwangerschaft findet sich dagegen die niedrigste mittlere Hämoglobinkonzentration bei den ältesten Müttern (Abbildung 3.6, Seite 53). Mütter ohne Berufsausbildung und diejenigen mit dem niedrigsten Body-Mass-Index weisen ebenfalls die niedrigsten Hämoglobinkonzentrationen sowohl in als auch nach der Schwangerschaft auf. 


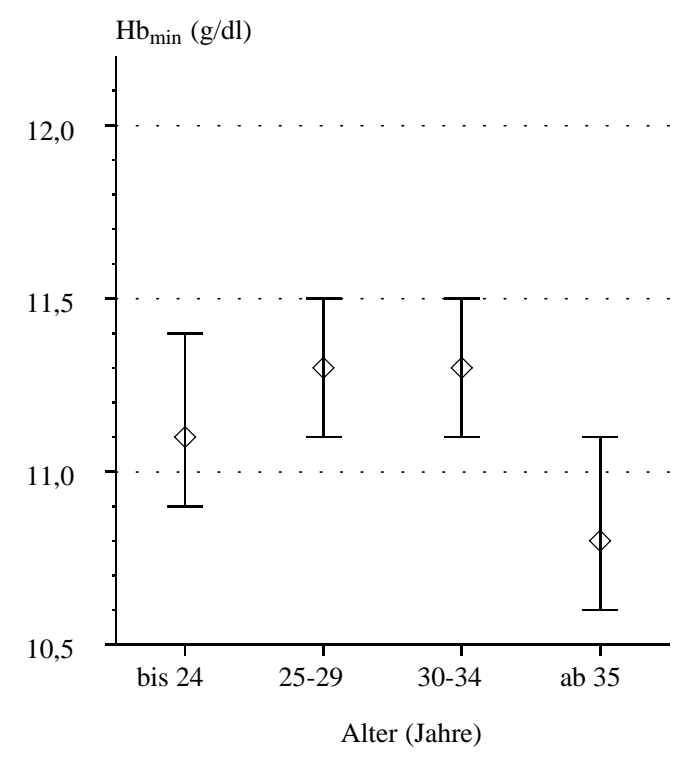

Abbildung 3.6: Mittelwerte und 95\%-Konfidenzintervalle der minimalen Hämoglobinkonzentration der Mutter in der Schwangerschaft in Abhängigkeit vom Alter.

Alter Die höchste Prävalenz von Anämie weisen die jüngsten Mütter von bis 24 Jahren auf (9,8 $\%, \overline{\mathrm{y}}=13,6 \mathrm{~g} / \mathrm{dl}, \mathrm{CI}=13,2-13,9 \mathrm{~g} / \mathrm{dl}$, Odds-Ratio = 1). Bis zu einem Alter von 34 Jahren sinkt die Prävalenz ab (25-29 Jahre: 3,7 \%, $\overline{\mathrm{y}}=13,61 \mathrm{~g} / \mathrm{dl}, \mathrm{CI}=13,4-13,8 \mathrm{~g} / \mathrm{dl}$; 30-34 Jahre: 1,3 \%, $\overline{\mathrm{y}}$ $=13,9 \mathrm{~g} / \mathrm{dl}, \mathrm{CI}=13,7-14,1 \mathrm{~g} / \mathrm{dl}$, Odds-Ratio =0,12), um bei den ältesten Müttern ab 35 wieder anzusteigen $(3,3 \%, \bar{y}=13,8 \mathrm{~g} / \mathrm{dl}, \mathrm{CI}=13,6-14,1 \mathrm{~g} / \mathrm{dl})$. In der Schwangerschaft findet sich dagegen bei den ältesten Müttern der niedrigste Mittelwert der minimalen Hämoglobinkonzentration von allen Altersgruppen $(\overline{\mathrm{y}}=10,8 \mathrm{~g} / \mathrm{dl}, \mathrm{CI}=10,6-11,1 \mathrm{~g} / \mathrm{dl})$ und bei den jüngsten der zweitniedrigste Mittelwert ( $\overline{\mathrm{y}}=11,1 \mathrm{~g} / \mathrm{dl}, \mathrm{CI}=10,9-11,4 \mathrm{~g} / \mathrm{dl})$.

Berufsausbildung Sowohl zum Zeitpunkt der Befragung ( $\overline{\mathrm{y}}=13,5 \mathrm{~g} / \mathrm{dl}, \mathrm{CI}=13,3-13,8 \mathrm{~g} / \mathrm{dl}$ ) als auch in der Schwangerschaft $(\overline{\mathrm{y}}=11,0 \mathrm{~g} / \mathrm{dl}, \mathrm{CI}=10,8-11,2 \mathrm{~g} / \mathrm{dl})$ finden sich die niedrigsten mittleren Hämoglobinkonzentrationen bei den Müttern, die (noch) keine abgeschlossene Berufsausbildung vorweisen können. Diejenigen mit Hochschulabschluß weisen die zweitniedrigsten mittleren Hämoglobinkonzentration zum Zeitpunkt der Befragung ( $\overline{\mathrm{y}}=13,7 \mathrm{~g} / \mathrm{dl}, \mathrm{CI}=13,4-13,9$ $\mathrm{g} / \mathrm{dl})$ wie auch in der Schwangerschaft $(\overline{\mathrm{y}}=11,3 \mathrm{~g} / \mathrm{dl}, \mathrm{CI}=11,1-11,5 \mathrm{~g} / \mathrm{dl})$ auf. Dabei stimmt der Mittelwert von Hämoglobin in der Schwangerschaft der Mütter mit Lehre ( $\bar{y}=11,3 \mathrm{~g} / \mathrm{dl}$, CI = 11,1-11,5 g/dl) mit dem der Hochschulabsolventinnen überein. Die aktuelle mittlere Hämoglobinkonzentration bei Müttern mit Lehre ( $\overline{\mathrm{y}}=13,8 \mathrm{~g} / \mathrm{dl}, \mathrm{CI}=13,6-14,0 \mathrm{~g} / \mathrm{dl})$ liegt nur knapp über der von den Hochschulabsolventinnen. Die höchsten mittleren Hämoglobinkonzentrationen finden sich sowohl in $(\overline{\mathrm{y}}=11,4 \mathrm{~g} / \mathrm{dl}, \mathrm{CI}=11,2-11,7 \mathrm{~g} / \mathrm{dl})$ als auch nach der Schwangerschaft $(\overline{\mathrm{y}}=14,0$ $\mathrm{g} / \mathrm{dl}, \mathrm{CI}=13,7-14,4 \mathrm{~g} / \mathrm{dl}$ ) bei den Müttern mit Fachschulabschluß.

Somit finden sich die höchsten Hämoglobinkonzentrationen bei den Müttern mit Fachschulab- 
schluß und die geringsten bei denen ohne Berufsausbildung.

Für Mütter mit unterschiedlichen Berufsausbildungen zeigen sich weder in Bezug auf die Prävalenzen von Anämie und zellulärem Eisenmangel, noch in Bezug auf die mittleren Konzentrationen des sTfR signifikante Unterschiede.
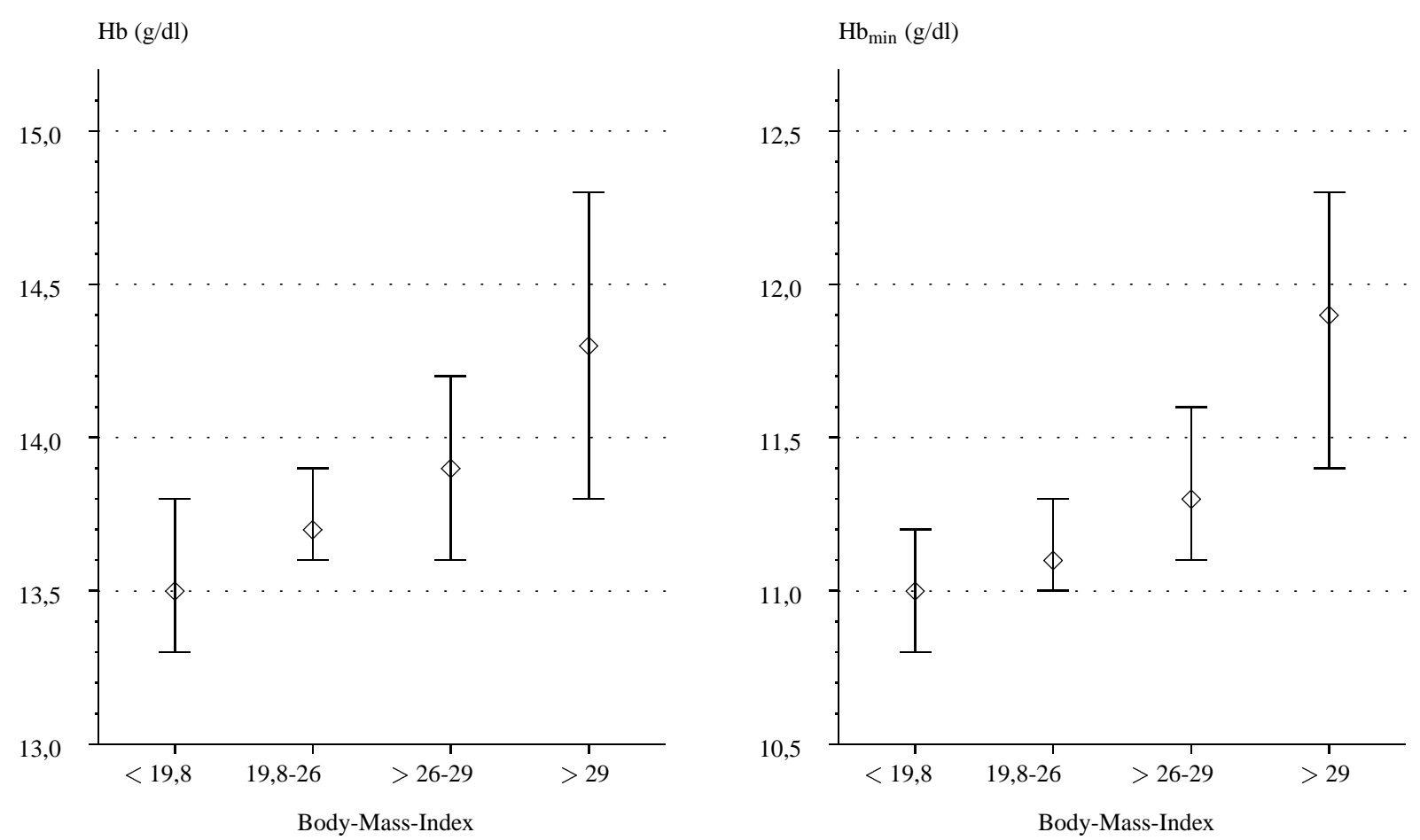

Abbildung 3.7: Unterschiedlicher Body-Mass-Index der Mutter mit Mittelwerten und 95\%-Konfidenzintervallen der aktuellen Hämoglobinkonzentration und der minimalen Hämoglobinkonzentration in der Schwangerschaft.

Body-Mass-Index Mit steigendem Body-Mass-Index der Mutter nimmt sowohl ihre mittlere aktuelle Hämoglobinkonzentration als auch der Mittelwert ihrer minimalen Hämoglobinkonzentration in der Schwangerschaft zu. Dabei sind die Unterschiede zwischen den verschiedenen BodyMass-Indices bei aktueller und in der Schwangerschaft gemessener Hämoglobinkonzentration nahezu identisch, wie aus Abbildung 3.7 auf Seite 54 hervorgeht. Allerdings zeigt sich bei Frauen mit geringem Body-Mass-Index weder signifikant häufiger eine Anämie noch zellulärer Eisenmangel noch höhere mittlere sTfR-Konzentrationen.

\section{Vegetarische Ernährung}

Bei Müttern, die sich ausschließlich vegetarisch ernähren, findet sich sowohl die höchste Prävalenz von zellulärem Eisenmangel zum Zeitpunkt der Befragung $(16,7 \%$, Odds-Ratio = 1,5) als auch der niedrigste Mittelwert der minimalen Hämoglobinkonzentration in der Schwangerschaft $(\overline{\mathrm{y}}=$ 

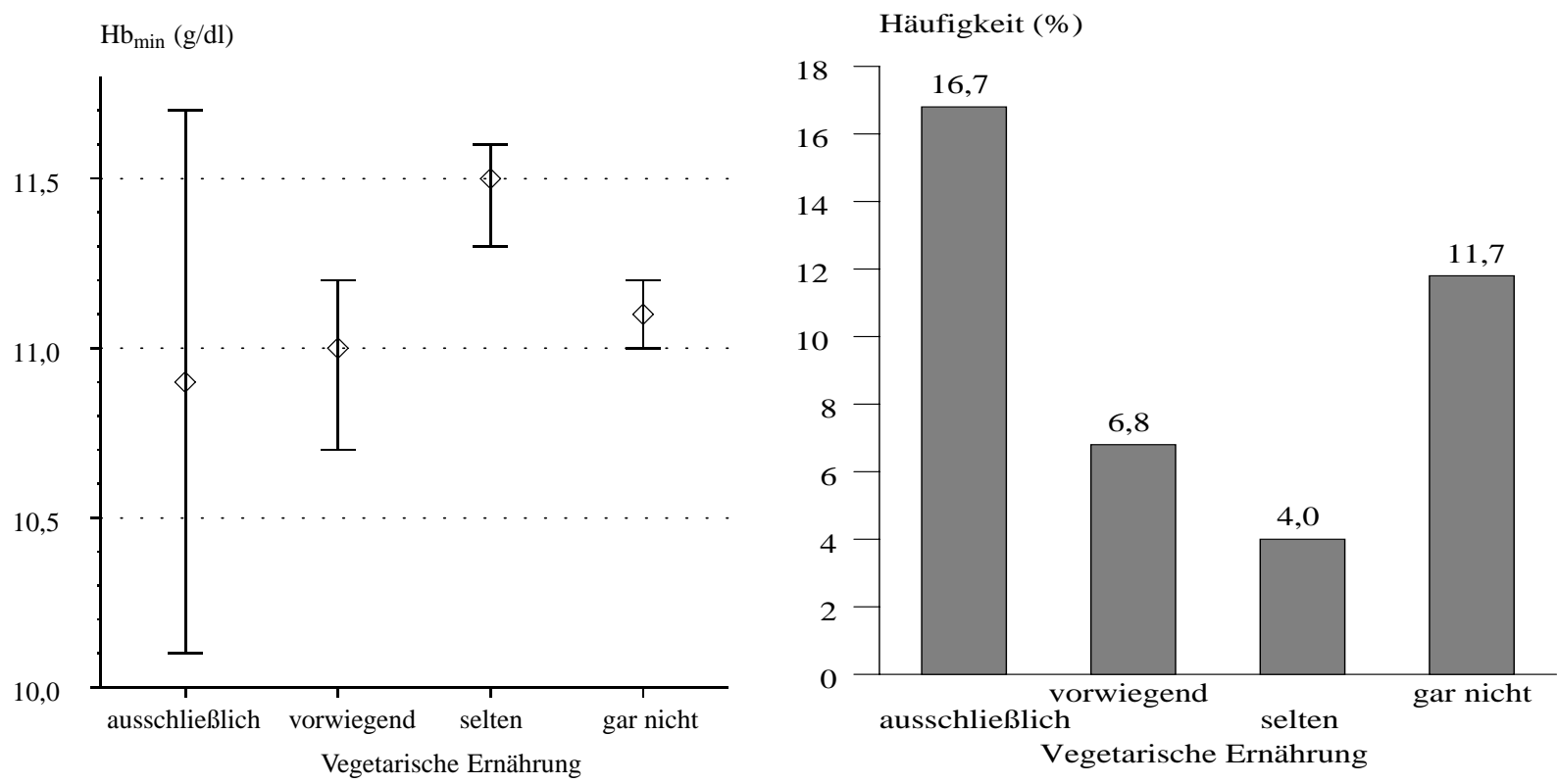

Abbildung 3.8: Mütter mit rein vegetarischer Ernährung weisen häufiger einen zellulären Eisenmangel und in der Schwangerschaft geringere mittlere Hb-Konzentrationen auf als diejenigen, die Fleisch essen (Mittelwerte und 95\%-Konfidenzintervalle).

$10,9 \mathrm{~g} / \mathrm{dl}, \mathrm{CI}=10,1-11,7 \mathrm{~g} / \mathrm{dl})$.

Diejenigen, die gar keine vegetarische Kost zu sich nehmen, weisen die zweithöchste Prävalenz von zellulärem Eisenmangel auf $(11,7 \%$, Odds-Ratio $=1)$. Sie zeigen zwar die zweithöchste mittlere minimale Hämoglobinkonzentration in der Schwangerschaft $(\overline{\mathrm{y}}=11,0 \mathrm{~g} / \mathrm{dl}, \mathrm{CI}=10,7-11,3$ $\mathrm{g} / \mathrm{dl})$, jedoch unterscheidet sich diese immer noch signifikant von der höchsten, die sich bei den Müttern findet, die sich selten vegetarisch ernähren.

Diejenigen, die selten vegetarische Kost zu sich nehmen, haben von allen die geringste Prävalenz an zellulärem Eisenmangel $(4,0 \%$, Odds-Ratio $=0,32)$ und den höchsten Mittelwert der minimalen Hämoglobinkonzentration in der Schwangerschaft ( $\overline{\mathrm{y}}=11,5 \mathrm{~g} / \mathrm{dl}, \mathrm{CI}=11,3-11,6 \mathrm{~g} / \mathrm{dl})$.

Bei den Müttern, die vorwiegend vegetarische Kost zu sich nehmen, findet sich die zweitniedrigste Prävalenz $(6,8 \%$, Odds-Ratio $=0,55)$ an zellulärem Eisenmangel, allerdings auch die zweitniedrigste mittlere minimale Hämoglobinkonzentration in der Schwangerschaft $(\overline{\mathrm{y}}=11,0 \mathrm{~g} / \mathrm{dl}, \mathrm{CI}=$ 110,7-11,3 g/dl), wie auch aus Abbildung 3.8 auf Seite 55 hervorgeht (Wagener et al., 1999a), (Wagener et al., 1999b), (Wagener et al., 2000).

Insgesamt findet sich also am seltensten zellulärer Eisenmangel und die höchste mittlere Hämoglobinkonzentration in der Schwangerschaft bei den Müttern, die sich selten vegetarisch ernähren und bei den reinen Vegetarierinnen am häufigsten zellulärer Eisenmangel sowie die niedrigste Hämoglobinkonzentration in der Schwangerschaft.. 


\section{Rauchen in der Schwangerschaft}

Signifikante Prävalenzunterschiede finden sich bei in der Schwangerschaft rauchenden im Vergleich zu nicht rauchenden Müttern nur in Bezug auf die aktuelle Hämoglobinkonzentration der Mutter. Die Mütter, die in der Schwangerschaft rauchten, weisen eine höhere mittlere Hämoglobinkonzentration auf $(\overline{\mathrm{y}}=13,9 \mathrm{~g} / \mathrm{dl}, \mathrm{CI}=13,7-14,1 \mathrm{~g} / \mathrm{dl})$ als diejenigen, die in der Schwangerschaft auf das Rauchen verzichteten $(\overline{\mathrm{y}}=13,7 \mathrm{~g} / \mathrm{dl}, \mathrm{CI}=13,5-13,8 \mathrm{~g} / \mathrm{dl})$. Dabei stimmen die Mittelwerte und Konfidenzintervalle von Raucherinnen und Nichtraucherinnen in der Schwangerschaft mit denen von Raucherinnen und Nichtraucherinnen zum Zeitpunkt der Befragung überein.

\section{Zahl der Kinder und Einsetzen der Menstruation nach der Geburt}

Die Probandinnen mit der höchsten Kinderzahl und diejenigen, deren Menstruation nach der Geburt nicht einsetzte, weisen am häufigsten einen zellulären Eisenmangel auf.

Zahl der Kinder Mit steigender Zahl der Kinder findet sich bei den Müttern ein Anstieg der mittleren Konzentration des sTfR. So weisen Mütter mit nur einem Kind die geringste mittlere Konzentration auf ( $\overline{\mathrm{y}}=2,0 \mathrm{mg} / \mathrm{l}, \mathrm{CI}=1,9-2,2 \mathrm{mg} / \mathrm{l})$, gefolgt von den Müttern mit zwei Kindern $(\overline{\mathrm{y}}$ $=2,2 \mathrm{mg} / \mathrm{l}, \mathrm{CI}=2,0-2,4 \mathrm{mg} / \mathrm{l})$ und denjenigen mit mindestens drei Kindern $(\overline{\mathrm{y}}=2,6 \mathrm{mg} / \mathrm{l}, \mathrm{CI}=$ 2,2-2,9 mg/l). Obwohl das Signifikanzniveau für den Unterschied der Prävalenzen von zellulärem Eisenmangel mit $\mathrm{p}=0,176$ überschritten wird, zeigt sich hier ein vergleichbarer Trend. Die Mütter mit der höchsten Kinderzahl haben am häufigsten einen zellulären Eisenmangel (ein Kind: 6,4 \%, Odds-Ratio $=1$, zwei Kinder: 10,5 \%, Odds-Ratio $=1,71$, ab drei Kinder: 14,8 \%, Odds-Ratio $=$ 2,59) (Wagener et al., 1999a), (Wagener et al., 1999b), (Wagener et al., 2000).

Einsetzen der Menstruation nach der Geburt Ein Fünftel der Mütter, deren Menstruation zum Zeitpunkt der Studie noch nicht wieder eingesetzt hatte weisen einen zellulären Eisenmangel auf $(20,6 \%$, Odds-Ratio = 3,42). Korrespondierend dazu weist diese Gruppe den höchsten Mittelwert der Konzentration des sTfR auf ( $\bar{y}=2,6 \mathrm{mg} / \mathrm{l}, \mathrm{CI}=2,1-3,0 \mathrm{mg} / \mathrm{l})$. Die Mütter, deren Menstruation nach der Geburt regelmäßig wieder einsetzte, weisen eine Prävalenz an zellulärem Eisenmangel auf, die weniger als die Hälfte von der der erstgenannten Gruppe ausmacht und zeigen auch einen geringeren Mittelwert $(7,1 \%, \bar{y}=2,2 \mathrm{mg} / \mathrm{l}, \mathrm{CI}=2,1-2,3 \mathrm{mg} / \mathrm{l}$, Odds-Ratio = 1). Am geringsten ist die Prävalenz von zellulärem Eisenmangel und die mittlere Konzentration des sTfR bei den Müttern, deren Menstruation nach der Geburt unregelmäßig einsetzte $(6,6 \%, \bar{y}=2,0 \mathrm{mg} / \mathrm{l}, \mathrm{CI}=$ $1,9-2,2 \mathrm{mg} / \mathrm{l})$.

\section{Alkoholkonsum in der Schwangerschaft}

Die Mütter mit dem größten Alkoholkonsum in der Schwangerschaft weisen die niedrigste mittlere minimale Hämoglobinkonzentration in der Schwangerschaft auf ( $\overline{\mathrm{y}}=$ 9,9 g/dl, CI = 8,5-11,2 g/dl). 
Bei denjenigen, die selten Alkohol tranken, findet sich der höchste Mittelwert $(\overline{\mathrm{y}}=11,4 \mathrm{~g} / \mathrm{dl}, \mathrm{CI}=$ 11,2-11,5 g/dl), wobei der Mittelwert der Mütter, die gar keinen Alkohol in der Schwangerschaft zu sich nahmen, nur wenig darunter liegt ( $\overline{\mathrm{y}}=11,2 \mathrm{~g} / \mathrm{dl}, \mathrm{CI}=11,0-11,3 \mathrm{~g} / \mathrm{dl})$.

\section{Einzelfälle mit Eisenmangelanämie zu dem Zeitpunkt der Befragung}

Da nur zehn Mütter zum Zeitpunkt der Studie eine Eisenmangelanämie aufweisen, werden im Folgenden zwei Fälle exemplarisch beschrieben. Tabelle A.10 (Anhang A, Seite X) faßt die Ergebnisse der beiden Fälle zusammen.

Fall 1 weist abgesehen davon, daß die Konzentration von Hämoglobin (11,6 g/dl) unter der Anämiegrenze und die des sTfR (5,29 mg/l) über dem Grenzwert für Anämie liegt, auch andere Eisenindikatoren auf, die auf eine Anämie hindeuten. So deutet die erniedrigte Ferritinkonzentration $(6 \mathrm{ng} / \mathrm{ml})$ wie auch das geringe mittlere Erythrozytenvolumen $(78 \mathrm{fl})$ und die erniedrigte Transferrinsättigung $(11,19 \%)$ ebenfalls auf das Vorliegen einer Eisenmangelanämie hin.

Die höchste in der Schwangerschaft gemessene Hämoglobinkonzentration dieser Mutter (12,8 $\mathrm{g} / \mathrm{dl}$ ) liegt im Normbereich für die Schwangerschaft. Dagegen unterschreitet die geringste in der Schwangerschaft gemessene Hämoglobinkonzentration (10,1 g/dl) die Anämiegrenze für das zweite Trimenon und somit alle in der Schwangerschaft geltenden Grenzwerte für Anämie, obwohl diese Mutter Eisen-, Magnesium- und Jodpräparate in der Schwangerschaft einnahm. Dabei ist nicht klar, welche Ursache diese Anämie hat.

Bei der 37-jährigen deutschen Mutter handelt es sich um eine berufstätige Frau mit hohem Bildungsniveau (Abitur und Hochschulabschluß) und einem gehobenem Familiennettoeinkommen (6000 DM im Monat). Sie lebt in fester Partnerschaft und mit einer 12- und einer 1-jährigen Tochter in Teltow, wobei sie schon seit ihrer Geburt in Deutschland lebt.

Sie war sowohl in der Schwangerschaft als auch zu dem Zeitpunkt der Studie Nichtraucherin und hielt sich in der Schwangerschaft auch nie in verrauchten Räumen auf. Außerdem trank sie in der Schwangerschaft nie und danach nur selten Alkohol. Ihre Ernährung ist vorwiegend vegetarisch, wobei sie sowohl in als auch nach der Schwangerschaft einmal in der Woche Fleisch zu sich nimmt. Die Mutter stillte ihre zum Zeitpunkt der Studie einjährige Tochter sechs Monate lang. Ihre Menstruation setzte zwar nach der Schwangerschaft wieder regelmäßig ein, dauert aber nur drei Tage bei geringen Blutmengen und einer Zyklusdauer von 30 Tagen.

Der Body-Mass-Index dieser Mutter lag zu dem Zeitpunkt der Studie mit 20,1 im unteren Normbereich (Größe: 1,64m, Gewicht: 54 kg). Bezogen auf ihren ersten in der Schwangerschaft (16. Schwangerschaftswoche) gemessenen Body-Mass-Index $(23,2)$ liegt ihre Gewichtszunahme in der Schwangerschaft unter der empfohlenen Norm $(9,9 \mathrm{~kg})$. Einer regelmäßigen sportlichen Betätigung kam diese Mutter weder in noch nach der Schwangerschaft nach. 
Fall 2 mit Eisenmangelanämie (Hb: 10,2 g/dl und sTfR: 8,5 mg/l) weist zu dem Studienzeitpunkt ebenfalls eine erniedrigte Ferritinkonzentration ( $5 \mathrm{ng} / \mathrm{ml})$, ein verringertes mittleres Erythrozytenvolumen auf (67 fl) und eine zu geringe Eisenbindungskapazität auf (4,76\%). Diese Frau zeigte in der Schwangerschaft im Gegensatz zu der ersten Mutter eine im Normbereich liegende Hämoglobinkonzentration $\left(\mathrm{Hb}_{\min }: 11,0 \mathrm{~g} / \mathrm{dl}\right)$. Dabei nahm auch diese Mutter in der Schwangerschaft Eisen und Magnesiumpräparate ein.

Anders als Fall 1 stammt diese 36-jährige Mutter aus Afrika, lebt erst seit 1990 in Deutschland und ist auch nicht berufstätig, wobei sie einen Realschulabschluß besitzt. Sie lebt ebenfalls in fester Partnerschaft mit vier Kindern in Kreuzberg. Das Nettoeinkommen ihrer Familie liegt bei 2500 DM im Monat.

Wie die erste Mutter rauchte diese Frau weder in noch nach der Schwangerschaft, noch war sie in der Schwangerschaft Zigarettenrauch ausgesetzt. Sie trank aber weder in der Schwangerschaft noch danach Alkohol. Außerdem ernährt sie sich nur selten vegetarisch, wobei sie in der Schwangerschaft einmal und danach dreimal in der Woche Fleisch zu sich nahm. Ihre einjährige Tochter stillte sie gar nicht, wobei die Menstruation nach der Schwangerschaft wieder regelmäßig einsetzte mit mäßiger Blutung und einer Menstruationsdauer von 4 sowie einer Zyklusdauer von 24 Tagen.

Der aktuelle Body-Mass-Index dieser Mutter liegt im mittleren Normbereich (22,2; Größe: 1,56 m, Gewicht: 54 kg). In Bezug auf den Body-Mass-Index, den sie bei der ersten Schwangerenvorsorgeuntersuchung hatte (21,8; ebenfalls Normbereich) ist ihre Gewichtszunahme in der Schwangerschaft jedoch zu gering $(8 \mathrm{~kg})$. Wie die erste Mutter betrieb auch diese weder in der Schwangerschaft noch danach regelmäßig Sport.

\subsubsection{Korrelationen}

Es besteht ein Zusammenhang zwischen mütterlichen und kindlichen Eisenstatusindikatoren, was im Folgenden beschrieben wird (Anhang A, Tabelle A.12, Seite XI). Außerdem folgt eine Erläuterung des linearen Zusammenhangs zwischen Eisenstatusindikatoren und signifikanten gruppenbildenden Variablen aus der multiplen linearen Regression (Anhang A, Tabelle A.13, Seite XI, Kapitel 3.2.4, Seite 59).

\section{Korrelation: Eisenstatus Mutter-Kind}

Bei der Korrelationsanalyse der mütterlichen und kindlichen Konzentrationen von Hämoglobin und löslichen Transferrinrezeptor finden sich signifikante Korrelationen zwischen

1. Hämoglobinkonzentration der Mutter und der des Kindes (Wagener et al., 1999a), (Wagener et al., 1999b), (Wagener et al., 2000), 
2. Konzentration des löslichen Transferrinrezeptors der Mutter und der des Kindes (Wagener et al., 1999a), (Wagener et al., 1999b), (Wagener et al., 2000),

3. Hämoglobinkonzentration der Mutter und Konzentration des löslichen Transferrinrezeptors der Mutter,

4. Hämoglobinkonzentration der Mutter und minimaler Hämoglobinkonzentration in der Schwangerschaft.

Zwischen den aktuellen Hämoglobinkonzentrationen der Mutter und des Kindes besteht eine positive Korrelation von 0,218. Eine positive Korrelation von 0,139 besteht außerdem zwischen der mütterlichen und der kindlichen Konzentration des sTfR.

Die Hämoglobinkonzentration der Mutter zeigt außerdem eine negative Korrelation mit ihrer Konzentration des sTfR $(r=-0,170)$. Des weiteren korreliert ihre Hämoglobinkonzentration mit ihrer minimalen Hämoglobinkonzentration in der Schwangerschaft $(r=0,253)$.

\section{Korrelation: Eisenstatus der Mutter-gruppenbildende Variablen}

Hämoglobinkonzentration Der Alkoholkonsum der Probandinnen nach der Schwangerschaft $(r=0,182)$ zeigt ebenso wie ihr Body-Mass-Index $(r=0,138)$ auch bei der Einzelkorrelation eine signifikante positive Korrelation mit der aktuellen Hämoglobinkonzentration der Mutter.

Konzentration des löslichen Transferrinrezeptors Der Alkoholkonsum nach der Schwangerschaft korreliert ebenfalls signifikant mit der aktuellen Konzentration des sTfR der Mutter. Diese Korrelation ist allerdings negativ $(\mathrm{r}=-0,210)$. Außerdem findet sich eine signifikante positive Korrelation $(r=0,223)$ zwischen steigender Kinderzahl und Konzentration des sTfR.

Minimale Hämoglobinkonzentration in der Schwangerschaft Die einzige Variable, die bei der Einzelkorrelation ein signifikantes Ergebnis erzielt, ist der Body-Mass-Index der Mutter. Dieser korreliert positiv mit der minimalen Hämoglobinkonzentration der Mutter in der Schwangerschaft $(\mathrm{r}=0,194)$. Tabelle A.13 (Anhang A, Seite XI) zeigt alle Einflußvariablen, die bei der linearen Regression einen signifikanten Zusammenhang mit der minimalen Hämoglobinkonzentration in der Schwangerschaft aufweisen.

\subsubsection{Multiple lineare Regressionsanalyse}

Für insgesamt acht Einflußvariablen findet sich ein signifikanter linearer Zusammenhang mit der aktuellen mütterlichen Hämoglobinkonzentration, der aktuellen Konzentration des sTfR oder der minimalen mütterlichen Hämoglobinkonzentration in der Schwangerschaft, (Anhang A, Tabelle A.16, Seite XII). Dabei wurden für die Analyse der aktuellen Hämoglobinkonzentration fünf, für 
die des sTfR zwei und für die der minimalen Hämoglobinkonzentration in der Schwangerschaft zwei Modelle berechnet (Anhang A, Tabelle A.15, Seite XII).

6,5 \% der Varianz der aktuellen mütterlichen Hämoglobinkonzentration, 3,4 \% der Konzentration ihres sTfR und 5,9\% ihrer minimalen Hämoglobinkonzentration in der Schwangerschaft werden durch das jeweils beschriebene Modell erklärt (Anhang A, Tabelle A.14, Seite XII). Die bei der Analyse für die drei abhängigen Variablen ausgeschlossenen Variablen finden sich in Tabelle A.17 (Anhang A, Seite XIII).

\section{Alkoholkonsum nach der Schwangerschaft und Body-Mass-Index}

Die einzige Variable, die sowohl mit der Konzentration von Hämoglobin als auch der des sTfR zum Zeitpunkt der Befragung einen signifikanten linearen Zusammenhang aufweist, ist der Alkoholkonsum nach der Schwangerschaft. Der Body-Mass-Index hingegen zeigt für die aktuelle und die minimale Hämoglobinkonzentration in der Schwangerschaft signifikante Ergebnisse.

Je höher der Alkoholkonsum der Mutter nach der Schwangerschaft ist, umso niedrigere Konzentrationen weist ihr sTfR auf (Beta $=-0,147)$, und umso höher ist ihre Hämoglobinkonzentration $($ Beta $=0,220)$.

Sowohl mit der Hämoglobinkonzentration zum Zeitpunkt der Befragung (Beta $=0,147$ ) als auch mit der minimalen Hämoglobinkonzentration in der Schwangerschaft (Beta $=0,260$ ) zeigt der Body-Mass-Index der Mutter einen signifikanten positiven Zusammenhang.

\section{Alkoholkonsum und Rauchen in der Schwangerschaft und Alter der Mutter}

Der Alkoholkonsum und Raucherstatus der Mutter in der Schwangerschaft und ihr Alter zeigen in der multivariaten Analyse ausschließlich mit der aktuellen mütterlichen Hämoglobinkonzentration einen signifikanten Zusammenhang.

Entgegengesetzt zu der Menge des konsumierten Alkohols nach der Schwangerschaft steigt die aktuelle Hämoglobinkonzentration der Mütter mit sinkendem Alkoholkonsum in der Schwangerschaft $($ Beta $=-0,120)$.

Die Hämoglobinkonzentrationen der Mütter, die in der Schwangerschaft nicht rauchten, sind wiederum niedriger als bei in der Schwangerschaft rauchenden Müttern (Beta = -0,104).

Mit steigendem Alter der Mutter steigt auch ihre Hämoglobinkonzentration (Beta = 0,094).

\section{Zahl der Kinder}

Abgesehen von dem Alkoholkonsum nach der Schwangerschaft zeigt die Zahl der Kinder einen signifikanten Zusammenhang mit der aktuellen Konzentration des sTfR. 
Je mehr Kinder die Mutter hat (Beta $=0,129)$, umso höher ist ihre Konzentration des sTfR zum Zeitpunkt der Befragung.

\section{Geburtsgewicht des Kindes}

Das Geburtsgewicht des Kindes weist nur mit der minimalen mütterlichen Hämoglobinkonzentration in der Schwangerschaft einen signifikanten linearen Zusammenhang auf.

Je höher das Geburtsgewicht des zu dem Zeitpunkt der Befragung einjährigen Kindes war, umso niedriger ist die minimale in der Schwangerschaft gemessene Hämoglobinkonzentration der Mutter $($ Beta $=-0,190)$.

\subsubsection{Multiple logistische Regressionsanalyse}

In Bezug auf eine unter $12 \mathrm{~g} / \mathrm{dl}$ erniedrigte Hämoglobinkonzentration ergibt sich eine geringere Odds-Ratio für Mütter, die nach der Schwangerschaft selten Alkohol tranken (Odds-Ratio = 0,26, $\mathrm{CI}=$ 0,07-0,92) gegenüber Müttern, die zu der Zeit nie Alkohol tranken (Odds-Ratio = 1).

Bei Betrachtung des sTfR findet sich eine erhöhte Odds-Ratio für über 3,3 mg/l erhöhte Konzentrationen bei Müttern, deren Menstruation nach der Geburt zum Zeitpunkt der Befragung noch nicht eingesetzt hat (Odds-Ratio = 3,83, CI = 1,09-13,51) gegenüber denen, deren Menstruation regelmäßig wieder einsetzte (Odds-Ratio = 1) (Anhang A, Tabelle A.18, Seite XIII).

\subsection{Zusammenfassung der Ergebnisse}

In der Untersuchung konnte bei 9,5\% der jungen Mütter ein zellulärer Eisenmangel, bei $4 \%$ eine Anämie und bei 2,2 \% eine Eisenmangelanämie festgestellt werden. Es besteht eine positive Korrelation zwischen sTfR-Konzentrationen von Müttern und Kindern und zwischen Hämoglobinkonzentrationen von Müttern und Kindern.

Insgesamt zeigen 15 von 21 untersuchten Variablen einen signifikanten Zusammenhang mit dem mütterlichen Eisenstatus bei mindestens einer Analyse (Anhang A, Tabelle A.20, Seite XV).

Die Risikofaktoren für Eisenmangel bei den Probandinnen der Studie setzen sich zusammen aus soziodemographischen Merkmalen und solchen der Ernährung und Lebensweise. Faktoren, die einen zellulären Eisenmangel vorhersagen, sind fehlendes Einsetzen der Menstruation post partum (wichtigster Faktor in der multivariaten Analyse), fehlender Alkoholkonsum (beide in mehr als einer Analyse signifikant) und vegetarische Ernährung (in einer Analyse signifikant) (OddsRatios siehe Abbildung 3.9 auf Seite 62). Hohe Kinderzahl (signifikant in mehr als einer Analyse), andere Nationalität als deutsch und fehlendes Rauchen (je in einer Analyse signifikant) weisen erhöhte sTfR-Konzentrationen auf, mit dem Trend zu häufigerem zellulären Eisenmangel (die 


\section{Odds-Ratios und 95\%-Konfidenzintervalle für zellulären Eisenmangel (einfache logistische Regression)}

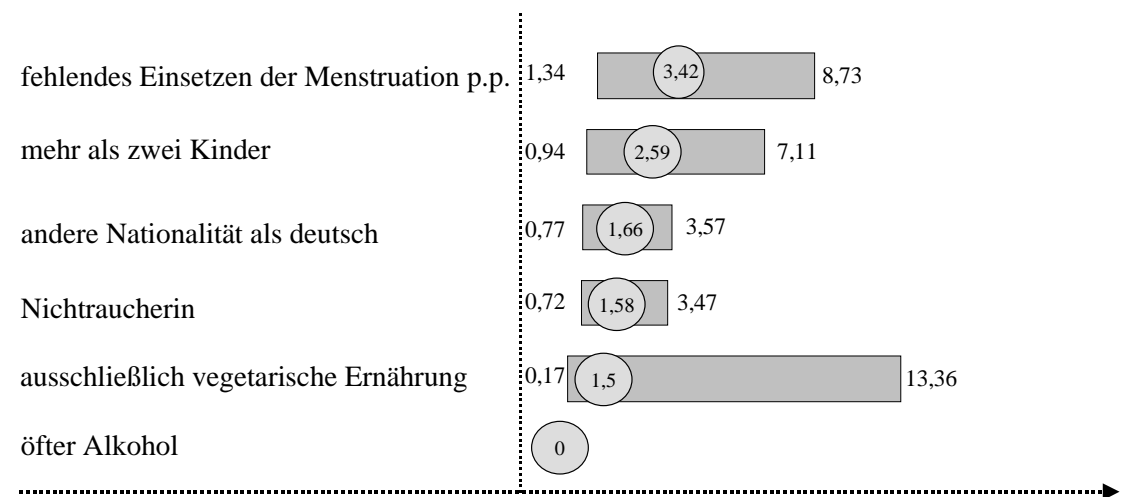

Abbildung 3.9: Odds-Ratios der wichtigsten Risikofaktoren für zellulären Eisenmangel.

Prävalenzunterschiede von zellulärem Eisenmangel überschreiten bei diesen Variablen geringfügig das Signifikanzniveau). Dabei zeigt sich bei Ausländerinnen und fehlendem Alkohol- (wichtigster Faktor in der multivariaten Analyse) und Zigarettenkonsum zusätzlich eine geringere Hämoglobinkonzentration zum Zeitpunkt der Studie und bei Vegetarierinnen eine geringere Hämoglobinkonzentration in der Schwangerschaft.

Ein Risiko für geringe mütterliche Hämoglobinkonzentrationen stellen dar sowohl in als auch nach der Schwangerschaft: geringer Body-Mass-Index und fehlende Berufsausbildung, geringes Alter nach und sowohl geringes als auch hohes Alter in der Schwangerschaft; nur in der Schwangerschaft: hohes Geburtsgewicht. Im Gegensatz zu dem positiven Zusammenhang, der zwischen aktuellem Alkoholkonsum und aktuellem Eisenstatus besteht, haben Mütter mit steigendem Alkoholkonsum in der Schwangerschaft geringere aktuelle Hämoglobinkonzentrationen und Mütter mit mäßigem Alkoholkonsum in der Schwangerschaft höhere Hämoglobinkonzentrationen als diejenigen, die gar nicht oder häufiger Alkohol trinken.

Unauffällig bleiben dagegen Schulabschluß, wobei sich der Trend zu häufigerem Eisenmangel bei fehlendem Schulabschluß zeigt, Passivrauchen, Einkommen, Sport, Stärke der Menstruationsblutung, Stilldauer und Schwangerschaftsdauer. 


\section{Kapitel 4}

\section{Diskussion}

In der Untersuchung konnte festgestellt werden, daß bei 9,5\% der Studienteilnehmerinnen ein zellulärer Eisenmangel, bei $4 \%$ eine Anämie ohne Eisenmangel und bei 2,2 \% eine Eisenmangelanämie vorliegt. Außerdem korrelieren die mütterlichen und kindlichen sTfR-Konzentrationen ( $\mathrm{r}$ $=0,139, p=0,003)$ sowie die mütterlichen und kindlichen Hämoglobinkonzentrationen $(r=0,218$, $\mathrm{p}=0,000)$ positiv miteinander.

Die wichtigsten Prädiktoren für zellulären Eisenmangel sind fehlendes Einsetzen der Menstruation post partum, Abstinenz von Alkohol und vegetarische Ernährung. Höhere Konzentrationen des sTfR ohne signifikant erhöhte Prävalenz von zellulärem Eisenmangel finden sich bei Probandinnen mit ausländischer Nationalität, mehr als zwei Kindern und Nichtraucherinnen.

Zusätzlich geringere Hämoglobinkonzentrationen finden sich bei Müttern mit folgenden Merkmalen: Abstinenz von Alkohol, Nikotin und Fleisch sowie nicht-deutsche Nationalität.

Ohne Zusammenhang zur Konzentration des sTfR aber assoziiert mit geringeren mütterliche Hämoglobinkonzentrationen sind geringer Body-Mass-Index, fehlende Berufsausbildung, geringes Alter und hohes Geburtsgewicht. Im Gegensatz zu dem positiven Zusammenhang, der zwischen aktuellem Alkoholkonsum und aktuellem Eisenstatus besteht, haben Mütter mit steigendem Alkoholkonsum in der Schwangerschaft geringere aktuelle Hämoglobinkonzentrationen. Mütter mit mäßigem Alkoholkonsum in der Schwangerschaft weisen in der Schwangerschaft höhere Hämoglobinkonzentrationen auf als diejenigen, die gar keinen Alkohol trinken.

Keinen Einfluß auf den Eisenstatus hatten in der vorliegenden Untersuchung Berufstätigkeit, Schulabschluß, Einkommen, Passivrauchen in der Schwangerschaft, Sport, Stärke der Menstruationsblutung, Still- und Schwangerschaftsdauer. 


\subsection{Fehlermöglichkeiten}

Trotz des erheblichen Aufwandes, alle Kinderarztpraxen Berlins einzuschließen und alle innerhalb von drei Monaten erscheinenden Patienten zu erfassen, um eine für Berlin repräsentative Stichprobe zu erhalten, ließen sich Verzerrungen nicht ausschließen. Denn wenn es um die freiwillige Teilnahme an einem schmerzhaften Eingriff geht, wie zum Beispiel die Blutabnahme, können nur diejenigen erfaßt werden, die diese ohne größere Probleme tolerieren. Die Abweichungen der Stichprobe werden aber aufgezeigt durch den Vergleich mit der bundesweiten, repräsentativen Stichprobe von Müttern und den Daten des Statistischen Landesamts Berlin.

Auch der Aufbau des Fragebogens, sowie die Gewinnung und Auswertung der Blutproben können auf die Ergebnisse Einfluß haben. Die Stichprobe, die unter Einfluß dieser Faktoren entsteht, beeinflußt die Vergleichbarkeit des Gesamtergebnisses in Bezug auf Berlin und die gesamte Bundesrepublik.

\subsubsection{Population und untersuchte Stichprobe}

Die Mütter und Kinder, die an der Studie teilnahmen, stammen aus einer Population von etwa 25000 einjährigen Kindern und ihren Müttern in Berlin. Nach Angaben der AOK/Kassenärztlichen Vereinigung aus dem Jahr 1995 erscheinen 97,8 \% davon zur U6. Die 2,2 \%, die nicht in der Abrechnungsstatistik vorkommen, sind nach Meinung der Ärzte des Öffentlichen Gesundheitsdienstes möglicherweise sozial schlechter gestellte und Ausländer.

Von den 97,8 \% (24450) gehen etwa 670 (rund 2,7\%) innerhalb eines Jahres zur U6 in die Gesundheitsämter. Da die Ärzte des Gesundheitsdienstes weder Impfungen vornehmen dürfen noch Geld an der U6 verdienen, liegt ihre Hauptaufgabe in der Beratung und Behandlung von Personen ohne Krankenschein, ohne Kinderarzt, von auffälligen und vernachlässigten Kindern oder bei Menschen mit Sprachproblemen. Einige wenige gehen aus Gewohnheit (geographische Nähe, Freundschaft mit dortigen Ärzten) zu den Vorsorgeuntersuchungen in die Gesundheitsämter.

Folglich handelt es sich bei den 4,9 \% der Einjährigen und Mütter, die von vornherein nicht mit der Studie erfaßt wurden, überwiegend um Flüchtlinge, Aussiedler, Asylanten, Ausländer allgemein und sozial Schwache.

Genau diese Gruppen sind es auch, die im Verlauf der Studie zu einem geringerem Anteil erfaßt wurden. Gründe dafür sind zum einen Verständigungsschwierigkeiten durch ausländische Nationalität und damit auch zu erwartende Probleme beim Ausfüllen des Fragebogens. Zum anderen sprachen die Kinderärzte bevorzugt Frauen mit höherem Bildungsniveau an. Diesen Frauen fiel möglicherweise das Ausfüllen des Fragebogens leichter und auch die Teilnahmebereitschaft mag höher gewesen sein.

\footnotetext{
${ }^{1}$ nach telefonischen Angaben der leitenden Ärzte der Kinder- und Jugendgesundheitsdienste in Berlin
} 
Dies spricht dafür, daß die Prävalenz von Eisenmangel in Berlin noch viel höher ist, als hier erfaßt.

\subsubsection{Kinderarztpraxen}

Inwieweit die Auswahl der Kinderarztpraxen die Stichprobe der Mütter und ihrer Kinder beeinflußt ist unklar. Die 69 Praxen, die teilnahmen, haben zum größten Teil eine geringere Patientenzahl und damit mehr Zeit, sich an der Studie zu beteiligen. Es ist daher möglich, daß die Kinder und eventuell auch die Mütter in diesen Praxen besser betreut sind, als in den Praxen, die aus Zeitmangel nicht an der Studie teilnahmen. Hinzu kommt, daß möglicherweise eher Ärzte teilnahmen, die sich sowieso schon mit Eisenmangel beschäftigten und deswegen auch schon eher die Kinder mit Eisen therapiert haben könnten. Das verringert die Prävalenz von Eisenmangel in dem Kollektiv.

Zwar war vorgesehen, daß die Ärzte auch die Mütter und Kinder in die Liste eintragen sollten, die nicht teilnahmen, um die Begründung für fehlende Teilnahme zu erfassen. Doch in den meisten Praxen wurden diese fehlenden Probanden weder registriert noch ihre Beweggründe festgehalten. Von den uns vorliegenden Gründen stand die Angst der Mütter vor einer Blutabnahme im Vordergrund. Diese Angst bezieht sich sowohl auf das Wohl des Kindes als auch auf das eigene Wohlergehen. Ein weiterer Grund für die Ablehnung der Studie ist der Fragebogen. Dabei spielt zum einen das Unvermögen, diesen auszufüllen, zum anderen die Angst vor der Registrierung zu persönlicher Angaben (zum Beispiel Einkommen) eine Rolle. Die Angst vor der Blutabnahme ist aber vermutlich nicht spezifisch für eine bestimmte soziale Schicht, vielleicht sogar eher in besser gestellten Familien vorhanden.

\subsubsection{Sozialstatus}

Insgesamt sind in der untersuchten Stichprobe mehrfachgebärende Mütter (Anfang 30) aus besser gestellten Familien, in denen sich gut ausgebildete Frauen (zunächst) ohne Berufstätigkeit um ihre Kinder kümmern können, im Vergleich zur Berliner Bevölkerung häufiger vertreten. Im Vergleich zur Bundesrepublik überwiegen in der Studie die gebildeteren Mütter, die entweder einen Hochschulabschluß oder noch keine Berufsausbildung abschließen konnten.

\section{Einkommen und Altersstruktur}

Die Verteilung des Einkommens in der Stichprobe ist der einzige soziodemographische Faktor, der sich nicht signifikant von der Berliner Bevölkerung unterscheiden (bundesweite Angaben lagen nicht vor). Die Altersstruktur der Mütter ist vergleichbar mit der bundesweiten, aber nicht vergleichbar mit der von Berliner Müttern. Ältere Mütter (ab 35) sind unter-, Mütter zwischen 30 und 34 Jahren dagegen überrepräsentiert. Die geringere Zahl von ab 35-jährigen Probandinnen kann vielleicht mit größerer Besorgnis dieser Mütter um ihre Kinder zusammenhängen. Hier sind 
möglicherweise mehr Mütter mit geplanten und lang ersehnten Wunschkindern vertreten, die demzufolge eher überfürsorglich sind und damit einer Studie ablehnender gegenüberstehen. Die 30- bis 34-jährigen sind wiederum häufiger vertreten. Diese Frauen haben möglicherweise ein Studium in den letzten Jahren abgeschlossen und sind deshalb der Forschung gegenüber aufgeschlossener.

\section{Kinderzahl}

Signifikant höher als in Gesamt-Berlin ist der Anteil der Mütter mit mehr als drei Kindern, dagegen unterrepräsentiert die Zahl der Frauen mit nur einem Kind (zu der Frage liegen keine bundesweiten Daten vor). Daß nur 322 Mütter von 507 diese Frage überhaupt beantworteten, kann schon ein Grund für die von Berlin abweichenden Ergebnisse sein. Andererseits kann dieses auch dadurch erklärt werden, daß die Mütter mit nur einem Kind noch besorgter sind und eine Blutabnahme nicht zulassen wollen. Die Mütter mit mehr als zwei Kindern, sind dagegen möglicherweise kooperativer, da sie eher einschätzen können, was ihrem Kind zugemutet werden kann. Ein weiterer Grund für den Unterschied ist, daß im Berliner Mikrozensus nur die Kinder gezählt werden, die noch zu Hause leben. Dabei wird das Alter nicht berücksichtigt. Deswegen sind die Mütter mit nur einem Kind scheinbar häufiger vertreten (auch die mit mehr als einem Kind, bei denen aber nur ein Kind zu Hause lebt und die anderen schon ausgezogen sind).

Damit können die Unterschiede der Kinderzahl sowohl durch einen systematischen Fehler in der Studie als auch durch verfälschte Zahlen für Berlin verursacht sein.

\section{Bildungsstruktur und Berufstätigkeit}

Verglichen mit der Bundesrepublik finden sich in der vorliegenden Studie signifikant mehr Abiturientinnen und dafür weniger Mütter mit Haupt- und Realschulabschluß (für Berlin liegen keine Daten zu Bildungsabschlüssen vor).

Das hohe Bildungsniveau der Mütter zeigt sich auch an der Verteilung der Berufsausbildungen (mehr Hochschulabsolventinnen im Vergleich zu bundesweiten Daten). Eine mögliche Ursache dafür könnte sein, daß sich Mütter mit höherem Bildungsniveau eher für Forschung und somit Studien interessieren und deswegen bevorzugt an der Untersuchung teilnehmen. Die häufigere Präsenz gebildeterer Mütter kann aber auch durch die Kinderärzte verursacht sein, die zum Teil weniger gebildete Mütter gar nicht erst auf die Studie aufmerksam machten, da sie von diesen eine Verweigerung der Teilnahme erwarteten.

Andererseits nahmen im Vergleich zur deutschlandweiten Befragung besonders viele Mütter an der Studie teil, die sich entweder in der Ausbildung befinden oder aus anderen Gründen keine abgeschlossene Berufsausbildung vorweisen können. Die Ursache dafür kann der gemessen an der bundesweiten Befragung hohe Ausländerinnenanteil sein. Diese Mütter dürfen vielleicht aufgrund der Tradition (die Mehrzahl der Ausländerinnen sind Türkinnen) keine Ausbildung anfan- 
gen, sondern kümmern sich um den Haushalt und die Kinder. Desweiteren ist anzunehmen, daß Berlin einen größeren Studentinnenanteil aufweist als die gesamte Bundesrepublik (dazu liegen für Berlin keine Zahlen vor). Diese Studentinnen vergrößern ebenfalls die Gruppe der Mütter ohne Berufsausbildung.

Der geringe Anteil der Berufstätigen unter den Probandinnen wiederum im Vergleich mit Berlin läßt sich wahrscheinlich darauf zurückführen, daß die Zahlen des statistischen Landesamtes für Mütter mit Kindern bis zu drei Jahren gelten (für Deutschland liegen keine Zahlen vor). Bei diesen ist ein Einstieg oder Wiedereinstieg in das Berufsleben wahrscheinlicher als bei Müttern, deren Kind erst ein Jahr alt ist. Auch kann ein Grund sein, daß die berufstätigen Mütter sich nicht die Zeit für die Studie und die Beantwortung des Fragebogens nehmen konnten.

\section{Nationalität}

Der Ausländerinnenanteil der Probandinnen liegt signifikant über dem der bundesweiten Befragung, da hier Ausländerinnen, die der deutschen Sprache nicht mächtig waren, ausgeschlossen waren. Obwohl der Ausländerinnenanteil der Studie bei einem Fünftel liegt, ist er hier signifikant niedriger als in der Berliner Bevölkerung $(26,4 \%)$ vertreten, was wahrscheinlich auf Sprachprobleme zurückzuführen ist.

\subsubsection{Probleme des Fragebogens}

Das durch den Fragebogen erfaßte Spektrum an möglichen Risikofaktoren für Eisenmangel ist breit gehalten, um möglichst viele Risikofaktoren zu erfassen. Dadurch werden die einzelnen Risikofaktoren nicht im Detail erfaßt. So kann zum Beispiel nicht genau gesagt werden, wieviel Alkohol eine Frau nun wirklich trinkt, wenn sie angibt, ,öfters“ Alkohol zu trinken. Auch die Angaben zu vegetarischer Ernährung lassen nicht darauf schließen, wieviel Gramm Fleisch pro Woche die Frauen tatsächlich essen. So gab etwa eine Frau an, die sich nach eigener Aussage gar nicht vegetarisch ernährte, nur einmal die Woche Fleisch zu essen. Auch bei Rauchen, Passivrauchen, Sport und Stärke der Menstruation sind die quantitativen Angaben nicht genau. Für den Zweck, mögliche Risikofaktoren zu ermitteln, reicht die Differenziertheit der hier gestellten Fragen nicht aus. In Folgeuntersuchungen sollte die Präzision der Fragen erhöht werden.

\subsubsection{Blutproben, Labor und Dateneingabe}

Eine Verfälschung der Eisenindikatoren kann durch die unterschiedlich lange Lagerungszeit der Blutproben entstanden sein. Bei einem Versuch der Arbeitsgruppe an vier Probanden zeigte sich aber nach bis zu 24 Stunden Lagerung keine wesentliche Änderung der Hämoglobin- und der Ferritinkonzentrationen. Es gibt aber Autoren, die eine Zunahme der sTfR-Konzentration nach 8 Stunden Lagerung (unzentrifugiert, 4 Grad Celsius) registrierten $(n=10)$ (Jongh et al., 1997). 
Somit lassen sich durch Lagerung verursachte Beeinflussungen der Hämoglobinkonzentrationen weitgehend ausschließen, die Konzentrationen des sTfR sind möglicherweise durch die Transportzeiten erhöht. Es gibt aber kein plausibler Zusammenhang zwischen Lagerungszeiten und den Haupteinflußfaktoren, die sich in dieser Untersuchung als wichtig erwiesen. Somit entsteht durch unterschiedliche Lagerungszeiten kein systematischer Fehler in Bezug auf die Risikofaktoren, aber möglicherweise in Bezug auf die Prävalenz von zellulärem Eisenmangel.

Da die Methoden in der Literatur als geläufig beschrieben sind, ist von Seiten des Labors eine Validität der Meßwerte zu erwarten.

Die Hämoglobinkonzentrationen in der Schwangerschaft, die aus den Mutterpässen entnommen sind, können hingegen nur einen Trend anzeigen. Denn in dieser Arbeit werden die minimalen Hämoglobinkonzentrationen unabhängig von der Schwangerschaftswoche betrachtet. Die jeweilige Schwangerschaftswoche ist aber insofern wichtig, als daß in den drei Trimena unterschiedliche Grenzwerte existieren (US Preventive Services Task Force, 1993). Außerdem hat eine Anämie, je nachdem in welcher Schwangerschaftswoche sie auftritt, verschieden starke Auswirkungen auf das Kind (zum Beispiel im Hinblick auf Frühgeburtlichkeit) (Zhou et al., 1998) und so möglicherweise auch auf die Mutter. Außerdem wurden die Hämoglobinkonzentrationen, die in den Mutterpässen stehen im schlechtesten Fall für jede Mutter in einem anderen Labor bestimmt, was zu weiteren Ungenauigkeiten führt.

Dadurch, daß die aktuellen Eisenstatus-Indikatoren doppelt in die Datenbank eingegeben wurden, ist hier die Wahrscheinlichkeit eines Fehlers durch falsche Eingabe sehr gering. Bei den Fragebögen, die nur einmal eingegeben wurden, sind hingegen Eingabefehler möglich, die die Ergebnisse hinsichtlich der Risikofaktoren verfälscht haben könnten. In wieweit diese Fehler vorliegen würde eine komplette zweite Eingabe zeigen. Allerdings ist auch hier kein systematischer Fehler zu erwarten.

\subsection{Interpretation der Ergebnisse}

In der Untersuchung zeigte sich bei 9,5\% der Stichprobe ein zellulärer Eisenmangel, bei $4 \%$ eine Anämie und bei 2,2 \% eine Eisenmangelanämie. Demnach ist eine andere Ursache als Eisenmangel für fast die Hälfte der Anämien verantwortlich. Daher sind die wichtigsten Risikofaktoren für Eisenmangel diejenigen, die in der vorliegenden Untersuchung zellulären Eisenmangel oder erhöhte sTfR-Konzentrationen voraussagen (fehlendes Einsetzen der Menstruation post partum, fehlender Alkoholkonsum, vegetarische Ernährung, nicht-deutsche Nationalität, mehr als zwei Kindern und fehlendes Rauchen). Die Tatsache, daß fehlender Alkoholkonsum post partum, nicht-deutsche Nationalität, Rauchen und vegetarische Ernährung zusätzlich mit geringeren Hämoglobinkonzentrationen assoziiert sind, bestärkt diese Faktoren in ihrer Rolle als Prädiktoren für Eisenmangel und möglicherweise schon für beginnende Anämie. 
Die Faktoren, die geringere Hämoglobinkonzentrationen ein Jahr nach der Geburt aber keine erhöhten sTfR-Konzentrationen voraussagen (geringes Alter, geringer Body-Mass-Index, fehlende Berufsausbildung, fehlendes Rauchen in der Schwangerschaft und Alkoholkonsum in der Schwangerschaft), deuten möglicherweise auf eine Anämie durch andere Ursache als Eisenmangel (zum Beispiel Thalassämie) hin. Faktoren hingegen, die mit geringeren Hämoglobinkonzentrationen in der Schwangerschaft aber nicht mit erhöhten sTfR-Konzentrationen ein Jahr post partum assoziiert sind (geringes und hohes Alter, geringer Body-Mass-Index, fehlende Berufsausbildung, sowohl fehlender als auch häufiger Alkoholkonsum in der Schwangerschaft und hohes Geburtsgewicht), können hinsichtlich ihres Zusammenhangs mit Eisenmangel kaum beurteilt werden, da aus der Schwangerschaft kein Indikator für zellulären Eisenmangel oder Speichereisen vorliegt.

Bei den Faktoren, die ebenfalls eine Assoziation mit der Hämoglobinkonzentration ein Jahr post partum aufweisen, kann vermutet werden, daß sie auch in der Schwangerschaft keinen signifikanten Zusammenhang mit zellulärem Eisenmangel aufweisen. Wieweit aber das hohe Geburtsgewicht der Kinder in der Stichprobe auch eine Auswirkung auf zellulären Eisenmangel in der Schwangerschaft hat, bleibt offen. Für nicht-deutsche Nationalität und vegetarische Ernährung kann wiederum angenommen werden, daß sie, da sie auch ein Jahr post partum mit höheren sTfRKonzentrationen assoziiert sind, auch in der Schwangerschaft mit Eisenmangel einhergehen.

Kein Einfluß auf den Eisenstatus konnte in der vorliegenden Untersuchung festgestellt werden durch Berufstätigkeit, Schulabschluß, Einkommen, Passivrauchen in der Schwangerschaft, Sport, Stärke der Menstruationsblutung, Still- und Schwangerschaftsdauer.

Des weiteren konnte eine positive Korrelation zwischen mütterlichen und kindlichen sTfR$(r=0,139, p=0,003)$ sowie mütterlichen und kindlichen Hämoglobinkonzentrationen $(r=0,218$, $\mathrm{p}=0,000)$ festgestellt werden.

\subsubsection{Vergleichbarkeit der Stichprobe}

Die vorliegende Arbeit zeigt, daß Eisenmangel häufig und damit ein Problem für junge Mütter ist. Dabei ist die Prävalenz von zellulärem Eisenmangel und von Eisenmangelanämie in der Studie vergleichbar mit der bundesweiten Prävalenz von Eisenmangel bei Frauen im gebärfähigen Alter nach Thefeld und Ellert (1998). Da jedoch die Soziodemographie der Probandinnen in den meisten Punkten von der deutscher (Ausnahme: Altersverteilung) und der Berliner Mütter (Ausnahme: Einkommen) signifikant abweicht, muß die Übertragbarkeit des Untersuchungsergebnisses auf Berlin und die gesamte Bundesrepublik diskutiert werden.

Bei der Berechnung der Prävalenz von zellulärem Eisenmangel und Anämie für eine Verteilung der gruppenbildenden Variablen wie sie in Berlin und in Deutschland vorkommt, zeigen sich Prävalenzunterschiede entsprechend der jeweiligen Risikogruppe (Tabelle 4.1, Seite 70).

So läge beispielsweise die Prävalenz von Eisenmangel höher (zellulärer Eisenmangel Studie: 
Tabelle 4.1: Prävalenz von Eisenmangel bei verschiedenen gruppenbildenden Variablen: Vergleich StudieBerlin/Studie-Deutschland; U.n.s. = Unterschied nicht signifikant, $\mathrm{p}=\mathrm{p}$-Wert des Binomialtests.

\begin{tabular}{|c|c|c|c|c|c|c|c|c|c|c|}
\hline & \multicolumn{5}{|c|}{$\mathrm{sTfR}>3,3 \mathrm{mg} / 1$} & \multicolumn{5}{|c|}{$\mathrm{Hb}<12 \mathrm{~g} / \mathrm{dl}$} \\
\hline & \multirow{2}{*}{$\begin{array}{c}\text { Studie } \\
\%\end{array}$} & \multicolumn{2}{|c|}{ Berlin } & \multicolumn{2}{|c|}{ Deutschland } & \multirow{2}{*}{$\begin{array}{c}\text { Studie } \\
\%\end{array}$} & \multicolumn{2}{|c|}{ Berlin } & \multicolumn{2}{|c|}{ Deutschland } \\
\hline & & $\%$ & $\mathrm{p}$ & $\%$ & $\mathrm{p}$ & & $\%$ & $\mathrm{p}$ & $\%$ & $\mathrm{p}$ \\
\hline Alter & 8,7 & 8,6 & 0,428 & U.n.s. & & 3,7 & 3,5 & 0,357 & U.n.s. & \\
\hline Nationalität & 8,9 & 9,3 & 0,429 & 8,2 & 0,264 & 3,8 & 4,1 & 0,436 & 3,4 & 0,272 \\
\hline Zahl der Kinder & 9,4 & 9,0 & 0,647 & & & 2,9 & 2,8 & 0,359 & & \\
\hline Schulabschluß & 9,3 & & & 9,9 & 0,380 & 3,9 & & & 4,2 & 0,469 \\
\hline Berufsausbildung & 8,7 & & & 8,2 & 0,329 & 3,7 & & & 3,8 & 0,548 \\
\hline
\end{tabular}

8,9\%, Berlin: 9,3\%), wenn in der Stichprobe der gleiche Ausländerinnenanteil vorläge wie Berlinweit, da Ausländerinnen häufiger einen Eisenmangel aufweisen als deutsche Frauen. Im Gegensatz dazu müßte die Prävalenz von Eisenmangel bei den bundesweit erfaßten Frauen geringer sein (8,3 $\%)$, da hier weniger Ausländerinnen befragt wurden als in der vorliegenden Untersuchung.

Prüft man jedoch die Unterschiede zwischen den Prävalenzen der Studie und Berlin beziehungsweise Deutschland auf ihre Signifikanz (Binomialtest, siehe Tabelle 4.1, Seite 70), so zeigt sich, daß die Unterschiede nicht signifikant sind. Damit lassen sich die Ergebnisse der Untersuchung trotz abweichender Soziodemographie weitgehend auf Berlin und Deutschland übertragen.

\subsubsection{Einsetzen der Menstruation post partum}

Die Variation des menstruellen Blutverlustes bestimmt in stärkerem Ausmaß den Eisenstatus menstruierender Frauen als die Unterschiede in der Ernährung (Hallberg and Rossander-Hultén, 1991). Jedoch zeigt sich kein Zusammenhang zwischen Dauer der postpartalen Amenorrhoe bei stillenden Frauen und der Ferritinkonzentration nach der Stillzeit (Kalkwarf and Harrast, 1998).

Die Einnahme oraler Kontrazeptiva senkt das Risiko für Eisenmangel um mehr als die Hälfte (Odds Ratio: 0,47). Dies hängt mit dem geringeren Blutverlust bei der Menstruation unter deren Einnahme zusammen (Thefeld and Ellert, 1998), der etwa um die Hälfte verringert wird (Hallberg, 1994). Auch nach Brussaard et al. (1997) korreliert die Einnahme oraler Kontrazeptiva positiv mit der Hämoglobinkonzentration.

Es ist schwierig zu ermitteln, warum das fehlende Einsetzen der Menstruation nach der Schwangerschaft in der vorliegenden Untersuchung mit höheren Konzentrationen des löslichen Transferrinrezeptors einhergeht. Dabei ist der naheliegendste Grund für ein spätes Einsetzen der Menstruation langes Stillen. Stillt eine Mutter ihr Kind lange, bleiben die menstruationsbedingten Eisenverluste aus und der Eisenstatus ist bis zum sechsten Monat post partum besser, nach einem Jahr gleich aber zumindest nicht schlechter als bei nicht stillenden Frauen (Kalkwarf and Harrast, 1998). Da also geringere Blutverluste durch die fehlende Menstruation, die eigentlich zu einem besseren Eisenstatus führen müßten, mit geringeren Eisenreserven einhergehen, liegt nahe, daß beides durch eine 
andere Ursache ausgelöst wird. Mögliche Krankheiten der Mütter, die mit fehlender Menstruation und Eisenmangel einhergehen, werden durch die Studie nicht erfaßt.

Auch ist nicht erfaßt, welche Mutter bis zur Schwangerschaft regelmäßig Blut gespendet hat. Dabei spielt das Blutspenden als Ursache für einen Eisenmangel eine wichtige Rolle (Wick et al., 1996). Allerdings dürfen Schwangere und junge Mütter nach den Richtlinien für Labor und Transfusionsmedizin bis zu einem Jahr nach der Geburt kein Blut mehr spenden. Ob das Blutspenden vor der Schwangerschaft noch Auswirkungen auf den Eisenstatus nach der Schwangerschaft hat, müßte noch untersucht werden.

\subsubsection{Alkoholkonsum}

Zwar wird auch in anderen Untersuchungen ein besserer Eisenstatus bei zunehmendem Alkoholkonsum (Milman et al., 1995), ein Dosis-abhängiger Ferritinanstieg bei steigendem Alkoholkonsum (Fleming et al., 1998) und eine Akkumulation von Eisen in der Leber von chronischen Alkoholikern beschrieben (Gonzalez-Reimers et al., 1998), jedoch gibt es über den Mechanismus dieses Zusammenhangs in der Literatur keine schlüssigen Erklärungen. Erklärungsansätze reichen von einer unklaren intestinalen Absorptionssteigerung von Eisen durch Alkohol bis zu exzessiver Eisenaufnahme über alkoholische Getränke (Gonzalez-Reimers et al., 1998). Dabei wird der positive Einfluß von akutem Alkoholkonsum auf die Nicht-Häm-Resorption von verschiedenen Autoren kontrovers diskutiert, wohingegen bei chronischen Alkoholikern eine gesteigerte Ferritinsekretion nachgewiesen wurde (Fleming et al., 1998).

Ein weiterer Grund für erhöhte Hämoglobinkonzentrationen bei steigendem Alkoholkonsum könnte die Freisetzung von Adiuretin durch Alkohol sein (Pschyrembel et al., 1990). Dadurch erhöht sich die Plasmaosmolalität und scheinbar auch die Konzentration von Hämoglobin. Allerdings würde dieser Effekt auch die Konzentration des sTfR erhöhen, was wiederum Eisenmangel vortäuschen würde. Dagegen nimmt diese bei steigendem Alkoholkonsum ab. Vielleicht wird aber auch durch Alkoholkonsum die Zellmauserung des Darms verzögert, die für die größten Eisenverluste des Körpers verantwortlich ist.

Der Alkoholkonsum ist auch in der multivariaten Regressionsanalyse eine bedeutsame Erklärung für die aktuellen Konzentrationen von Hämoglobin und sTfR. Deswegen ist die Wahrscheinlichkeit dafür, daß Alkohol an sich tatsächlich einen ursächlichen Einfluß auf die Eisenversorgung hat einerseits erhöht. Andererseits besteht auch die Möglichkeit, daß der Alkoholkonsum mit höherem Fleischkonsum assoziiert ist.

Vielleicht spiegelt der angegebene Alkoholkonsum der Mütter besser die tatsächlich konsumierte Fleischmenge wieder, als die Frage nach der vegetarischen Ernährung. Denn bei einzelnen Stichproben stellt sich heraus, daß manche Mütter, die nur einmal in der Woche Fleisch essen, bei Beantwortung des Fragebogens angeben, sich gar nicht vegetarisch zu ernähren. Diese Tatsache 
läßt vermuten, daß auch andere Mütter die Frage nach der vegetarischen Ernährung nicht dem tatsächlichen Fleischkonsum entsprechend beantworteten.

Möglicherweise besteht auch ein Unterschied zwischen der Persönlichkeitsstruktur von Müttern, die keinen Alkohol trinken und Alkohol-trinkenden Müttern. Vielleicht sind diejenigen, die nie Alkohol trinken auch in anderen Dingen abstinent, die mit Genuß zu tun haben. Neben Enthaltsamkeit gegenüber anderen suchterzeugende Mitteln meiden diese Mütter möglicherweise auch gutes und abwechslungsreiches Essen (auch häufigeres Essen im Restaurant). Für viele gehört zu einem guten Essen auch ein Glas Wein, was den Alkoholkonsum in Zusammenhang mit möglicherweise Eisen-haltigerem Essen verbinden würde.

Der Zusammenhang zwischen Alkoholkonsum in der Schwangerschaft und aktueller mütterlicher Hämoglobinkonzentration zeigt sich nur als signifikant in der multivariaten linearen Regressionsanalyse. Hier nimmt die Hämoglobinkonzentration mit steigendem Alkoholkonsum ab. Dieses Ergebnis zeigt, daß in der Schwangerschaft andere Mütter regelmäßig Alkohol trinken als nach der Schwangerschaft. Die Gruppe der Mütter, die nach der Schwangerschaft häufiger Alkohol trinken (35), ist während der Schwangerschaft deutlich kleiner (4). Auch einige von den Müttern, die sonst einen mittleren Alkoholkonsum hatten (232), verzichteten in der Schwangerschaft auf Alkohol (nur noch 113 mit mittlerem Alkoholkonsum). Diese Veränderung der Gruppenzusammensetzung führt dazu, daß Mütter mit besserem Eisenstatus in Gruppen mit geringem Alkoholkonsum verschoben werden. Möglicherweise trinken sogar diejenigen, die sonst häufiger Alkohol zu sich nehmen, bewußt in der Schwangerschaft gar keinen Alkohol, was zusätzlich eine Umkehrung der Verhältnisse erklären würde. Da sich dieses Ergebnis jedoch in keiner anderen Analyse reproduzieren läßt, ist auch eine Verzerrung durch die kleinere Fallzahl bei der multivariaten Auswertung denkbar. Dieser Zusammenhang darf damit nicht zu hoch bewertet werden.

Aus diesen Ergebnissen darf aber nicht der Schluß gezogen werden, daß Frauen mit Eisenmangel möglichst viel Alkohol trinken sollten. In der Schwangerschaft sind die Auswirkungen von Alkohol auf den Feten erheblich. So kommt es zu irreversiblen Schäden (mentale Retardierung, Mikrozephalie, Wachstumsretardierung (Spohr et al., 1993)). Auch Langzeitschäden (koronare Herzerkrankung, Hypertonie, Diabetes) wurden bei diesen Kindern gefunden (Barker, 1997). Alkoholkonsum kann ebenso während der Stillzeit zu Entwicklungsverzögerung bei dem Kind führen (Little et al., 1989).

Insgesamt ist Alkoholkonsum in der Untersuchung ein wichtiger Faktor, der, wenn er fehlt, sowohl zellulären Eisenmangel als auch Anämie voraussagt. Für diesen Zusammenhang sind aber noch keine schlüssigen Ursachen bekannt. 


\subsubsection{Vegetarische Ernährung}

Fleisch ist der einzige Nahrungsbestandteil, der eine konsistente positive Korrelation mit den Eisenspeichern aufweist (Lynch, 1997). Zusätzlich fördert Ascorbinsäure die Eisenabsorption. Ascorbinsäure fördert auch die Speicherung und den Transport von Eisen im Körper. So besteht bei Ascorbinsäuremangel ein Defekt der Eisenfreisetzung aus retikuloendothelialen Zellen. Außerdem beeinflußt Ascorbinsäure die Ferritinsynthese. Die Förderung der Absorption geschieht über eine Senkung des pH-Wertes im Gastrointestinaltraktes und gleichzeitiger Bindung von Eisen an Ascorbinsäure. Der Eisen-Ascorbinsäure-Komplex bleibt wiederum über eine große Spanne des pH-Wertes löslich. Diese Vorgänge erhöhen die Löslichkeit von Eisen und somit die Absorption. Auch andere organische Säuren wie Citrat, Malat, Tartrat und Lactat haben eine absorptionsfördernde Wirkung auf Eisen (Lynch, 1997).

Insgesamt fördert eine fleischreiche Ernährung in Kombination mit Ascorbinsäure in Form von Obst (oder Obstsaft) und Gemüse die Eisenabsorption (Wick et al., 1996).

Rein vegetarische Ernährung kann durch schlechtere Absorption des Nicht-Häm-Eisens (Hallberg, 1994), welches dann die einzige Eisenquelle darstellt, erklärt werden. Aufgrund des starken positiven Einflusses auf den Eisenstatus, der Fleisch in der Literatur zugeschrieben wird, ist eigentlich erstaunlich, daß die fleischlose Ernährung in der vorliegenden Untersuchung nur mit häufigerem zellulären Eisenmangel und geringeren Hämoglobinkonzentrationen in der Schwangerschaft, aber nicht mit den aktuellen Hämoglobinkonzentrationen der Mütter in Zusammenhang steht. Möglicherweise wäre das Ergebnis bei einer präziseren Formulierung dieser Frage (z. B.:,Wie viele Tage in der Woche essen Sie Fleisch?“) deutlicher.

Interessant bei den vorliegenden Ergebnissen ist, daß bei jedem der drei betrachteten Eisenstatusindikatoren (sTfR, $\mathrm{Hb}$ und $\mathrm{Hb}_{\text {min }}$ ) das Konfidenzintervall für die reinen Vegetarierinnen sehr groß ist. Das bedeutet, daß in dieser Gruppe ( $n=5$ bzw. 6) große interindividuelle Unterschiede in Bezug auf den Eisenstatus bestehen (sowohl sehr geringe Eisenspeicher als auch hoch-normale Eisenspeicher).

Außerdem bemerkenswert ist, daß bei jedem signifikanten Ergebnis der Eisenstatusindikatoren in Bezug auf vegetarische Nahrung diejenigen, die selten vegetarisch essen, einen signifikant besseren Eisenstatus aufweisen als die, die sich gar nicht vegetarisch ernähren. Mütter, die angeben, sich gar nicht vegetarisch zu ernähren, ernähren sich möglicherweise von den Gruppen am wenigsten bewußt und damit möglicherweise am wenigsten abwechslungsreich und gesund. Außerdem könnte diese Antwort verstärkt von Müttern mit nicht-deutscher Nationalität gewählt worden sein, die nicht wissen, was mit vegetarisch gemeint ist. Damit sammeln sich in dieser Gruppe Probandinnen aus einer anderen Risikogruppe (Ausländerinnen). Die Mütter, die sich selten vegetarisch ernähren haben in der Ernährung möglicherweise ein gesundes Mittelmaß aus fleischhaltiger und fleischloser Ernährung gefunden und ernähren sich damit bewußter als die, die vegetarisches Essen 
völlig ablehnen.

Nach dem Nationalen Gesundheitssurvey 1990/91 und dem Survey Ost (1991/92) bestätigt sich das Ergebnis der vorliegenden Untersuchung. Danach haben menstruierende Frauen in Deutschland, die selten oder nie Fleisch essen, eine fast doppelt so hohe Odds-Ratio (Odds Ratio:1,76) in Bezug auf Eisenmangel wie fleischessende Frauen (Thefeld and Ellert, 1998).

Insgesamt stützt die vorliegende Untersuchung die vorangegangenen Arbeiten, in denen ein positiver Einfluß von Fleischkonsum auf den Eisenstatus festgestellt wurde. Trotzdem haben nicht die, die sich gar nicht vegetarisch ernähren sondern diejenigen, die selten vegetarisch essen, den besten Eisenstatus.

\subsubsection{Nationalität}

$\mathrm{Daß}$ die nicht-deutschen Studienteilnehmerinnen (hauptsächlich Türkinnen) zu höheren sTfR- und niedrigeren Hämoglobinkonzentrationen zum Studienzeitpunkt und in der Schwangerschaft neigen, entspricht Angaben aus der Literatur. Dabei kann die schwierige Anpassung an die deutsche Ernährung und Nahrungsmittel eine Rolle spielen (Marx, 1997).

Möglicherweise spielen bei dieser Gruppe auch Faktoren wie höhere Inzidenz von Krankheiten aufgrund der Umstellung an die neuen Lebensumstände oder aufgrund schlechterer medizinischer Versorgung in dem Herkunftsland eine ursächliche Rolle.

\subsubsection{Kinderzahl}

Mit steigender Kinderzahl kommt es zunehmend häufiger zu Eisenmangel bei den Müttern. In Bezug auf den löslichen Transferrinrezeptor bleibt dieser Zusammenhang sogar in der multivariaten linearen Auswertung bestehen. Eine mögliche Ursache ist die starke Steigerung des Eisenbedarfs in der Schwangerschaft (Hallberg, 1988). Mit steigender Geburtenzahl werden bei fehlendem Ausgleich des erhöhten Eisenbedarfs die Eisenspeicher immer stärker erschöpft.

Des weiteren ist vielleicht die Compliance in Bezug auf die Einnahme von Eisenpräparaten bei Erstgebärenden größer. Diese Frauen wollen unter Umständen noch alles genau richtig machen. Mehrgebärende dagegen haben schon ihre Erfahrung mit der Schwangerschaft und für sich vielleicht entschieden, daß die zusätzliche Einnahme von Eisen überflüssig ist. Allerdings zeigt die Zahl der Kinder keinen Einfluß auf die Hämoglobinkonzentration. Vielleicht ist aber die Konzentration des löslichen Transferrinrezeptors dieser Frauen in der Schwangerschaft ebenfalls erhöht, was in einer weiteren Studie geklärt werden müßte.

Zunehmende Kinderzahl ist somit ein Faktor, der zwar eine Tendenz zu häufigerem zellulären Eisenmangel zeigt, jedoch noch nicht mit einer Verminderung des Funktionseisens einhergeht. 


\subsubsection{Rauchen}

Daß Rauchen an sich die Eisenvorräte erhöht läßt sich möglicherweise über die Bildung von COHämoglobin (bis zu 20 \% des Hämoglobins) bei Rauchern erklären (Petrides, 1997). Durch den so entstandenen Sauerstoffmangel wird die Erythropoese über Erythropoietin aktiviert. Dadurch steigt der Eisenbedarf und somit die Eisenabsorption des Körpers (Wick et al., 1996).

Außerdem ist bei Rauchern eine erhöhte Konzentration von Ferritin-gebundenem Eisen in den Lungenoberlappen bekannt. Die dafür verantwortlichen Mechanismen sind unbekannt. Jedoch weiß man, daß Zigarettenrauch Eisen aus Ferritin mobilisieren kann und daß Makrophagen unter dem Einfluß von Zigarettenrauch verstärkt Ferritin-gebundenes Eisen freisetzen (Nelson et al., 1996).

Frauen mit Eisenmangel kann aber keinesfalls das Rauchen zur Verbesserung der Eisenspeicher empfohlen werden. Zwar fanden auch Thefeld und Ellert (1998) seltener Eisenmangel bei Raucherinnen, jedoch erhöht Rauchen das Risiko für viele Karzinomarten (Lungen-, Oesophagus-, Magen-, Leber-Karzinom), chronische obstruktive Lungenerkrankungen, koronare Herzerkrankungen und Apoplex und führt so zu einer geringeren Lebenserwartung (Liu et al., 1998). Dabei wird die Ansammlung von Eisen in der Lunge unter anderem für die karzinogene Wirkung des Rauchs verantwortlich gemacht (oxidativer Gewebeschaden). Eine vermehrte Konzentration von Eisen in anderen Organen soll ebenfalls das Karzinomrisiko erhöhen (Nelson et al., 1996).

Auch die Auswirkung von Rauchen in der Schwangerschaft auf den Feten sind beachtenswert (z. B. höherer Fehl- und Frühgeburtenanteil, geringere Retikulozyten- und Leukozytenzahlen (Mercelina-Roumans et al., 1996), häufiger plötzlicher Tod im Säuglingsalter (Schellscheidt et al., 1998), langfristig beeinträchtigte Lungenfunktion (Lødrup Carlsen et al., 1997)).

Alles in allem ist ein besserer Eisenstatus bei Raucherinnen in der Literatur bekannt; es lassen sich jedoch noch keine schlüssigen Ursachen für diesen Zusammenhang ermitteln.

\subsubsection{Body-Mass-Index}

Ein zunehmender Body-Mass-Index ist mit höheren Hämoglobinkonzentrationen der Mütter sowohl in als auch nach der Schwangerschaft assoziiert. Die Tatsache, daß der lösliche Transferrinrezeptor von dem Body-Mass-Index unbeeinflußt bleibt, legt nahe, daß auch der Eisenstatus unbeeinflußt von dieser Variable bleibt. Im Gegenteil findet sich bei höherem Body-Mass-Index sogar ein Trend zu höheren mittleren Konzentrationen des löslichen Transferrinrezeptors. Der Zusammenhang mit den Hämoglobinkonzentrationen ist dagegen so groß, daß der Body-Mass-Index auch in der multiplen linearen Regression signifikante Zusammenhänge mit diesen aufweist.

Eine Ursache für diese Assoziation kann die größere Nahrungsmenge sein, die dickere Frauen aufnehmen, da in größeren Nahrungsmengen mit höherer Wahrscheinlichkeit ausreichend Eisen 
enthalten ist. Dementsprechend ist bei den Frauen, die geringere Nahrungsmengen zu sich nehmen auch die Wahrscheinlichkeit größer, daß die Nahrung nicht genug Vitamine und Mineralstoffe enthält. Die kleinen Nahrungsmengen, die dünne Frauen zu sich nehmen müßten also höherwertiger sein und mehr Eisen enthalten, als die großen Mengen, die beleibtere Frauen verspeisen, damit der gleiche Eisenstatus erreicht wird.

Diese Vermutungen werden von Scholl et al. (1992) bestätigt. In der Literatur findet sich auch eine positive Korrelation zwischen Body-Mass-Index und Serum-Ferritin. Damit zeigt sich, im Gegensatz zu der vorliegenden Untersuchung, doch ein Zusammenhang zwischen Body-Mass-Index und Eisenspeichern. Es wird auch ein neues Syndrom der Eisenüberladung beschrieben, bei dem Patienten mit Übergewicht, Hyperlipidämie, Hypertonus oder gestörtem Glukose-Metabolismus abnormal hohe Ferritinkonzentrationen aufweisen. Auch für diese Wechselbeziehungen ist der ursächliche Mechanismus noch nicht bekannt (Moirand et al., 1997).

Im Gegensatz zu den vorliegenden Ergebnissen ist in der Literatur eine positive Korrelation nicht nur zwischen Body-Mass-Index und Hämoglobinkonzentration sondern auch zwischen Body-MassIndex und Ferritinkonzentration bekannt. Über die Ursache für den Zusammenhang kann zur Zeit nur spekuliert werden.

\subsubsection{Bildungsstand}

Fehlende Berufsausbildung ist ebenfalls häufiger mit niedrigeren Hämoglobinkonzentrationen in und nach der Schwangerschaft assoziiert. Dagegen zeigen sich die höchsten Hämoglobinkonzentrationen bei Müttern mit Fachschulabschluß.

Möglicherweise führt bei Frauen ohne Berufsausbildung das niedrigere Bildungsniveau zu geringerem Interesse an gesunder Ernährung. Deswegen ernähren sich diese Mütter möglicherweise eher einseitig. Vielleicht ist hier aber auch die Compliance in Bezug auf die Einnahme von Eisenpräparaten in der Schwangerschaft geringer. Deswegen wurden die Eisenspeicher dieser Frauen durch die Schwangerschaft möglicherweise stärker entleert, und demzufolge ist die Gefahr eines nachfolgenden Eisenmangels ebenfalls erhöht. Andererseits kann auch ein Eisenmangel das Maß der Aktivität und Aufmerksamkeit beeinträchtigen (Allen, 1997). Somit ist auch denkbar, daß Eisenmangel schlechtere schulische Leistungen auslöst und deswegen Frauen mit Eisenmangel einen häufigeren Trend zu fehlendem Schulabschluß zeigen.

Allerdings fallen unter Frauen ohne Berufsausbildung in der Untersuchung auch diejenigen, die sich noch in der Ausbildung befinden. Dazu zählen auch die Mütter mit Abitur und insgesamt die jüngeren Mütter, die ebenfalls zu geringeren Hämoglobinkonzentrationen neigen (siehe unten). Möglicherweise finden sich in unter den Frauen ohne Berufsausbildung auch häufiger Ausländerinnen, die aus rechtlichen oder religiösen Gründen keine Berufsausbildung abschließen dürfen.

Insgesamt ist eine Erklärung für den schlechteren Eisenstatus bei Müttern ohne Berufsausbildung 
vermutlich eher in einer Anhäufung von Risikogruppen in dieser Untergruppe verantwortlich als direkt die geringere Bildung, die diese Mütter möglicherweise aufweisen könnten.

\subsubsection{Alter}

Bei jüngeren Müttern (bis 24) finden sich insbesondere häufiger Anämien zum Zeitpunkt der Studie. Aber auch bei den älteren (ab 35 Jahren) ist die Hämoglobinkonzentration sowohl in der Schwangerschaft als auch zum Zeitpunkt der Studie wieder geringer. Für den löslichen Transferrinrezeptor besteht passend dazu in diesen Altersgruppen der Trend zu höheren Konzentrationen (das Ergebnis ist allerdings nicht signifikant).

Nach Brussaard et al. (1997) ist das Alter sogar eine der Variablen, die am besten die Hämoglobinkonzentration von Frauen erklärt (positive Korrelation). Die zunehmende Prävalenz von Eisenmangelanämien bei steigendem Alter deckt sich mit den Ergebnissen für Deutschland nach Thefeld und Ellert (1998) (zwischen 25 und 54 Jahren). Die Prävalenz von Eisenmangelanämie bei Frauen vor der Menopause in Deutschland steigt nach Thefeld und Ellert (1998) mit zunehmendem Alter von 1,2 \% bei den 25- bis 29-jährigen auf 4,5\% bei den 50- bis 54-jährigen Frauen. Die 40- bis 49-jährigen weisen mit 10,4 \% die höchste Prävalenz von zellulärem Eisenmangel auf, im Alter von 50 bis 54 Jahren findet sich dagegen am seltensten ein zellulärer Eisenmangel (4,5 $\%)$.

Der Grund dafür wird auf die häufigere Einnahme oraler Kontrazeptiva von jungen Frauen zurückgeführt, unter deren Berücksichtigung als Einflußgröße der Alterseinfluß verschwindet (Thefeld and Ellert, 1998). Dabei ist bekannt, daß orale Kontrazeptiva den menstruellen Blutverlust (und damit Eisenverlust) auf weniger als $50 \%$ reduzieren können (Mishell, 1993). So findet sich Eisenmangel bei 25- bis 39-jährigen Frauen, die selten oder nie Fleisch essen und keine oralen Kontrazeptiva einnehmen zu 14,5\%, dagegen bei fleischessenden Frauen mit oraler Kontrazeption nur bei 5,5\% (Thefeld and Ellert, 1998). Daß bei den Probandinnen der vorliegenden Studie gerade die jüngsten Mütter (bis 24 Jahre) auch häufiger einen Eisenmangel haben, läßt vermuten, daß sie aufgrund ihrer Einstellung seltener orale Kontrazeptiva nehmen. Eine weitere Erklärung wäre, daß diese jungen Mütter verstärkt auf ihre Figur achten und deswegen insgesamt weniger essen als die älteren Mütter.

Eine inadäquate Eisenaufnahme von Frauen zwischen 18 und 24 Jahren wird nach Hendricks und Herbold (1998) in verschiedenen Untersuchungen bestätigt. Damit neigen sie eher zu einem Eisenmangel als ältere Frauen, die möglicherweise ausreichend Nahrung zu sich nehmen (Scholl et al., 1992). Bei einer Untersuchung an jungen Frauen in Dänemark fand sich passend zu den Ergebnissen der vorliegenden Untersuchung vom 16. Lebensjahr bis zum Alter von 30 Jahren eine Abnahme des Eisenmangels (Milman et al., 1995).

Wie in der vorliegenden Untersuchung wurde in anderen Studien häufiger Eisenmangel bei jünge- 
ren (bis 24) und älteren Müttern (ab 40) festgestellt. Mögliche Gründe dafür sind seltenere Einnahme oraler Kontrazeptiva dieser Altersgruppen oder, besonders bei den jungen Müttern, geringere Nahrungsaufnahme.

\subsubsection{Geburtsgewicht}

Der Zusammenhang zwischen höherem Geburtsgewicht des Kindes und niedrigeren Hämoglobinkonzentrationen der Mutter in der Schwangerschaft kann darin bestehen, daß größere Feten mehr Nährstoffe von der Mutter benötigen.

Auch in anderen Untersuchungen wurde ein Zusammenhang zwischen erhöhten Hämoglobinkonzentrationen der Mutter in der Schwangerschaft und niedrigerem Geburtsgewicht des Kindes festgestellt (Knottnerus et al., 1990). Dabei wird die Hypothese aufgestellt, daß erhöhte Blutviskosität zu einer verminderten Plazentaperfusion und somit zu einer geringeren Entwicklung der Plazenta führt (Knottnerus et al., 1990) (Zhou et al., 1998). Allerdings kommt es nach Zhou et al. (1998) und Scholl et al. (1992) auch bei Anämie und Eisenmangelanämie der Schwangeren zu erniedrigtem Geburtsgewicht und Frühgeburtlichkeit.

\subsubsection{Einzelfälle mit Eisenmangelanämie}

Unterschiede der beiden detailliert besprochenen Mütter mit Eisenmangelanämie bestehen in der Nationalität (eine ist Afrikanerin, die andere Deutsche), Bildungsniveau (eine hat einen Realschulabschluß und keine Berufsausbildung, die andere einen Hochschulabschluß), Berufstätigkeit (eine ist nicht berufstätig bei 2500 DM im Monat, die andere arbeitet bei 6000 DM im Monat) und Stillzeit (eine stillte ihr Kind gar nicht, die andere sechs Monate lang).

Gemeinsam ist den beiden aber ein geringer Fleischkonsum, eine zu geringe Gewichtszunahme in der Schwangerschaft, ein Body-Mass-Index im Normbereich, ein geringer Alkohol- und fehlender Zigarettenkonsum und regelmäßiges Einsetzen der Menstruation nach der Geburt. Somit häufen sich bei beiden Müttern Faktoren, die mit geringen Eisenreserven assoziiert sind, wie fehlender Alkohol- und Zigarettenkonsum und geringer Fleischverzehr. Eine weitere Ursache für den Eisenmangel kann bei beiden Frauen ein Blutverlust sein. Als Ursachen kommen hier beispielsweise Darmerkrankungen (z. B. M. Crohn, Wurmbefall) oder auch ein größerer Blutverlust (im Rahmen einer Operation oder eines Unfalls) in Frage.

\subsubsection{Zusammenhang Mutter-Kind}

Bei der Korrelation der mütterlichen und kindlichen Konzentrationen von Hämoglobin und von dem löslichen Transferrinrezeptor findet sich eine signifikanter Zusammenhang. Auch neigen Kinder verstärkt zu Eisenmangel, wenn die Mutter in der Schwangerschaft eine Hämoglobinkonzen- 
tration unter $10 \mathrm{~g} / \mathrm{dl}$ aufweist (Eisenreich, 2000; Wagener et al., 1999b).

Das bedeutet, daß Kinder von Müttern mit Eisenmangel ebenfalls verstärkt zu einem Eisenmangel neigen. Auch in einer anderen Untersuchung wiesen Kinder von Schwangeren mit Anämie im Verlauf des ersten Lebensjahrs häufiger Eisenmangel auf als Kinder von Schwangeren ohne Anämie. Dabei zeigte sich im Nabelschnurblut noch kein Unterschied (Kilbride et al., 1999).

Es ist also sinnvoll, bei Kindern von Müttern mit Eisenmangel ebenfalls den Eisenstatus zu kontrollieren. Andersherum sollten Mütter von Kindern mit Eisenmangel ihrerseits hinsichtlich ihres Eisenstatus' untersucht werden. Die Ursache dieses Zusammenhangs kann in ähnlicher Ernährung von Mutter und Kind liegen. Andererseits ist auch denkbar, daß Kinder von Müttern mit Eisenmangel in der Schwangerschaft nicht ausreichend große Eisenspeicher aufbauen können und deswegen mit einem Jahr diese Speicher erschöpft sind.

\subsection{Schlußfolgerungen}

Die drei wichtigsten aus der Studie resultierenden Ergebnisse sind:

1. Die Prävalenz von zellulärem Eisenmangel bei gesunden jungen Müttern liegt bei 9,5\% und ist damit hoch.

2. Es gibt bestimmte Risikofaktoren, die einen Eisenmangel voraussagen können.

3. Es besteht eine positive Korrelation zwischen den mütterlichen und kindlichen Indikatoren des Eisenstatus'.

Trotz geringfügiger soziodemographischen Unterschiede der vorliegenden Stichprobe von der Berlin- und bundesweiten Bevölkerung lassen sich die vorliegenden Ergebnisse weitgehend auf Berlin und die Bundesrepublik übertragen.

Es zeigt sich insgesamt ein sehr komplexes Bild von Risikofaktoren, anhand derer besonders gefährdete Mütter erkannt werden können. Die Mechanismen, über die diese Risikofaktoren zu Eisenmangel führen, sind noch nicht bekannt (Ausnahme: vegetarische Ernährung).

Hervorzuheben ist der Konsum von Alkohol, der als einziger Faktor in der multivariaten Analyse sowohl die Varianz der sTfR- als auch die der Hämoglobinkonzentrationen klärt und auch in anderen Untersuchungen mit einem besserem Eisenstatus assoziiert ist. Trotzdem läßt sich noch keine ausreichende Erklärung für diesen Zusammenhang finden.

In der vorliegenden Arbeit wird deutlich, daß Armut in Deutschland als Risikofaktor für Eisenmangel nicht so eine bedeutende Rolle spielt, wie in weniger entwickelten Ländern (Allen, 1997) oder den USA (MMRW, 1998; Looker et al., 1997). Zwar sind sowohl Deutschland als auch die USA 
sogenannte entwickelte Länder, jedoch weicht die Sozialstruktur voneinander ab. Die größere Diskrepanz zwischen arm und reich führt in den USA dazu, daß die Armen häufiger mit schlechter Ernährung und mangelnder medizinischer Versorgung auskommen müssen. So kann hier ein Eisenmangel sowohl als Symptom von nicht behandelten Krankheiten als auch von unzureichender Ernährung auftreten.

In Deutschland sind auch sozial schlechter gestellte in der Regel gut medizinisch versorgt und können ausreichend Grundnahrungsmittel kaufen. Deswegen treten in Deutschland Faktoren wie Lebensweise, Kinderzahl, Ernährung, Bildung und Nationalität in den Vordergrund. Es kommt in Deutschland somit auch bei besser ausgebildeten Frauen gehäuft zu Eisenmangel, die versuchen, besonders gesund zu leben (nicht rauchen, kein Alkohol, kein Fleisch). Die Mechanismen, die bei Vorliegen dieser Risikofaktoren zu Eisenmangel führen sind (abgesehen von dem Mechanismus, durch den fehlender Fleischkonsum zu Eisenmangel führt) noch nicht bekannt. Diese Zusammenhänge könnten durch weitere Forschungsarbeiten geklärt werden. Entsprechende Konsequenzen könnten dann in der Prävention und Therapie von Eisenmangel gezogen werden.

Aufgrund der unspezifischen Symptomatik (Abgeschlagenheit, herabgesetzte Konzentrationsfähigkeit, vermindertes Erinnerungsvermögen (Hendricks and Herbold, 1998)) bleibt Eisenmangel häufig unerkannt. Auch dadurch, daß als Screening-Indikator für Eisenmangel zunächst die Hämoglobinkonzentration verwendet wird, wird ein zellulärer Eisenmangel nicht entdeckt. Ein gesunder Mensch kann auch mit einem Eisenmangel subjektiv unbeeinträchtigt leben. Treten jedoch Faktoren wie beispielsweise Streß, ungesunde Ernährung, Krankheitserreger und andere Umwelteinflüsse hinzu, ist ein Mensch mit Eisenmangel angreifbarer und zugänglicher für Infekte, die sowohl den Gesundheitszustand beeinträchtigen, als auch die Behandlungskosten steigern.

Wird eine Frau mit Eisenmangel schwanger, so hat dieser Eisenmangel erst eine erhöhte Frühgeburtlichkeit zur Folge, wenn sich eine Eisenmangelanämie entwickelt (Scholl et al., 1992). Jedoch bleiben zu Beginn einer Schwangerschaft vorhandene niedrige mütterliche Hämatokritwerte im Verlauf dieser Schwangerschaft bestehen, unabhängig von der Einnahme von Eisenpräparaten (Kilbride et al., 1999). Die Ursache dafür ist der bis auf das Zehnfache gesteigerte Eisenbedarf in der Schwangerschaft. Dieser hohe Bedarf würde gedeckt, wenn die Schwangeren über Eisenspeicher von mindestens $300 \mathrm{mg}$ (bei sehr Fleisch- und Ascorbinsäure-reicher Ernährung), bei durchschnittlicher westlicher Ernährung besser $500 \mathrm{mg}$ verfügen würden. Bei Untersuchungen in Schweden und den USA fanden sich aber bei nur bei etwa $12 \%$ der prämenopausalen Frauen Eisenspeicher von 300 mg und bei keiner Frau von 500 mg (Hallberg, 1992) (Abbildung 4.1 auf Seite 81). Das bedeutet, daß höchstens $12 \%$ dieser Frauen ausreichend für eine Schwangerschaft ausgestattet sind.

Aus der vorliegenden Untersuchung geht eine Korrelation zwischen mütterlichen und kindlichen Indikatoren des Eisenstatus' hervor. Außerdem geht kindlicher Eisenmangel mit Anämie der Mutter in der Schwangerschaft einher. Deswegen muß noch stärker auf eine ausreichende Versorgung 


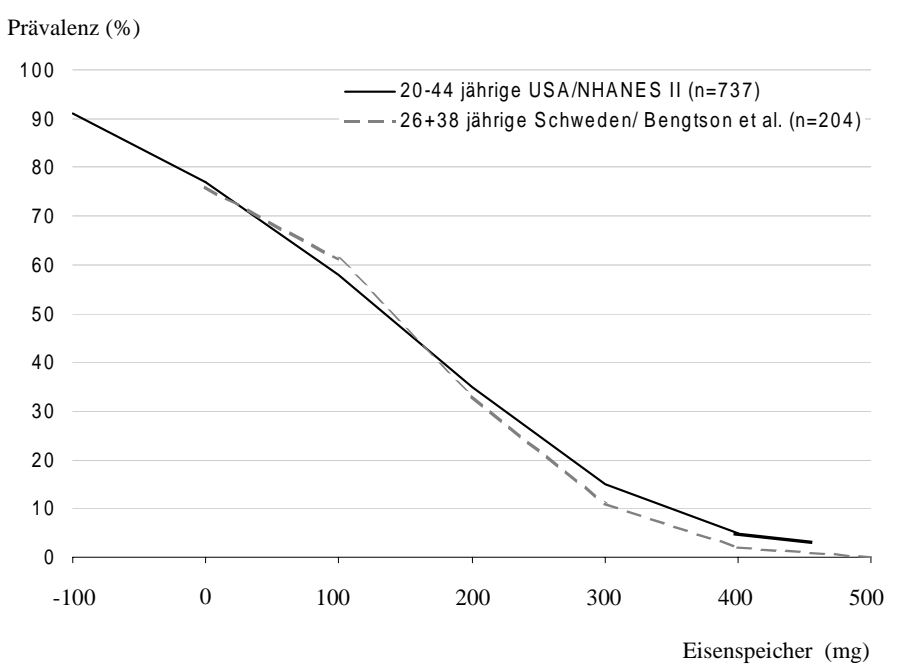

Abbildung 4.1: Verteilung der Eisenspeicher von Frauen im gebärfähigen Alter in den USA und Schweden (Hallberg, 1992).

der Schwangeren geachtet werden. Denn bei Kindern mit Eisenmangel wurden eine Verzögerung der psychomotorischen Entwicklung (Walter, 1992) und Verhaltensauffälligkeiten beobachtet (Lozoff et al., 1998).

Diese Tatsache macht eine Intervention umso wichtiger. Es gibt vier verschiedene Möglichkeiten, die Prävalenz von Eisenmangel bei den jungen Müttern zu vermindern:

1. Screening und gegebenenfalls Therapie,

2. Umstellung der Ernährung,

3. Supplementierung von Frauen im gebärfähigen Alter mit vorliegenden Risikofaktoren,

4. Supplementierung aller Frauen im gebärfähigen Alter.

Das Screening von gesunden jungen Frauen ist nicht einfach durchzuführen, wenn man den Eisenmangel vor dem Beginn einer Schwangerschaft therapieren möchte. Denn bei diesen Frauen werden in der Regel keine routinemäßigen Blutentnahmen durchgeführt. Es müßte also bei der Vorsorgeuntersuchung beim Gynäkologen eine zusätzliche Blutabnahme vorgenommen und eine Ferritinbestimmung durchgeführt werden. Das ist ein zusätzlicher Aufwand und verursacht Kosten. Außerdem würden so diejenigen nicht erfaßt, bei denen die Ferritinkonzentration aufgrund von Infektionen erhöht ist. Dazu kommen dann noch die Kosten für die Supplementierung bei den etwa $10 \%$ der Frauen mit unzureichenden Eisenspeichern. Auch kann eine vollständige Erfassung aller Frauen dadurch erschwert sein, daß die Vorsorgeuntersuchungen nicht von allen 
Frauen regelmäßig wahrgenommen werden. Spätestens aber dann, wenn unsupplementierte Frauen schwanger werden, sollten die Eisenspeicher, möglichst durch die genauere sTfR-Bestimmung, aber mindestens durch eine Ferritinbestimmung überprüft und gegebenenfalls aufgefüllt werden, um ein für Kind und Mutter optimales Schwangerschaftsergebnis zu erzielen.

Alle Frauen zu einer Umstellung ihrer Ernährungsgewohnheiten zu bewegen, ist eine schwierige Aufgabe, die höchstwahrscheinlich nicht den ausreichenden Erfolg haben würde. Denn gerade die Frauen, die kein Fleisch essen, tun das aus Überzeugung und wären nur schwer durch Argumente umzustimmen. Außerdem ist wegen der individuellen Ernährung jedes Einzelnen auch trotz einer Umstellung eine ausreichende Eisenversorgung nicht unbedingt gegeben.

Eisen ist mit einem Anteil von über $95 \%$ an allen in der Schwangerschaft eingenommen Präparaten das von Schwangeren in Magdeburg am häufigsten eingenommene Medikament (Rösch et al., 1998). Auch in Wien wird Eisen als häufigstes Supplement von Schwangeren eingenommen (etwa $41 \%$ ) (Szallai, 1997).

Ob der durch Supplemente verbesserte Eisenstatus der Mutter auch ihrem Gesundheitszustand (und langfristig dem des Kindes) zugute kommt, ist noch nicht ausreichend erforscht (US Preventive Services Task Force, 1993). Manche Autoren diskutieren sogar, ob eine prophylaktische Eiseneinnahme in der Schwangerschaft tatsächlich die Gesundheit von Mutter und Kind verbessert (Allen, 1997). Die Einnahme von Eisensupplementen in der Schwangerschaft steigert nach verschiedenen Studien das Geburtsgewicht nicht (Allen, 1997). Nur in wenigen Untersuchungen erhöhten Eisenpräparate (und die gleichzeitige Einnahme von Vitaminen) das Geburtsgewicht (nur bei Jungen) oder verminderten das Risiko für eine Frühgeburt (US Preventive Services Task Force, 1993). Werden sie allerdings von Schwangeren mit Eisenmangel eingenommen, erhöht sich das Geburtsgewicht ihrer Kinder (Agarwal et al., 1991).

Eine Verbesserung des Eisenstatus' durch Eisenpräparate wurde in verschiedenen Studien ausreichend nachgewiesen (Puolakka et al., 1980; Simmons et al., 1993). Ein Anstieg von Hämoglobin, Hämatokrit, MCV, Ferritin, Serum-Eisen und Transferrinsättigung findet sich innerhalb von drei Monaten, die Entleerung der mütterlichen Eisenspeicher wird reduziert (Puolakka et al., 1980) oder verhindert (Svanberg et al., 1976). Sogar sechs Monate post partum wurden noch signifikant höhere Ferritinkonzentrationen bei Frauen gefunden, die während der Schwangerschaft Eisenpräparate benutzten. Die Hämoglobinkonzentrationen dagegen unterschieden sich nicht von denen der unsupplementierten Frauen (Puolakka et al., 1980).

Es gibt widersprüchliche Untersuchungen über die Auswirkungen von der Einnahme von Eisenpräparaten in der Schwangerschaft auf die Eisenkonzentration des Nabelschnurbluts. Manche Autoren fanden in ihren Studien keine Korrelationen des Eisenstatus' von Müttern, die über ausreichende Eisenreserven verfügten oder Eisenpräparate eingenommen hatten und dem Eisenstatus des Nabelschnurbluts (Allen, 1997). Andere fanden bei supplementierten Müttern signifikant höhere 
Ferritinkonzentrationen im Vergleich zur Plazebogruppe sowohl im mütterlichen Blut in der 30. Schwangerschaftswoche als auch im Nabelschnurblut und im Blut der Neugeborenen (Barrada et al., 1991). Außerdem weisen Kinder von Müttern, die in der Schwangerschaft keine Eisensupplemente eingenommen haben, mit einem Alter von sechs Monaten niedrigere Ferritinwerte auf als Kinder supplementierter Mütter (Hallberg, 1992).

Das Institute of Medicine empfiehlt die routinemäßige Einnahme von Eisenpräparaten (30 mg pro Tag) ab der 12. Schwangerschaftswoche (Institute of Medicine, 1990). In der Diskussion ist noch, ob eine wöchentliche oder intermittierende Einnahme von Eisenpräparaten ebenso effektvoll ist wie eine tägliche Eisensubstitution (Galloway and McGuire, 1996; Solomons, 1997). Für eine wöchentliche Einnahme spricht, daß in einer Untersuchung in Indonesien ein vergleichbarer Eisenstatus bei Schwangeren mit wöchentlicher und solchen mit täglicher Supplementierung gefunden wurde (Ridwan et al., 1996). Auch die Kosten für eine wöchentliche Einnahme sind geringer als für die tägliche (Yip, 1996; Solomons, 1997). Die Ursache für den gleichen Eisenstatus der Frauen bei wöchentlicher im Vergleich zur täglichen Eiseneinnahme kann aber auch sein, daß die Frauen die tägliche Einnahme nicht einhielten, sondern seltener (womöglich auch nur einmal pro Woche) eine Eisentablette einnahmen. Weiterhin vermuten manche Autoren, daß durch häufige Eiseneinnahme ein mukosaler Block und damit eine mangelnde Eisenabsorption hervorgerufen wird. Diese Theorie wird aber durch mehrere Studien widerlegt. Danach unterscheidet sich der Anteil von absorbiertem Eisen bei täglicher Einnahme nicht von dem bei wöchentlicher Einnahme, was wiederum die tägliche Einnahme effektiver macht (Hallberg, 1998). Auch bei nicht schwangeren Frauen wurde keine bessere Absorption bei weniger als einmal täglich eingenommenen Präparaten festgestellt. Dabei ist fraglich, ob die Compliance bei der wöchentlichen Einnahme auf lange Sicht gesehen besser ist (möglicherweise wird bei täglicher Supplementierung durch Gewöhnung an die Einnahme die Compliance verbessert). Außerdem können die Nebenwirkungen der höheren Dosis bei der wöchentlichen Supplementation stärker sein als bei der geringeren Dosierung für die tägliche Einnahme und deswegen die Compliance verschlechtern (Yip, 1996). Insgesamt erscheint eine tägliche Einnahme von gering dosierten Eisenpräparaten $(30 \mathrm{mg})$ der wöchentlichen, höheren Dosierung überlegen.

Anhand der vorliegenden Daten können die Mütter mit besonders hohen Eisenspeichern (hoher Fleisch-, Alkohol- und Zigarettenkonsum) von einer allgemeinen Eisensupplementierung ausgeschlossen werden, um bei ihnen eine Eisenüberladung zu vermeiden. Man könnte aber auch nur denjenigen eine Eisensupplementierung empfehlen, die besonders Eisenmangel-gefährdet sind (Vegetarierinnen, Nichtraucherinnen, Ausländerinnen). Diese Methode würde das Risiko einer Eisenüberladung der Frauen senken, jedoch ist auch die Gefahr größer, daß potentiell gefährdete Frauen übersehen werden.

Wegen der hohen Prävalenz von Eisenmangel ist trotz der Kenntnis von Risikofaktoren eine tägliche Supplementierung aller Frauen im gebärfähigen Alter mit niedrig dosierten Eisenpräparaten 
am sinnvollsten. Der Vorteil daran ist die vollständige Erfassung jeder potentiell gefährdeten Frau. Die tägliche Verabreichung kann durch Gewöhnung zu einer regelmäßigen Einnahme führen. Die Dosierung sollte $30 \mathrm{mg}$ nicht überschreiten, da dieses die für Schwangere empfohlene Dosis mit einem ausreichendem Effekt und trotzdem minimalen Nebenwirkungen darstellt (Allen, 1997). Da der Eisenbedarf außerhalb der Schwangerschaft deutlich geringer ist, müßte eine Dosierung von 10 bis $15 \mathrm{mg}$ pro Tag für eine Prävention ausreichen. Bei dieser geringen Menge sind toxische Nebenwirkungen (etwa durch freie Eisenionen (Wick et al., 1996)) nicht zu erwarten. Eine Eisenüberladung könnte an zu hohen Hämoglobinkonzentrationen erkannt werden.

Aufgrund der weiten Verbreitung von Eisenmangel bei jungen Müttern in Deutschland und mit Blick auf die übermäßige Steigerung des Eisenbedarfs in der Schwangerschaft halte ich eine Prävention von Eisenmangel bei allen Frauen im gebärfähigen Alter für sinnvoll. Am sichersten zur Deckung des vollen Eisenbedarfs ist die tägliche Einnahme von niedrig dosierten Präparaten mit wenigen Nebenwirkungen.

Damit würde das Wohlbefinden der Frauen verbessert und Risiken für einen ungünstigen Schwangerschafts- sowie Geburtsverlauf vermindert. Außerdem würde ein Beitrag geleistet zur gesunden Entwicklung des Kindes und zur Vermeidung von Krankheiten. 


\section{Kapitel 5}

\section{Zusammenfassung}

Lebensqualität und Leistungsfähigkeit werden durch unbemerkten Eisenmangel beeinträchtigt. Frauen im gebärfähigen Alter haben einen erhöhten Eisenbedarf, der in der Schwangerschaft bis auf das Zehnfache ansteigt. Dabei geht dem Funktionseisenabbau (Hämoglobinverminderung) die Erschöpfung der Eisenspeicher voraus. Diese bleibt wegen der noch nicht veränderten Hämoglobinkonzentration meist unbemerkt.

In der vorliegenden Untersuchung wurde der Eisenstatus von 507 Müttern erfaßt, die mit ihrem einjährigen Kind zur sechsten Vorsorgeuntersuchung (U6) in 69 Berliner Kinderarztpraxen erschienen. Datenquellen waren venöse Blutabnahme, Mutterpaß und Fragebogen. Als Leitindikator für einen Eisenmangel diente die Konzentration des löslichen Transferrinrezeptors (sTfR). Diese repräsentiert das Ausmaß des zellulären Eisenmangels und steht sowohl für die Eisenspeicher als auch für das Funktionseisen. Je größer das Ausmaß des Eisenmangels, umso höher die Konzentration des löslichen Transferrinrezeptors. Gegenüber Ferritin hat der lösliche Transferrinrezeptor den Vorteil, daß er kein Akute-Phase-Protein ist.

Fast jede zehnte junge Mutter (9,5\%) in Berlin leidet ein Jahr nach der Schwangerschaft an einem zellulären Eisenmangel (sTfR $>3,3 \mathrm{mg} / \mathrm{l})$. Dagegen kommt eine Eisenmangelanämie $(\mathrm{Hb}<12$ $\mathrm{g} / \mathrm{dl}$, sTfR $>3,3 \mathrm{mg} / \mathrm{l}$ ) nur bei 2,2 \% aller Mütter vor. Es besteht eine positive Korrelation zwischen sTfR-Konzentrationen von Müttern und Kindern und zwischen Hämoglobinkonzentrationen von Müttern und Kindern.

Die Untersuchungsergebnisse sind weitgehend repräsentativ für die Bundesrepublik, obwohl Mütter mit Abitur signifikant häufiger in der Untersuchung vertreten sind als bundesweit. Die Altersverteilung der Probandinnen ist dagegen vergleichbar mit einer bundesweiten repräsentativen Stichprobe.

Wichtige Risikofaktoren für Eisenmangel liegen in soziodemographischen Merkmalen, unterschiedlicher Lebensweise und Ernährung. Faktoren, die einen zellulären Eisenmangel voraussagen, sind fehlendes Einsetzen der Menstruation post partum, vegetarische Ernährung, nicht-deutsche Na- 
tionalität und Multiparität. Alkoholkonsum und Rauchen dagegen scheinen vor Eisenmangel zu schützen.

Assoziiert mit geringeren mütterlichen Hämoglobinkonzentrationen sind geringer Body-MassIndex, fehlende Berufsausbildung, geringes Alter und hohes Geburtsgewicht.

Ohne signifikanten Einfluß auf den Eisenstatus bleiben in der vorliegenden Untersuchung Berufstätigkeit, Schulabschluß, Einkommen, Passivrauchen in der Schwangerschaft, Sport, Stärke der Menstruationsblutung, Still- und Schwangerschaftsdauer.

Die Mechanismen, über die die genannten Risikofaktoren zu Eisenmangel führen, sind weitgehend unbekannt (Ausnahme: vegetarische Ernährung) und müßten in weiteren Untersuchungen erforscht werden.

Ein Eisenmangel in der Schwangerschaft kann ebenfalls zu Eisenmangel beim Kind und damit zu einer möglichen Entwicklungsverzögerung führen. Da aus der Literatur hervorgeht, daß ein schlechter Eisenstatus zu Beginn einer Schwangerschaft auch über die gesamte Schwangerschaft bestehen bleibt, ist es besonders wichtig, daß die Frauen schon vor der Schwangerschaft über ausreichende Eisenreserven verfügen.

Die Ergebnisse der Untersuchung zeigen, daß Mütter mit hohem Alkohol-, Zigaretten- und Fleischkonsum weniger gefährdet sind und damit von einer Prävention ausgeschlossen werden könnten. Auch die gefundenen Risikofaktoren für Eisenmangel könnten bei Präventionskonzepten berücksichtigt werden. Aufgrund der hohen Prävalenz von Eisenmangel erscheint aber eine Supplementierung mit niedrig dosierten Eisenpräparaten bei allen Frauen im gebärfähigen Alter am sinnvollsten, um eine optimale Eisenversorgung sicherzustellen . 


\section{Literaturverzeichnis}

Åkesson, A., Bjellerup, P., Berglund, M., Bremme, K., and Vahter, M. (1998). Serum transferrin receptor: a specific marker of iron deficiency in pregnancy. The American Journal of Clinical Nutrition, 68:1241-1246.

Adish, A. A., Esrey, S. A., Gyorkos, T. W., Jean-Baptiste, J., and Rojhani, A. (1999). Effect of consumption of food cooked in iron pots on iron status and growth of young chlidren: a randomised trial. The Lancet, 353:712-716.

Agarwal, K. N., Agarwal, D. K., and Mishra, K. P. (1991). Impact of anaemia prophylaxis in pregnancy on maternal hemoglobin, serum ferritin and birth weight. Indian Journal of Medical Research, 94:277-280.

Agrawal, R. M. D., Tripathi, A. M., and Agrawal, K. N. (1983). Cord blood haemoglobin, iron and ferritin status in maternal anaemia. Acta Paediatrica Scandinavica, 72:545-548.

Ajayi, O. A. (1988). Iron stores in pregnant nigerians and their infants at term. European Journal of Clinical Nutrition, 42:23-28.

Allen, J., Backstrom, K. R., Cooper, J. A., Cooper, M. C., Detwiler, T. C., Essex, D. W., Fritz, R. P., Means, R. T., Meier, P. B., Pearlman, S. R., Roitman-Johnson, B., and Seligman, P. A. (1998). Measurement of souble transferrin receptor in serum of healthy adults. Clinical Chemistry, 44(1):35-39.

Allen, L. H. (1997). Pregnancy and iron deficiency: Unresolved issues. Nutrition Reviews, 55(4):91-101.

Andelman, M. B. and Sered, B. R. (1966). Utilization of dietary iron by term infants. American Journal of Disorders in Childhood, 111:45-55.

Ballabriga, A. (1988). Vitamins and minerals in pregnancy and lactation: An introduction. In Berger, H., editor, Vitamins and Minerals in Pregnancy and Lactation, volume 16 of Nestlé Nutrition Workshop Series, pages 231-244. Nestec Ltd., Vevey Raven Press, Ltd., New York. 
Barker, D. J. P. (1997). The fetal origins of coronary heart disease. Acta Paediatrica Supplemente, 422:78-82.

Barrada, M., Pateisky, N., Schatten, C., Salzer, H., Vavra, N., Spona, J., and Sevelda, P. (1991). Ferritinspiegel von neugeborenen nach präpartaler eisenmedikation. Geburtshilfe und Frauenheilkunde, 51:366-368.

Bärtsch, P., Mairbäurl, H., and Friedmann, B. (1998). Pseudoanämie durch sport. Therapeutische Umschau, 55(4):251-255.

Baynes, R. D. (1996). Assessment of iron status. Clinical Biochemistry, 29(3):209-215.

Baynes, R. D., Shih, Y. J., and Cook, J. D. (1991). Production of soluble transferrin receptor by k562 erythroleukaemia cells. British Journal of Haematology, 78:450-455.

Beard, J. L. (1994). Iron deficiency: assessment during pregnancy and its importance in pregnent adolescents. The American Journal of Clinical Nutrition, 59:502S-510S.

Beard, J. L., Dawson, H., and Piñero, D. J. (1996). Iron metabolism: A comprehensive review. Nutrition Reviews, 54(10):295-317.

Bergmann, K. E., Bergmann, R. L., and Jung, G. (1978). Vorkommen von eisenmangel bei einer stichprobe frankfurter kinder. Monatsschrift für Kinderheilkunde, 126:184-190.

Bergmann, R., Bergler, H., Moshoudis, E., Bergmann, E., Lachmann, E., and Bergmann, K. E. (1989). Prävention von eisenmangel bei gestillten säuglingen durch geeignete beikost. Monatsschrift Kinderheilkunde, 137:775-779.

Bergmann, R. L., Huch, R., Bergmann, K. E., and Dudenhausen, J. W. (1997). Ernährungsprävention während der schwangerschaft. Deutsches Ärzteblatt, Sonderdruck, 94(38):1-8.

Bergmann, R. L., Kamtsiuris, P., Bergmann, K. E., Huber, M., and Dudenhausen, J. W. (2000). Kompetente elternschaft: Erwartungen von jungen eltern an die beratung in der schwangerschaft und an die entbindung. im Druck.

bmb+f (1998). Grund- und Strukturdaten 1998/99. Bundesministerium für Bildung und Forschung Referat für Öffentlichkeitsarbeit.

Brussaard, J. H., Brants, H. A. M., Bouman, M., and Löwik, M. R. H. (1997). Iron intake and iron status among adults in the netherlands. European Journal of Clinical Nutrition, 51:S51-S58.

Carriaga, M. T., Skikne, B. S., Finley, B., Cutler, B., and Cook, J. D. (1991). Serum transferrin receptor for the detection of iron deficiency in pregnancy. The American Journal of Clinical Nutrition, 54:1077-1081. 
Chan, L.-N. L. and Gerhardt, E. M. (1992). Transferrin receptor gene is hyperexpressed and transcriptionally regulated in differentiating erythroid cells. The Journal of Biological Chemistry, 267(12):8254-8259.

Clauß, G. and Ebner, H., editors (1977). Grundlagen der Statistik, pages 172-176. Frankfurt: Verlag Harri Deutsch.

Colomer, J. et al. (1990). Anaemia during pregnancy as a risk factor for infant iron deficiency: report from the valencia infant anaemia cohort (viac) study. Paediatric and Perinatal Epidemiology, 4:196-204.

Cook, J. D. (1982). Clinical evaluation of iron deficiency. Seminars in Hematology, 19(1):6-18.

Cook, J. D. and Lynch, S. R. (1986). The liabilities of iron deficiency. Blood, 68(4):803-809.

Cook, J. D., Skikne, B. S., and Baynes, R. D. (1992). Screening strategies for nutritional iron deficiency. In Fomon, S. J. and Zlotkin, S., editors, Nutritional Anemias, pages 159-165. Nestec Ltd., Vevey/Reven Press, Ltd. New York.

Cook, J. D., Skikne, B. S., and Baynes, R. D. (1993). Serum transferrin receptor. Annual Reviews of Medicine, 44:63-74.

Cook, J. D., Skikne, B. S., Lynch, S. R., and Reusser, M. E. (1986). Estimates of iron sufficiency in the us population. Blood, 68(3):726-731.

Cooper, M. J. and Zlotkin, S. H. (1996). Day-to-day variation of transferrin receptor and ferritin in healthy men and women. The American Journal of Clinical Nutrition, 64:738-742.

Deutsche Gesellschaft für Ernährung (1991). Empfehlungen für die Nährstoffzufuhr. Umschau Verlag, Frankfurt (Main).

Eaton, S. B. and Konner, M. (1985). Paleolithic nutrition - a consideration of its nature and current implications. The New England Journal of Medicine, 312(5):283-289.

Eisenreich, B. (2000). Prävalenz und Risikofaktoren von Eisenmangel bei einjährigen Kindern. $\mathrm{PhD}$ thesis, Kaiserin-Auguste-Viktoria-Institut für präventive Pädiatrie. im Druck.

Eisenstein, R. S. and Blemings, K. P. (1998). Iron regulatory proteins, iron responsive elements and iron homeostasis. American Society for Nutritional Sciences, pages 2295-2298.

Ferguson, B. J., Skikne, B. S., Simpson, K. M., Baynes, R. D., and Cook, J. D. (1992). Serum transferrin receptor distinguishes the anemia of chronic disease from iron deficiency anemia. Journal of Labor and Clinical Medicine, 119(4):385-390. 
Fleming, D. J., Jacques, P. F., Dallal, G. E., Tucker, K. L., Wilson, P. W. F., and Wood, R. J. (1998). Dietary determinants of iron stores in a free-living elderly population: The framingham heart study. The American Journal of Clinical Nutrition, 67:722-733.

Flowers, C. H., Skikne, B. S., Covell, A. M., and Cook, J. D. (1989). The clinical measurement of serum transferrin receptor. Journal of Labor and Clinical Medicine, 114(4):368-377.

Galloway, R. and McGuire, J. (1996). Daily versus weekly: How many iron pills do pregnant women need? Nutrition Reviews, 54(10):318-323.

Gaspar, M. J., Ortrega, R. M., and Moreiras, O. (1993). Relationship between iron status in pregnant women and their newborn babies. Acta Obstetritica et Gynecologica Scandinavia, 72:534-537.

Gibson, R. S. (1997). Technological approaches to combatting iron deficiency. European Journal of Clinical Nutrition, 51:S25-S27.

Godfrey, K. M., Redman, C. W. G., Barker, D. J. P., and Osmond, C. (1991). The effect of maternal anaemia and iron deficiency on the ratio of fetal weight to placental weight. British Journal of Obstetrics and Gynaecology, 98:886-891.

Goerke, K., Steller, J., and Valet, A. (1997). Klinikleitfaden Gynäkologie Geburtshilfe: Untersuchung, Diagnostik, Therapie, Notfall. Gustav Fischer, 4. edition.

Gonzalez-Reimers, E., Martinez-Riera, A., Santolaria-Fernandez, F., Mas-Pascual, A., RodriguezMoreno, F., Galindo-Martin, L., Molina-Perez, M., and Barros-Lopez, N. (1998). Relative and combined effects of ethanol and protein deficiency on zinc, iron, copper, and manganese contents in different organs and urinary and fecal excretion. Alcohol, 16(1):7-12.

Guesry, P. (1998). The role of nutrition in brain development. Preventive Medicine, 27:189-194.

Hallberg, L. (1988). Iron balance in pregnancy. In Berger, H., editor, Vitamins and Minerals in Pregnancy and Lactation, volume 16 of Nestlé Nutrition Workshop Series, pages 115-127. Nestec Ltd., Vevey Raven Press, Ltd., New York.

Hallberg, L. (1992). Iron balance in pregnancy and lactation. In Fomon, S. J. and Zlotkin, S., editors, Nutritional Anemias, volume 30 of Nestlé Nutrition Workshop Series, pages 13-28. Nestec Ltd., Vevey/Raven Press, Ltd.,New York.

Hallberg, L. (1994). Prevention of iron deficiency. Baillère's Clinical Haematology, 7(4):805-814.

Hallberg, L. (1998). Combating iron deficiency: daily administration of iron is far superior to weekly administration. The American Journal of Clinical Nutrition, 68:213-217. 
Hallberg, L. and Rossander-Hultén, L. (1991). Iron requirements in menstruating women. The American Journal of Clinical Nutrition, 54:1047-1058.

Hallquist, S. A., Mcneil, L. K., lockwood, J. F., and Sherman, A. R. (1992). Maternal-irondeficiency effects on peritoneal macrophage and peritoneal natural-killer-cell cytotoxicity in rat pups. The American Journal of Clinical Nurition, 55:741-746.

Hendricks, K. M. and Herbold, N. H. (1998). Diet, activity, and other health-related behaviors in college-age women. Nutrition Reviews, 56(3):65-75.

Howe, D., Wheeler, T., and Osmond, C. (1995). The influence of maternal haemoglobin and ferritin on mid-pregnancy fetal volume. British Journal of Obstetrics and Gynaecology, 102:213-219.

Huebers, H. A., Beguin, Y., Pootrakul, P., Einspahr, D., and Finch, C. A. (1990). Intact transferrin receptors in human plasma and their relation to erythropoiesis. Blood, 75(1):102-107.

Idjradinata, P. and Pollitt, E. (1993). Reversal of developmental delays in iron-deficient anaemic infants treated with iron. The Lancet, 341:1-4.

Institut für Klinische Chemie und Biochemie, Virchow-Klinikum (1997). Vorläufige Referenzbereiche für Kinder.

Institute of Medicine (1990). Nutrition During Pregnancy. National Academy Press, Washington, D. C.

Jongh, R. D., Vranken, J., Vundelinckx, G., Bosmans, E., Maes, M., and Heylen, R. (1997). The effects of anticoagulation and processing on assays of il-6, sil-6r, sil-2r and soluble transferrin receptor. Cytokine, 9(9):696-701.

Kalkwarf, H. J. and Harrast, S. D. (1998). Effects of calcium supplementation and lactation on iron status. The American Journal of Clinical Nutrition, 67:1244-1249.

Khumalo, H., Gomo, Z. A. R., Moyo, V. M., Gordeuk, V. R., Saungweme, T., Rouault, T. A., and Gangaidzo, I. T. (1998). Serum transferrin receptors are decreased in the presence of iron overload. Clinical Chemistry, 44(1):40-44.

Kilbride, J., Baker, T. G., Parapia, L. A., Khoury, S. A., Shuqaidef, S. W., and Jerwood, D. (1999). Anaemia during pregnancy as a risk factor for iron-deficiency anaemia in infancy: a casecontrol study in jordan. International Epidemiological Association, 28:461-468.

Kim, I., Yetley, E. A., and Calvo, M. S. (1993). Variations in iron-status measures during the menstrual cycle. The American Journal of Clinical Nutrition, 58:705-509. 
Klemow, D., Einsphar, D., Brown, T. A., Flowers, C. H., and Skikne, B. S. (1990). Serum transferrin receptor measurments in hematologic malignancies. American Journal of Hematology, 34:193-198.

Knottnerus, J. A., Delgado, L. R., Knipschild, P. G., Essed, G. G. M., and Smits, F. (1990). Haematologic parameters and pregnancy outcome. Journal of Clinical Epidemiology, 43(5):461466.

Kuiper-Kramer, E. P. A., Baerts, W., Bakker, R., van Eyck, J., van Raan, J., and van Eijk, H. G. (1998). Evaluation of the iron status of the newborn by soluble transferrin receptors in serum. Clinical Chemistry and Labor Medicin, 36(1):17-21.

Kulig, M., Bergmann, R. L., Tacke, U., Wahn, U., Guggenmoos-Holzmann, I., and Group, M. S. (1998). Long-lasting sensitization to food during the first two years precedes allergic airway disease. Pediatric Allergy and Immunology, 9(2):61-67.

Kuvibidila, S., Warrier, R. P., Ode, D., and Yu, L. (1996). Serum transferrin receptor concentrations in women with mild malnutrition. The American Journal of Clinical Nutrition, 63:596-601.

Lechtig, A., Habicht, J.-P., Delgado, H., Klein, R. E., Yarbrough, C., and Martorell, R. (1975). Effects of food supplementation during pregnancy on birthweight. Pediatrics, 56(4):508-520.

Little, R. E., Anderson, K. W., Ervin, C. H., Worthington-Roberts, B., and Clarren, S. K. (1989). Maternal alcohol use during breast-feeding and infant mental and motor development at one year. The New England Journal of Medicine, 321(7):425-430.

Liu, B. Q., Peto, R., Chen, Z. M., Boreham, J., Wu, Y. P., Li, J. Z., Campbell, T. C., and Chen, J. S. (1998). Emerging tobacco hazards in china: 1. retrospective proportional mortality study of one million deaths. British Medical Association, 317:1411-1422.

Lönnerdal, B. and Dewey, K. G. (1995). Epidemiologie des eisenmangels bei säuglingen und kindern. In Eisenmangel beim Kind, volume 53:1 of Nestlé Nutrition Services, pages 12-19. Nestec AG.

Looker, A. C., Dallman, P. R., Carrol, M. D., Gunter, E. W., and Johnson, C. L. (1997). Prevalence of iron deficiency in the united states. The Journal of the American Medical Association, 277(12):973-976.

Looker, A. C., Gunter, E. W., and Johnson, C. L. (1995). Methods to assess iron status in various nhanes surveys. Nutrition Reviews, 53(9):246-254.

Looker, A. C., Sempos, C. T., Liu, K., Johnson, C. L., and Gunter, E. W. (1990). Within-person variance in biochemical indicators of iron status: effects on prevalence estimates. The American Journal of Clinical Nutrition, 52:541-547. 
Lødrup Carlsen, K. C., Jaakkola, J. J. K., Nafstad, P., and Carlsen, K.-H. (1997). In utero exposure to cigarette smoking influences lung function at birth. European Respiratory Journals, 10:1774-1779.

Lozoff, B., Klein, N. K., Nelson, E. C., McClish, D. K., Manuel, M., and Chacon, M. E. (1998). Behavior of infants with iron-deficiency anemia. Child Development, 69(1):24-36.

LSRO (Life Science Research Office) (1984). Assessment of the Iron Nutritional Status of the U. S. Population Based on Data Collected in the Second National Health and Nutrition Examniation Survey, 1976-1980. Federation of American Societies for Experimental Biology, Bethesda, M.d. (zitiert nach [Institute of Medicine, 1990]).

Lynch, S. R. (1997). Interaction of iron with other nutrients. Nutrition Reviews, 55(4):102-110.

Marx, J. J. M. (1997). Iron deficiency in developed countries: prevalance, influence of lifestyle factors and hazards of prevention. European Jorunal of Clinical Nutrition, 51:491-494.

Mast, A. E., Blinder, M. A., Gronowski, A. M., Chumley, C., and Scott, M. G. (1998). Clinical utility of the soluble transferrin receptor and comparison wirh serum ferritin in several populations. Clinical Chemistry, 44(1):45-51.

Mercelina-Roumans, P. E. A. M., Breukers, R. B. G. E., Ubachs, J. M. H., and van Wersch, J. W. J. (1996). Hematological variables in cord blood of neonates of smoking and nonsmoking mothers. Journal of Clinical Epidemiology, 49(4):449-454.

Milman, N., Clausen, J. O., and Jordal, R. (1995). Iron status in young danish men and women: a population survey comprising 548 individuals. Annals of Hematology, 70(4):215-221.

Mishell, D. R. (1993). Noncontraceptive benefits of oral contraceptives. The Journal of Reproductive Medicine (Supplements), 38(12):1021-1029.

MMRW (1998). Recommendations to prevent and control iron deficiency in the united states. centers for disease control and prevention.

Moirand, R., Mortaji, A. M., Loréal, O., Paillard, F., Brissot, P., and Deugnier, Y. (1997). A new syndrome of liver iron overload with normal transferrin saturation. The Lancet, 349:95-97.

Müller, G., editor (1993). Klinisch-chemische Diagnostik: ein Leitfaden und Ratgeber für die medizinische Praxis zur Auswerteung und Interpretation von klinisch-chemischen Laborwerten. Gustav Fischer Verlag Jena.

Nelson, M. E., O’Brien-Ladner, A. R., and Wesselius, L. J. (1996). Regional variation in iron and iron-binding proteins within the lungs of smokers. American Journal of Respiration and Critical Care in Medicine, 153:1353-1358. 
Perry, G. S., Byers, T., Yip, R., and Margen, S. (1992). Iron nutrition does not account for the hemoglobin differences between blacks and whites. The Journal of Nutriticals, 122:14171424.

Petrides, P. E. (1997). Spurenelemente. In Löffler, G. and Petrides, P. E., editors, Biochemie und Pathobiochemie, pages 624-635. Springer-Verlag Berlin Heidelberg New York.

Pollitt, E. (1997). Iron deficiency and educational deficieny. Nutrition Reviews, 55(4):133-141.

Pschyrembel, W., Strauss, G., and Petri, E., editors (1990). Pschyrembel Klinisches Wörterbuch, pages 20-21. de Gruyter Berlin.

Punnonen, K., Irjala, K., and Rajamaki, A. (1997). Serum transferrin receptor and its ratio to serum ferritin in the diagnosis of iron deficiency. Blood, 89(3):1052-1057.

Puolakka, J., Janne, O., Pakarinen, A., and Vihko, R. (1980). Serum ferritin as a measure of stores during and after normal pregnancy with and wthout iron supplements. Acta Obstetrica et Gynecologica Scandinavica Supplements, 95:43-51.

Reuter, J. M. and Wozniak, J. R., editors (1996). The Kent Infant Development (KID) Scale. Kent Development Metrics, Inc., 3. edition.

Ridwan, E., Schultink, W., Dillon, D., and Gross, R. (1996). Effects of weekly iron supplementation on pregnant indonesian women are similar to those of daily supplementation. The American Journal of Clinical Nutrition, 63:884-890.

Rios, E., Lipschitz, D. A., Cook, J. D., et al. (1975). Relationship of maternal and infant iron stores as assessed by determination of plasma ferritin. Pediatrics, 55:694-699.

Rösch, C., Schröter, C., Lehmann, R., and Steinbicker, V. (1998). Prospektive erfassung von arzneimitteleinnahmen in der schwangerschaft im rahmen des fehlbildungsmonitoring im regierungsbezirk magdeburg. Ärzteblatt Sachsen-Anhalt, 9:14-6.

Rutledge, E. A., Root, B. J., Lucas, J. J., and Enns, C. A. (1994). Elimination of the o-linked glycosylation site at thr 104 results in the generation of a soluble human-transferrin receptor. Blood, 83(2):580-586.

Schellscheidt, J., Jorch, G., and Menke, J. (1998). Effects of heavy maternal smoking on intrauterine growth patterns in sudden infant death victims and surviving infants. European Journal of Pediatrics, 157(3):246-251.

Scholl, T. O., Hediger, M. L., Fischer, R. L., and Shearer, J. W. (1992). Anemia vs iron deficiency: increased risk of preterm delivery in a prospective study. The American Journal of Clinical Nutrition, 55:985-988. 
Shih, Y. J., Baynes, R. D., Hudson, B. G., Flowers, C. H., Skikne, B. S., and Cook, J. D. (1990). Serum transferrin receptor is a truncated form of tissue receptor. The Journal of Biological Chemistry, 265(31):19077-19081.

Simmons, W. K., Cook, J. D., Bingham, K. C., Thomas, M., Jackson, J., Jackson, M., Ahluwalia, N., Kahn, S. G., and Patterson, A. W. (1993). Evaluation of a gastric delivery system for iron supplementation in pregnancy. The American Journal of Clinical Nutrition, 58:622-626.

Skikne, B. S., Flowers, C. H., and Cook, J. D. (1990). Serum transferrin receptor: A quantitative measure of tissue iron deficiency. Blood, 75(9):1870-1876.

Solomons, N. W. (1997). Letter to the editor - daily versus weekly iron: We still might not be asking the right questions. Nutrition Reviews, 55(4):141-142.

Spohr, H.-L., Willms, J., and Steinhausen, H.-C. (1993). Prenatal alcohol exposure and long-term developmental consequences. The Lancet, 341(8850):907-910.

Starreveld, J. S., Kroos, M. J., van Suijlen, J. D., et al. (1995). Ferritin in cultured human cytotrophoblasts: synthesis and subunit distribution. Placenta, 16:383-395.

Statistisches Landesamt Berlin (1997). Mikrozensus für berlin im april 1997.

Statistisches Landesamt Berlin (1998). Mikrozensus für berliner mütter mit kindern unter drei jahren im april 1998.

Strauss, M. B. (1933). Anemia of infancy from maternal iron deficiency in pregnancy. Journal of Clinical Investment, 12:345-353.

Suominen, P., Punnonen, K., and Irjala, K. (1998). Serum transferrin receptor and transferrin receptor-ferritin index identify healthy subjects with subclinical iron deficits. Blood, 92(8):2934-2939.

Suominen, P., Punnonen, K., Rajamäki, A., and Irjala, K. (1997). Evaluation of new immunoenzymometric assay for measuring soluble transferrin receptor to detect iron deficiency in anemic patients. Clinical Chemistry, 43(9):1641-1646.

Svanberg, B., Arvidsson, B., Norrby, A., et al. (1976). Absorption of supplemental iron during pregnancy - a longitundinal study with repeated bone-marrow studies and absorption measurements. Acta Obstetrica et Gynecologica Scandinavica Supplements, 48:87-108.

Szallai, M. (1997). Der Ernährungszustand von Schwangeren, Stillenden und Säuglingen in Wien. $\mathrm{PhD}$ thesis, Wien. 
Thefeld, W. and Ellert, U. (1998). Eisenversorgung bei frauen vor der menopause. Bundesgesundheitsblatt, 11:502-504.

Theil, E. C., Burton, J. W., and Beard, J. L. (1997). A sustainable solution for dietary iron deficiency through plant biotechnology and breeding to increase seed ferritin control. European Journal of Clinical Nutrition, 51:S28-S31.

Thomas, L., editor (1992). Labor und Diagnose. Die Medizinische Verlagsgesellschaft mbH Marburg, 4. edition.

Thorstensen, K. and Romslo, I. (1990). The role of transferrin in the mechanism of cellular iron uptake. Biochemistry Journal, 271:1-10.

Thorstensen, K. and Romslo, I. (1993). The transferrin receptor: Its diagnostic value and its potential as therapeutic target. Scandinavian Journal of Clinical Labor and Investment, 53(Suppl. 215):113-120.

Untoro, J., Gross, R., Schultink, W., and Sediaoetama, D. (1998). The association between bmi and haemoglobin and work productivity among indonesian female factory workers. European Journal of Clinical Nutrition, 52:131-135.

US Preventive Services Task Force (1993). Routine iron supplementation during pregnancy.

Viteri, F. E. (1997). Effective iron supplementation does not happen in isolation. The American Journal of Clinical Nutrition, 65:889-890.

Wagener, I., Bergmann, R. L., Kamtsiuris, P., Eisenreich, B., Andres, B., Bergmann, K. E., and Dudenhausen, J. W. (1999a). Prävalenz und risikofaktoren von eisenmangel bei jungen müttern. Kongress: Public Health - Entwicklungen und Potentiale (Vortrag).

Wagener, I., Bergmann, R. L., Kamtsiuris, P., Eisenreich, B., Andres, B., Bergmann, K. E., and Dudenhausen, J. W. (1999b). Prävalenz und risikofaktoren von eisenmangel bei jungen müttern. 19. Deutscher Kongress für Perinatale Medizin (Poster).

Wagener, I. E., Bergmann, R. L., Kamtsiuris, P., Eisenreich, B., Andres, B., Eckert, C., Dudenhausen, J. W., and Bergmann, K. E. (2000). Pävalenz und risikofaktoren von eisenmangel bei jungen müttern. Das Gesundheitswesen, 62.

Walter, T. (1992). Early and long-term effect of iron deficiency anemia on child development. In Fomon, S. J. and Zlotkin, S., editors, Nutrtional Anemias, volume 30 of Nestlé Nutrition Series, pages 81-92. Nestec Ltd., Vevey/Raven Press, Ltd., New York.

Walter, T., Olivares, M., Pizarro, F., and Muñoz, C. (1997). Iron, anemia, and infection. Nutrition Reviews, 55(4):111-124. 
Wheeler, T., Sollero, C., Alderman, S., et al. (1994). Relation between maternal haemoglobin and placental hormone concentratiooons in early pregnancy. The Lancet, 343:511-513.

Wick, M., Pinggera, W., and Lehmann, P. (1996). Eisenstoffwechsel Diagnostik und Therapie der Anämien. Springer-Verlag/Wien, 4. edition.

Worwood, M. (1995). Regulation des eisenstoffwechsels. In Eisenmangel beim Kind, volume 53:1 of Nestlé Nutrition Services, pages 1-11. Nestec AG.

Worwood, M. (1997). The laboratory assessment of iron status - an update. Clinica Chimica Acta, 259:3-23.

Yehuda, S. and Youdim, M. B. H. (1989). Brain iron: a; lesson from animal models. The American Journal of Clinical Nutrition, 50:618-629.

Yip, R. (1989). Iron nutritonal status defined. In L. J. Filer, J., editor, Dietary Iron: Birth to Two Years, pages 19-36. Raven Press, Ltd., New York.

Yip, R. (1996). Iron supplementation during pregnancy: is it effective? The American Journal of Clinical Nutrition, 63:853-855.

Yip, R. (1997). The challenge of improving iron nutition: limitations and potentials of major intervention approaches. European Journal of Clinical Nutrition, 51:S16-S24.

Zhou, L.-M., Yang, W.-W., Hua, J.-Z., Deng, C.-Q., Tao, X., and Stoltzfus, R. J. (1998). Relation of hemoglobin measured at different times in pregnancy to preterm birth and low birth weight in shanghai, china. American Journal of Epidemiology, 148(10):998-1006. 


\section{Anhang A}

\section{Tabellen}

Tabelle A.1: Soziodemographie der Stichprobe im Vergleich zur Berlin- (statistisches Landesamt Berlin, 1998) und zur bundesweiten (Bergmann et al.,

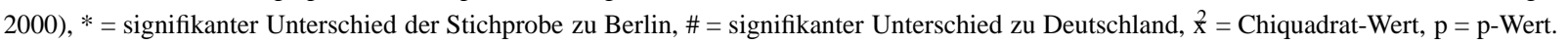

\begin{tabular}{|c|c|c|c|c|c|c|c|c|c|}
\hline \multicolumn{10}{|c|}{ Soziodemographie } \\
\hline & & \multirow[b]{2}{*}{$\mathrm{n}_{\text {gesamt }}$} & \multicolumn{3}{|c|}{ Studie } & \multicolumn{2}{|r|}{ Berlin } & \multicolumn{2}{|c|}{ Deutschland } \\
\hline & & & $\mathrm{n}$ & $\%$ & CI & $\%$ & & $\%$ & \\
\hline \multirow{2}{*}{ Nationalität } & andere $* \#$ & \multirow{2}{*}{449} & 86 & 19,2 & $15,6-22,8$ & 26,4 & $x^{2}=13,188$ & 4,5 & $x^{2}=175,704$ \\
\hline & deutsch *\# & & 363 & 80,8 & $77,2-84,4$ & 72,2 & $\mathrm{p}=0,000$ & 95,5 & $\mathrm{p}<0,000$ \\
\hline \multirow{4}{*}{ Alter (Jahre) } & bis 24 & \multirow{4}{*}{432} & 67 & 15,5 & $12,1-18,9$ & 15,3 & $x^{2}=79,415$ & 13,4 & $x^{2}=1,460$ \\
\hline & 25 bis 29 & & 142 & 32,9 & $28,5-37,3$ & 33,3 & $\mathrm{p}=0,000$ & 34,8 & $\mathrm{p}=0,691$ \\
\hline & 30 bis $34 *$ & & 159 & 36,8 & $32,3-37,3$ & 31,9 & & 36,0 & \\
\hline & $\mathrm{ab} 35 *$ & & 64 & 14,8 & $11,5-18,1$ & 19,4 & & 15,8 & \\
\hline \multirow{5}{*}{ Schulabschluß } & Schule beendet ohne Abschluß & \multirow{5}{*}{406} & 19 & 4,7 & $2,6-6,8$ & & & 3,0 & $x^{2}=36,030$ \\
\hline & Volks-/Hauptschulabschluß \# & & 73 & 18,0 & $14,3-21,7$ & & & 23,0 & $\mathrm{p}<0,000$ \\
\hline & Realschulabschluß \# & & 139 & 34,2 & $29,6-38,8$ & & & 41,0 & \\
\hline & Fachhochschulreife & & 34 & 8,4 & $5,7-11,1$ & & & 9,0 & \\
\hline & Abitur \# & & 141 & 34,7 & $30,1-39,3$ & & & 23,0 & \\
\hline \multirow{4}{*}{$\begin{array}{l}\text { abgeschlossene } \\
\text { Berufsausbildung }\end{array}$} & (noch) keine \# & \multirow{4}{*}{400} & 92 & 23,0 & $18,9-27,1$ & & & 10,0 & $\mathrm{x}^{2}=111,125$ \\
\hline & Lehre \# & & 164 & 41,0 & $37,2-44,8$ & & & 64,1 & $\mathrm{p}<0,000$ \\
\hline & Fachschule \# & & 65 & 16,3 & $11,7-20,8$ & & & 11,7 & \\
\hline & Hochschule \# & & 79 & 19,8 & $15,9-23,7$ & & & 12,3 & \\
\hline \multirow{3}{*}{ Anzahl der Kinder } & eins $*$ & \multirow{3}{*}{322} & 147 & 45,7 & $40,3-51,1$ & 55,6 & $x^{2}=27,295$ & & \\
\hline & zwei & & 119 & 37,0 & $31,7-42,3$ & 34,9 & $\mathrm{p}=0,000$ & & \\
\hline & ab drei $*$ & & 56 & 17,4 & $13,3-21,5$ & 9,5 & & & \\
\hline \multirow{2}{*}{ Berufstätigkeit } & nein $*$ & \multirow{2}{*}{450} & 363 & 80,7 & $77,1-84,3$ & 54,2 & $x^{2}=126,570$ & & \\
\hline & ja * & & 87 & 19,3 & $15,7-22,9$ & 45,8 & $\mathrm{p}=0,000$ & & \\
\hline \multirow{2}{*}{ Familiennettoeinkommen } & bis 1500 (Studie)/1400 (Berlin) & \multirow{2}{*}{ 1) 389} & 48 & 12,3 & $9,0-15,6$ & 15,1 & $x^{2}=2,257$ & & \\
\hline & ab $1500 / 1400$ & & 341 & 87,7 & $84,4-91,0$ & 84,9 & $\mathrm{p}=0,133$ & & \\
\hline \multirow{13}{*}{$\begin{array}{l}\text { ausländische } \\
\text { Nationalitäten }\end{array}$} & afrikanisch & \multirow{13}{*}{86} & 2 & 2,3 & & & & & \\
\hline & asiatisch & & 8 & 9,3 & & & & & \\
\hline & russisch & & 3 & 3,5 & & & & & \\
\hline & polnisch & & 7 & 8,1 & & & & & \\
\hline & portugiesisch & & 1 & 1,2 & & & & & \\
\hline & englisch & & 1 & 1,2 & & & & & \\
\hline & französisch & & 1 & 1,2 & & & & & \\
\hline & holländisch & & 1 & 1,2 & & & & & \\
\hline & italienisch & & 1 & 1,2 & & & & & \\
\hline & türkisch & & 36 & 41,9 & & & & & \\
\hline & albanisch & & 1 & 1,2 & & & & & \\
\hline & kroatisch & & 1 & 1,2 & & & & & \\
\hline & anders & & 23 & 26,7 & & & & & \\
\hline
\end{tabular}


Tabelle A.2: Lebensgewohnheiten und Schwangerschaft.

\begin{tabular}{|c|c|c|c|c|}
\hline \multicolumn{5}{|c|}{ Lebensgewohnheiten und Schwangerschaft } \\
\hline & & $\mathrm{n}_{\text {gesamt }}$ & $\mathrm{n}$ & $\%$ \\
\hline \multirow{3}{*}{$\begin{array}{l}\text { Alkoholkonsum in der } \\
\text { Schwangerschaft }\end{array}$} & nie & \multirow{3}{*}{445} & 322 & 72,4 \\
\hline & selten & & 119 & 26,7 \\
\hline & öfters & & 4 & 0,9 \\
\hline \multirow{3}{*}{$\begin{array}{l}\text { Alkoholkonsum nach der } \\
\text { Schwangerschaft }\end{array}$} & nie & \multirow{3}{*}{445} & 166 & 37,3 \\
\hline & selten & & 243 & 54,6 \\
\hline & öfters & & 36 & 8,1 \\
\hline \multirow{4}{*}{ Vegetarische Ernährung } & ausschließlich & \multirow{4}{*}{449} & 6 & 1,3 \\
\hline & vorwiegend & & 46 & 10,2 \\
\hline & selten & & 157 & 35,0 \\
\hline & gar nicht & & 240 & 53,5 \\
\hline \multirow{2}{*}{ Rauchen in der Schwangerschaft } & ja & \multirow{2}{*}{450} & 122 & 27,1 \\
\hline & nein & & 328 & 72,9 \\
\hline \multirow{2}{*}{ Rauchen zur Zeit } & ja & \multirow{2}{*}{450} & 159 & 35,3 \\
\hline & nein & & 291 & 64,7 \\
\hline \multirow{3}{*}{$\begin{array}{l}\text { Passivrauchen in der } \\
\text { Schwangerschaft }\end{array}$} & nie & \multirow{3}{*}{447} & 100 & 22,4 \\
\hline & selten & & 276 & 61,7 \\
\hline & öfters & & 71 & 15,9 \\
\hline \multirow{2}{*}{ Sport in der Schwangerschaft } & ja & \multirow{2}{*}{452} & 75 & 16,6 \\
\hline & nein & & 377 & 83,4 \\
\hline \multirow{2}{*}{ Sport nach der Schwangerschaft } & ja & \multirow{2}{*}{451} & 111 & 24,6 \\
\hline & nein & & 340 & 75,4 \\
\hline \multirow{3}{*}{ Einsetzen der Menstruation pp. } & ja, regelmäßig & \multirow{3}{*}{442} & 326 & $\overline{73,8}$ \\
\hline & ja, unregelmäßig & & 80 & 18,1 \\
\hline & nein, gar nicht & & 36 & 8,1 \\
\hline \multirow{3}{*}{ Stärke der Menstruationsblutung } & kaum & \multirow{3}{*}{385} & 10 & $\overline{2,6}$ \\
\hline & mäßig & & 229 & 59,5 \\
\hline & stark & & 146 & 37,9 \\
\hline \multirow{5}{*}{ Stilldauer (Monate) } & 0 bis 1 & \multirow{5}{*}{419} & 61 & $\overline{14,6}$ \\
\hline & 2 bis 4 & & 111 & 26,5 \\
\hline & 5 bis 6 & & 78 & 18,6 \\
\hline & 7 bis 9 & & 86 & 20,5 \\
\hline & über 9 & & 83 & 19,8 \\
\hline \multirow{4}{*}{ Body-Mass-Index } & $<19,8$ & & 88 & 20,4 \\
\hline & $19,8-26,0$ & & 252 & 58,5 \\
\hline & $>26,0-29,0$ & 431 & 55 & 12,8 \\
\hline & $>29,0$ & & 36 & 8,4 \\
\hline & bis 37 & & 49 & 14,5 \\
\hline & 38 & & 30 & 8,9 \\
\hline Schwangerschaftsdauer & 39 & & 53 & 15,7 \\
\hline & $40 / 41$ & 338 & 165 & 48,8 \\
\hline & $\mathrm{ab} 42$ & & 41 & 12,1 \\
\hline & $<2500$ & & 29 & 8,4 \\
\hline Geburtsgewicht (g) & $2500-4000$ & 345 & 274 & 79,4 \\
\hline & $>4000$ & & 42 & 12,2 \\
\hline
\end{tabular}


Tabelle A.3: Indikatoren für den Eisenstatus: Mittelwerte und Prävalenzen abweichender Werte.

\begin{tabular}{lcccrrr}
\hline \multicolumn{3}{c}{ Mittelwerte der Indikatoren und Prävalenzen abweichender Werte } \\
\hline & & & & \multicolumn{3}{c}{ Anteil } \\
\cline { 5 - 8 } & $\mathrm{n}_{\text {gesamt }}$ & $\bar{y}$ & $\mathrm{SD}$ & & $\mathrm{n}$ & $\%$ \\
\hline $\mathrm{sTfR}(\mathrm{mg} / \mathrm{l})$ & 483 & 2,22 & 1,09 & $>3,3:$ & 46 & 9,5 \\
\hline $\mathrm{Hb}(\mathrm{g} / \mathrm{dl})$ & 474 & 13,72 & 1,15 & $<12:$ & 19 & 4,0 \\
\hline Hämatokrit & 483 & 0,41 & 0,03 & $<0,36:$ & 18 & 3,1 \\
\hline Ferritin $(\mathrm{ng} / \mathrm{ml})$ & 494 & 35,69 & 26,80 & $<12:$ & 62 & 12,6 \\
\hline $\mathrm{MCV}(\mathrm{fl})$ & 483 & 86,81 & 4,59 & $<80:$ & 37 & 7,7 \\
\hline Transferrin $(\mathrm{mg} / \mathrm{dl})$ & 493 & 264,77 & 47,12 & $>310$ & 82 & 16,6 \\
\hline Transferrinsättigung $(\%):$ & 495 & 29,06 & 46,08 & $<16$ & 15 & 3,0 \\
\hline Eisen $(\mu \mathrm{g} / \mathrm{dl})$ & 496 & 94,30 & 7,36 & $<40:$ & 33 & 6,7 \\
\hline sTfR und $\mathrm{Hb}$ & 451 & $\mathrm{sTfR}>3,3$ und $\mathrm{Hb}<12:$ & 10 & 2,2 \\
\hline
\end{tabular}

Tabelle A.4: Perzentilen der Konzentration des löslichen Transferrinrezeptors (mg/l) bei den Müttern insgesamt und bei verschiedenem mütterlichem Alter.

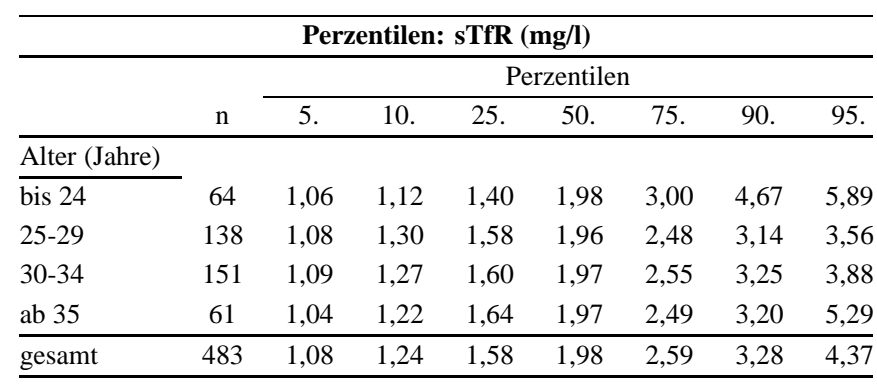

Tabelle A.5: Anteil der unter 12 g/dl liegenden Hämoglobinkonzentrationen der Mütter bei den unterschiedlichen gruppenbildenden Variablen mit Signifikanzen, Odds-Ratios und Signifikanzen der Odds-Ratios.

\begin{tabular}{llrcccc}
\hline \multicolumn{7}{c}{ Prävalenzen in Untergruppen: $\mathbf{H b}<\mathbf{1 2}$ g/dl } \\
\hline
\end{tabular}




\begin{tabular}{|c|c|c|c|c|c|c|}
\hline \multicolumn{7}{|c|}{ Fortsetzung Tabelle A.5: Prävalenzen in Untergruppen: $\mathrm{Hb}<12 \mathrm{~g} / \mathrm{dl}$} \\
\hline & & \multirow[b]{2}{*}{$\mathrm{n}$} & \multirow{2}{*}{$\begin{array}{c}\text { Anteil (\%) } \\
<12 \mathrm{~g} / \mathrm{dl}\end{array}$} & \multirow{2}{*}{$\begin{array}{l}\text { Pearson } \\
\text { p-Wert }\end{array}$} & \multirow{2}{*}{$\begin{array}{l}\text { Odds- } \\
\text { Ratio }\end{array}$} & \multirow[b]{2}{*}{$\mathrm{CI}$} \\
\hline & & & & & & \\
\hline \multirow{3}{*}{$\begin{array}{l}\text { Passivrauchen } \\
\text { i.d.SS. }\end{array}$} & nie & 95 & 6,3 & \multirow{3}{*}{0,171} & 1 & \\
\hline & selten & 261 & 2,3 & & 0,35 & $0,11-1,11$ \\
\hline & öfters & 64 & 4,7 & & 0,73 & $0,18-3,03$ \\
\hline Stärke der & kaum Blutungen & 10 & 10,0 & \multirow{3}{*}{0,193} & 1 & \\
\hline \multirow{2}{*}{$\begin{array}{l}\text { Menstruations- } \\
\text { blutung }\end{array}$} & mäßig Blutungen & 216 & 4,2 & & 0,39 & $0,4-3,41$ \\
\hline & starke Blutungen & 135 & 1,5 & & 0,14 & $0,01-1,65$ \\
\hline \multirow{2}{*}{ Berufstätigkeit } & nein & 338 & 4,1 & \multirow{2}{*}{0,201} & 1 & \\
\hline & ja & 82 & 1,2 & & 0,29 & $0,04-2,20$ \\
\hline \multirow{5}{*}{ Schulabschluß } & ohne Abschluß & 17 & 0,0 & \multirow{5}{*}{0,316} & 0,00 & $\overline{0,00-1,66 \mathrm{E}+18}$ \\
\hline & Volks-/Hauptschulabschluß & 69 & 4,3 & & 2,00 & $0,39-10,18$ \\
\hline & Realschulabschluß & 131 & 4,3 & & 1,75 & $0,41-7,46$ \\
\hline & Fachhochschulreife & 31 & 9,7 & & 4,71 & $0,90-24,58$ \\
\hline & Abitur & 132 & 2,2 & & 1 & \\
\hline \multirow{2}{*}{ Sport i.d.SS. } & ja & 68 & 5,9 & \multirow{2}{*}{0,317} & 1,80 & $0,56-5,75$ \\
\hline & nein & 357 & 3,4 & & 1 & \\
\hline \multirow{5}{*}{$\begin{array}{l}\text { Schwanger- } \\
\text { schaftsdauer } \\
\text { (Wochen) }\end{array}$} & bis 37 & 48 & 2,1 & \multirow{5}{*}{0,364} & 0,26 & $0,03-2,63$ \\
\hline & 38 & 27 & 3,7 & & 0,47 & $0,05-4,82$ \\
\hline & 39 & 52 & 7,7 & & 1,03 & $0,22-4,88$ \\
\hline & $40 / 41$ & 154 & 2,6 & & 0,33 & $0,07-1,53$ \\
\hline & ab 42 & 40 & 7,5 & & 1 & \\
\hline & eins & 139 & 1,4 & & 1 & \\
\hline Zahl der Kinder & zwei & 117 & 4,3 & 0,367 & 3,06 & $0,58-16,06$ \\
\hline & $\mathrm{ab}$ drei & 51 & 3,9 & & 2,85 & $0,39-20,82$ \\
\hline & bis 1500 & 45 & 4,4 & & 0,76 & $0,12-4,76$ \\
\hline Familiennettoein- & $1500-2500$ & 81 & 6,2 & & 1,07 & $0,25-4,70$ \\
\hline kommen & $2500-3500$ & 123 & 2,4 & 0,480 & 0,41 & $0,08-2,09$ \\
\hline (DM) & $3500-4500$ & 68 & 1,5 & & 0,24 & $0,02-2,41$ \\
\hline & ab 4500 & 52 & 5,8 & & 1 & \\
\hline & ja, regelmäßig & 303 & 3,6 & & 1 & \\
\hline $\begin{array}{l}\text { Einselzen der } \\
\text { Menstruation n }\end{array}$ & ja, unregelmäßig & 77 & 2,6 & 0,484 & 0,71 & $0,15-3,26$ \\
\hline & nein, gar nicht & 35 & 0,0 & & 0,00 & $0,00-4,25 \mathrm{E}+20$ \\
\hline & $<2500$ & 29 & 0,0 & & 1 & \\
\hline Geburtsgewicht & $2500-4000$ & 256 & 4,3 & 0,508 & 0,99 & $0,22-4,50$ \\
\hline & $>4000$ & 313 & 4,0 & & 0,94 & $0,15-6,10$ \\
\hline & (noch) keine & 80 & 5,0 & & 1 & \\
\hline Berufsausbildung & Lehre & 157 & 2,5 & 0.693 & 0,50 & $0,12-2,04$ \\
\hline Beruisausonitung & Fachschule & 60 & 3,3 & 0,093 & 0,66 & $0,12-3,70$ \\
\hline & Hochschule & 77 & 5,2 & & 1,04 & $0,25-4,32$ \\
\hline & ja & 114 & 4,4 & & 1 & \\
\hline Rauchen i.d.SS. & nein & 309 & 3,6 & 0,693 & 0,80 & $0,27-2,37$ \\
\hline Rauchen zur Zeit & ja & 148 & 3,4 & 0749 & 1 & \\
\hline der Studie & nein & 275 & 4,0 & 0,149 & 1,18 & $0,40-3,46$ \\
\hline & $<19,8$ & 81 & 3,7 & & 1 & \\
\hline Body-Mass- & $19,8-26$ & 236 & 3,8 & & 1,01 & $0,27-3,84$ \\
\hline Index & $26,01-29$ & 53 & 1,9 & 0,841 & 0,49 & $0,05-4,88$ \\
\hline & $>29$ & 34 & 5,9 & & 1,60 & $0,26-10,06$ \\
\hline & ja & 101 & 4,1 & 0.910 & 1,08 & $0,34-3,44$ \\
\hline sport p.p. & nein & 323 & 3,7 & 0,910 & 1 & \\
\hline & ausschließlich & 5 & 0,0 & & 0,02 & $0,00-1,83 \mathrm{E}+12$ \\
\hline Vegetarische & vorwiegend & 45 & 4,4 & & 1,26 & $0,26-6,15$ \\
\hline Ernährung & selten & 147 & 3,4 & 0,960 & 0,96 & $0,31-2,98$ \\
\hline & gar nicht & 225 & 3,6 & & 1 & \\
\hline
\end{tabular}


Tabelle A.6: Anteil der über 3,3 mg/l liegenden Konzentrationen des sTfR der Mütter bei den unterschiedlichen gruppenbildenden Variablen mit Signifikanzen, Odds-Ratios und Konfidenzintervallen der Odds-Ratios.

\begin{tabular}{|c|c|c|c|c|c|c|}
\hline \multicolumn{7}{|c|}{ Prävalenzen in Untergruppen; sTfR > 3,3 mg/l } \\
\hline & & & Anteil (\%) & Pearson & Odds- & \\
\hline & & $\mathrm{n}$ & $>3,3 \mathrm{mg} / \mathrm{l}$ & p-Wert & Ratio & $\mathrm{CI}$ \\
\hline \multirow{3}{*}{$\begin{array}{l}\text { Einsetzen der } \\
\text { Menstruation p.p. }\end{array}$} & ja, regelmäßig & 312 & 7,1 & \multirow{3}{*}{0,020} & 1 & \\
\hline & ja, unregelmäßig & 76 & 6,6 & & 0,93 & $0,34-2,54$ \\
\hline & nein, gar nicht & 34 & 20,6 & & 3,42 & $1,34-8,73$ \\
\hline \multirow{3}{*}{$\begin{array}{l}\text { Alkoholkonsum } \\
\text { p.p. }\end{array}$} & nie & 153 & 12,4 & \multirow{3}{*}{0,042} & 1 & \\
\hline & selten & 237 & 7,6 & & 0,58 & $0,29-1,14$ \\
\hline & öfters & 35 & 0,0 & & 0,00 & $0,00-1,54 \mathrm{E}+11$ \\
\hline \multirow{4}{*}{$\begin{array}{l}\text { Vegetarische } \\
\text { Ernährung }\end{array}$} & ausschließlich & 6 & 16,7 & \multirow{4}{*}{0,057} & 1,50 & $0,17-13,36$ \\
\hline & vorwiegend & 44 & 6,8 & & 0,55 & $0,16-1,90$ \\
\hline & selten & 149 & 4,0 & & 0,32 & $0,13-0,78$ \\
\hline & gar nicht & 230 & 11,7 & & 1 & \\
\hline \multirow{5}{*}{ Schulabschluß } & ohne Abschluß & 17 & 23,5 & \multirow{5}{*}{0,122} & 5,58 & $1,44-21,60$ \\
\hline & Volks-/Hauptschulabschluß & 70 & 11,4 & & 2,34 & $0,81-6,74$ \\
\hline & Realschulabschluß & 136 & 10,3 & & 2,08 & $0,81-5,33$ \\
\hline & Fachhochschulreife & 31 & 9,7 & & 1,94 & $0,47-7,97$ \\
\hline & Abitur & 134 & 5,2 & & 1 & \\
\hline Stärke der & kaum Blutungen & 10 & 20,0 & \multirow{3}{*}{0,145} & 1 & \\
\hline Menstruations- & mäßig Blutungen & 217 & 5,1 & & 0,21 & $0,04-1,12$ \\
\hline blutung & starke Blutungen & 141 & 6,4 & & 0,27 & $0,05-1,49$ \\
\hline \multirow{3}{*}{ Zahl der Kinder } & eins & 140 & 6,4 & \multirow{3}{*}{0,176} & 1 & \\
\hline & zwei & 114 & 10,5 & & 1,71 & $0,69-4,22$ \\
\hline & ab drei & 54 & 14,8 & & 2,59 & $0,94-7,11$ \\
\hline \multirow{2}{*}{ Nationalität } & andere & 78 & 12,8 & \multirow{2}{*}{0,179} & 1,66 & $0,77-3,57$ \\
\hline & deutsch & 349 & 8,0 & & 1 & \\
\hline \multirow{2}{*}{$\begin{array}{l}\text { Rauchen zur Zeit } \\
\text { der Studie }\end{array}$} & ja & 149 & 6,0 & \multirow{2}{*}{0,238} & 1 & \\
\hline & nein & 279 & 9,3 & & 1,58 & $0,72-3,47$ \\
\hline \multirow{2}{*}{ Berufstätigkeit } & nein & 342 & 9,6 & \multirow{2}{*}{0,299} & 1 & \\
\hline & ja & 83 & 6,0 & & 0,60 & $0,23-1,59$ \\
\hline \multirow{2}{*}{ Sport i.d.SS. } & ja & 68 & 5,9 & \multirow{2}{*}{0,317} & 0,78 & $0,33-1,83$ \\
\hline & nein & 357 & 3,4 & & 1 & \\
\hline & nie & 305 & 4,6 & & 1 & \\
\hline $\begin{array}{l}\text { Alkonolkonsum } \\
\text { id SS }\end{array}$ & selten & 115 & 6,1 & 0,395 & 0,59 & $0,25-1,39$ \\
\hline & öfters & 4 & 0,0 & & 0,01 & $0,00-2,73 \mathrm{E}+13$ \\
\hline & bis 24 & 64 & 14,1 & & 1 & \\
\hline Alter (Iahre) & 25 bis 29 & 138 & 7,2 & 0.421 & 0,48 & $0,18-1,24$ \\
\hline Anter (Jante) & 30 bis 34 & 151 & 7,9 & 0,421 & 0,53 & $0,21-1,32$ \\
\hline & ab 35 & 61 & 8,2 & & 0,55 & $0,17-1,73$ \\
\hline & $<19,8$ & 85 & 4,7 & & 1 & \\
\hline Body-Mass- & $19,8-26$ & 240 & 8,8 & 0.533 & 1,91 & $0,64-5,72$ \\
\hline Index & $26,01-29$ & 51 & 9,8 & 0,J35 & 2,17 & $0,56-8,48$ \\
\hline & $>29$ & 34 & 11,8 & & 2,66 & $0,63-11,32$ \\
\hline Sport p.p. & ja & 104 & 6,7 & 0,541 & 0,78 & $0,33-1,83$ \\
\hline sport p.p. & nein & 325 & 8,6 & 0,041 & 1 & \\
\hline Rauchen id SS & $\mathrm{ja}$ & 116 & 6,9 & 0.555 & 1 & \\
\hline Kaucnen 1.d.SS. & nein & 312 & 8,7 & 然, & 1,28 & $0,56-2,90$ \\
\hline & (noch) keine & 87 & 10,3 & & 1 & \\
\hline Berufsausbildung & Lehre & 158 & 8,2 & 0597 & 0,78 & $0,32-1,90$ \\
\hline & Fachschule & 62 & 11,3 & 0,591 & 1,10 & $0,39-3,14$ \\
\hline & Hochschule & 74 & 5,4 & & 0,50 & $0,15-1,68$ \\
\hline
\end{tabular}




\begin{tabular}{|c|c|c|c|c|c|c|}
\hline \multicolumn{7}{|c|}{ Fortsetzung Tabelle A.6: Prävalenzen in Untergruppen: sTfR $>3,3 \mathrm{mg} / \mathrm{l}$} \\
\hline & & & Anteil $(\%)$ & Pearson & Odds- & \\
\hline & & $\mathrm{n}$ & $>3,3 \mathrm{mg} / \mathrm{l}$ & p-Wert & Ratio & $\mathrm{CI}$ \\
\hline \multirow{5}{*}{$\begin{array}{l}\text { Stilldauer } \\
\text { (Monate) }\end{array}$} & 0 bis 1 & 57 & 12,3 & \multirow{5}{*}{0,679} & 1 & \\
\hline & 2 bis 4 & 108 & 9,3 & & 0,73 & $0,26-2,03$ \\
\hline & 5 bis 6 & 75 & 6,7 & & 0,52 & $0,16-1,73$ \\
\hline & 7 bis 9 & 79 & 6,3 & & 0,48 & $0,15-1,61$ \\
\hline & über 9 & 76 & 6,6 & & 0,49 & $0,15-1,63$ \\
\hline \multirow{5}{*}{$\begin{array}{l}\text { Schwanger- } \\
\text { schaftsdauer } \\
\text { (Wochen) }\end{array}$} & bis 37 & 44 & 9,1 & & 0,68 & $0,17-2,74$ \\
\hline & 38 & 28 & 7,1 & \multirow{4}{*}{0,810} & 0,52 & $0,09-2,91$ \\
\hline & 39 & 53 & 5,7 & & 0,41 & $0,09-1,82$ \\
\hline & $40 / 41$ & 157 & 8,3 & & 0,61 & $0,21-1,84$ \\
\hline & ab 42 & 39 & 12,8 & & 1 & \\
\hline \multirow{5}{*}{$\begin{array}{l}\text { Familiennettoein- } \\
\text { kommen } \\
\text { (DM) }\end{array}$} & bis 1500 & 46 & 6,5 & \multirow{5}{*}{0,849} & 0,67 & $0,15-2,97$ \\
\hline & $1500-2500$ & 83 & 12,0 & & 1,32 & $0,42-4,09$ \\
\hline & $2500-3500$ & 123 & 8,1 & & 0,85 & $0,28-2,62$ \\
\hline & $3500-4500$ & 65 & 9,2 & & 0,98 & $0,28-3,40$ \\
\hline & $>4500$ & 53 & 9,4 & & 1 & \\
\hline \multirow{3}{*}{$\begin{array}{l}\text { Passivrauchen } \\
\text { i.d.SS. }\end{array}$} & nie & 96 & 9,4 & \multirow{3}{*}{0,904} & 1 & \\
\hline & selten & 263 & 8,0 & & 0,84 & $0,37-1,90$ \\
\hline & öfters & 61 & 9,0 & & 0,95 & $0,32-2,81$ \\
\hline \multirow{3}{*}{$\begin{array}{l}\text { Geburtsgewicht } \\
\text { (g) }\end{array}$} & $<2500$ & 24 & 8,3 & \multirow{3}{*}{0,997} & 1 & \\
\hline & $2500-4000$ & 266 & 8,3 & & 0,99 & $0,22-4,50$ \\
\hline & $>4000$ & 38 & 7,9 & & 0,94 & $0,15-6,10$ \\
\hline
\end{tabular}

Tabelle A.7: Mittlere Hämoglobinkonzentrationen der Mütter bei unterschiedlichen gruppenbildenden Variablen mit Standardabweichungen und 95-\%-Konfidenzintervallen in g/dl sowie Signifikanzen von Levene-Test und ANOVA.

\begin{tabular}{|c|c|c|c|c|c|c|c|c|}
\hline \multicolumn{9}{|c|}{ Mittelwerte in Untergruppen: $\mathrm{Hb}$ (g/dl) } \\
\hline \multirow{2}{*}{\multicolumn{2}{|c|}{ Einflußgrößen }} & & & & & \multirow[b]{2}{*}{$\mathrm{n}_{\text {gesamt }}$} & \multirow{2}{*}{$\frac{\text { Levene-Test }}{\mathrm{p}}$} & \multirow{2}{*}{$\frac{\mathrm{ANOVA}}{\mathrm{p}}$} \\
\hline & & $\mathrm{n}$ & $\bar{y}$ & SD & $95 \%$-CI & & & \\
\hline \multirow{3}{*}{ Alkoholkonsum p.p. } & nie & 156 & 13,4 & 1,21 & $13,2-13,6$ & \multirow{3}{*}{420} & \multirow{3}{*}{0,116} & \multirow{3}{*}{0,000} \\
\hline & selten & 232 & 14,0 & 1,15 & $13,8-14,1$ & & & \\
\hline & öfters & 32 & 13,9 & 0,70 & $13,6-14,1$ & & & \\
\hline \multirow{4}{*}{$\begin{array}{l}\text { Body-Mass-Index der } \\
\text { Mutter }\end{array}$} & $<19,8$ & 81 & 13,5 & 1,08 & $13,3-13,8$ & \multirow{4}{*}{404} & \multirow{4}{*}{0,230} & \multirow{4}{*}{0,011} \\
\hline & 19,8 bis 26,0 & 236 & 13,7 & 1,15 & $13,6-13,9$ & & & \\
\hline & 26,01 bis 29 & 53 & 13,9 & 1,09 & $13,6-14,2$ & & & \\
\hline & $>29$ & 34 & 14,3 & 1,49 & $13,8-14,8$ & & & \\
\hline \multirow{2}{*}{ Nationalität } & andere & 77 & 13,4 & 1,31 & $13,2-13,7$ & \multirow{2}{*}{422} & \multirow{2}{*}{0,248} & \multirow{2}{*}{0,013} \\
\hline & deutsch & 345 & 13,8 & 1,10 & $13,6-14,1$ & & & \\
\hline \multirow{2}{*}{ Rauchen zur Zeit } & ja & 148 & 13,9 & 1,09 & $13,7-14,1$ & \multirow{2}{*}{423} & \multirow{2}{*}{0,927} & \multirow{2}{*}{0,045} \\
\hline & nein & 275 & 13,7 & 1,17 & $13,5-13,8$ & & & \\
\hline \multirow{4}{*}{ Alter (Jahre) } & bis 24 & 61 & 13,6 & 1,45 & $13,2-13,9$ & \multirow{4}{*}{408} & \multirow{4}{*}{0,311} & \multirow{4}{*}{0,059} \\
\hline & 25 bis 29 & 154 & 13,6 & 1,08 & $13,4-13,8$ & & & \\
\hline & 30 bis 34 & 128 & 13,9 & 1,09 & $13,7-14,1$ & & & \\
\hline & ab 35 & 50 & 13,8 & 0.98 & $13,6-14,1$ & & & \\
\hline \multirow{4}{*}{ Berufsausbildung } & (noch) keine & 80 & 13,5 & 1,28 & $13,2-13,8$ & \multirow{4}{*}{374} & \multirow{4}{*}{0,147} & \multirow{4}{*}{0,060} \\
\hline & Lehre & 157 & 13,8 & 1,10 & $13,6-14,0$ & & & \\
\hline & Fachschule & 60 & 14,0 & 1,31 & $13,7-14,4$ & & & \\
\hline & Hochschule & 77 & 13,7 & 1,00 & $13,4-13,9$ & & & \\
\hline \multirow{2}{*}{ Rauchen i.d.SS. } & ja & 114 & 13,9 & 1,05 & $13,7-14,1$ & \multirow{2}{*}{423} & & 0069 \\
\hline & nein & 309 & 13,7 & 1,18 & $13,5-13,8$ & & 0,720 & 0,069 \\
\hline & ausschließlich & 5 & 13,0 & 0,68 & $12,1-13,8$ & & & \\
\hline & vorwiegend & 45 & 13,5 & 0,90 & $13,2-13,8$ & & & \\
\hline Vegetarısche Ernăhrung & selten & 147 & 13,9 & 1,27 & $13,7-14,1$ & 422 & 0,470 & 0,117 \\
\hline & gar nicht & 225 & 13,8 & 1,13 & $13,6-13,9$ & & & \\
\hline
\end{tabular}




\begin{tabular}{|c|c|c|c|c|c|c|c|c|}
\hline \multicolumn{9}{|c|}{ Fortsetzung Tabelle A.7: Mittelwerte in Untergruppen: $\mathrm{Hb}$ (g/dl) } \\
\hline \multirow{2}{*}{\multicolumn{2}{|c|}{ Einflußgrößen }} & \multirow[b]{2}{*}{$\mathrm{n}$} & \multirow[b]{2}{*}{$\overline{\mathrm{y}}$} & \multirow[b]{2}{*}{ SD } & \multirow[b]{2}{*}{$95 \%-\mathrm{CI}$} & \multirow[b]{2}{*}{$\mathrm{n}_{\text {gesamt }}$} & \multirow{2}{*}{$\frac{\text { Levene-Test }}{\mathrm{p}}$} & \multirow{2}{*}{$\frac{\mathrm{ANOVA}}{\mathrm{p}}$} \\
\hline & & & & & & & & \\
\hline \multirow{6}{*}{$\begin{array}{l}\text { Familiennettoeinkommen } \\
\text { (DM) }\end{array}$} & bis 1500 & 46 & 13,8 & 1,32 & $13,4-14,2$ & \multirow{6}{*}{369} & \multirow{6}{*}{0,228} & \multirow{6}{*}{0,154} \\
\hline & 1500 bis 2500 & 81 & 13,5 & 0,97 & $13,3-13,7$ & & & \\
\hline & 2500 bis 3500 & 123 & 13,7 & 0,99 & $13,6-13,9$ & & & \\
\hline & 3500 bis 4500 & 67 & 14,0 & 1,31 & $13,7-14,3$ & & & \\
\hline & 4500 bis 5500 & 31 & 13,7 & 1,08 & $13,3-14,1$ & & & \\
\hline & mehr als 5500 & 21 & 13,8 & 1,03 & $13,3-14,2$ & & & \\
\hline \multirow{3}{*}{ Passivrauchen i.d.SS. } & nie & 95 & 13,6 & 1,05 & $13,4-13,8$ & \multirow{3}{*}{420} & \multirow{3}{*}{0,863} & \multirow{3}{*}{0,246} \\
\hline & selten & 261 & 13,8 & 1,17 & $13,6-13,9$ & & & \\
\hline & öfters & 64 & 13,8 & 1,07 & $13,5-14,0$ & & & \\
\hline \multirow{5}{*}{ Schulabschluß } & ohne Abschluß & 17 & 13,3 & 0,80 & $12,9-13,7$ & \multirow{5}{*}{383} & \multirow{5}{*}{0,154} & \multirow{5}{*}{0,323} \\
\hline & Volks-/Hauptschulabschluß & 69 & 13,7 & 1,18 & $13,4-14,0$ & & & \\
\hline & Realschulabschluß & 131 & 13,9 & 1,24 & $13,7-14,1$ & & & \\
\hline & Fachhochschulreife & 31 & 13,6 & 1,33 & $13,2-14,1$ & & & \\
\hline & Abitur & 135 & 13,7 & 1,00 & $13,6-13,9$ & & & \\
\hline & ja, regelmäßig & 303 & 13,7 & 1,12 & $13,6-13,9$ & & & \\
\hline Einsetzen der Menstruation & ja, unregelmäßig & 77 & 13,9 & 1,25 & $13,6-14,2$ & 415 & 0,476 & 0,346 \\
\hline p.p. & nein, gar nicht & 35 & 13,7 & 0,82 & $13,4-13,9$ & & & \\
\hline & 0 bis 1 & 56 & 13,8 & 1,13 & $13,5-14,1$ & & & \\
\hline & 2 bis 4 & 100 & 13,9 & 1,29 & $13,6-14,1$ & & & \\
\hline Stilldauer (Monate) & 5 bis 6 & 76 & 13,5 & 1,19 & $13,3-13,8$ & 392 & 0,200 & 0,402 \\
\hline & 7 bis 9 & 81 & 13,8 & 1,09 & $13,5-14,0$ & & & \\
\hline & über 9 & 79 & 13,8 & 0,96 & $13,6-14,0$ & & & \\
\hline & kaum Blutungen & 10 & 13,3 & 0,92 & $12,6-14,0$ & & & \\
\hline $\begin{array}{l}\text { Stärke der } \\
\text { Menctruation }\end{array}$ & mäßig Blutungen & 216 & 13,8 & 1,21 & $13,6-13,9$ & 361 & 0,075 & 0,410 \\
\hline & starke Blutungen & 135 & 13,8 & 1,00 & $13,6-14,0$ & & & \\
\hline Berufctötickeit & nein & 338 & 13,7 & 1,17 & $13,6-13,8$ & & 0.633 & 0.451 \\
\hline Berutstătigkeit & ja & 82 & 13,8 & 1,10 & $13,6-14,1$ & 420 & 0,633 & 0,451 \\
\hline & nie & 302 & 13,7 & 1,22 & $13,6-13,9$ & & & \\
\hline Alkoholkonsum i.d.SS. & selten & 113 & 13,9 & 1,00 & $13,7-14,0$ & 419 & 0,033 & 0,502 \\
\hline & öfters & 4 & 13,4 & 0,57 & $12,5-14,3$ & & & \\
\hline & $<2500$ & 29 & 14,0 & 0,96 & $13,6-14,3$ & & & \\
\hline Geburtsgewicht (g) & $2500-4000$ & 256 & 13,7 & 1,19 & $13,6-13,9$ & 326 & 0,681 & 0,513 \\
\hline & $>4000$ & 41 & 13,8 & 1,32 & $13,4-14,3$ & & & \\
\hline & eins & 139 & 13,8 & 1,06 & $13,6-14,0$ & & & \\
\hline Zahl der Kinder & zwei & 117 & 13,7 & 1,31 & $13,5-14,0$ & 307 & 0,294 & 0,699 \\
\hline & drei oder mehr & 51 & 13,7 & 1,00 & $13,4-13,9$ & & & \\
\hline Snort n n & ja & 101 & 13,8 & 1,11 & $13,6-14,0$ & 124 & 0735 & 7 701 \\
\hline Sport p.p. & nein & 323 & 13,7 & 1,18 & $13,6-13,9$ & 424 & 0,735 & 0,701 \\
\hline & bis 37 & 48 & 13,7 & 1,25 & $13,3-14,0$ & & & \\
\hline & 38 & 27 & 13,6 & 0,93 & $13,2-13,9$ & & & \\
\hline Schwangerschaftsdauer & 39 & 52 & 13,7 & 1,15 & $13,4-14,0$ & 321 & 0,418 & 0,933 \\
\hline (Wochen) & $40 / 41$ & 154 & 13,8 & 1,11 & $13,6-13,9$ & & & \\
\hline & ab 42 & 40 & 13,8 & 1,39 & $13,3-14,2$ & & & \\
\hline & ja & 68 & 13,8 & 1,06 & $13,5-14,0$ & & 0,560 & 0.965 \\
\hline & nein & 357 & 13,7 & 1,18 & $13,6-13,9$ & 425 & 0,560 & 0,965 \\
\hline
\end{tabular}


Tabelle A.8: Unterschiede der mittleren Konzentrationen des löslichen Transferrinrezeptors der Mütter bei unterschiedlichen gruppenbildenden Einflußvariablen mit Standardabweichung und 95\%-Konfidenzintervallen in mg/l sowie Signifikanzen von Levene-Test und ANOVA.

\begin{tabular}{|c|c|c|c|c|c|c|c|c|}
\hline \multicolumn{9}{|c|}{ Mittelwerte in Untergruppen: sTfR (mg/l) } \\
\hline \multirow{2}{*}{\multicolumn{2}{|c|}{ Einflußgrößen }} & \multirow[b]{2}{*}{$\mathrm{n}$} & \multirow[b]{2}{*}{$\overline{\mathrm{y}}$} & \multirow[b]{2}{*}{ SD } & \multirow[b]{2}{*}{$95 \%-\mathrm{CI}$} & \multirow[b]{2}{*}{$\mathrm{n}_{\text {gesamt }}$} & \multirow{2}{*}{$\frac{\text { Levene-Test }}{\mathrm{p}}$} & \multirow{2}{*}{$\frac{\text { ANOVA }}{p}$} \\
\hline & & & & & & & & \\
\hline \multirow{3}{*}{ Alkoholkonsum p.p. } & nie & 153 & 2,5 & 1,18 & $2,3-2,7$ & \multirow{3}{*}{425} & \multirow{3}{*}{0,068} & \multirow{3}{*}{0,000} \\
\hline & selten & 237 & 2,1 & 1,00 & $2,0-2,2$ & & & \\
\hline & öfters & 35 & 1,7 & 0,61 & $1,5-1,9$ & & & \\
\hline \multirow{2}{*}{ Nationalität } & andere & 78 & 2,5 & 1,29 & $2,2-2,8$ & \multirow{2}{*}{427} & \multirow{2}{*}{0,123} & \multirow{2}{*}{0,004} \\
\hline & deutsch & 349 & 2,1 & 1,01 & $2,0-2,2$ & & & \\
\hline \multirow{3}{*}{ Zahl der Kinder } & eins & 140 & 2,0 & 0,94 & $1,9-2,2$ & \multirow{3}{*}{308} & & \\
\hline & zwei & 114 & 2,2 & 1,09 & $2,0-2,4$ & & 0,110 & 0,013 \\
\hline & drei oder mehr & 54 & 2,6 & 1,37 & $2,2-2,9$ & & & \\
\hline Finsetzen der Menstruation & ja, regelmäßig & 312 & 2,2 & 1,06 & $2,1-2,3$ & & & \\
\hline Einsetzen der Menstruation & ja, unregelmäßig & 76 & 2,0 & 0,69 & $1,9-2,2$ & 422 & 0,063 & 0,034 \\
\hline p.p. & nein, gar nicht & 34 & 2,6 & 1,27 & $2,1-3,0$ & & & \\
\hline & ja & 149 & 2,1 & 0,98 & $1,9-2,2$ & & & \\
\hline Rauchen zur Zeit & nein & 279 & 2,3 & 1,10 & $2,1-2,4$ & 428 & 0,268 & 0,069 \\
\hline & ohne Abschluß & 17 & 2,7 & 1,30 & $2,1-3,4$ & & & \\
\hline & Volks-/Hauptschulabschluß & 70 & 2,3 & 1,17 & $2,1-2,6$ & & & \\
\hline Schulabschluß & Realschulabschluß & 136 & 2,2 & 1,20 & $2,0-2,4$ & 388 & 0,062 & 0,140 \\
\hline & Fachhochschulreife & 31 & 2,2 & 1,26 & $1,7-2,6$ & & & \\
\hline & Abitur & 134 & 2,1 & 0,84 & $1,9-2,2$ & & & \\
\hline Doushen id SC & ja & 116 & 2,1 & 0,97 & $1,9-2,2$ & 120 & 0228 & 0140 \\
\hline Kaucnen 1.d.ss. & nein & 312 & 2,2 & 1,10 & $2,1-2,4$ & 428 & $0,2<0$ & 0,142 \\
\hline & nie & 305 & 2,3 & 1,06 & $2,1-2,4$ & & & \\
\hline Alkoholkonsum i.d.SS. & selten & 115 & 2,1 & 1,09 & $1,9-2,3$ & 424 & 0,515 & 0,143 \\
\hline & öfters & 4 & 1,5 & 0,42 & $0,8-2,2$ & & & \\
\hline & bis 24 & 64 & 2,4 & 1,49 & $2,1-2,8$ & & & \\
\hline Alter (Jahre) & 25 bis 29 & 135 & 2,1 & 0,84 & $2,0-2,3$ & 414 & 0000 & 0147 \\
\hline Alter (Janre) & 30 bis 34 & 151 & 2,1 & 0,86 & $2,0-2,3$ & 414 & 0,000 & $0,14 /$ \\
\hline & $\mathrm{ab} 35$ & 61 & 2,3 & 1,26 & $1,9-2,6$ & & & \\
\hline & bis 17 & 6 & 1,7 & 0,33 & $1,3-2,0$ & & & \\
\hline & 18 bis 21 & 116 & 2,2 & 1,09 & $2,0-2,4$ & & & \\
\hline Body-Mass-Index der & 22 bis 25 & 120 & 2,1 & 1,06 & $1,9-2,3$ & 410 & 0,685 & 0,214 \\
\hline Mutter & 26 bis 29 & 51 & 2,4 & 1,33 & $2,0-2,8$ & & & \\
\hline & ab 30 & 29 & 2,4 & 1,03 & $2,0-2,8$ & & & \\
\hline & nein & 342 & 2,2 & 1,08 & $2,1-2,4$ & & & \\
\hline Berufstätigkeit & ja & 83 & 2,1 & 1,05 & $1,9-2,3$ & 425 & 0,492 & 0,298 \\
\hline & (noch) keine & 87 & 2,3 & 1,22 & $2,1-2,6$ & & & \\
\hline Berufcaushildung & Lehre & 158 & 2,2 & 1,01 & $2,0-2,3$ & 201 & 0036 & 0309 \\
\hline Berutsausbildung & Fachschule & 62 & 2,2 & 1,11 & $1,9-2,5$ & 381 & 0,036 & 0,392 \\
\hline & Hochschule & 74 & 2,1 & 0,71 & $1,9-2,2$ & & & \\
\hline & ausschließlich & 6 & 2,7 & 1,56 & $1,1-4,4$ & & & \\
\hline Vegetarische Frnährung & vorwiegend & 44 & 2,3 & 0,85 & $2,0-2,6$ & 120 & 0055 & 0402 \\
\hline Vegetarısche Ernăhrung & selten & 149 & 2,1 & 0,97 & $2,0-2,3$ & 429 & 0,055 & 0,402 \\
\hline & gar nicht & 230 & 2,2 & 1,11 & $2,1-2,4$ & & & \\
\hline & $<2500$ & 24 & 2,4 & 0,86 & $2,0-2,7$ & & & \\
\hline Geburtsgewicht (g) & $2500-4000$ & 266 & 2,2 & 0,99 & $2,0-2,3$ & 328 & 0,859 & 0,500 \\
\hline & $>4000$ & 38 & 2,1 & 1,04 & $1,8-2,4$ & & & \\
\hline & kaum Blutungen & 10 & 2,2 & 1,37 & $1,3-3,2$ & & & \\
\hline $\begin{array}{l}\text { Starke der } \\
\text { Menstruationsblutung }\end{array}$ & mäßig Blutungen & 217 & 2,1 & 0,85 & $2,0-2,2$ & 368 & 0,063 & 0,684 \\
\hline Menstruationsblutung & starke Blutungen & 141 & 2,2 & 1,08 & $2,0-2,3$ & & & \\
\hline
\end{tabular}




\begin{tabular}{|c|c|c|c|c|c|c|c|c|}
\hline \multicolumn{9}{|c|}{ Fortsetzung Tabelle A.8: Mittelwerte in Untergruppen: sTfR (mg/l) } \\
\hline \multirow{2}{*}{\multicolumn{2}{|c|}{ Einflußgrößen }} & \multirow[b]{2}{*}{$\mathrm{n}$} & \multirow[b]{2}{*}{$\overline{\mathrm{y}}$} & \multirow[b]{2}{*}{ SD } & \multirow[b]{2}{*}{$95 \%$-CI } & \multirow[b]{2}{*}{$\mathrm{n}_{\text {gesamt }}$} & \multirow{2}{*}{$\frac{\text { Levene-Test }}{\mathrm{p}}$} & \multirow{2}{*}{$\frac{\text { ANOVA }}{p}$} \\
\hline & & & & & & & & \\
\hline \multirow{2}{*}{ Sport i.d.SS. } & ja & 72 & 2,2 & 1,03 & $1,9-2,4$ & \multirow{2}{*}{430} & \multirow{2}{*}{0,803} & \multirow{2}{*}{0,791} \\
\hline & nein & 358 & 2,2 & 1,07 & $2,1-2,3$ & & & \\
\hline \multirow{3}{*}{ Passivrauchen i.d.SS. } & nie & 96 & 2,2 & 1,03 & $2,0-2,4$ & \multirow{3}{*}{426} & \multirow{3}{*}{0,826} & \multirow{3}{*}{0,829} \\
\hline & selten & 263 & 2,2 & 1,06 & $2,1-2,6$ & & & \\
\hline & öfters & 67 & 2,1 & 1,17 & $1,8-2,4$ & & & \\
\hline \multirow{5}{*}{$\begin{array}{l}\text { Schwangerschaftsdauer } \\
\text { (Wochen) }\end{array}$} & bis 37 & 44 & 2,3 & 0,86 & $2,0-2,5$ & \multirow{5}{*}{321} & \multirow{5}{*}{0,225} & \multirow{5}{*}{0,862} \\
\hline & 38 & 28 & 2,2 & 0,69 & $2,0-2,5$ & & & \\
\hline & 39 & 53 & 2,1 & 0,75 & $1,9-2,3$ & & & \\
\hline & $40 / 41$ & 157 & 2,2 & 1,14 & $2,0-2,4$ & & & \\
\hline & ab 42 & 39 & 2,2 & 1,02 & $1,9-2,5$ & & & \\
\hline \multirow{2}{*}{ Sport p.p. } & ja & 104 & 2,2 & 0,91 & $2,0-2,4$ & \multirow{2}{*}{429} & \multirow{2}{*}{0,524} & \multirow{2}{*}{0,904} \\
\hline & nein & 325 & 2,2 & 1,11 & $2,1-2,3$ & & & \\
\hline \multirow{6}{*}{$\begin{array}{l}\text { Familiennettoeinkommen } \\
\text { (DM) }\end{array}$} & bis 1500 & 47 & 2,2 & 1,00 & $1,9-2,5$ & \multirow{6}{*}{370} & \multirow{6}{*}{0,798} & \multirow{6}{*}{0,908} \\
\hline & 1500 bis 2500 & 83 & 2,2 & 1,22 & $2,0-2,5$ & & & \\
\hline & 2500 bis 3500 & 123 & 2,2 & 0,97 & $2,1-2,4$ & & & \\
\hline & 3500 bis 4500 & 64 & 2,2 & 1,06 & $1,9-2,4$ & & & \\
\hline & 4500 bis 5500 & 32 & 2,1 & 1,08 & $1,7-2,4$ & & & \\
\hline & mehr als 5500 & 21 & 2,0 & 0,93 & $1,6-2,4$ & & & \\
\hline \multirow{5}{*}{ Stilldauer (Monate) } & 0 bis 1 & 57 & 2,2 & 1,07 & $1,9-2,5$ & \multirow{5}{*}{395} & \multirow{5}{*}{0,226} & \\
\hline & 2 bis 4 & 108 & 2,2 & 1,09 & $2,0-2,4$ & & & \\
\hline & 5 bis 6 & 75 & 2,2 & 1,11 & $2,0-2,5$ & & & 0,987 \\
\hline & 7 bis 9 & 79 & 2,2 & 0,87 & $2,0-2,4$ & & & \\
\hline & über 9 & 76 & 2,1 & 0,82 & $1,9-2,3$ & & & \\
\hline
\end{tabular}

Tabelle A.9: Mittlere minimale Hämoglobinkonzentrationen in der Schwangerschaft bei unterschiedlichen gruppenbildenden Variablen mit Standardabweichungen und 95\%-Konfidenzintervallen in g/dl.

\begin{tabular}{|c|c|c|c|c|c|c|c|c|}
\hline \multicolumn{9}{|c|}{ Mittelwerte in Untergruppen: $\mathbf{H b}_{\min }(\mathrm{g} / \mathrm{dl})$} \\
\hline \multirow{2}{*}{\multicolumn{2}{|c|}{ Einflußgrößen }} & \multirow[b]{2}{*}{$\mathrm{n}$} & \multirow[b]{2}{*}{$\bar{y}$} & \multirow[b]{2}{*}{ SD } & \multirow[b]{2}{*}{$95 \%$-CI } & \multirow[b]{2}{*}{$\mathrm{n}_{\text {gesamt }}$} & \multirow{2}{*}{$\frac{\text { Levene-Test }}{\mathrm{p}}$} & \multirow{2}{*}{$\frac{\text { ANOVA }}{p}$} \\
\hline & & & & & & & & \\
\hline \multirow{4}{*}{ Body-Mass-Index } & $<19,8$ & 72 & 11,0 & 0,91 & $10,8-11,2$ & \multirow{4}{*}{368} & \multirow{4}{*}{0,610} & \multirow{4}{*}{0,001} \\
\hline & $19,8-26$ & 220 & 11,1 & 1,03 & $11,0-11,3$ & & & \\
\hline & $>26-29$ & 46 & 11,3 & 0,93 & $11,1-11,6$ & & & \\
\hline & $>29$ & 30 & 11,9 & 1,16 & $11,4-12,3$ & & & \\
\hline \multirow{2}{*}{ Nationalität } & andere & 61 & 10,8 & 1,12 & $10,6-11,1$ & \multirow{2}{*}{378} & \multirow{2}{*}{0,765} & \multirow{2}{*}{0,003} \\
\hline & deutsch & 317 & 11,3 & 1,01 & $11,2-11,4$ & & & \\
\hline \multirow{4}{*}{ Vegetarische Ernährung } & ausschließlich & 5 & 10,9 & 0,65 & $10,1-11,7$ & \multirow{4}{*}{381} & \multirow{4}{*}{0,407} & \multirow{4}{*}{0,011} \\
\hline & vorwiegend & 37 & 11,0 & 0,89 & $10,7-11,3$ & & & \\
\hline & selten & 129 & 11,5 & 1,04 & $11,3-11,6$ & & & \\
\hline & gar nicht & 210 & 11,1 & 1,04 & $11,0-11,2$ & & & \\
\hline \multirow{3}{*}{ Alkoholkonsum i.d.SS. } & nie & 268 & 11,2 & 1,08 & $11,0-11,3$ & \multirow{3}{*}{379} & \multirow{3}{*}{0,200} & \multirow{3}{*}{0,022} \\
\hline & selten & 108 & 11,4 & 0,89 & $11,2-11,5$ & & & \\
\hline & öfters & 3 & 9,9 & 0,55 & $8,5-11,2$ & & & \\
\hline \multirow{4}{*}{ Alter (Jahre) } & bis 24 & 53 & 11,1 & 0,95 & $10,9-11,4$ & \multirow{4}{*}{365} & \multirow{4}{*}{0,354} & \multirow{4}{*}{0,023} \\
\hline & 25 bis 29 & 124 & 11,3 & 1,12 & $11,1-11,5$ & & & \\
\hline & 30 bis 34 & 138 & 11,3 & 1,00 & $11,1-11,5$ & & & \\
\hline & ab 35 & 50 & 10,8 & 0,84 & $10,6-11,1$ & & & \\
\hline \multirow{4}{*}{ Berufsausbildung } & (noch) keine & 73 & 11,0 & 1,06 & $10,8-11,3$ & \multirow{4}{*}{338} & \multirow{4}{*}{0,724} & \\
\hline & Lehre & 145 & 11,3 & 1,05 & $11,1-11,5$ & & & \\
\hline & Fachschule & 56 & 11,4 & 0,97 & $11,2-11,7$ & & & 0,083 \\
\hline & Hochschule & 64 & 11,3 & 0,90 & $11,1-11,5$ & & & \\
\hline Snort id SS & ja & 67 & 11,3 & 0,92 & $11,1-11,6$ & & 0342 & 0219 \\
\hline Sport 1.d.Ss. & nein & 316 & 11,2 & 1,06 & $11,1-11,3$ & 383 & 0,342 & 0,219 \\
\hline
\end{tabular}




\begin{tabular}{|c|c|c|c|c|c|c|c|c|}
\hline \multicolumn{9}{|c|}{ Fortsetzung Tabelle A.9: Mittelwerte in Untergruppen: $\mathrm{Hb}_{\min }(\mathrm{g} / \mathrm{dl})$} \\
\hline \multirow{2}{*}{\multicolumn{2}{|c|}{ Einflußgrößen }} & \multirow[b]{2}{*}{$\mathrm{n}$} & \multirow[b]{2}{*}{$\bar{y}$} & \multirow[b]{2}{*}{$\mathrm{s}$} & \multirow[b]{2}{*}{ 95\%-CI } & \multirow[b]{2}{*}{$\mathrm{n}_{\text {gesamt }}$} & \multirow{2}{*}{$\frac{\text { Levene-Test }}{\mathrm{p}}$} & \multirow{2}{*}{$\frac{\mathrm{ANOVA}}{\mathrm{p}}$} \\
\hline & & & & & & & & \\
\hline \multirow{2}{*}{ Rauchen i.d.SS. } & ja & 111 & 11,3 & 1,07 & $11,1-11,5$ & \multirow{2}{*}{381} & \multirow{2}{*}{0,404} & \multirow{2}{*}{0,225} \\
\hline & nein & 270 & 11,2 & 1,03 & $11,0-11,3$ & & & \\
\hline \multirow{6}{*}{$\begin{array}{l}\text { Familiennettoeinkommen } \\
\text { (DM) }\end{array}$} & bis 1500 & 42 & 11,0 & 0,91 & $10,7-11,3$ & \multirow{6}{*}{329} & \multirow{6}{*}{0,703} & \multirow{6}{*}{0,241} \\
\hline & 1500 bis 2500 & 73 & 11,1 & 0,91 & $10,9-11,3$ & & & \\
\hline & 2500 bis 3500 & 110 & 11,2 & 1,10 & $11,0-11,5$ & & & \\
\hline & 3500 bis 4500 & 57 & 11,4 & 1,14 & $11,1-11,7$ & & & \\
\hline & 4500 bis 5500 & 30 & 11,4 & 1,01 & $11,0-11,8$ & & & \\
\hline & mehr als 5500 & 17 & 10,8 & 0,79 & $10,4-11,2$ & & & \\
\hline \multirow{5}{*}{ Schulabschluß } & ohne Abschluß & 13 & 11,0 & 0,91 & $10,4-11,5$ & \multirow{5}{*}{343} & \multirow{5}{*}{0,632} & \multirow{5}{*}{0,258} \\
\hline & Volks-/Hauptschulabschluß & 59 & 11,1 & 0,95 & $10,9-11,4$ & & & \\
\hline & Realschulabschluß & 122 & 11,3 & 1,10 & $11,1-11,5$ & & & \\
\hline & Fachhochschulreife & 28 & 10,9 & 0,87 & $10,6-11,3$ & & & \\
\hline & Abitur & 121 & 11,2 & 1,02 & $11,1-11,4$ & & & \\
\hline \multirow{3}{*}{ Geburtsgewicht (g) } & $<2500$ & 27 & 11,4 & 1,45 & $10,8-11,9$ & \multirow{3}{*}{326} & \multirow{3}{*}{0,079} & \multirow{3}{*}{0,571} \\
\hline & $2500-4000$ & 259 & 11,2 & 1,05 & $11,1-11,3$ & & & \\
\hline & $>4000$ & 40 & 11,1 & 1,13 & $10,7-11,4$ & & & \\
\hline \multirow{5}{*}{$\begin{array}{l}\text { Schwangerschaftsdauer } \\
\text { (Wochen) }\end{array}$} & bis 37 & 45 & 11,0 & 1,45 & $10,6-11,5$ & \multirow{5}{*}{319} & \multirow{5}{*}{0,039} & \multirow{5}{*}{0,583} \\
\hline & 38 & 27 & 11,1 & 1,33 & $10,5-11,6$ & & & \\
\hline & 39 & 51 & 11,4 & 0,95 & $11,1-11,6$ & & & \\
\hline & $40 / 41$ & 159 & 11,2 & 0,96 & $11,0-11,3$ & & & \\
\hline & $\mathrm{ab} 42$ & 37 & 11,3 & 1,16 & $10,9-11,7$ & & & \\
\hline \multirow{3}{*}{ Zahl der Kinder } & eins & 131 & 11,2 & 1,03 & $11,0-11,4$ & & & \\
\hline & zwei & 96 & 11,1 & 1,08 & $10,9-11,3$ & 269 & 0,982 & 0,667 \\
\hline & drei oder mehr & 42 & 11,2 & 0,97 & $10,9-11,5$ & & & \\
\hline & nie & 84 & 11,2 & 0,92 & $10,9-11,4$ & & & \\
\hline Passivrauchen i.d.SS. & selten & 234 & 11,2 & 1,10 & $11,1-11,4$ & 379 & 0,254 & 0,874 \\
\hline & öfters & 61 & 11,2 & 0,99 & $10,9-11,5$ & & & \\
\hline
\end{tabular}

Tabelle A.10: Charakteristik der Mütter mit Eisenmangelanämie.

\begin{tabular}{|c|c|c|c|c|c|}
\hline \multicolumn{6}{|c|}{ Fallbeispiele } \\
\hline & Fall 1 & Fall 2 & Fortsetzung & Fall 1 & Fall2 \\
\hline $\mathrm{Hb}(\mathrm{g} / \mathrm{dl})$ & 11,6 & 10,2 & Fleisch p.p. (Tage) & 1 & 3 \\
\hline sTfR (mg/l) & 5,29 & 8,5 & Vegetarische Ernährung & vorwiegend & selten \\
\hline Ferritin (ng/l) & 6,0 & 5,0 & Eisen i.d.SS. & ja & ja \\
\hline MCV (fl) & 78 & 67 & Magnesium i.d.SS. & ja & ja \\
\hline $\operatorname{Trfs}(\%)$ & 11,19 & 4,76 & Jod i.d.SS. & ja & - \\
\hline $\mathrm{Hb}_{\min }(\mathrm{g} / \mathrm{dl})$ & 10,1 & 11,0 & Gewichtszunahme i.d.SS. (kg) & 9,9 & 6,0 \\
\hline Alter (Jahre) & 37 & 36 & Body-Mass-Index & 20,1 & 22,2 \\
\hline feste Partnerschaft & ja & ja & Alkohol i.d.SS. & nie & nie \\
\hline Nationalität & deutsch & afrikanisch & Alkohol p.p. & selten & nie \\
\hline Wohnsitz in Deutschland seit & 1961 & 1990 & Rauchen i.d.SS. & nein & nein \\
\hline Wohnbezirk & Teltow & Kreuzberg & Rauchen p.p. & nein & nein \\
\hline Schulabschluß & Abitur & Realschulabschluß & Passivrauchen i.d.SS. & nie & nie \\
\hline Berufsausbildung & Hochschule & - & Menstruation: Einsetzen p.p. & regelmäßig & regelmäßig \\
\hline Berufstätigkeit & ja & nein & Blutungsdauer (Tage) & 3 & 4 \\
\hline Familiennettoeinkommen (DM) & 6000 & 2500 & Blutungsstärke & kaum & mäßig \\
\hline Kinderzahl & 2 & 4 & Zyklusdauer (Tage) & 30 & 24 \\
\hline Stilldauer & 6 & 0 & Sport i.d.SS. & nein & nein \\
\hline Fleisch i.d.SS. (Tage) & 1 & 1 & Sport p.p. & nein & nein \\
\hline
\end{tabular}


Tabelle A.12: Korrelationen zwischen den Hämoglobinkonzentrationen und den Konzentrationen des löslichen Transferrinrezeptors bei der Mutter und bei der Mutter im Vergleich zu den Werten des Kindes.

\begin{tabular}{lcccc}
\hline \multicolumn{5}{c}{ Korrelationen: Hämoglobin und löslicher Transferrinrezeptor } \\
\hline \multirow{4}{*}{$\mathrm{Hb}$} & $\mathrm{s}$ & $-0,171$ & & $\mathrm{Hb}$ \\
& $\mathrm{p}$ & 0,000 & & \\
& $\mathrm{n}$ & 451 & & \\
\hline \multirow{3}{*}{$\mathrm{Hb}_{\min }$} & $\mathrm{r}$ & $-0,084$ & 0,253 & \\
& $\mathrm{p}$ & 0,099 & 0,000 & \\
& $\mathrm{n}$ & 390 & 381 & \\
\hline \multirow{3}{*}{$\mathrm{Hb}_{K}{ }^{1}$} & $\mathrm{r}$ & $-0,042$ & 0,218 & $-0,065$ \\
& $\mathrm{p}$ & 0,391 & 0,000 & 0,197 \\
& $\mathrm{n}$ & 427 & 433 & 394 \\
\hline \multirow{3}{*}{$\mathrm{sTfR}_{K}{ }^{2}$} & $\mathrm{r}$ & 0,139 & $-0,063$ & 0,088 \\
& $\mathrm{p}$ & 0,003 & 0,181 & 0,092 \\
& $\mathrm{n}$ & 468 & 454 & 367 \\
\hline
\end{tabular}

Tabelle A.13: Korrelationen der für die multiple lineare Regression signifikanten Einflußvariablen mit $\mathrm{Hb}$, sTfR und $\mathrm{Hb}_{\text {min }}$ der Mutter.

\begin{tabular}{|c|c|c|c|c|}
\hline \multicolumn{5}{|c|}{ Korrelation: $\mathrm{Hb}, \mathbf{s T f R}, \mathrm{Hb}_{\min }$-gruppenbildende Variablen } \\
\hline & & $\mathrm{Hb}$ & sTfr & $\mathrm{Hb}_{\text {min }}$ \\
\hline \multirow{3}{*}{ Alkoholkonsum p.p. } & $\mathrm{r}$ & 0,182 & $-0,210$ & \\
\hline & $\mathrm{p}$ & 0,000 & 0,000 & \\
\hline & $\mathrm{n}$ & 420 & 425 & \\
\hline \multirow{3}{*}{ Body-Mass-Index } & $\mathrm{r}$ & 0,138 & 0,086 & 0,194 \\
\hline & $\mathrm{p}$ & 0,005 & 0,083 & 0,000 \\
\hline & $\mathrm{n}$ & 0,405 & 0,411 & 369 \\
\hline \multirow{3}{*}{ Alter } & $\mathrm{r}$ & 0,084 & $-0,059$ & $-0,058$ \\
\hline & $\mathrm{p}$ & 0,091 & 0,232 & 0,266 \\
\hline & $\mathrm{n}$ & 408 & 414 & 365 \\
\hline \multirow{3}{*}{ Rauchen i.d.SS. } & $\mathrm{r}$ & $-0,089$ & 0,071 & $-0,062$ \\
\hline & $\mathrm{p}$ & 0,069 & 0,142 & 0,225 \\
\hline & $\mathrm{n}$ & 423 & 428 & 381 \\
\hline \multirow{3}{*}{ Alkohokonusm i.d.SS. } & $\mathrm{r}$ & 0,035 & $-0,089$ & 0,040 \\
\hline & $\mathrm{p}$ & 0,475 & 0,068 & 0,437 \\
\hline & $\mathrm{n}$ & 419 & 424 & 379 \\
\hline \multirow{3}{*}{ Zahl der Kinder } & $\mathrm{r}$ & $-0,056$ & 0,223 & $-0,067$ \\
\hline & $\mathrm{p}$ & 0,326 & 0,000 & 0,276 \\
\hline & $\mathrm{n}$ & 306 & 307 & 268 \\
\hline \multirow{3}{*}{ Geburtsgewicht } & $\mathrm{r}$ & 0,025 & $-0,016$ & $-0,083$ \\
\hline & $\mathrm{p}$ & 0,658 & 0,772 & 0,133 \\
\hline & $\mathrm{n}$ & 326 & 328 & 326 \\
\hline \multirow{3}{*}{ Berufstätigkeit } & $\mathrm{r}$ & 0,037 & $-0,051$ & 0,079 \\
\hline & $\mathrm{p}$ & 0,451 & 0,298 & 0,124 \\
\hline & $\mathrm{n}$ & 420 & 425 & 378 \\
\hline \multirow{3}{*}{ Berufstätigkeit } & $\mathrm{r}$ & & & 0,079 \\
\hline & $\mathrm{p}$ & & & 0,124 \\
\hline & $\mathrm{n}$ & & & 378 \\
\hline \multirow{3}{*}{ Geburtsgewicht } & $\mathrm{r}$ & & & $-0,083$ \\
\hline & $\mathrm{p}$ & & & 0,133 \\
\hline & $\mathrm{n}$ & & & 326 \\
\hline
\end{tabular}


Tabelle A.14: Korrelationskoeffizienten (r), Bestimmtheitsmaß $\left(\mathrm{r}^{2}\right)$, korrigiertes Bestimmtheitsmaß und Standardfehler der verschiedenen Modelle für die aktuellen Konzentrationen von Hämoglobin und löslichem Transferrinrezeptor sowie der minimalen Hämoglobinkonzentration in der Schwangerschaft

\begin{tabular}{llcccc}
\hline \multicolumn{5}{c}{ Lineare Regression: } & Bestimmtheitsmaße für $\mathbf{H b}, \mathbf{s T f R}$ und $\mathbf{H b}_{\text {min }}$ \\
\hline & Modell & $\mathrm{r}$ & $\mathrm{r}^{2}$ & korrigiertes $^{2}$ & Standarfehler des Schätzers \\
\hline \multirow{4}{*}{$\mathrm{Hb}$} & 1 & 0,171 & 0,029 & 0,026 & 1,1056 \\
& 2 & 0,230 & 0,053 & 0,047 & 1,0445 \\
& 3 & 0,251 & 0,063 & 0,054 & 1,0404 \\
& 4 & 0,268 & 0,072 & 0,060 & 1,0374 \\
& 5 & 0,283 & 0,080 & 0,065 & 1,0344 \\
\hline \multirow{3}{*}{$\mathrm{sTfR}$} & 1 & 0,161 & 0,022 & 0,048 & 0,9997 \\
& 2 & 0,206 & 0,042 & 0,034 & 0,9934 \\
$\mathrm{Hb}_{\min }$ & 1 & 0,207 & 0,043 & 0,039 & 0,9979 \\
\hline
\end{tabular}

Tabelle A.15: Varianzanalyse des linearen Zusammenhangs der Modelle in Bezug auf Hb, sTfR und $\mathrm{Hb}_{\min }$ mit Quadratsumme, Freiheitsgraden (df), Mittel der Quadrate für Regression und Residuen, F-Wert und Signifikanz (p).

\begin{tabular}{|c|c|c|c|c|c|c|c|}
\hline \multicolumn{8}{|c|}{ Lineare Regression: Varianzanalyse für $\mathrm{Hb}$, sTfR und $\mathrm{Hb}_{\min }$} \\
\hline & \multirow[b]{2}{*}{ Modell } & \multirow[b]{2}{*}{ Quadratsumme } & \multirow[b]{2}{*}{ df } & \multicolumn{2}{|c|}{ Mittel der Quadrate } & \multirow[b]{2}{*}{ F-Wert } & \multirow[b]{2}{*}{$\mathrm{p}$} \\
\hline & & & & Regression & Residuen & & \\
\hline \multirow{6}{*}{$\mathrm{Hb}$} & 1 & 10,396 & 1 & 10,396 & 1,114 & 9,329 & 0,002 \\
\hline & 2 & 18,743 & 2 & 9,371 & 1,091 & 8,591 & 0,000 \\
\hline & 3 & 22,423 & 3 & 7,474 & 1,082 & 6,905 & 0,000 \\
\hline & 4 & 25,418 & 4 & 6,355 & 1,076 & 5,905 & 0,000 \\
\hline & 5 & 28,393 & 5 & 5,679 & 1,070 & 5,307 & 0,000 \\
\hline & gesamt & 354,736 & 310 & & & & \\
\hline \multirow{3}{*}{ sTfR } & 1 & 5,964 & 1 & 5,964 & 0,999 & 5,967 & 0,015 \\
\hline & 2 & 9,774 & 2 & 4,887 & 0,987 & 4,952 & 0,008 \\
\hline & gesamt & 230,832 & 226 & & & & \\
\hline \multirow{3}{*}{$\mathrm{Hb}_{\min }$} & 1 & 10,235 & 1 & 110,235 & 0,996 & 10,278 & 0,002 \\
\hline & 2 & 16,054 & 2 & 8,027 & 0,975 & 8,234 & 0,000 \\
\hline & gesamt & 239,280 & 231 & & & & \\
\hline
\end{tabular}

Tabelle A.16: Koeffizienten der beschriebenen Modelle für $\mathrm{Hb}$, sTfR und $\mathrm{Hb}_{\text {min }}$.

\begin{tabular}{|c|c|c|c|c|c|c|}
\hline \multicolumn{7}{|c|}{ Lineare Regression: Koeffizienten für $\mathrm{Hb}$, sTfR und $\mathrm{Hb}_{\min }$} \\
\hline & Einflußvariablen & $\mathrm{B}$ & Standardfehler von B & Beta & $\mathrm{T}$ & $\mathrm{p}$ \\
\hline \multirow{6}{*}{$\mathrm{Hb}$} & Konstante & 12,296 & 0,559 & & 21,996 & $\overline{0,000}$ \\
\hline & Alkoholkonsum p.p. & 0,403 & 0,116 & 0,220 & 3,479 & 0,001 \\
\hline & Body-Mass-Index & 0,038 & 0,014 & 0,147 & 2,651 & 0,008 \\
\hline & Alkoholkonsum i.d.SS. & $-0,268$ & 0,139 & $-0,120$ & $-1,930$ & 0,055 \\
\hline & Rauchen i.d.SS. & $-0,248$ & 0,133 & $-0,104$ & $-1,865$ & 0,063 \\
\hline & Alter & 0,027 & 0,012 & 0,094 & 1,667 & 0,096 \\
\hline \multirow{3}{*}{ sTfR } & Konstante & 2,329 & 0,280 & & 8,303 & $\overline{0,000}$ \\
\hline & Alkoholkonsum p.p. & $-0,258$ & 0,115 & $-0,147$ & $-2,238$ & 0,026 \\
\hline & Zahl der Kinder & 0,175 & 0,089 & 0,129 & 1,965 & 0,051 \\
\hline \multirow{3}{*}{$\mathrm{Hb}_{\text {min }}$} & Konstante & 10,809 & 0,448 & & 24,116 & 0,000 \\
\hline & Body-Mass-Index & 0,054 & 0,015 & 0,227 & 3,529 & 0,001 \\
\hline & Geburtsgewicht & $-0,0003$ & 0,000 & $-0,157$ & $-2,443$ & 0,015 \\
\hline
\end{tabular}


Tabelle A.17: Ausgeschlossene Variablen bei der linearen Regression von $\mathrm{Hb}$, sTfR und $\mathrm{Hb}_{\min }$ der Mutter.

\begin{tabular}{|c|c|c|c|c|c|c|c|c|c|}
\hline \multicolumn{10}{|c|}{ Lineare Regression: ausgeschlossene Variablen für $\mathrm{Hb}$, sTfR und $\mathrm{Hb}_{\min }$} \\
\hline \multirow{2}{*}{$\begin{array}{l}\text { ausgeschlossene } \\
\text { Variablen }\end{array}$} & \multicolumn{3}{|c|}{$\mathrm{Hb}$} & \multicolumn{3}{|c|}{ sTfR } & \multicolumn{3}{|c|}{$\mathrm{Hb}_{\min }$} \\
\hline & Beta ln & $T$ & $p$ & Beta ln & $\mathrm{T}$ & $p$ & Beta ln & $\mathrm{T}$ & $p$ \\
\hline Einsetzen der Menstruation p.p. & 0,057 & 1,023 & 0,307 & 0,088 & 1,340 & 0,182 & & & \\
\hline Berufstätigkeit & 0,024 & 0,419 & 0,676 & 0,028 & 0,421 & 0,674 & & & \\
\hline Rauchen zur Zeit der Befragung & $-0,021$ & $-0,259$ & 0,796 & 0,010 & 0,156 & 0,876 & & & \\
\hline Alkoholkonsum i.d.SS. & \multicolumn{3}{|c|}{ aufgenommen für $\mathrm{Hb}$} & 0,024 & 0,348 & 0,728 & 0,018 & $-0,277$ & 0,782 \\
\hline Vegetarische Ernährung & 0,036 & 0,632 & 0,528 & $-0,031$ & $-0,472$ & 0,637 & $-0,033$ & $-0,509$ & 0,611 \\
\hline Nationalität & 0,081 & 1,374 & 0,170 & 0,020 & 0,282 & 0,778 & 0,071 & 1,109 & 0,269 \\
\hline Body-Mass-Index & \multicolumn{3}{|c|}{ aufgenommen für $\mathrm{Hb}$} & $-0,001$ & $-0,008$ & 0,994 & \multicolumn{3}{|c|}{ aufgenommen für $\mathrm{Hb}_{\min }$} \\
\hline Berufsausbildung & 0,028 & 0,443 & 0,658 & 0,029 & 0,441 & 0,660 & 0,045 & 0,704 & 0,482 \\
\hline Schulabschluß & 0,029 & 0,462 & 0,644 & 0,015 & 0,225 & 0,822 & 0,068 & 1,048 & 0,296 \\
\hline Rauchen i.d.SS. & \multicolumn{3}{|c|}{ aufgenommen für $\mathrm{Hb}$} & 0,059 & 0,902 & 0,368 & $-0,019$ & $-0,298$ & 0,766 \\
\hline Alter & \multicolumn{3}{|c|}{ aufgenommen für $\mathrm{Hb}$} & 0,041 & 0,575 & 0,566 & $-0,102$ & $-1,588$ & 0,114 \\
\hline Geburtsgewicht & & & & & & & \multicolumn{3}{|c|}{ aufgenommen für $\mathrm{Hb}_{\min }$} \\
\hline
\end{tabular}

Tabelle A.18: Odds-Ratios der multiplen logistischen Regression für die Konzentrationen von Hämoglobin und der des löslichen Transferrinrezeptors der Mutter.

\begin{tabular}{|c|c|c|c|}
\hline \multicolumn{4}{|c|}{ Odds-Ratios: Hb und sTfR } \\
\hline & & Odds-Ratio & CI \\
\hline \multirow{3}{*}{$\begin{array}{l}\mathrm{Hb}<12 \mathrm{~g} / \mathrm{dl} \text { : } \\
\text { Alkoholkonsum p.p. }\end{array}$} & nie & 1,00 & \\
\hline & selten & 0,26 & $0,07-0,92$ \\
\hline & öfters & 0,00 & $0,00-01,21 \mathrm{E}+24$ \\
\hline sTfR $>3,3 \mathrm{mg} / \mathrm{l}:$ & ja, regelmäßig & 1 & \\
\hline Einsetzen der & ja, unregelmäßig & 1,23 & $0,33-4,64$ \\
\hline Menstruation p.p. & nein, gar nicht & 3,83 & $1,09-13,51$ \\
\hline
\end{tabular}


Tabelle A.19: Multiple logistische Regression: Rangwerte und Signifikanzen für Hb und sTfR.

\begin{tabular}{|c|c|c|c|c|}
\hline \multicolumn{5}{|c|}{ Rangwerte: Hb und sTfR } \\
\hline & \multicolumn{2}{|c|}{$\mathrm{Hb}$} & \multicolumn{2}{|c|}{ sTfR } \\
\hline & Score & $\mathrm{p}$ & Score & $\mathrm{p}$ \\
\hline Alkoholkonsum p.p. & \multicolumn{2}{|c|}{ signifikant } & 2,62 & 0,2696 \\
\hline selten & & & 0,07 & 0,7941 \\
\hline öfters & & & 1,79 & 0,1814 \\
\hline Einsetzen der Menstruation p.p. & 2,30 & 0,317 & \multirow{3}{*}{\multicolumn{2}{|c|}{ signifikant }} \\
\hline unregelmäßig & 0,61 & 0,434 & & \\
\hline gar nicht & 1,34 & 0,248 & & \\
\hline Body-Mass-Index & 0,53 & 0,913 & 1,84 & 0,607 \\
\hline $19,8-26,0$ & 0,01 & 0,908 & 1,18 & 0,278 \\
\hline$>26,0-29,0$ & 0,01 & 0,914 & 0,09 & 0,768 \\
\hline$>29$ & 0,49 & 0,485 & 0,24 & 0,626 \\
\hline Alkoholkonsum i.d.SS. & 0,45 & 0,798 & 0,34 & 0,842 \\
\hline selten & 0,45 & 0,502 & 0,16 & 0,688 \\
\hline öfters & 0,00 & 0,993 & 0,16 & 0,691 \\
\hline Rauchen i.d.SS. & 0,49 & 0,483 & 0,71 & 0,400 \\
\hline Alter & 1,83 & 0,609 & 2,52 & 0,472 \\
\hline $25-29$ & 0,00 & 0,964 & 1,82 & 0,178 \\
\hline $30-34$ & 1,20 & 0,274 & 0,18 & 0,671 \\
\hline ab 35 & 0,27 & 0,603 & 1,37 & 0,242 \\
\hline vegetarische Ernährung & 0,40 & 0,817 & 2,29 & 0,318 \\
\hline selten & 0,07 & 0,791 & 1,91 & 0,167 \\
\hline gar nicht & 0,24 & 0,626 & 0,00 & 0,999 \\
\hline Nationalität & 1,03 & 0,311 & 0,00 & 0,984 \\
\hline Rauchen zur Zeit der Befragung & 0,01 & 0,909 & 0,23 & 0,635 \\
\hline Berufsausbildung & 0,88 & 0,831 & 1,00 & 0,800 \\
\hline Lehre & 0,12 & 0,727 & 0,01 & 0,909 \\
\hline Fachschule & 0,23 & 0,629 & 0,88 & 0,347 \\
\hline Hochschule & 0,42 & 0,519 & 0,32 & 0,572 \\
\hline Berufstätigkeit & 0,44 & 0,508 & 0,00 & 0,984 \\
\hline Schulabschluß & 1,42 & 0,842 & 2,93 & 0,470 \\
\hline Realschulabschluß & 0,01 & 0,905 & 0,34 & 0,562 \\
\hline Volks-/Hauptschulabschluß & 0,66 & 0,417 & 0,00 & 0,984 \\
\hline ohne Abschluß & 0,85 & 0,356 & 1,94 & 0,164 \\
\hline Zahl der Kinder & & & 2,29 & 0,318 \\
\hline zwei & & & 0,09 & 0,762 \\
\hline$a b$ drei & & & 1,73 & 0,189 \\
\hline
\end{tabular}


Tabelle A.20: Zusammenfassung der Ergebnisse für die Variablen in Bezug auf die aktuellen Konzentrationen von Hämoglobin und dem löslichen Transferrinrezeptor der Mutter. Dargestellt werden signifikante (+) und nicht-signifikante (-) Ergebnisse sowieVariablen, die in bestimmte Analysen nicht einbezogen wurden (/).

\begin{tabular}{|c|c|c|c|c|c|c|c|c|c|c|c|}
\hline \multicolumn{12}{|c|}{ Zusammenfassung der Ergebnisse } \\
\hline & \multicolumn{4}{|c|}{$\mathrm{Hb}$} & \multicolumn{4}{|c|}{ sTfr } & \multicolumn{3}{|c|}{$\mathrm{Hb}_{\min }$} \\
\hline & Präv. & Korr. & Lin.RA & Log. RA & Präv. & Korr. & Lin.RA & Log.RA & Präv. & Korr. & Lin.RA \\
\hline Nationalität & + & I & - & - & + & 1 & - & - & + & I & - \\
\hline Alkoholkonsum p.p. & + & + & + & + & + & + & + & - & / & / & I \\
\hline Rauchen zur Zeit der Befragung & + & I & - & - & + & l & - & - & I & I & I \\
\hline Body-Mass-Index & + & + & + & - & - & - & - & - & + & + & + \\
\hline Alter & + & - & + & - & - & - & - & - & + & - & - \\
\hline Alkoholkonsum i.d.SS. & - & - & + & - & - & - & - & - & + & - & - \\
\hline Berufsausbildung & + & I & - & - & - & I & - & - & + & I & - \\
\hline Vegetarische Ernährung & - & I & - & - & + & I & - & - & + & I & - \\
\hline Rauchen i.d.SS. & + & - & + & - & - & - & - & - & - & - & - \\
\hline Zahl der Kinder & - & - & / & I & + & + & + & - & - & I & I \\
\hline Einsetzen der Menstruation p.p. & - & l & - & - & + & I & - & + & l & / & / \\
\hline Geburtsgewicht & - & - & I & I & - & - & I & I & I & - & + \\
\hline Berufstätigkeit & - & 1 & - & - & - & 1 & - & - & - & I & - \\
\hline Schulabschluß & - & I & - & - & - & / & - & - & - & / & I \\
\hline Passivrauchen i.d.SS. & - & I & I & I & - & / & I & / & - & / & I \\
\hline Familiennettoeinkommen & - & l & l & l & - & l & l & l & - & I & I \\
\hline Sport i.d.SS. & - & I & I & I & - & I & I & I & - & I & / \\
\hline Sport p.p. & - & / & / & / & - & / & / & / & / & / & / \\
\hline Stärke der Menstruationsblutung & - & / & l & / & - & / & / & / & / & l & / \\
\hline Stilldauer & - & I & I & I & - & I & I & I & I & I & I \\
\hline Schwangerschaftsdauer & - & I & 1 & I & - & I & I & I & - & I & I \\
\hline
\end{tabular}




\section{Anhang B}

\section{Fragebogen (Ausschnitt)}

\section{Teil 1:}

\section{Angaben zur Lebenssituation}

1.) Welche Personen gehören zu Ihrem Haushalt, Sie selbst einbezogen (Altersangaben bitte in Jahren)?

\begin{tabular}{lccc}
\hline Mutter & $\square$ & Alter: ... & Jahre \\
Vater & $\square$ & Alter: .. . & Jahre \\
\hline & Junge & Mädchen & Alter \\
1. Kind & $\square$ & $\square$ & $\ldots$ \\
2. Kind & $\square$ & $\square$ & $\ldots$ \\
3. Kind & $\square$ & $\square$ & $\ldots$ \\
4. Kind & $\square$ & $\square$ & $\ldots$ \\
5. Kind & $\square$ & $\square$ & $\ldots$ \\
\hline Anzahl weiterer Kinder ... & \\
\hline
\end{tabular}

3.) Schulabschluß der Eltern/Erziehungsberechtigten:

$\begin{array}{rcc} & \text { Mutter } & \text { Vater } \\ \text { Schule beendet ohne Abschluß: } & \square & \square \\ \text { Volks-/Hauptschulabschluß: } & \square & \square \\ \text { mittlere Reife, Realschulabschluß: } & \square & \square \\ \text { Fachhochschulreife } & \square & \square \\ \text { Abitur: } & \square & \square \\ \text { keine Angabe: } & \square & \square \\ \text { anders, nämlich: } & \ldots \ldots \ldots \ldots & \ldots \ldots \ldots \ldots\end{array}$


4.) Abgeschlossene Berufsausbildung der Eltern:

$\begin{array}{rcc} & \text { Mutter } & \text { Vater } \\ \text { (noch) keine: } & \square & \square \\ \text { Lehre: } & \square & \square \\ \text { Fachschule: } & \square & \square \\ \text { Hochschule } & \square & \square \\ \text { anders, nämlich: } & \ldots \ldots \ldots \ldots & \ldots \ldots \ldots\end{array}$

5.) Sind Sie zur Zeit berufstätig?

$$
\begin{array}{cc}
\text { Mutter: } & \square \text { ja } \quad \square \text { nein } \\
\text { Vater: } & \square \text { ja } \quad \square \text { nein }
\end{array}
$$

7.) Monatlich verfügbares Familiennettoeinkommen:

(Erläuterung: Das Familiennettoeinkommen ist die Summe aller Einkünfte nach Abzug von Steuern, Sozialabgaben un Versicherungsbeiträgen.)

$\begin{array}{rrr}\text { bis zu 750 DM: } \square & \text { bis zu } 3000 \text { DM: } \square & \text { bis zu } 5500 \text { DM: } \\ \text { 1000 DM: } \square & \text { 3500 DM: } \square & 6000 \text { DM: } \\ \text { 1500 DM: } \square & 4000 \text { DM: } \square & 6500 \text { DM: } \\ \text { 2000 DM: } \square & 4500 \text { DM: } \square & 7000 \text { DM: } \\ \text { 2500 DM: } \square & \text { 5000 DM: } \square & \text { über } 7000 \text { DM: }\end{array}$

8.) Nationalität der Eltern:

$\begin{array}{lcclcc} & \text { Mutter } & \text { Vater } & \text { Mutter } & \text { Vater } \\ \text { afrikanisch } & \square & \square & \text { französisch } & \square & \square \\ \text { albanisch } & \square & \square & \text { griechisch } & \square & \square \\ \text { amerikanisch } & \square & \square & \text { holländisch } & \square & \square \\ \text { asiatisch } & \square & \square & \text { indisch } & \square & \square \\ \text { deutsch } & \square & \square & \text { italienisch } & \square & \square \\ \text { polnisch } & \square & \square & \text { spanisch } & \square & \square \\ \text { portugiesisch } & \square & \square & \text { türkisch } & \square & \square \\ \text { russisch } & \square & \square & \text { kroatisch } & \square & \square \\ \text { englisch } & \square & \square & \text { anders } & \square & \square\end{array}$




\section{Angaben zur Schwangerschaft}

2.) Wie häufig haben Sie Alkohol genossen?

$\begin{array}{lll}\text { Während der Schwangerschaft: } & \text { nie } \square & \text { selten } \square \quad \text { öfters } \square \\ \text { Im vergangenen Jahr nach der Schwangerschaft: } & \text { nie } \square \quad \text { selten } \square \quad \text { öfters } \square\end{array}$

4.) Haben Sie sich vegetarisch ernährt?

$$
\text { ausschließlich } \square \text { vorwiegend } \square \text { selten } \square \text { gar nicht }
$$

6.) Haben Sie während der Schwangerschaft geraucht?

$$
\text { nein } \square \quad \text { ja } \square
$$

7.) Hielten Sie sich während der Schwangerschaft in verrauchten Räumen auf (sog. Passivrau(hen)?

$$
\square \text { nie } \square \text { selten } \square \text { öfters }
$$

8.) Rauchen Sie zur Zeit?

$$
\text { nein } \square \quad \text { ja } \square
$$

9.) Wie groß sind Sie?

10.) Wieviel wiegen Sie zur Zeit? $\quad \ldots \ldots \ldots \ldots \ldots$ kg
13.) Haben Sie während der Schwangerschaft regelmäßig Sport getrieben?

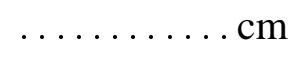

$$
\text { ja } \square \quad \text { nein } \square
$$

14.) Haben Sie nach der Schwangerschaft regelmäßig Sport getrieben?

$$
\text { ja } \square \quad \text { nein } \square
$$

17.) Setzte die Menstruation nach der Geburt wieder ein und wie?

$\square$ ja, regelmäßig $\square$ ja, unregelmäßig $\square$ nein, gar nicht

Falls ja: wie stark: $\square$ kaum Blutungen $\square$ mäßig Blutungen $\square$ starke Blutungen 


\section{Lebenslauf}

Name: $\quad$ Wagener, Iris Elisabeth

Geburtsdatum: $\quad 04.10 .1973$

Geburtsort: $\quad$ Köln

Familienstand: $\quad$ ledig

Schulabschluß: $\quad$ Mai 1993: Abitur, Georg-Herwegh-Oberschule Berlin

Studium: $\quad$ Oktober 1993-März 1996: Humanmedizin, Freie Universität Berlin

März 1996:

Ärztliche Vorprüfung, Berlin

seit April 1996:

Humanmedizin, Humboldt-Universität zu Berlin

März 1997:

August 1999:

Erster Abschnitt der Ärztlichen Prüfung, Berlin

Herbst 2000: Zweiter Abschnitt der Ärztlichen Prüfung, Berlin Voraussichtlich dritter Abschnitt der Ärztlichen Prüfung

Veröffentlichungen: $\quad$ Vortrag: Wagener I., Bergmann R. L., Kamtsiuris P., Eisenreich B., Andres B., Bergmann K. E., Dudenhausen J. W. (1999). Prävalenz und Risikofaktoren von Eisenmangel bei jungen Müttern. Kongress: Public Health - Entwicklungen und Potentiale

Poster: Wagener I., Bergmann R. L., Kamtsiuris P., Eisenreich B., Andres B., Bergmann K. E., Dudenhausen J. W. (1999). Prävalenz und Risikofaktoren von Eisenmangel bei jungen Müttern. 19. Kongress für Perinatale Medizin Artikel: Wagener I. E., Bergmann R. L., Kamtsiuris P., Eisenreich B., Andres B., Eckert C., Dudenhausen J. W. und Bergmann K. E. (2000). Prävalenz und Risikofaktoren von Eisenmangel bei jungen Müttern. Das Gesundheitswesen, 62. 